YIA

TEXILA

INTERNATIONAL JOURNAL

OF ACADEMIC RESEARCH

Volume 9 | Issue $1 \quad$ ISSN: 2520-3088

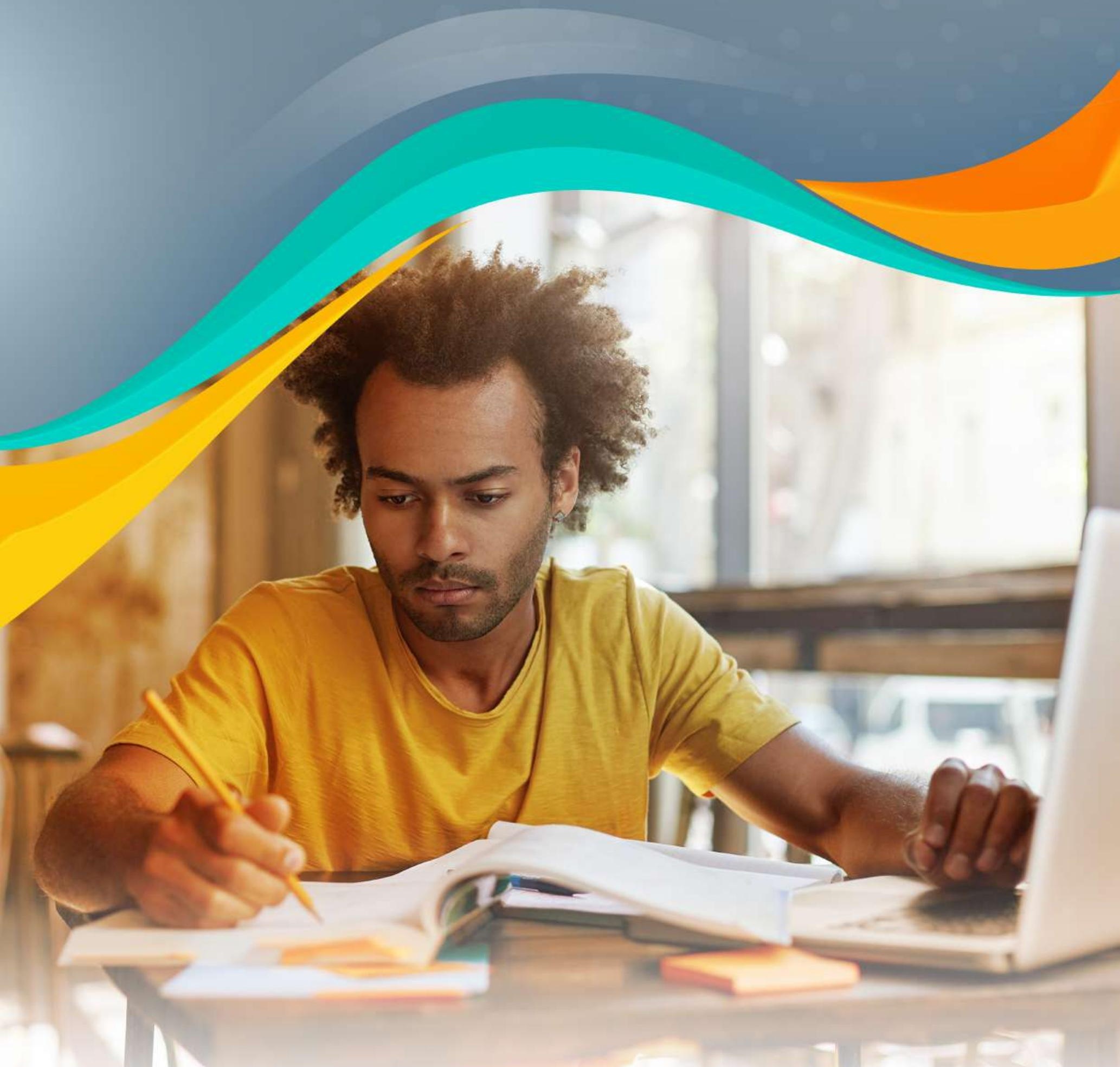




\section{EDITORIAL POLICY}

Papers must be submitted with the understanding that they have not been published elsewhere (except in the form of an abstract or as part of a published lecture, review, or thesis) and are not currently under consideration by another journal published or any other publisher. The submitting (Corresponding) author is responsible for ensuring that the article's publication has been approved by all the other coauthors. It is also the authors' responsibility to ensure that the articles coming from a particular institution are submitted with the approval of the necessary institution. Only an acknowledgment from the editorial office officially establishes the date of receipt. It is a condition for submission of a paper that the authors permit editing of the paper for readability. All enquiries concerning the publication of accepted papers should be addressed to ejournal.assist@tau.edu.gy.

\section{EDITORIAL BOARD MEMBERS}

Dr. Rakesh Ranjan, Educational Management and Administration, MAEERs Vishwashanti Gurukul School, Solapur.

Dr. Rakesh Kumar, Manger Examinations, Texila Educational and Management Services.

Dr. T. Selvankumar, Professor and Head, Mahendra Arts and Science College. 


\section{ABOUT PLAGIARISM}

Plagiarism is the use or close imitation of the language and ideas of another author and representation of them as one's own original work. Duplicate publication, sometimes called self-plagiarism, occurs when an author reuses substantial parts of his or her own published work without providing the appropriate references. This can range from getting an identical paper published in multiple journals, where authors add small amounts of new data to a previous paper.

Plagiarism can be said to have clearly occurred when large chunks of text have been cut and pasted. Such manuscripts would not be considered for publication in TIJN Journal. But minor plagiarism without dishonest intent is relatively frequent, for example when an author reuses parts of an introduction from an earlier paper. The editors will judge any case of which they become aware (either by their own knowledge of and reading about the literature, or when alerted by referees) on its own merits.

The paper containing the plagiarism will be obviously returned back to the author's for review, but we earnestly request the authors to avoid submitting plagiarized. 


\section{DISCLAIMER}

Texila International Journal of Academic Research (TIAR) make every effort to ensure the accuracy of all the information (the "Content") contained in its publications. However, the TIAR and its agents make no representations or warranties whatsoever as to the accuracy, completeness or suitability for any purpose of the Content and disclaim all such representations and warranties whether express or implied to the maximum extent permitted by law. Any views expressed in this publication are the views of the authors and are not necessarily the views of the Editor's or Texila International Journal of Academic Research. 


\section{TABLE OF CONTENT}

1 Effect of Duffy Antigen Receptor for Chemokines on Severity in Sickle Cell

Disease

Aquel Rene Lopez

2 A Systematic Review to Observe the Impact of Risk-Based Monitoring as

Compared to Conventional On-Site Monitoring in Randomised Clinical Trials and

Quality Management in Large Cohort Studies

Shubhra Bansal

3 Impact of Cultural Diversity on Overall Organizational Performance: A

Moderating Role Education

Laar David Diam

4 Resettlement of Internally Displaced Persons in the North Central Geopolitical Zone of Nigeria

Askederin, F. M

5 Integration of Mind and Skin; Psychological Co-morbidity in Dermatology and Skin Signs in Psychiatry

Bushra Khan

6 Basic Academic Research Structure and Format Guiding Principles for Students

Aquila Hakim M. Jongroor

7 An Assessment of Covid-19 Factors which Influence Non-Compliance of

Payments in Respect of Social Security Contributions in Ghana

Samuel Nii Attoh Abbey

8 Government Expenditure on Economic Growth: Empirical Evidence from Ghana

Joshua Akanyonge

9 Impact of Human Resources Budgeting on Human Resource Management Accountability in Metropolitan, Municipal and District Assemblies in the Ashanti Region 
10 Tales of Early Childhood Education Teachers in Government Schools in Chipata, Zambia

Daniel L. Mpolomoka

11 The Role Professional Accountant Firms play within the Liberian Market in Terms of Strategic Implementation of Financial Statement Audit

Jerome M. Kesselly

12 4Dimensional X Strain and 2Dimensional Speckle Tracking Echocardiographic Study: Normative Values of Strain Parameters of Left Ventricle and Tissue Doppler Imaging of Ascending Aorta in Healthy Adults -A Single Centre Indian Study 


\title{
Effect of Duffy Antigen Receptor for Chemokines on Severity in Sickle Cell Disease
}

\author{
Aquel Rene Lopez ${ }^{*}$, Charles Brown ${ }^{2}$, Eli Dzandu ${ }^{1}$, Clement Amedor ${ }^{3}$, Richard Adom- \\ Akessah $^{1}$, Isaac Asare ${ }^{4}$, Julia Karikari ${ }^{5}$ \\ 'Tetteh Quarshie Memorial Hospital, Mampong, Ghana \\ ${ }^{2}$ School of Biomedical and Allied Health Science, University of Ghana, Accra, Ghana \\ ${ }^{3}$ Tamale Teaching Hospital, Tamale, Ghana \\ ${ }^{4}$ St.Domics Hospital, Akwatia, Ghana \\ ${ }^{5}$ Tema General Hospital, Tema, Ghana
}

\begin{abstract}
Sickle-cell disease is among the commonest severe monogenic global disorders. At the centre of sickle cell disease physiopathology is the polymerisation haemoglobin, resulting in erythrocytes become rigid and vascular occlusion. It has been hypothesized that the Duffy glycoprotein (Fy) on erythrocytes may enhance clearance of inflammatory cytokines. This may have an impact on the initiation and development of vascular occlusion in Sickle cell disease. The aim of this study was to determine whether or not the Duffy genotype is in any way linked with the severity of clinical disease in Sickle cell disease patients. Those who were hospitalized $>4$ times in the previous year because of Vaso-occlusive crisis were classified as having a severe phenotype. Duffy genotypes were determined by polymerase chain reaction (PCR), then Styl restriction endonuclease enzyme analysis. A total of 193 participants (133 cases and 60 controls) were recruited for the study. Vaso-occlusive crises were absent in more than half (58.5\%) of the cases. Vaso-occlusive crisis per year occurred three times and four times at 5.2\% and $1.65 \%$, respectively. The number of vascular occlusions per year was highest in the 18-28 years and 29-39 years age groups. All the participants were genotyped as homozygotes for Duffy null genotype $\left(F Y^{*} B-33 / F Y^{*} B-33\right)$ and categorised as $F y(a-b-)$. No associations between Duffy genotype and number of VOCs per year was obtained. All the samples analysed were genotyped as Duffy negative homozygous [Fy(a-b-)]. No association between Duffy genotype and number of was vascular occlusion found.
\end{abstract}

Keywords: Chemokine, Duffy antigen, Sickle cell, Vascular occlusion.

\section{Introduction}

Sickle Cell Disease (SCD) is the most common genetic disorder of haemoglobin in sub-Saharan Africa [1, 2]. In Africa, it is estimated that about 200,000 children are born with the disease annually [3]. A point mutation on the $6^{\text {th }}$ codon of the beta-globin gene located on the short arm of chromosome 11 produces a defective beta-globin chain, which under low oxygen tension polymerizes into long fibres that eventually lead to abnormally deformed (sickled) red cell. The red cells thus become sticky, adhere to the endothelium, and clump together, plugging micro-vessels [4] and also damage large blood vessels that can become severely stenotic or occluded. In addition, sickle red cells have a much-shortened life span making chronic haemolytic anaemia a constant

*Corresponding Author: lonnet2001@ya hoo.com 
feature of SCD. The combination of Vasoocclusion and haemolytic anaemia contributes to the basic presentation of the disease and associated complications, of which some are life-threatening. Biomedical technology is moving very fast to use hematopoietic stem cell transplantation and gene therapy in the management of the disease in developed countries. However, only very few SCD patients have been successfully treated with hematopoietic stem cell transplantation [5] and, gene therapy has not been successful yet in curing SCD.[6] In general, the disease is managed using a combination of preventive and symptomatic therapies [7]. Two principal antigens, Fy(a) and Fy(b) are produced by the FYA and FYB codominant alleles. There are four main phenotypes: $\mathrm{Fy}(\mathrm{a}+\mathrm{b}-), \mathrm{Fy}(\mathrm{a}+\mathrm{b}+)$, $\mathrm{Fy}(\mathrm{a}-\mathrm{b}+)$ and $\mathrm{Fy}(\mathrm{a}-\mathrm{b}-)$. The Duffy negative phenotype, Fy(a-b-), is uncommon among Caucasians but has a high prevalence in West Africans and in approximately 1 in every 500 African Americans [8].

The Duffy negative phenotype occurs because of a mutation in the "GATA promoter region upstream of the FY allele". This alteration stops the activity of the GATA site and prevents erythroid cell gene transcription of the Duffy glycoprotein [9].

The Duffy glycoprotein (DARC) also functions as the erythrocyte entry point for invasion by Plasmodium vivax and P. knowlesi [8]. However, the biological role of DARC is not clear; normal erythrocytes and a typical immune response is seen in persons with the null Duffy phenotype [10].

Both laboratory and animal studies have been carried out to determine DARC's functional role. Studies carried out in vitro that demonstrated that "red cell absorption of IL-8 may function to limit stimulation of leukocytes by IL-8 released into blood" [11] and in vivo using FY gene knockout animals [10] all point to the fact that erythrocyte Duffy antigens have "a dual role as a chemokine sink to both prevent WBC activation in the systemic circulation and impede chemokine dissemination from the blood into organs." Active research is ongoing to determine the function of cytokines as likely regulators of the complications of SCD [12]. Cytokines seem to play a role in several possible mechanisms in the pathogenesis of Vasoocclusive phenomena in SCD. Interleukin-8, especially, appears to be engaged in the pathological process of Vaso-occlusion in SCD, and serum IL-8 levels are raised in severe Vasoocclusive crises in SCD [13]. Increased adherence to endothelium has been demonstrated in vitro when sickle RBCs are exposed to IL-8 [14].

\section{Materials and Methods}

\section{Study Design}

The research was a case-control study. This design was chosen because the study was observational; it did not involve any intervention, and the course of the disease was not altered in any way. Retrospectively, a determination was made of the exposure to the risk factor of interest from each of the two study groups of individuals (cases and controls).

\section{Study Site}

The study was conducted at the Ghana Institute of Clinical Genetics, also known as Sickle Cell Clinic, located within the Korle-Bu Teaching Hospital (KBTH), Accra, Ghana. Korle-Bu Teaching Hospital was established on October 9, 1923. KBTH is currently the thirdlargest hospital in Africa and the leading national referral centre in Ghana [15]. Currently, the Hospital has 2,000 beds and 17 clinical and diagnostic Departments/Units. The average daily attendance is 1,500 patients and about 250 patient admissions [15].

The Ghana Institute of Clinical Genetics is a referral health facility that receives SCD patients from all over Ghana. The Institute was established in 1974 and is funded by the Ministry of Health and the Managing Trustees of Volta Aluminium Company Limited (VALCO) [16]. 


\section{Sample Size Calculation}

The sample size was calculated using a simple formula. Using a confidence interval of $95 \%$ and a margin of error of $2 \%$, the calculation was as follows:

$$
\begin{gathered}
\mathrm{n}=\frac{[Z]^{2} \mathrm{P}(1-\mathrm{P})}{\mathrm{E}^{2}} \\
\mathrm{n}=\frac{[1.96]^{2}(0.98)(1-0.98)}{0.02^{2}}=189 \text { participants. }
\end{gathered}
$$

where:

$\mathrm{n}=$ is estimated minimum sample size.

$\mathrm{E}=$ is the allowable margin of error.

$\mathrm{z}=$ is the critical $\mathrm{z}$ score based on the desired level of significance.

$\mathrm{P}=$ Overall prevalence of Duffy negative genotype in West Africa, is $98 \%$ [17].

\section{Data Collection}

\section{Retrieval of Patient Clinical Information}

Clinical and demographic data were obtained by a structured questionnaire using information from the hospital records. Dependent variables included age, sex, and genotype. The estimated number of admissions due to sickle cell crisis was used as an indicator for the severity of the systemic disease.

\section{Collection and Storage of Blood Specimens}

Blood samples ( $40 \mu l 1$ each) from participants were spotted on Whatman 4 FTA cards
(Whatman Inc., Brentford, UK) and allowed to air dry for 24 hours at room temperature $\left(27^{\circ} \mathrm{C}\right)$ and then kept in separate clean zipper bags.

\section{Statistical Analysis}

Differences between FY+ and FY- patients in demographic characteristics, clinical and overall disease severity were tested. Analyses were carried out using IBM ${ }^{\circledR}$ SPSS ${ }^{\circledR}$ Statistics version 24 for Windows and GraphPad Prism version 7.00 for Windows. Continuous variables were compared with the t-test. Chi-square tests or Fisher's exact tests were used for nominal variables. A $p$-value of less than 0.05 was considered significant. Odds ratios (ORs with 95\% CIs) were used to measure the strength of the statistical associations between the outcomes and exposures.

\section{Results and Discussion}

A total of 193 subjects participated in the study and with participants' age ranging between 18 - 67 years $(29.84 \pm 8.85$ years). The study subjects were made up of 133 (53.4\%) cases, and $60(46.6 \%)$ controls. Figure 1 shows the gender distribution of cases and controls. No statistically significant difference $(p=0.1864)$ was found between the ages of the cases and controls. 


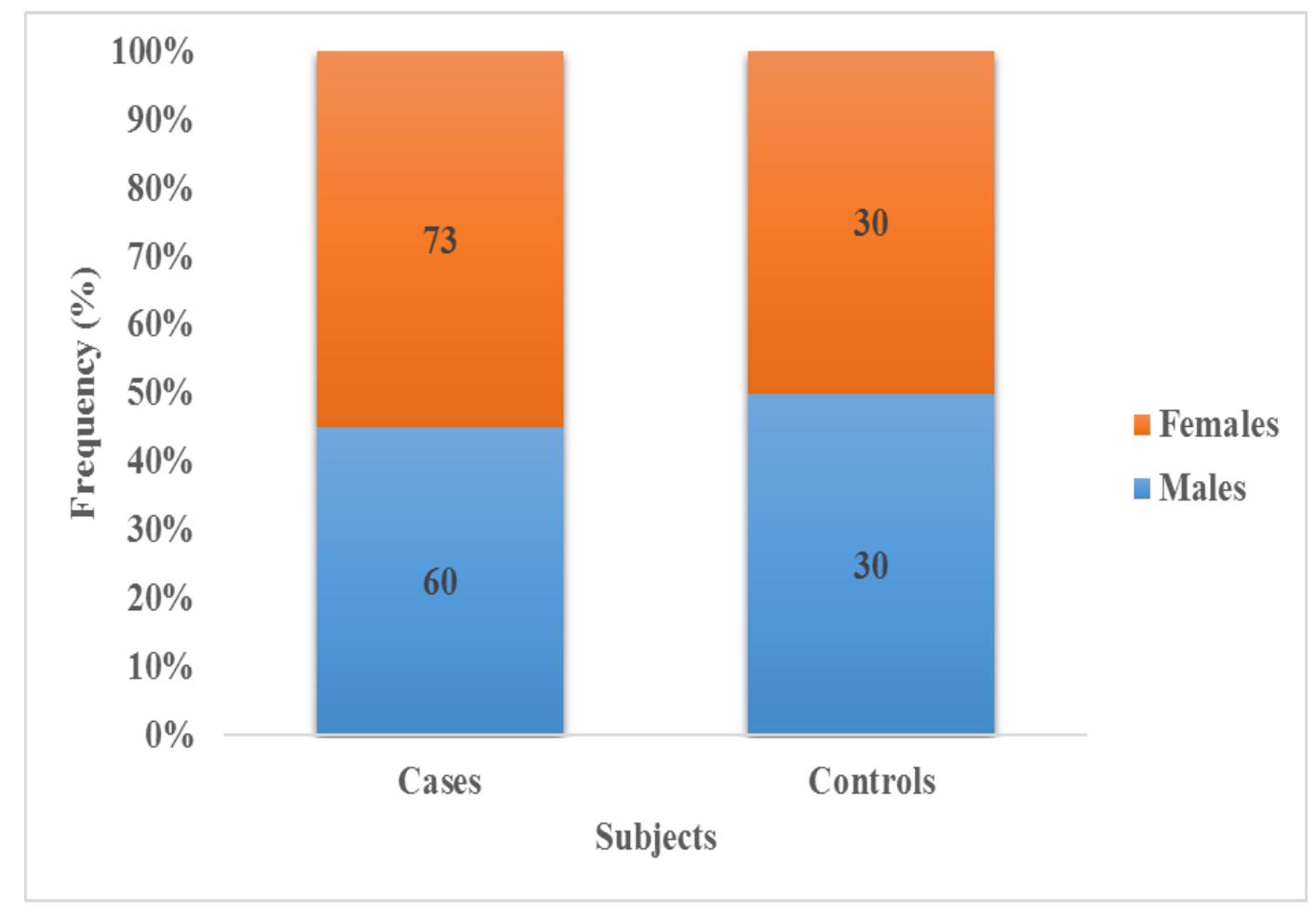

Figure. 1. Age Distribution of the Participants

\section{Clinical History of Cases}

The majority of the cases $(94.7 \%)$ were $\mathrm{Hb}$ SS, with only a few being $\mathrm{Hb}$ SC (5.3\%). Figure. 2 shows the clinical history of the cases. No VOCs occurred in $59(44.4 \%)$ of the cases.
Vaso-occlusive crisis per year occurred three times and four times in $7.5 \%$ and $2.2 \%$ of the cases, respectively. The number of VOCs per year was highest in the 18-28 years and 29-39 years groups (Table 1).

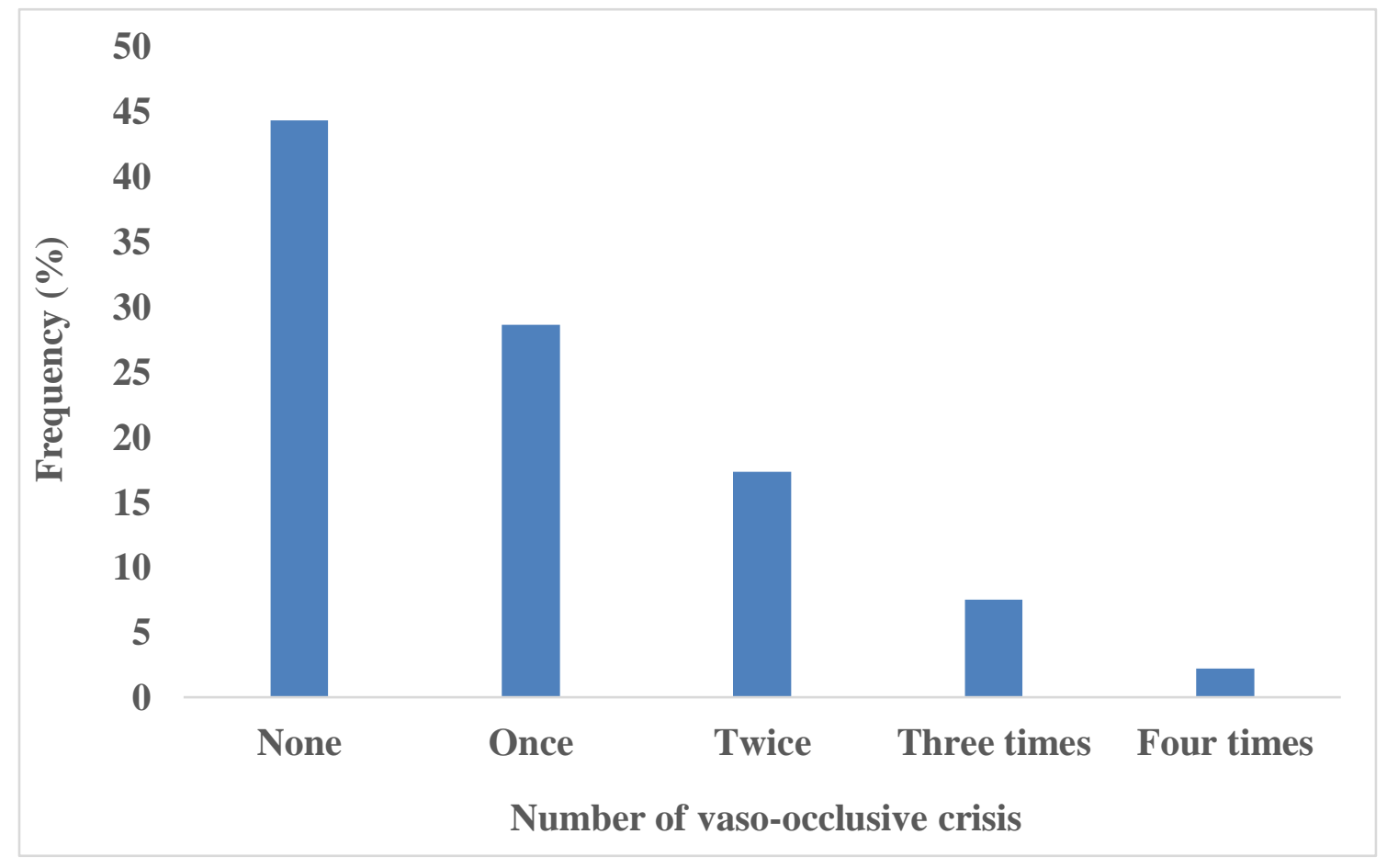

Figure. 2. Frequency of Number of Vaso-occlusive Crisis per Year 
Table 1. Occurrence of Vaso-occlusive Crises per Year in Relation to Age Groups

\begin{tabular}{|l|l|l|l|l|l|l|}
\hline \multirow{2}{*}{ Age group (years) } & \multicolumn{7}{l|}{ Vaso-occlusive crises/year } & \\
\cline { 2 - 6 } & None & Once & Twice & Three times & Four times & Total \\
\hline $\mathbf{1 8 - 2 8}$ & 30 & 18 & 11 & 4 & 3 & $\mathbf{6 6}$ \\
\hline $\mathbf{2 9 - 3 9}$ & 22 & 14 & 9 & 5 & 0 & $\mathbf{5 0}$ \\
\hline $\mathbf{4 0 - 5 0}$ & 5 & 6 & 3 & 1 & 0 & $\mathbf{1 5}$ \\
\hline $\mathbf{5 1 - 6 1}$ & 1 & 0 & 0 & 0 & 0 & $\mathbf{1}$ \\
\hline $\mathbf{6 2 - 7 2}$ & 1 & 0 & 0 & 0 & 0 & $\mathbf{1}$ \\
\hline Total & $\mathbf{1 1 3}$ & $\mathbf{5 9}$ & $\mathbf{3 8}$ & $\mathbf{2 3}$ & $\mathbf{1 0}$ & $\mathbf{1 3 3}$ \\
\hline
\end{tabular}

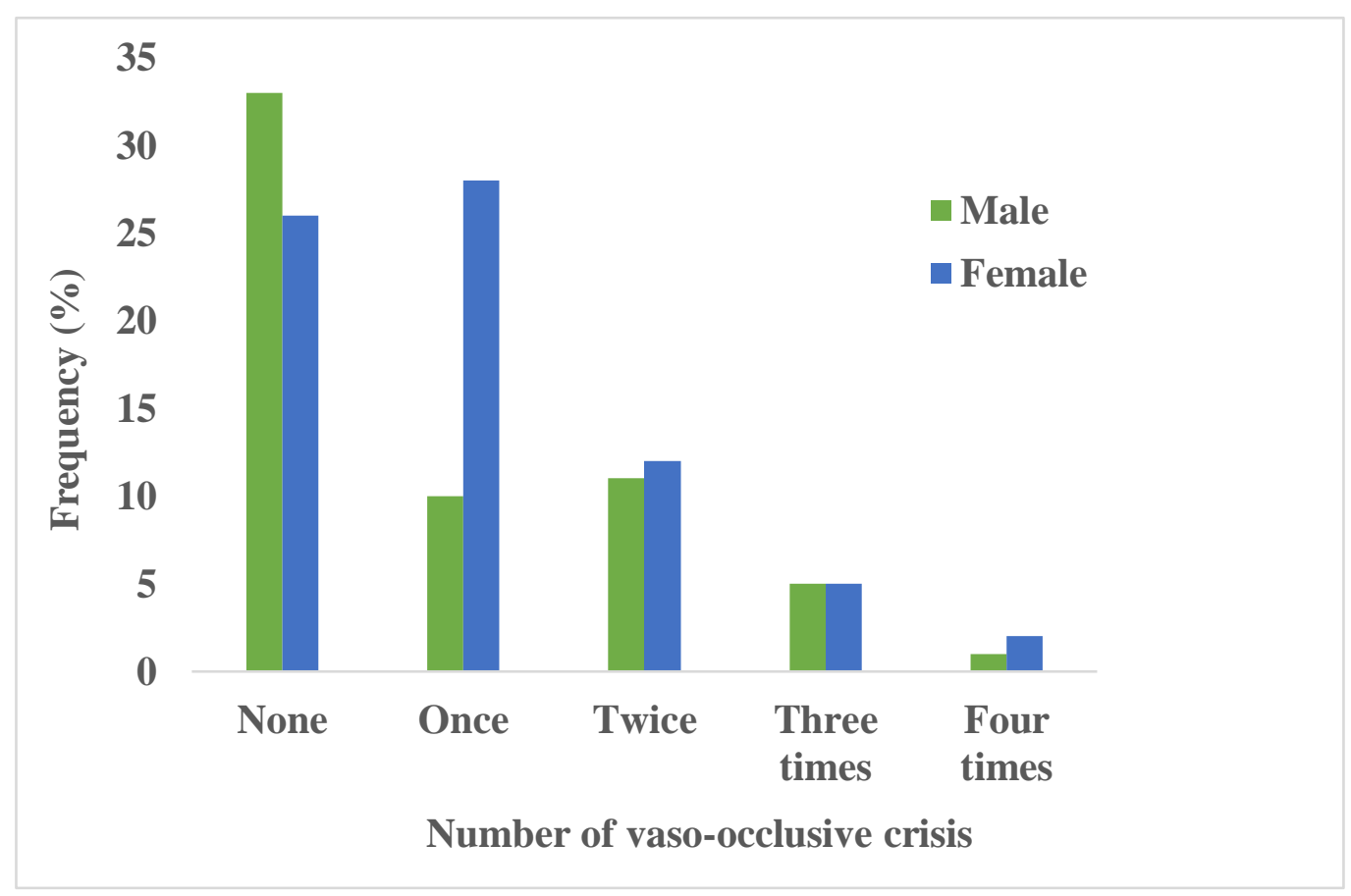

Figure 3. Gender in Relation to Number of Vaso-occlusive Crises per Year

Vaso-occlusive crises per year occurred more in females than males (Figure. 3). There was no statistically significant difference $(p=0.1463)$ between gender and the number of Vasoocclusive crises per year.

\section{Frequencies of Duffy Genotypes}

All the participants were genotyped for the Duffy gene by PCR-RFLP. Restriction fragment analysis of all the amplicons yielded 82, 65, 64, and $12 \mathrm{bp}$ for Duffy negative genotypes (Figure. 4). However, the fragment of $12 \mathrm{bp}$ was not considered due to the low molecular weight, not visible in the gel. All the samples analysed were thus genotyped as FY*B-33/FY*B-33 (Duffy negative homozygous) being therefore classified as Fy(a-b-). 


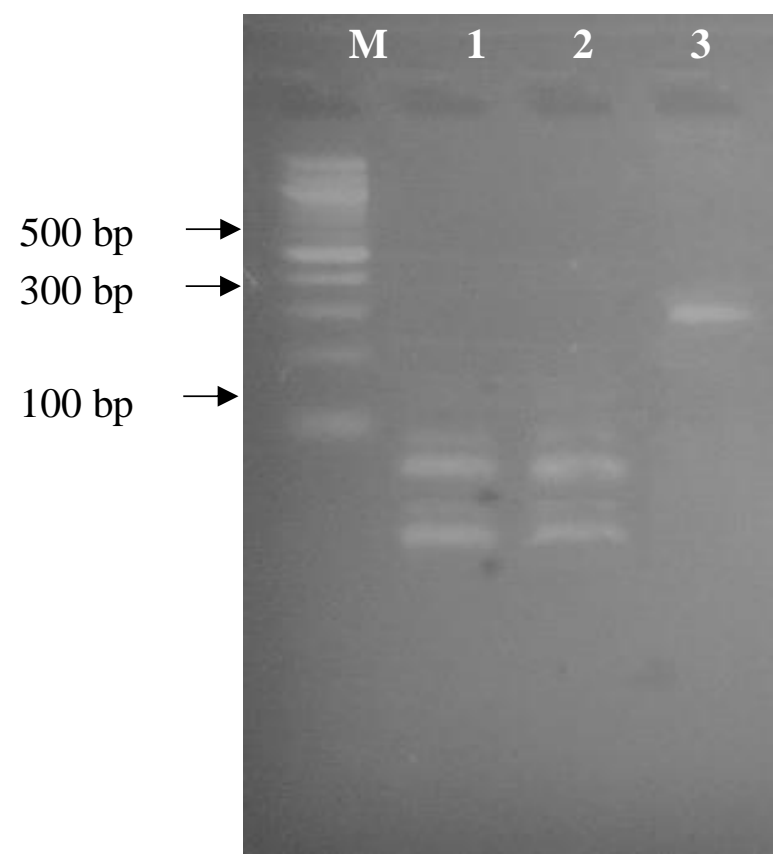

Figure 4. Ethidium Bromide-Stained 2.0\% Agarose gel Electrophoregram of StyI Digestion of Amplicons obtained using the P38 and P39 Primers

Lane $\mathrm{M}=100 \mathrm{bp}$ marker (New England Biolabs Inc., Ipswich, MA, USA); Lanes 1 and 2 $=$ PCR positives $16 \mathrm{~S}$ rDNA genes; Lanes $3=$ Undigested amplicon.

\section{Association of Duffy Genotypes with Scd Severity}

No associations ( $p=0.999)$ between Duffy genotype and the number of vaso-occlusive crises per year were obtained.

The pathophysiology that results in complications in SCD is not fully understood, thus genetic changes likely to affect the severity of the disease carry a high value. Consequently, studies that look at how individual blood group antigens function to in ways that affect SCD expression are required. For instance, antigens of the Lutheran and LW blood groups provide adhesion receptors with several functions that studies have established to play a role in the pathological initiation of erythrocyte adhesion in SCD $[18,19]$.

This study looked at the likelihood of any link between the expression Duffy blood group antigen as reflected by the FY genotype at the GATA site of the FY promoter and severity of clinical disease among patients with HbSS.
Investigations of the associations between biomarkers which can predict SCD severity have provided inconclusive results [20].

Sickle cell disease is characterised by a broad range of disorders, including chronic haemolytic anaemia and Vaso-occlusion of both macro-and microvasculature, resulting in continuing pain and major organs at the end getting damaged. The Vaso-occlusive crisis was absent in more than half $(58.5 \%)$ of the cases, and this could be due to the effective management of the SCD patients who attend the sickle cell clinic. Crisis occurred three times and four times per year in the 18-28-year group than in any other year group. [21] in their study also reported that young adults (20-29 years) had more crises (49.9\%) than other age groups.

Vaso-occlusive crises per year occurred more in females than males. However, there was no statistically significant difference $(p=0.1463)$ between gender and the occurrence of vasoocclusive crises. This agrees with the study by [21], who reported more females had crises than males in the vaso-occlusive group and also a non- significant relationship between crises type and sex $(\mathrm{p}=0.282)$. 
All the patients tested negative for the Duffy phenotype $F y(a-b-)$. The Duffy negative phenotype occurs due to a GATA promoter region mutation upstream of the FY allele. This mutation stops the activity of the GATA site and prevents erythroid cell gene transcription of the Duffy glycoprotein [9]. Most West Africans and $68 \%$ of African Americans, both of whom exhibit the Duffy null phenotype, do not produce Duffy antigens on their erythrocytes [22]. Thus, the results from this study were not surprising.

The Duffy glycoprotein (Fy) on RBCs has been hypothesized to promote clearance of inflammatory cytokines, which may play a role in the pathogenesis of Vaso-occlusion in SCD. Persons with the African-type Fy $(a-b-)$ phenotype whose RBCs lack expression of Duffy may less efficiently clear inflammatory cytokines [20]. Therefore, the Duffy-negative genotype may be associated with the more severe disease among patients with SCD. In this study, there were no associations between the Duffy genotype and the number of Vasoocclusive crises per year, and this result did not differ from that of [24], who used a sample size that was six times the size of this study.[20] in contrast, we have found that the Duffy genotype at the GATA site may serve as a biomarker that can predict in advance damage that can be caused later on to major organs and particularly for abnormal kidney function in SCD. However, in their study, almost all the entire population was self-identified as African American while in this present study, the entire sample was

\section{References}

[1] Weatherall, D.J., Clegg J.B. (2001) Inherited haemoglobin disorders: an increasing global health problem. Bull World Health Organ. 79(8):704-12.

[2] Angastiniotis, M., Modell, B. (1998) Global Epidemiology of Hemoglobin Disorders. Annals of the New York Academy of Sciences 850:251-69.

[3] Diallo, D., Tchernia, G. (2000) Sickle cell disease in Africa. Curr Opin Hematol. 9(2):111-6. identified as African or of African descent. Added to this, the final determinants in their investigations also included measures of endorgan abnormal function to assess chronic organ damage. In contrast, the relationship between the FY-genotype and end-organ abnormal function found in their study might have been as a result of a higher likelihood of other SNPs with their root from Africa or in genes located close to the FY locus.

\section{Conclusions}

All the samples analysed were genotyped Duffy negative homozygous [Fy(a-b-)]. No associations between Duffy genotype and the number of Vaso-occlusive crises were found.

\section{Recommendation}

1. Future studies will need to be conducted with a larger sample number to confirm the association between Duffy genotype and Vaso-occlusion.

2. In addition, a prospective study would be needed to assess and clarify the role of Duffy antigen expression in the development of Vaso-occlusion.

\section{Acknowledgment}

I would like to acknowledge Dr. Charles Brown for his immerse contribution.

\section{Conflict of Interest}

There is no conflict of interest.

[4] Bunn, H.F. (1997) Pathogenesis and treatment of sickle cell disease. N Engl J Med. 11; 337(11):762-9. [5] Marziali, M., Isgrò, A., Gaziev, J., Lucarelli, G. (2009). Hematopoietic stem cell transplantation in thalassemia and sickle cell disease. Unicenter experience in a multi-ethnic population. Mediterr $\mathbf{J}$ Hematol Infect Dis.1 (1).

[6] Walters, M.C. (2005) Stem cell therapy for sickle cell disease: transplantation and gene therapy. 
Hematology Am Soc Hematol Educ Program. pp. 6673.

[7] Shapiro, B.S., Dinges, D.F., Orne, E.C., Bauer, N., Reilly, L.B., Whitehouse, W.G., et al. (1995). Home management of sickle cell-related pain in children and adolescents: natural history and impact on school attendance. Pain. 61(1):139-44.

[8] Hadley, T.J \& Peiper, S.C (1997). From malaria to chemokine receptor: the emerging physiologic role of the Duffy blood group antigen. Blood 89 (30): 7791.

[9] Tournamille, C., Colin, Y., Cartron J.P \& Le Van Kim, C (1995). Disruption of a GATA motif in the Duffy gene promoter abolishes erythroid gene expression in Duffy-individuals. Nat Genet. 10(2):224-228.

[10] Rot A (2005). Contribution of Duffy antigen to chemokine function. Cytokine Growth Factor Rev. 16(6): 87-94.

[11]Darbonne, W.C., Rice, G.C., Mohler, M.A., Apple, T., Hébert, C.A., Valente, A.J \& Baker, J.B (1991) Red blood cells are a sink for interleukin 8, a leukocyte chemotaxin. J Clin Invest 88(4):13621369.

[12] Jison, M.L., Munson, P.J., Barb, J.J., Suffredini, A.F., Talwar, S., Logun, C., Raghavachari, N., Beigel, J. H., Shelhamer, J. H., Danner, R. L \& Gladwin, M.T. (2004) Blood mononuclear cell gene expression profiles characterize the oxidant, hemolytic, and inflammatory stress of sickle cell disease. Blood 104:270-280.

[13] Duits, A. J., Schnog, J. B., Lard, L. R., Saleh, A.W \& Rojer, R.A (1998). Elevated IL-8 levels during sickle cell crisis. Eur J Haematol 61(5):302305.

[14] Kumar, A., Eckmam, J. R., Swerlick, R. A., Wick, T.M. (1996) Phorbol ester stimulation increase sickle erythrocyte adherence to endothelium: a novel pathway involving alpha 4 beta 1 integrin receptors on sickle reticulocytes and fibronectin. Blood. 88 (11):4348-4358
[15]. KBTH (1923), About KBTH retrieved from: https://kbth.gov.gh/.

[16] GICG (1974), History of GICG retrieved from: http://www.clinicalgeneticsgh.com/history.html.

[17]Culleton, R. \& Carter, R. (2012). African Plasmodium vivax: Distribution and origins. Int $J$ Parasitol. 42(12):1091-1097.

[18]Zennadi, R., Hines, P. C., De Castro, L.M., Cartron, J, P., Parise, L.V. \& Telen, M. J. (2004). Epinephrine acts through erythroid signaling pathways to activate sickle cell adhesion to endothelium via $\mathrm{LW}$-alphavbeta3 interactions. Blood 104(12):3774-3781.

[19]Eyler, C.E. \& Telen, M. J. (2006). The Lutheran glycoprotein: a multifunctional adhesion receptor. Transfusion 46(4):668-677.

[20] Afenyi-Annan, A., Kail, M., Combs, M. R, Orringer, E. P., Ashley-Koch, A. \& Telen, M. J. (2008). Lack of Duffy antigen expression is associated with organ damage in patients with sickle cell disease. Transfusion.48(5):917-924.

[21] Olabode, J.O. \& Shokunbi, W.A (2006). Types of crises in sickle cell disease patients presenting at the haematology day care unit (HDCU), University College Hospital (UCH), Ibadan. West Afr J Med 25(4):284-288.

[22] Peiper, S.C., Wang, Z. X., Neote, K., Martin, A.W., Showell, H.J., Conklyn, M. J., Ogborne, K., Hadley, T. J., Lu, Z. H., Hesselgesser, J. \& Horuk, R. (1995). The Duffy antigen/receptor for chemokines (DARC) is expressed in endothelial cells of Duffy negative individuals who lack the erythrocyte receptor. J Exp Med.181(4):1311-1317.

[23]Pogo AO \& Chaudhuri A (2000). The Duffy protein: a malarial and chemokine receptor. Semin Hematol 37:122-129.

[24] Schnog JB, Keli SO, Pieters RA, Rojer RA \& Duits AJ (2000). Duffy phenotype does not influence the clinical severity of sickle cell disease. Clin Immunol 96(3):264-268. 


\title{
A Systematic Review to Observe the Impact of Risk-Based Monitoring as Compared to Conventional On-Site Monitoring in Randomised Clinical Trials and Quality Management in Large Cohort Studies
}

\author{
Shubhra Bansal ${ }^{*}$, Neha Chawla ${ }^{2}$ \\ ${ }^{1}$ Clinical Research, Texila American University, India \\ ${ }^{2}$ Clinical Development Services Agency, Translational Health \& Science Technology \\ Institute, India
}

\begin{abstract}
International Council for Harmonisation, Good Clinical Practice R2 (ICH GCP R2) focuses on quality management as per risk-based methodology, and there has been a lot of focus on monitoring strategy, which is a mixed method of on-site and centralised monitoring. This systematic review was planned to search for the articles providing the evidence for the impact of risk-based monitoring methodology and monitoring standards for cohort studies. A literature search was performed on MEDLINE, COCHRANE, and WEB OF SCIENCE were as per the keyword's searches. All the publications were reviewed for the data that provides evidence risk-based monitoring for randomised clinical trials and its impact to ensure that data integrity, patient safety, and results obtained were reliable. The search resulted in four articles that were qualified that discussed about the comparison between monitoring techniques and the risk-based monitoring methodology in randomised control trials and other interventional trials. Two publications suggested that the SDV\% can be $<8 \%$ and range from 20-50\%, respectively, depending on the assessed factors and risks. Although there is research being conducted to generate the evidence for risk-based monitoring and reduced SDV linked to data errors, further empirical quantitative research should happen to show the impact of risk-based methodology for clinical trials. There is a lack of systematic and empirical data for monitoring as part of quality management in cohort studies.
\end{abstract}

Keywords: Cohort, monitoring, Quality management, Risk-based monitoring, Source data verification.

\section{Introduction}

ICH-GCP E6 R2 guideline [1] for Good Clinical Practice (GCP) states that "the sponsor should implement a system to manage quality throughout all stages of the trial process. Sponsors should focus on trial activities essential to ensuring human subject protection and the reliability of trial results". The guidelines advise that the quality management system should use a risk-based approach. The guideline also defines monitoring as "the act of overseeing the progress of a clinical trial, and of ensuring that it is conducted, recorded, and reported in accordance with the protocol, Standard Operating Procedures (SOPs), Good Clinical Practice (GCP), and the applicable regulatory requirement(s)" and has further added that it is the responsibility of the sponsor to develop a systematic, prioritized, risk-based approach to monitoring clinical trials. It provides flexibility in the extent and nature of monitoring by providing the following approaches that improve the effectiveness and efficiency of monitoring, with appropriate explanation to the approach.

1. On-site monitoring.

2. A combination of on-site and centralized monitoring.

\section{*Corresponding Author: shubhra6@gmail.com}

Received: 31.10 .2021

Accepted: 09.12.2021

Published on: 28.01.2022 
3. Centralized monitoring only, where justified.

As one of the purposes of monitoring is to ensure that the reported trial data are accurate, complete, and verifiable from source documents, sponsors have relied on $100 \%$ source data verification (SDV) as a primary method of monitoring. However, this approach does not guarantee error-free data and reliable results. Historically, the 1988 FDA Guidance on Monitoring of Clinical Investigations stressed personal contact between the monitor and investigator. USFDA withdrew the same in 2010 as evidence grew for the need of a shift in monitoring approach. The 1996 ICH E6 (GCP Guideline) provided flexibility in how trials are monitored; centralized monitoring alone is appropriate only in exceptional circumstances. In 1998, USFDA issued a guidance document in which the agency suggested that monitoring can be flexible so far it is acceptable and provides data standards for studies with minimal on-site monitoring. In 2009 Clinical Trial Transformation Initiative (CTTI) was formed, and the mission was to identify practices that, through broad adoption, will increase the quality and efficiency of clinical trials. CTTI included 120 members from FDA, academia, industry, government, and patients and investigators. The project was to identify current monitoring practices and link it with Quality by Design (QbD [2] principles to clinical trials. During the period of 2009 and 2010, there were more FDA Warning Letters issued to Sponsors with findings of failure to adequately monitor clinical investigators. These findings included an improper selection of investigators who subsequently failed to meet GCP requirements, failure of monitors to find protocol compliance issues, and/or failure of sponsors to promptly take actions to correct deficiencies when identified through monitoring.

In 2011 two draft documents were issued from the FDA and the EMA to modify our monitoring practices. In 2013, the FDA and EMA each finalized their guidance documents.
The landmark shift happened in 2014 when Trancelerate issued a position paper on Riskbased monitoring (RBM) methodology [3]. The paper that suggested to shift the monitoring processes from an excessive concentration on Source Data Verification to comprehensive risk driven monitoring. The impact of RBM was targeted to have earlier detection of issues, with a greater focus on resolution and prevention of issue recurrence, reduction in efforts expended on low-value activities through centralization and data analysis, cost reductions through more focused centralized monitoring activities, and targeted on-site monitoring, greater compliance with Good Clinical Practice (GCP), relevant regulatory requirements and a more collaborative cross-functional team approach the coordination of monitors, data managers, statisticians, medical monitors, and site staff.

Since then, there have been research studies and systematic reviews in monitoring methodology for clinical trials to show that reduced $\%$ of SDV is non-inferior to $100 \%$ SDV [4]. However, the systematic review research has been limited to interventional randomised control trials where monitoring is conducted in routine settings [4]. Systematic review for clinical trials shows that one hundred percent SDV is not a rational method of ensuring data integrity and subject safety based on the high cost, and this literature review indicates that reduced SDV is a viable monitoring method [5]. There has been no work done in Cohort studies. However, it is important and significant to have the monitoring techniques defined as a standard practice in Cohort studies also, as the data collected need to be reliable as they feed into policy and give the pathway to translational research.

The data is critical, and safety is important as these are extra test beyond standard of care for collection of data. With Cohort studies, the monitoring is conducted with a different approach and has been an area, which lacks research. With the above background, the systematic review is aimed to identify, examine, 
and investigate the available literature for the monitoring approaches executed in cohort studies.

\section{Methods}

There have been several clinical research systematic reviews, however, primarily for clinical settings and disease indication. A systematic review is an approach towards identifying the literature and analysing the literature data. This review provides the basis to identify, examine and investigate the available literature for the monitoring approaches in interventional clinical trials and cohort studies. We conducted a search by defining the protocol with primary objective to identify, examine and investigate the published papers for the monitoring approaches in clinical studies for randomised control trials (update systematic review for other interventional clinical studies) and cohort studies. We planned to extract data on different monitoring approaches, identify the factors that may be involved in the monitoring approaches. These other factors included risk levels for trial and participating sites, type of data management system, recruitment numbers, and critical data fields assessment. Additionally, it was planned to detail the components of risk monitoring: informed consent document, critical data fields, critical processes, on-site monitoring, central monitoring, and explore the proportion of Source Data Verification (SDV) undertaken. It was also intended to describe the use of a collaborative team approach for reducing the errors, clarify the evidence linking the percentage source data verification percentage with error rates and assess the impact of risk-based monitoring techniques on the subject safety, data integrity, and cost reductions. The Population, Intervention, Comparison, and Outcomes (PICO) criteria were used for including the studies in the review (Table 1). While developing the protocol for search, PRISMA guideline was followed. The search was conducted by using MEDLINE, COCHRANE, and WEB OF SCIENCE electronic search databases for the last 10 years; from 1 Jan 2009 - 25 Sep 2019 by the first reviewer and a second reviewer independently using free text to include all the available published papers. A detailed search strategy is provided on Table 2.

Table 1. The Population, Intervention, Comparison, and Outcomes (PICO) Criteria

\begin{tabular}{|l|l|}
\hline $\begin{array}{l}\text { Population, or participants and } \\
\text { conditions of interest }\end{array}$ & $\begin{array}{l}\text { For this search, the defined condition of interest is } \\
\text { interventional clinical trials and Cohort studies (no } \\
\text { restriction to disease and population). }\end{array}$ \\
\hline Interventions or exposures & $\begin{array}{l}\text { For this search, monitoring is considered as an } \\
\text { intervention. Monitoring could be an internal quality } \\
\text { improvement or external monitoring as part of sponsor } \\
\text { responsibilities. Monitoring includes data monitoring, } \\
\text { process monitoring, or safety monitoring as part of } \\
\text { sponsor responsibilities. }\end{array}$ \\
\hline Comparisons or control groups & $\begin{array}{l}\text { This search is based on the comparison being 'No } \\
\text { monitoring' is considered as the comparator for the } \\
\text { cohort studies and 'risk-based monitoring' for } \\
\text { randomised control trials and other interventional } \\
\text { clinical trials. }\end{array}$ \\
\hline Outcomes of interest & $\begin{array}{l}\text { The outcomes of interest are error rates, subject safety, } \\
\text { data integrity, and cost reductions }\end{array}$ \\
\hline
\end{tabular}




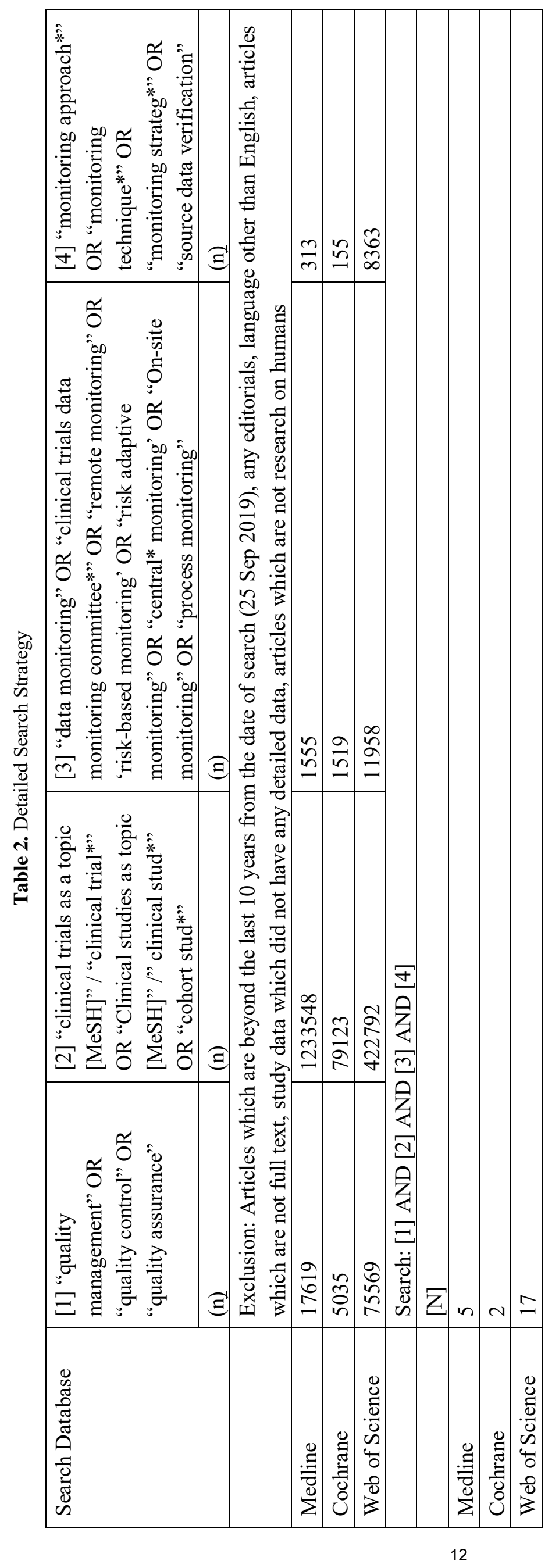




\section{Results and Discussion}

Our search strategy and keywords resulted in the 5 full-text articles as per MEDLINE [6-10], 2 full-text articles from COCHRANE [4, 11] search, and 17 full-text articles from Web of Science [6-9, 12-24]. The search resulted in a total of 19 publications from MEDLINE, COCHRANE, and WEB OF SCIENCE, after removing duplicates from the total of 24 articles as shown in Figure 1. 14 articles described methods for quality management, monitoring of clinical trial activities in varying levels of detail by the clinical team in clinical settings, data management process, central statistical monitoring, technology systems for central monitoring, these were not referring the monitoring techniques and approaches in clinical trials or cohort studies. These were also not describing the research conducted on monitoring techniques and comparison for quality management and therefore were excluded. 1 article was excluded as the full text was not available in English, though the title abstract was available in English. 4 articles were qualified based on the information available in abstracts and title to be included in the systematic review. These articles discussed about the comparison between monitoring techniques and the risk-based monitoring methodology in randomised control trials and other interventional trials. A summary of all the included publications is listed on table 4.0 with the limitations.

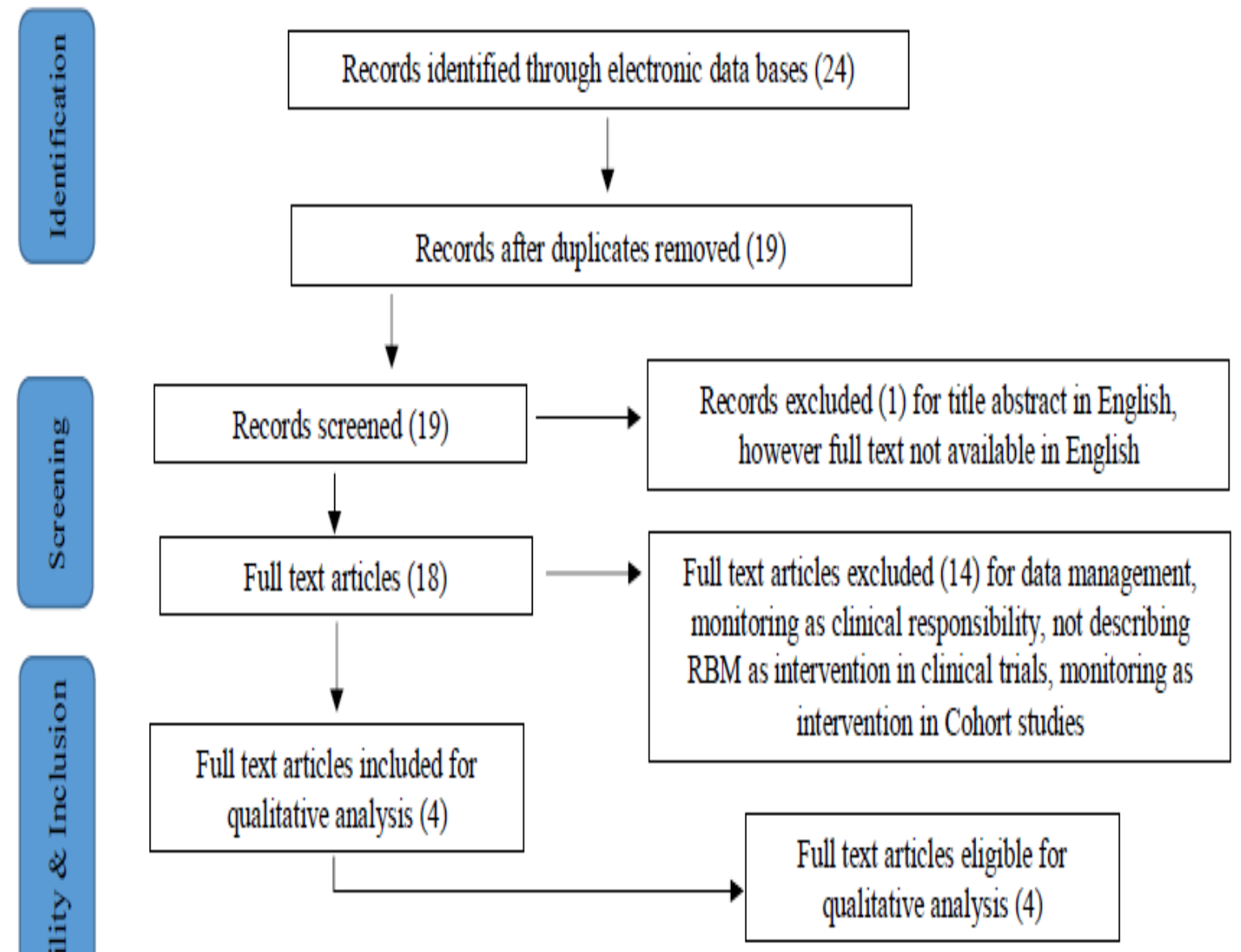

Figure 1. Literature Search Protocol Design and Results 


\begin{tabular}{|c|c|c|c|c|}
\hline 产 & 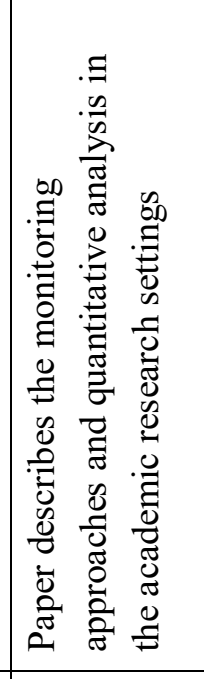 & 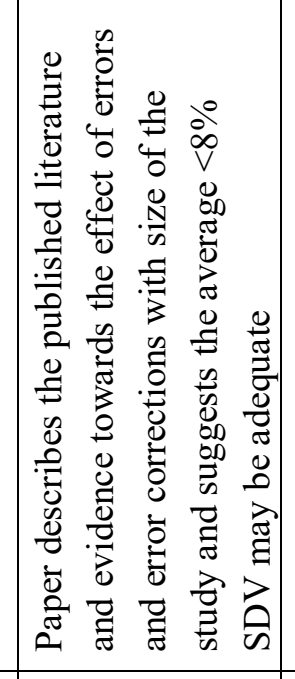 & 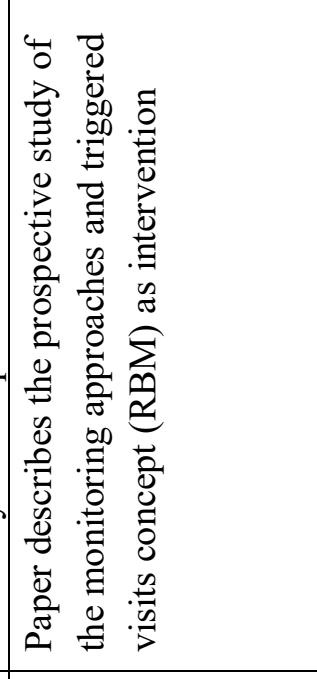 & 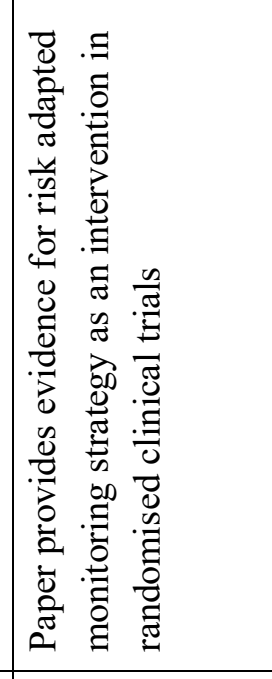 \\
\hline 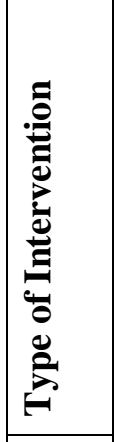 & 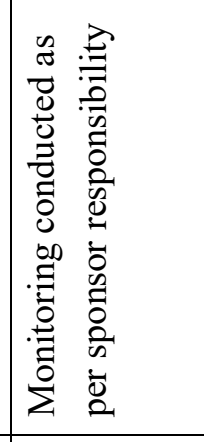 & 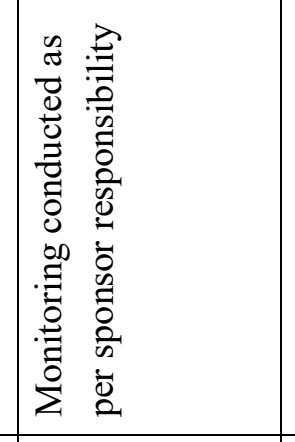 & 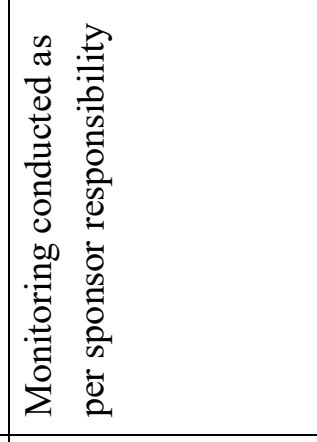 & 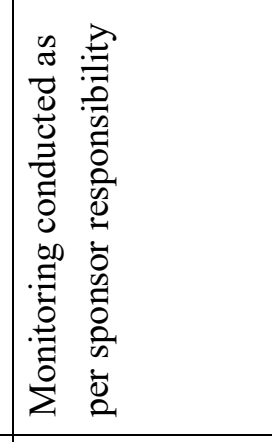 \\
\hline 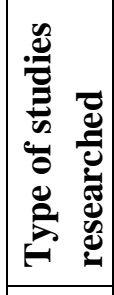 & 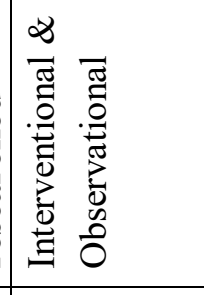 & 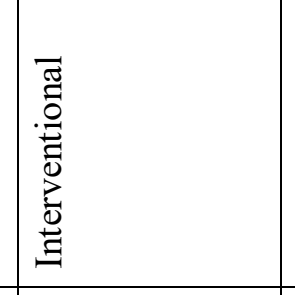 & 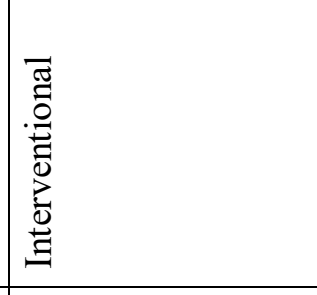 & 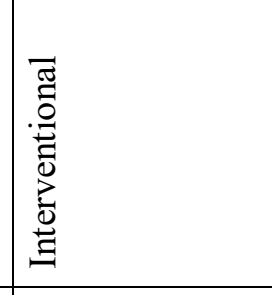 \\
\hline 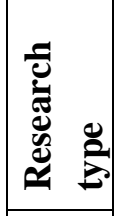 & 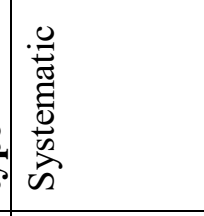 & 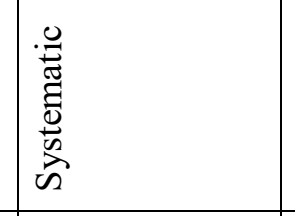 & 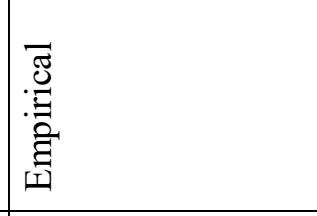 & 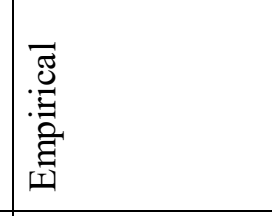 \\
\hline 童 & 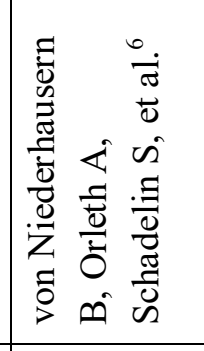 & 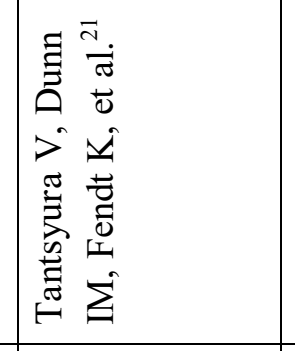 & 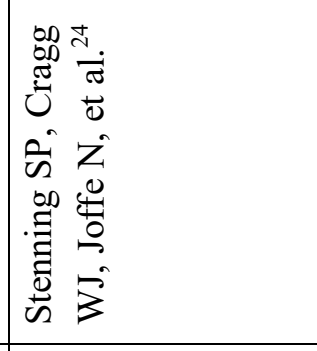 & 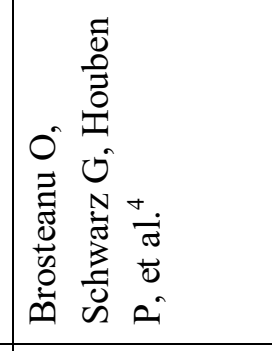 \\
\hline 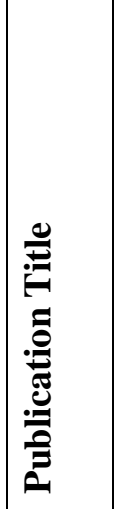 & 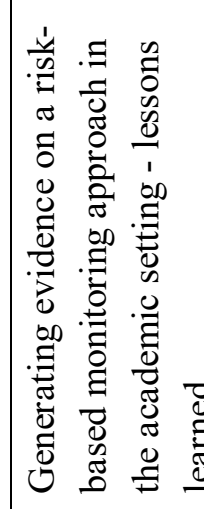 & 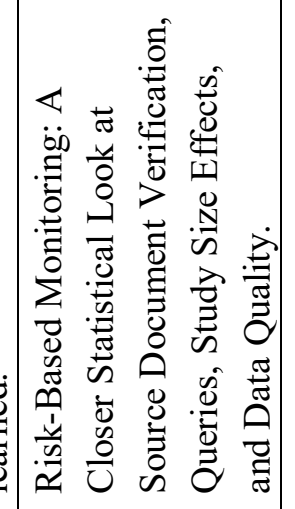 & 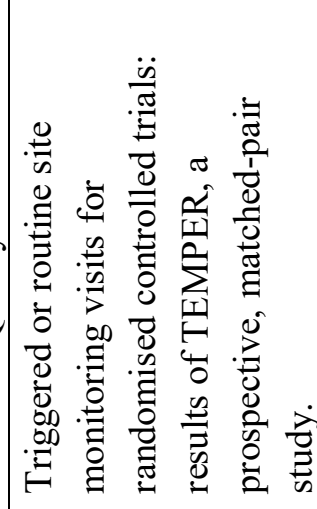 & 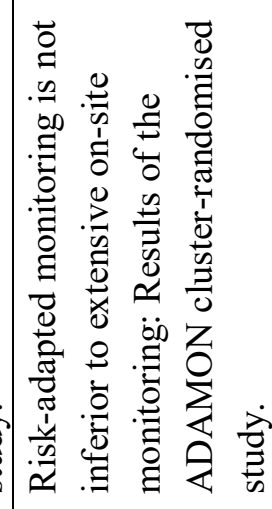 \\
\hline
\end{tabular}




\section{Monitoring Strategy and Factors Defining Monitoring Strategy}

The challenge is to have the evidence for how much SDV is sufficient to meet the fundamental requirement of GCP as safety and well-being of participants and reliable results.

The evidence on the effects of errors from the literature published [21] for the period of 20112014 was studied. They suggested the operational considerations for minimising the impact of data error on the study conclusion by mitigating the factors that poses risk. These were (a) risk of error occurrence further categorising into data never queried / never changed, queries leading to no change, changes (non-key data), changes (key data points), and initially missing data that are added later without query (usually as a result of monitoring activities) (b) probability that error will not be detected and corrected and (c) error severity. They estimated the SDV effectiveness, SDV redundancy, study size effect, and error hierarchy by severity. It was recommended that SDV, rather than just focussing on the key primary efficacy and safety outcomes, focus on data clarification queries as highly discrepant (and the riskiest) data. They suggested that the monitoring strategy should take the study size effect into consideration, focusing SDV on "high-value"' data points.

Risk ADApted MONitoring (ADAMON) ${ }^{4}$ study was conducted to investigate whether a trial-specific, risk-adapted, reduced on-site monitoring strategy is as effective as an extensive, non-targeted on-site monitoring strategy in preventing major or critical violation of GCP objectives, as ascertained by independent audits at the end of the trial. ADAMON was designed to be a stratified, cluster-randomised non-inferiority study. Trial sites within participating clinical trials were randomised either to extensive or to risk adapted monitoring. Their results showed that the average number of monitoring visits and Time spent on-site was 2.1 and 2.7 times higher in onsite monitoring than in risk-adapted monitoring, respectively. The findings were identified in $18 \%-99 \%$ of the audited patients after monitoring. The study demonstrated that riskadapted monitoring is non-inferior to extensive on-site monitoring. This benchmark study also showed that Risk-adapted monitoring in only a sample of patients is sufficient to identify systematic problems in the conduct of clinical trials. It was concluded that Risk-adapted monitoring has a part to play in quality control and should be part of a comprehensive quality management approach covering the entire trial lifecycle. Another critical aspect innovated during ADAMON study was a classification of trials based on risk identified. The criteria's used were standard to classify as $\mathrm{K} 2$, intermediaterisk, and $\mathrm{K} 3$, low-risk trials based on publication [20] describing the risk-adapted on-site monitoring in non-commercial trials.

Another literature article that focussed on the monitoring strategy was titled as Triggered or routine site monitoring visits for randomised controlled trials: the result of TEMPER, a prospective, matched-pair study ${ }^{24}$. The study was designed as a prospective study to assess the value of triggered monitoring in distinguishing sites with important protocol or GCP compliance issues which are not identified by central monitoring. The primary analysis showed that $88.1 \%$ of triggered monitoring visits had at least 1 new Major or Critical finding when compared to $81.0 \%$ of untriggered monitoring visits. Several re-consent issues were found during these visits; therefore, once reconsent findings were excluded, it resulted in $85.7 \%$ versus $59.5 \%$. It was suggested that a triggered monitoring approach might be used but needs to be complimented and improved with an investigation of further central monitoring triggers.

\section{Evidence Based Linking the Percentage Source Data Verification Percentage and Error Rates}

It was concluded that the value of SDV is currently hugely overestimated, and for large 
studies, SDV produces no detectable return on investment [21]. The research group estimated that manual SDV is approximately 15 times less effective than computerized data validation by deriving from data from [25] and TransCelerate [3], respectively. Their analysis demonstrated that the true effectiveness value of SDV (measured as a proportion of key data points modified because of SDV) is minimal $(0.1 \%$ $1.4 \%$ ), especially when the acceptability of error by industry is $5 \%$ alpha error. The important aspect that was shown is that overall, $97 \%$ of data in a typical study never change, and only $0.9 \%$ of key data that are typically modified after original entry and need possible attention. It was estimated that non-queried data is $0.22 \%$ and bears risk, if any, and therefore no intervention is required, including on-site SDV. Their analysis demonstrated minimal effects of errors and error corrections on study results and study conclusions, with diminishing effect as the study size increases. It was also suggested that, on average, $<8 \% \mathrm{SDV}$ is adequate to ensure data quality, with perhaps higher SDV rates for smaller studies and virtually $0 \%$ SDV for large studies. The limitation of the monitoring model described was that it was based on assumptions that the query generation process, including data validation and centralized monitoring, is comprehensive and focused on key data points; (2) that errors are distributed randomly across subjects and variables; and (3) that the $80 \%$ of prospective data changes are identified and captured as "queries".

The evidence was generated on a risk-based monitoring approach in academic settings [6]. The mixed-method study was conducted at the Clinical trials unit of the University Hospital in Basel. The studies were selected according to the assessed base don ADAMON for a stipulated duration between 2012-2014. The study had quantitative retrospective analysis with the study level variables as study design, study type, study sponsor, study design, type of research, study phase (I-IV), and type of study population (e.g., the inclusion of vulnerable population). The variables further were specifically selected for site-level information as site location, ADAMON risk category, presence of electronic database, principal investigator, and whether he/she changed during conduct, staff experience, and a number of planned subjects at the site.

At the level of each monitoring visit, information collected was a type of visit (i.e., initiation, interim, close-out), the number of findings categorised by administrative, patient rights, patient safety, laboratory/biological specimen, data point confirmation, and endpoint related. The study also conducted prospective semi-structured interviews of the monitors involved on these studies. It was concluded that the risk-based approach majorly identified administrative findings contributing $46.2 \%$ of total findings and right subject findings contributed $49.1 \%$ of total findings. The interviews with monitors resulted in the conclusion that the monitors understand the positive aspects of a risk-based approach but fear missing systematic errors due to the low frequency of visits concluding that a risk-based on-site approach should further be complemented by centralized monitoring for trial data quality.

\section{Monitoring in Cohort Studies}

The search showed that there is literature available for the randomised control trials and other interventional trials. There is gap in literature for quality management and monitoring in cohort studies. Systematic and empirical research is required for research in data and process monitoring in the cohort studies.

\section{Conclusion}

Risk-based monitoring is imperative advancement in clinical trial monitoring methodology. Evidence shows that reduced onsite monitoring is a viable method of monitoring in randomised clinical trials. Evidence has been generated that a risk-based monitoring approach for clinical trials complimented with centralised 
monitoring is the way forward for randomised clinical trials. However, there is no data is available for quality management and monitoring in the large cohort studies. As known, cohort studies come with their own specifications as these are large in sample size, longitudinal in design with several facets. These contribute largely to evidence generation for indication study at the population level, and therefore, the quality management for these studies should not be underestimated. In conclusion, cohort study has a large magnitude. The data generated from these cohort studies should be of utmost quality as these are the primary source for feeding the data for policy generation. As there is a gap in the literature for

\section{References}

[1] Integrated Addendum to Ich E6(R1): Guideline for Good Clinical Practice E6(R2). Published online November 9, 2016.

https://database.ich.org/sites/default/files/E6 R2 Ad dendum.pdf.

[2] Quality by Design. Published online 2009. https:/ctti-clinicaltrials.org/X.

[3] Position Paper: Risk-based Monitoring Methodology. In: TransCelerate; 2014. http://www.transceleratebiopharmainc.com/wpcontent/uploads/2016/01/TransCelerate-RBMPosition-Paper-FINAL-30MAY2013.pdf.pdf.

[4] Brosteanu O, Schwarz G, Houben P, et al., 2017, Risk-adapted monitoring is not inferior to extensive on-site monitoring: Results of the ADAMON clusterrandomized study. Clin Trials Lond Engl., 14(6):584596. doi:10.1177/1740774517724165.

[5] Hurley C, Shiely F, Power J, et al., 2016, Riskbased monitoring (RBM) tools for clinical trials: A systematic review. Contemp Clin Trials., 51:15-27. doi: 10.1016/j.cct.2016.09.003.

[6] Von Niederhausern B, Orleth A, Schadelin S, et al., 2017, Generating evidence on a risk-based monitoring approach in the academic setting - lessons learned. Bmc Med Res Methodol., 17:26. doi:10.1186/s12874-017-0308-6. quality management in cohort studies, research needs to be conducted for standardising the quality management and monitoring methods for cohort studies.

\section{Acknowledgement}

The author thanks Dr. Usha Menon, Dr. Shinjini Bhatnagar, and Dr. Nitya Wadhwa of Translational Health Science and Technology Institute (THSTI), Faridabad, India, for their continued support and guidance.

\section{Declaration of Conflicting Interests}

The author(s) declared no potential conflicts of interest with respect to the research, authorship, and/or publication of this article.

[7] Morrison BW, Cochran CJ, White JG, et al., 2011, Monitoring the quality of conduct of clinical trials: a survey of current practices. Clin Trials., 8(3):342349. doi:10.1177/1740774511402703.

[8] Oba K., 2016, Statistical challenges for central monitoring in clinical trials: a review. Int $J$ Clin Oncol., 21(1):28-37. doi:10.1007/s10147-015-09144.

[9] Timmermans C, Doffagne E, Venet D, et al.,2016, Statistical monitoring of data quality and consistency in the Stomach Cancer Adjuvant Multi-Institutional Trial Group Trial. Gastric Cancer., 19(1):24-30. doi:10.1007/s10120-015-0533-9.

[10] Tudur Smith C, Stocken DD, Dunn J, et al., 2012, The value of source data verification in a cancer clinical trial. PloS One., 7(12): e51623. doi: 10.1371/journal.pone.0051623.

[11]Klingberg S, Wittorf A, Meisner C, et al.,2010, Cognitive behavioural therapy versus supportive therapy for persistent positive symptoms in psychotic disorders: the POSITIVE Study, a multicenter, prospective, single-blind, randomised controlled clinical trial. Trials., 11:123. doi:10.1186/1745-621511-123.

[12] Wilson B, Provencher T, Gough J, et al., 2014, Defining a Central Monitoring Capability: Sharing the Experience of TransCelerate BioPharma's 
Approach, Part 1. Ther Innov Regul Sci., 48(5):529535. doi:10.1177/2168479014546335.

[13] Van den Bor RM, Oosterman BJ, Oostendorp MB, Grobbee DE, Roes KCB., 2016, Efficient Source Data Verification Using Statistical Acceptance Sampling: A Simulation Study. Ther Innov Regul Sci., 50(1):82-90. doi:10.1177/2168479015602042.

[14] Sheetz N, Wilson B, Benedict J, et al., 2014, Evaluating Source Data Verification as a Quality Control Measure in Clinical Trials. Ther Innov Regul Sci., 48(6):671-680. doi: $10.1177 / 2168479014554400$.

[15] Houston L, Probst Y, Yu P, Martin A., 2018, Exploring Data Quality Management within Clinical Trials. Appl Clin Inform., 9(1):72-81. doi:10.1055/s0037-1621702.

[16]Hullsiek KH, Kagan JM, Engen N, et al., 2015, Investigating the Efficacy of Clinical Trial Monitoring Strategies: Design and Implementation of the Cluster Randomized START Monitoring Substudy. Ther Innov Regul Sci., 49(2):225-233. doi:10.1177/2168479014555912.

[17] Sudo T, Sato A., 2017, Investigation of the Factors Affecting Risk-Based Quality Management of Investigator-Initiated Investigational New-Drug Trials for Unapproved Anticancer Drugs in Japan. Ther Innov Regul Sci., 51(5):589-596. doi:10.1177/2168479017705155.

[18] Rosenberg MJ., 2014, Key Considerations in the Transition to Risk-Based Monitoring. Ther Innov Regul Sci., $\quad 48(4): 428-435$. doi:10.1177/2168479013519631.

[19] Cornu C, Binquet C, Thalamas C, et al., 2013, Public Clinical Trials: which Kind of Monitoring
Should be Used? Therapie., 68(3):135-141. doi:10.2515/therapie/2013032.

[20] Brosteanu O, Houben P, Ihrig K, et al., 2009, Risk analysis and risk-adapted on-site monitoring in non-commercial clinical trials. Clin Trials., 6(6):585596. doi:10.1177/1740774509347398.

[21] Tantsyura V, Dunn IM, Fendt K, Kim YJ, Waters J, Mitchel J., 2015, Risk-Based Monitoring: A Closer Statistical Look at Source Document Verification, Queries, Study Size Effects, and Data Quality. Ther Innov Regul Sci., $\quad 49(6): 903-910$. doi:10.1177/2168479015586001.

[22] Barnes S, Katta N, Sanford N, Staigers T, Verish T., 2014, Technology Considerations to Enable the Risk-Based Monitoring Methodology. Ther Innov Regul Sci., $\quad 48(5): 536-545$. doi: $10.1177 / 2168479014546336$.

[23] Smith CT, Stocken DD, Dunn J, et al., 2012, The Value of Source Data Verification in a Cancer Clinical Trial. Plos One., 7(12): e51623. doi: 10.1371/journal.pone.0051623.

[24] Stenning SP, Cragg WJ, Joffe N, et al., 2018, Triggered or routine site monitoring visits for randomised controlled trials: results of TEMPER, a prospective, matched-pair study. Clin Trials., 15(6):600-609. doi:10.1177/1740774518793379.

[25] Mtchel J, Cho T, Gittleman D., 2014, Time to change the clinical trial monitoring paradigm: results from multicenter clinical trial using quality by design methodology, risk-based monitoring, and real-time direct data entry. Appl Clin Trials. (Published online January 17). 


\title{
Impact of Cultural Diversity on Overall Organizational Performance: A Moderating Role Education
}

\author{
Laar David Diam \\ Doctor of Philosophy in Management, Texila American University, Ghana
}

\begin{abstract}
This study focused on the impact of cultural diversity on organizational performance as moderated by employees' educational attainment. The study measured cultural diversity as language, religious and value system diversity. Organizational performance was measured as team building, communication, and employee productivity. The study collected primary data from 353 employees from ten different manufacturing companies in the Ashanti and Greater Accra Regions of Ghana. The study employed mean and standard deviation for descriptive analysis. The study employed a structural equation model for the estimation. Cultural diversity was found to be prevalence in the sampled companies. However, team building, and communication were effective, and employee productivity was high. The educational attainment of employees significantly reduced the negative impact of language, religious, and value system diversity on each organizational performance indicator. Stakeholders in Ghana's manufacturing industry should encourage continued human resource development through the pursuance of higher education, internal and external training, and seminars.
\end{abstract}

Keywords: Cultural Diversity, Educational attainment, Organizational Performance.

\section{Introduction}

Organizations and their workers operate in a distinct culture or socio-cultural context [1]. This is increasing in recent times because of globalization, where people from different socio-cultural backgrounds are hired by the organization [1], increasing cultural diversity in an organization. The term "diversity" refers to a group's variety and distinctions [2]. Individual distinctions such as ethnicity, age, religion, handicap status, geographic location, personality, sexual preferences, and a slew of other personal, demographic, and organizational traits can all be included in the definition of diversity. As a result, diversity may be a broad phrase that encompasses people from a variety of backgrounds [3].

Although mutual respect is the foundation of workplace diversity, accommodating each different worker's attitudes and opinions can be a huge task for companies, making diversity management challenging [4]. Employee work restrictions such as race, religion, and culture can be burdensome at times, especially if the organization's diversity is so great that the firm needs to hire a full-time staff to keep track of the employees' requirements [5]. Some Muslim employees, for example, may choose not to work on Fridays because it is a holy day for them. In such cases, employers must make arrangements for someone to fill in for them when the need arises.

Several organizations such as Canopy Health [6] have identified team building, employee productivity and communication as key indicators of organizational performance in a culturally diverse work environment. In a culturally diverse workplace, team building is a 
key tool employed by management to enhance productivity [7]. Effective team building can help achieve the vision and mission of an organization and help to foster a healthier workplace [8].

Employee productivity, on the other hand, as defined by Barcenas [89], is the amount of work (or output) produced by an employee in a specific period of time. Employees Productivity increases the overall efficiency of an organization $[9,10]$.

However, empirical studies on the impact of cultural diversity on organizational performance have produced mixed findings. For example, Mecheo [11] found that religion has a detrimental impact on employee productivity but has a positive impact on job dedication. Similarly, Oduro, Yalley, Sarpong, Kweitsu, and Danso [12] found that cultural diversity and its management has an impact on not just organizational competitiveness but also the organization's capacity to fulfill its objectives. Also, Qiaoxin and Liswandi [13] have shown that religion, language, and age all have a substantial impact on employee happiness, but gender has no impact on employee satisfaction in the firm.

Though the above studies and others have paid much attention to cultural diversity, less attention has been given to how the educational attainment of employees influences the relationship between cultural diversity and organizational performance indicators [14]. Though globalization is increasing, deeping the cultural diversity in organizations, literacy or educational attainment is increasing as well. Thus, the question is, does education effect the impact of cultural diversity on organizational performance indicators? This study sought to address this important vacuum in empirical studies.

This study would help to place cultural diversity in good perceptive in the phase of increasing the educational attainment of employees.

\section{Methods}

\section{Description of the Site}

This study was conducted in the Ashanti and Greater Accra Regions of Ghana. The Ashanti Region is located in south Ghana, and it is the third largest of 16 administrative regions, occupying a total land surface of $24,389 \mathrm{~km}^{2}$ $(9,417 \mathrm{sq} \mathrm{mi})$ or 10.2 percent of the total land area of Ghana. In terms of population, however, it is the most populated region with a population of 4,780,380 according to the 2010 census, accounting for $19.4 \%$ of Ghana's total population. Kumasi is the capital town of the Ashanti Region.

The Greater Accra Region is the smallest in terms of land area among the 16 administrative regions in Ghana. The region occupies a total land surface of 3,245 square kilometres. Greater Accra is the second populous region with a population of 4,010,054 in 2010, accounting for 16.3 percent of Ghana's total population [15]. The region is, however, the most urbanized where $87.4 \%$ of its population in lives in urban communities. Accra is the capital of the Greater Accra Region and the capital town of Ghana. These two regions host most of the Ghana's industries, manufacturing, services, construction, agro-processing, among others.

\section{Description of Experiment}

The study through Yamane [16] sample size determination formulae used 353 employees from ten manufacturing firms, as shown in Table 1. The employees were sampled from each firm using simple random sampling via the lottery method. The number of employees from each company is shown in Table 1 . 
Table 1. Population of Staff and Locations of the Accessible Companies

\begin{tabular}{|l|l|l|l|l|}
\hline No. & Companies & Staff population & Relative freq. (rf) & Sample size (rf*353) \\
\hline 1 & Guinness Ghana Breweries & 420 & 0.140 & 49 \\
\hline 2 & Dannex Ayrton Starwin Drugs & 713 & 0.237 & 84 \\
\hline 3 & Kasapreko & 437 & 0.145 & 51 \\
\hline 4 & Camelot Print Ghana & 66 & 0.022 & 8 \\
\hline 5 & Karma Pharmaceuticals & 235 & 0.078 & 28 \\
\hline 6 & Kinapharma Limited & 148 & 0.049 & 17 \\
\hline 7 & Latex foam & 66 & 0.022 & 8 \\
\hline 8 & Ashfoam & 83 & 0.028 & 10 \\
\hline 9 & Unilever: & 713 & 0.237 & 84 \\
\hline 10 & Tobinco Pharmaceuticals & 123 & 0.042 & 14 \\
\hline Total & 3,004 & 1.000 & 353 \\
\hline
\end{tabular}

Source: Administrations of the Selected Companies (July 2021)

The study used the questionnaire to collect the data from the staff of the selected companies. The questionnaire had four sections. Part I: Socio-demographic characteristics of respondents comprised of gender, age, educational level, religious affiliation, working experience, and tribe. Section II focused on culture diversity. The section had two subsections, including religion and the value system. Religion construct had nine (9) items, and whiles value system construct had nine (9) items. The items under of religious and value system diversities were adapted from Merk et al. (2017). Section III focused on communication, and the items under this were adapted from Mechheo (2014).

Communication competence had two main components, namely interpersonal skills (7 items) and cultural empathy (3 items). Section IV focused on team effectiveness, and it had 11 items. Section V focused on employee's Productivity and had 9 items. All the questions under each part (with the exception of Section I) were in the form of five-point Likert, ranging from strongly disagree to strongly agree.

The questionnaire was reliability with an overall Cronbach's Alpha of 0.887 (i.e., $\alpha=0.887$ ) and valid with Factor Loading Score for each item more than 0.4 and the KaiserMeyer-Olkin (KMO) for each construct was more than 0.8 .

\section{Statistical Method}

The data were analysed using Statistical Package for Social Sciences (SPSS), version 21.0, and STATA version 13.0. The study edited the data, coded the data, and entered them into the software for analysis. The study used SPSS for all the descriptive analysis, and whiles STATA was used to estimate of the model. The descriptive analysis was done using mean, standard deviations, skewness, and kurtosis. The mean score range of 1.00-3.49 is an indication that cultural diversity or organizational performance indicators are low. On the other hand, the mean score range of 3.50-5.00 suggests that cultural diversity and performance indicators are high.

To determine the effect of education on the impact of cultural diversity indicators (religion, language, and value system) on organization performance indicators (team building, communication, and employee productivity), this study used Structural Equation Model as suggested by Kline [17]. The models are specified below.

$$
\begin{aligned}
P R O D V=\propto_{0}+ & \propto_{1} R E L * E D U C+\propto_{2} \text { LANG } \\
& * \text { EDUC }++\propto_{3} \text { VSYSTEM } \\
& * \text { EDUC }+\propto_{4} \text { GENDER } \\
& +\propto_{5} A G E \\
& +\varepsilon \ldots \ldots \ldots \ldots \ldots \text {. Model } 1
\end{aligned}
$$




$$
\begin{array}{rl}
\text { TEAMB }=\propto_{0}+ & \propto_{1} \text { REL } * \text { EDUC }+\propto_{2} \text { LANG } \\
& * E D U C++\propto_{3} \text { VSYSTEM } \\
& * \text { EDUC }+\propto_{4} \text { GENDER } \\
& +\propto_{5} \text { AGE } \\
& +\varepsilon \ldots \ldots \ldots \ldots \ldots \text { Model } 2 \\
\text { COM } \propto_{0}+\propto_{1} & R E L * E D U C+\propto_{2} \text { LANG } \\
& * E D U C++\propto_{3} \text { VSYSTEM } \\
& * E D U C+\propto_{4} \text { GENDER } \\
& +\propto_{5} \text { AGE } \\
& +\varepsilon \ldots \ldots \ldots \ldots \ldots \text { Model } 3
\end{array}
$$

Where PRODV is Productivity, TEAMB is team building, and COM is communication, REL*EDUC is the interaction of religious diversity and educational attainment, VSYSTEM*EDUC is the interaction of value system diversity and educational attainment, LANG*EDUC is the interaction of language diversity and educational attainment, GENDER is the gender of respondents and AGE is the age of respondents. Team building, communication, and employee productivity were measured qualitatively based on a scale by Mechheo [18]. The cultural diversity (language, religious and value system diversity) were measured based on a scale by Merk [19]. Age was a continuous variables, while gender was a nominal variable with a female as the reference category.

\section{Results}

\section{Socio-demographic Characteristics of the Respondents}

\begin{tabular}{|c|c|c|c|}
\hline Characteristics & Variable & Frequency $(\mathbf{N})$ & Percentage $(\%)$ \\
\hline \multirow[t]{2}{*}{ Sex } & Male & 195 & 55.2 \\
\hline & Female & 158 & 44.8 \\
\hline \multirow[t]{7}{*}{ Educational Attainment } & None & 16 & 4.5 \\
\hline & Basic School & 35 & 9.9 \\
\hline & Senior High & 85 & 24.1 \\
\hline & Diploma/HND & 68 & 19.3 \\
\hline & First Degree & 92 & 261 \\
\hline & Masters' Degree & 43 & 12.2 \\
\hline & $\mathrm{PhD}$ & 14 & 4.0 \\
\hline \multirow[t]{4}{*}{ Level of Experience } & Less than 5 years & 62 & 17.6 \\
\hline & $5-9$ years & 127 & 36.0 \\
\hline & $10-14$ years & 126 & 35. \\
\hline & At least 15 years & 38 & 10.8 \\
\hline \multirow[t]{5}{*}{ Religious Affiliation } & Atheist & 5 & 1.4 \\
\hline & Christian & 167 & 47.3 \\
\hline & Muslim & 125 & 35.4 \\
\hline & Traditionalist & 43 & 12.2 \\
\hline & Buddhist & 13 & 3.7 \\
\hline \multirow[t]{4}{*}{ Tribe } & Akan & 122 & 34.6 \\
\hline & Hausa & 67 & 19.0 \\
\hline & Mole-Dagbani & 22 & 6.2 \\
\hline & Ewe & 43 & 12.2 \\
\hline
\end{tabular}

As part of the survey, data were gathered on the demographic characteristics of the various respondents considered in this study. The main aspects of the socio-demographic characteristics of the respondents included sex, educational attainment, level of experience of working in the organization, religious affiliation, and the tribe of these respondents. A summary of the results is displayed in Table 2 .

Table 2. Socio-Demographic Characteristics of Respondents 


\begin{tabular}{|l|l|l|l|}
\hline & Nzema & 32 & 9.1 \\
\cline { 2 - 4 } & Krobo/Ga/Adangbe & 49 & 13.9 \\
\cline { 2 - 4 } & Others & 18 & 5.1 \\
\hline
\end{tabular}

Source: Field Data (2021)

From the results, though males dominated over females, the gap is very close. The higher number of employees had at least second cycle education, a cumulative of which is $85.7 \%$ of the entire population. Table 2 reports that the majority of the respondents had at most 5 years of working experience. Table 2 reports that 5 and $13(3.7 \%)$ of the employees considered in this study were Atheists, Christians, Muslims, Traditionalists, and Buddhists respectively.

\section{Descriptions of Study Variables}

The key variables used in this study are described in Table 3. (1.4\%), 167 (47.3\%), 125 (35.4\%), 43 (12.2\%),

Table 3. Descriptions of Study Variables

\begin{tabular}{|l|l|l|l|l|l|l|l|}
\hline $\begin{array}{l}\text { Main } \\
\text { Variables }\end{array}$ & Specific variables & Min. & Max. & Mean & Std. & Skewness & Kurtosis \\
\hline $\begin{array}{l}\text { Cultural } \\
\text { diversity }\end{array}$ & Religion & 1 & 5 & 3.8677 & 0.1181 & -0.003 & -0.824 \\
\cline { 2 - 8 } & Value system & 1 & 5 & 3.6956 & 1.0061 & -0.617 & 0.330 \\
\hline \multirow{2}{*}{$\begin{array}{l}\text { Performance } \\
\text { indicators }\end{array}$} & Team building & 1 & 5 & 3.3732 & 0.9345 & 0.325 & 0.276 \\
\cline { 2 - 8 } & Communication & 1 & 5 & 3.7377 & 1.0113 & -0.216 & -0.583 \\
\cline { 2 - 8 } & $\begin{array}{l}\text { Employee } \\
\text { productivity }\end{array}$ & 1 & 5 & 4.0019 & 0.1817 & 0.316 & 0.438 \\
\hline
\end{tabular}

Source: Filed Data (2021)

The results in Table 3 show that cultural diversity in the areas of religion and value system were eminent in the sampled organization. The sampled companies had high team building, organizational communication, and employee productivity.

\section{Estimation of the Models}

The study first estimated the impact of cultural diversity on performance indicators without the moderating role of education, as shown in Table 4.

Table 4. Impact of Cultural Diversity on Organizational Performance

\begin{tabular}{|l|l|l|l|}
\hline \multirow{2}{*}{ Variables } & Model 1 & Model 2 & Model 3 \\
\cline { 2 - 4 } & $($ Team Building) & (Communication) & (Employee Productivity) \\
\hline \multirow{3}{*}{ Language diversity } & -0.0047 & -.0260 & -0.4316 \\
\cline { 2 - 4 } & $(0.0269)$ & $(0.0516)$ & $(0.0519)^{* *}$ \\
\hline \multirow{2}{*}{ Religious diversity } & -0.0314 & -.0726 & -0.0289 \\
\cline { 2 - 4 } & $(0.0203)$ & $(0.0389)$ & $(0.0392)$ \\
\hline \multirow{2}{*}{ Gender } & -0.1853 & .2069 & -0.5416 \\
\cline { 2 - 4 } & $(0.0649)^{*}$ & $(0.1244)$ & $(0.1253)^{* *}$ \\
\hline \multirow{2}{*}{ Educational attainment } & -0.0498 & -.0311 & -.0690 \\
\cline { 2 - 4 } & $(0.0377)$ & $(0.0723)$ & $(0.0729)$ \\
\hline \multirow{2}{*}{$\begin{array}{l}\text { Years of working } \\
\text { experience }\end{array}$} & 0.0844 & .0577 & .1521 \\
\cline { 2 - 4 } & $(0.0138)^{* *}$ & $(0.0265)^{*}$ & $(0.0268)^{* *}$ \\
\cline { 2 - 4 } & -0.0926 & 0.0146 & -.0205 \\
\hline
\end{tabular}




\begin{tabular}{|l|l|l|l|}
\hline \multirow{2}{*}{ Constant } & 4.3798 & 2.6678 & 4.4913 \\
\cline { 2 - 4 } & $\left(0.2773^{* *}\right)$ & $(0.5319)^{* *}$ & $(0.5357)$ \\
\hline Chi-sq. & 74.912 & 13.270 & 123.807 \\
\hline p-value & 0.000 & 0.039 & 0.000 \\
\hline
\end{tabular}

Source: Field Data (2021)

From Table 4, language diversity significantly reduces employee productivity $(\beta=$ -0.4316) but had no significant impact on team building and communication. Religious diversity had no significant impact on team building, communication, and employee productivity. Value system diversity had a significant negative impact on team building ( $\beta$

$=-0.1853)$ and employee productivity $(\beta=-$ $0.5416)$.

The study further estimates the moderation role of education in the impact of cultural diversity indicators on organizational performance indicators to determine the impact would be in the presence of education, and the results are summarized in Table 5.

Table 5. Role of Education on the Impact of Cultural Diversity on Organizational Performance Indicators

\begin{tabular}{|c|c|c|c|c|c|c|c|c|c|}
\hline \multicolumn{10}{|l|}{ Model } \\
\hline \multirow[t]{2}{*}{ Variables } & \multicolumn{3}{|c|}{ Communication Effectiveness } & \multicolumn{3}{|c|}{ Team Effectiveness } & \multicolumn{3}{|c|}{ Productivity } \\
\hline & Coef. & Std. Err & $\mathbf{p}>|\mathbf{z}|$ & Coef. & Std. Err & $\mathbf{p}>|\mathbf{z}|$ & Coef. & Std. Err & $\mathbf{p}>|\mathbf{z}|$ \\
\hline Lang*Edu & .0001823 & .0124737 & 0.988 & $-.009374)$ & .0066587 & 0.159 & .0881448 & .0131782 & 0.000 \\
\hline Relig*Edu & -.0268523 & .0091781 & 0.003 & .0142465 & .0048994 & 0.004 & .0035617 & .0096964 & 0.713 \\
\hline Value*Edu & .0324529 & .0117846 & 0.006 & $.0135124)$ & .0375523 & 0.032 & -.0139407 & .0124502 & 0.263 \\
\hline Gender & -.0411628 & .070347 & 0.558 & -.0203443 & .035523 & 0.588 & -.004836 & .0743198 & 0.948 \\
\hline YExp & .0178142 & .0421847 & 0.673 & -.0914127 & .0225189 & 0.000 & -.0431194 & .0445671 & 0.333 \\
\hline cons & 3.225698 & .1950056 & 0.000 & 3.77766 & .104097 & 0.000 & 3.252543 & .2060185 & 0.000 \\
\hline Chi2_bs (6) & 17.306 & & & 62.247 & & & 94.097 & $\begin{array}{l}\text { Baseline vs } \\
\text { saturated }\end{array}$ & \\
\hline$p>$ chi2 & 0.004 & & & 0.000 & & & 0.000 & & \\
\hline
\end{tabular}

Source: Field Data (2021); Lang*Edu=Language Diversity moderated by educational attainment; Reli*Edu=Religious diversity moderated by educational attainment; Value*Edu= Value Diversity moderated by educational attainment; YExp=Years of working in the Organization

Table 5 reports that, amongst highly educated employees, language diversity does not have significant influence on communication effectiveness $(\beta=.0001823 ; p$-value $=0.988)$ and team effectiveness $(\beta=-.009374 ; \mathrm{p}$-value $=$ 0.159). These statistics, however, suggests that, among the educated workforce, language diversity significantly improves Productivity $(\beta=0.881448 ; p$-value $=0.000)$ in the workplace. Table 5 reports that education moderates the influence of religious beliefs in the workplace. These statistics indicates that, interaction of education and religious diversity significantly reduces communication effectiveness $(\beta=-$ $.0268523 ; \mathrm{p}$-value $=0.003)$ but significantly improves team effectiveness $(\beta=.0142465$; $\mathrm{p}$ value $=0.004)$.

However, interaction of education and religious diversity did not significantly influence productivity $(\beta=.0035617$; $p$-value $=0.713)$ in the workplace. Table 5 reports that, amongst educated employee's employee value system significantly improves communication effectiveness $(\beta=.0324529$; $p$-value $=0.006)$ and team effectives $(\beta=.0135124 ; p=$ value $=0.032)$. However, the interaction of education and value system did not significantly influence employee productivity $(\beta=-.0139407$; $p$-value $=0.263)$ in the workplace. 


\section{Discussions}

Thus, inferring from the results, as the level of education of employees increases, the detrimental effects of language diversity on communication and team building is minimized, which leads to improving Productivity. Comparing the effects of employee language diversity on Productivity prior to the inclusion of the moderator variable in the model and after estimating the model, it can be seen that there is a higher change in productivity coefficient. Hence, education influences the role of language diversity on Productivity through enhanced skills set and communication competence of employees [14]. Chenov and Chernova [19] are also of the view that educational competence is unquestionably a competitive advantage for individuals working in culturally diverse business settings as it enhances employee productivity. Neo [20] posits that it is critical for employees to understand how people from various cross-cultural backgrounds interpret, communicate, and make decisions. Education now becomes a key variable in this endeavour which may have impacts on the degree of communication and enhance the Productivity in the workplace. Although it may be difficult to comprehend some comments and behaviours, education leads to a shared notion of acceptance and open-mindedness. These may have significant impacts on Productivity in the workplace.

Also, education leads to a sense of tolerance which makes the effects of employee religion on team building seemingly negligent. Peltonen's [21] indicated that religion, like ethnocentrism and stereotyping, hinders communication by creating a distinct picture of individuals who follow various religions irrespective of the level of education of these individual. Persons find it challenging to communicate with people of various religious beliefs. People's attitudes toward others are influenced by their religious beliefs. As a result, even very education which has been tried and proved may not be sufficient to completely eliminate the impact of religion in the workplace, which may have negative consequences for overall company efficiency. Piga [22] provides contradiction to these findings when he found that good education may remedy the negative impacts of religiosity in the workplace. Hence, when employees are highly educated, the negative impact of cultural diversity is minimized.

Similarly, education reduces the negative impact of value system diversity on communication, team building, and Productivity. The results in this study are in line with Mecheo's [11] results, which indicated that cultural values had a favorable impact on organizational performance. According to Barret [23], an employee can react with every circumstance in one of three ways. They can respond using their beliefs, ideals, or intuition. Barrett goes on to say that if workers make judgments based on their views, such conclusions would reflect their previous experience dealing with comparable situations, making the decision a gamble. Past history is constantly lived and contextualized, and beliefs are unprepared to deal with complicated new situations that have never been encountered before. As a result, in the absence of education and training programmes, in the workplace, workers may make judgments based on their own values and beliefs, which may not be the best option for the company and may have an influence on how they operate and their overall performance.

The result in this study further provides support for Ringov [24] in their work which indicated that education and training enable employees to discover genuine and meaningful alignment between their personal values and that of the organization, a strong relationship is formed in such instances. This link opens up a slew of opportunities for personal development and business productivity, manifesting itself in a variety of ways, including reducing the impacts of employee value diversity in favour of a single common company value system. As a result, when a company and its employees join together 
around a same set of values, they become more flexible, less hierarchical, and less bureaucratic, and they build a stronger capacity for collective action. When employees share not only identical values, but also a same vision, a company's performance improves.

\section{Conclusion}

The study aimed at assessing the effects education in the impact of cultural diversity on organizational performance, using various manufacturing companies in Ghana. It was observed that cultural diversity is high as well as team building, communication, and Productivity. The study concludes that education plays a crucial moderating role by minimizing the negative impact of cultural diversity on team building, communication, and employee productivity.

Based on these findings, employees should be encouraged to undergoing constant training in cultural diversity and further their education to enhance their knowledge, skills, and exposure. This will help the employees to relate well with each other, despite their cultural differences, to help improve organizational performance.

Despite interesting findings in this paper, the researcher believes that the implications of

\section{References}

[1] Hofstede, G. (2001). Cultural Consequences: Comparing values, behaviors, institutions, and Organizations across nations. (2nd ed) Thousand oaks, ca: sage publication inc.

[2] Nile, M. \& Dyer, G. (2004). Human capital and learning as a source of sustainable competitive advantage Strategic Management Journal Volume 25, Issue 12, pages 1155-1178.

[3] Herring, C. (2009). Does diversity pay? Race, gender, and the business case for diversity. American sociological review, 74(2), 208-224.

[4] Ashton, V. (2010). Does ethnicity matter? Social workers' personal attitudes and professional behaviors in reporting child maltreatment. Advances in Social Work, 11(2), 129-143. cultural diversity can be far stretched than just three variables that were studied. Therefore, further research may focus on exploring the implications of cultural diversity on other variables like employee retention/commitment, employee job satisfaction, global competitiveness of organizations, among others.

\section{Acknowledgement}

My sincerest gratitude to Dr. Freda Ocansey, Mr. Prince Amoako who offered very valuable contributions and were very supportive in the compilation of this article. I take this opportunity to thank Anitha, my research mentor, my office secretary, who did the typesetting of this manuscript. Ms. Mary Yigal, how can I forget you? Your kindness and love were just indescribable.

I will remain grateful. Mrs. Diam Lilian Laar, my wife, you were, and you remain my solid aids and support. I could not have made it without you.

\section{Conflict of Interest}

The author declares that there is no conflict of interest with regards to this paper.

[5] Dike, P. (2013). The impact of workplace diversity on organisations.

[6] Canopy Health. (2018). Productive TeamBuilding Exercises at the Workplace. Canopy Health. [7] Bright HR. (2020). The Importance of Teamwork in the Workplace Bright HR undefined. Brighthr.com. [8] Brady, D. (2016). The Positive Impact of Team Building - TTB. Total Team Building.

[9] Barcenas, M. (2020). Employee Productivity: The Ultimate Guide for Managers. Fellow.app.

[10] Yoshifumi, H., Sammogram, S., \& ManzumaNdaaba, N. M. (2018). Effect of Productivity and Perceived Quality on Organizational Performance from Lean Management Practice Perspective. Science Alert.

[11] Mecheo, K. N. (2016). The Effect of Employee Cultural Diversity on Organizational Performance: 
A Case Study of Oilybia-Kenya (Doctoral dissertation, United States International UniversityAfrica).

[12]Danso, L., Oduro, F., Yalley, F., Sarpong, A., \& Tetteh Kweitsu, M. A. R. T. I. N. (2019). Management of Cultural Diversity: Implication for Organizational Competitiveness. A Case Study of Asokore Rural Bank Limited, of orikrom and Kwadaso Branches, Kumasi (Doctoral dissertation). [13] Qiaoxin, M., \& Liswandi, L. (2018). Analysis of Cultural Diversity Factors Influencing Employees Satisfaction. International Journal of Management, Accounting and Economics, 5(12), 955-965.

[14] Abugre, J. B., \& Debrah, Y. A. (2019). Assessing the impact of cross-cultural communication competence on expatriate business operations in multinational corporations of a Sub-Saharan African context. International Journal of Cross-Cultural Management, 19(1), 85-104.

[15] Ghana Statistical Service, 2010 Population and Housing Census.

[16] Yamane, T., (1967). Elementary Sampling Theory, New Jersey: Prentice-Hall, here is a list of some books, articles, and websites that either used Slovin's formula inappropriately or presented the formula without mentioning its assumptions.

[17]Kline, R. B. (2011). Principles and practice of structural equation modeling (3rd ed.). Guilford Press.
[18]Mechheo, C.W. (2014), Effects of Communication strategies on organizational performance: A case study of Kenya ports authority. European Journal of Business and Management 6(11) 6- 10. Retrieved from www.iiste.org. [19] Chernov, S. \& Chernova, L. (2018). Algorithm for the simplification of solution to discrete optimization problems. Eastern European Journal of Advanced Technologies, (3 (4)), 34-43.

[20]Neo, H. (2015). Modelling green urbanism in China. Area, 47(2), 132-140.

[21]Peltonen, K. (2019). From Cultural Differences to Identity Politics: A Critical Discursive Approach to National Identity in Professor.

[22]Piga, D. (2020). Computation of Parameter Dependent Robust Invariant Sets for LPV Models with Guaranteed Performance. arXiv preprint arXiv:2009.09778.

[23] Barret, O., (2005). Monte Carlo simulation and scatter correction of the GE advance PET scanner with SimSET and Geant4. Physics in Medicine \& Biology, 50(20), 4823.

[24]Ringov, D., \& Zollo, M. (2017). The impact of national culture on corporate social performance. Corporate Governance: The international Journal of business in society, 7(4), 476-485. 


\title{
Resettlement of Internally Displaced Persons in the North Central Geopolitical Zone of Nigeria
}

\author{
Askederin, F. $\mathrm{M}^{1 *}$, Omole, D. $\mathrm{K}^{2}$, Shonibare. D. $\mathrm{O}^{2}$ \\ ${ }^{1}$ Department of Public Administration, Texila American University, Georgetown, Guyana \\ ${ }^{2}$ Nigerian Educational Research and Development Council, Sheda, Abuja, Nigeria
}

\begin{abstract}
This paper investigated the Humanitarian Crisis in the North Central zone of Nigeria and the resettlement challenges faced by Internally Displaced Persons (IDPs). It was designed to find out the types and causes of Displacement in the zone and determine the readiness of IDPs to return to their original communities before Displacement. The Research was carried out in three states of the North Central Geopolitical Zone, which are Nasarawa, Niger, and the Federal Capital Territory using a total of nine IDP camps. It was conducted using a combination of research designs by applying quantitative and qualitative research methods. Data was collected using three data collection tools which are questionnaires, observation schedule, and focus group discussions schedule. Results revealed that the internally displaced persons found in the North Central geopolitical zone in the states of Nasarawa and the FCT come mostly from the Northeastern states of Borno, Adamawa, and Yobe, and were displaced due to the Boko Haram insurgency. Those living in Niger State come from within Niger and were displaced due to Banditry. Results also revealed that the majority of IDPs live in deplorable conditions within the North Central Geopolitical zone with limited access to food, education, health services, water, sanitation, and hygiene facilities. The Research further revealed that most IDPs are willing to return to their original homes, and their first deciding factor to return is the restoration of security back in their communities, the second factor is their family ties, third is funding to support their return, and then fourth is government legislation that may compel relocation of displaced persons.
\end{abstract}

Keywords: Humanitarian, Insurgency, Internally Displaced Persons, Refugees, Resettlement.

\section{Introduction}

Nigeria is the most populous Country in Africa, with an estimated population of 193 million individuals as at 2016 [1]. The Country comprises of 36 states and the Federal Capital Territory (FCT). It is divided into six geopolitical zones: the North Central, Northwest, Northeast, Southwest, South-South, and the Southeast. Each region comprises 6 states except for the Northwest and Southeast, which have seven and five states, respectively. In the last twelve years, Nigeria has experienced several disasters that led to Displacement in different parts of the Country. As at the end of
2019, there are about 2.6 million people in Nigeria displaced by disasters majorly caused by the insurgency, banditry, and flooding [2].

The United Nations Refugee Commission defined displaced people as persons who have had to leave their homes as a result of a natural, technological, or deliberate event, and include two categories of people; internally displaced people (people who remain in their own countries), and refugees (people who cross international borders) [3]. Displacement is caused by natural disasters like floods, earthquakes, hurricanes, famine and can also be man-made, like conflict, prosecution, and 
development projects. Due to the effect of Displacement, individuals flee their lands, means of livelihood, and leave behind their homes and assets. According to UNHCR, over 70 million people were displaced worldwide as of January 2019 [3]. About 14.6 million people constitute new Internal Displacement across 127 countries between January and June 2020 alone, with disasters responsible for about 9.8 million, while conflict and violence triggered the other 4.8 million displacements [4]. Displacement breaks family and community ties. It forces persons affected to lose their valuables, including documentation which could result to denial of services or means of seeking compensation [5]. In Nigeria, major causes of Displacement include Insurgency, Banditry, and Floods [6].

The concept of Internal Displacement emerged in the early 1990s with no clear definition of what it is. However, it was clear that it needed to be differentiated from the concept of Refugees who are already clearly defined by International Law. While both Refugees and Internally Displaced Persons (IDPs) are displaced persons, a Refugee is one who has crossed an internationally recognized border, while an IDP is a displaced person who remains within his/her country of citizenship or habitual residence. Both groups face several forms of vulnerability due to their inability to access basic services, loss of their properties, and even legal documentation.

Nigeria is in the twelfth year of the Boko Haram insurgency, and the conflict has led to the Displacement of over two million people who currently reside in Internally Displaced Persons (IDP) camps within the Country. The problem of internal Displacement in Nigeria has become a recurrent challenge largely due to the insurgency in the Northeastern part of the Country caused by Boko Haram terrorist. Many citizens from communities in the Northeastern states of Borno, Adamawa, and Yobe have become displaced due to attacks by insurgents, and this has led to the movement of individuals from their homes to settlements and camps within and outside the Country, these people have suffered a great deal losing their livelihood and access to services [79].

Another category of Displacement has emerged in the last few years due to the increased incidence of Banditry in the northcentral and north-western states [10]. Communities in the northwest, north central, and other states of the country have seen an increased incidence of this problem in recent years largely due to desertification and increased unemployment among youths. Over 200,000 people were displaced in Katsina, Sokoto, and Zamfara states between January and August 2019; although a number of them have been returned to their communities, the displaced persons had faced major challenges, which include the loss of properties and livelihood, as well as fear of future attacks [11].

According to 2020 data from the National Emergency Management Agency (NEMA), there are three hundred and seventy-five (375) IDP Camps in the Country holding IDPs, with the north-central states of Niger, Nasarawa, and the FCT having thirty-one (31) camps. This research aims at exploring reasons why many IDPs residing in the camps are yet to return to their original communities even after the security agencies have recovered such communities from the control of insurgents or bandits. The IDPs have continued to live in congested camps with dilapidated infrastructure and poor living conditions. This is especially true for those living in informal camps like the once found in the north-central geopolitical zone, especially the Federal Capital Territory. This Research will provide a framework that is aimed at guiding the government, national and international partners on the strategies to rehabilitate and resettle IDPs. It will identify the main factors that will support resettlement and relocation of IDPs from Camps.

There are two government agencies, and a Federal Ministry that directly carter to the needs of IDPs in Nigeria. These are the National 
Commission for Refugees, Migrants, and Internally Displaced Persons (NCFRMI) and the National Emergency Management Agency (NEMA). In 2019, the Federal Ministry of Humanitarian Affairs, Disaster Management, and Social Development was created to coordinate humanitarian activities, and these agencies fall under its purview. These Agencies and the Ministry provided background information on the plight of IDPs in Nigeria and help support the Research with valuable information on the location and population.

Data collected from locations where resettlement has taken place some years back showed that it came with some challenges. Studies that attempted to explore the issue of resettlement among Nigerian IDPs reveal some concerns from the affected population. Firstly, IDPs feared that people who have returned from the IDP camps prematurely due to coercion or force have suffered financially and materially, and some have become displaced again due to renewed attacks or killing; secondly, many find their homes and local infrastructure completely destroyed, and some who went back said they wish that they never went back due to continuous attacks [12].

The absence of an appropriate legal framework, dearth of reliable statistics, ineffective mechanisms for accountability, and repatriations of IDPs are some of the major challenges affecting the rehabilitation of IDPs in Nigeria [13]. They explained that IDPs find it difficult to return home because they have lost most of their property and often have nothing to return to and, there are no measures for compensation. These are being addressed by the current government, particularly in Borno state, by developing programmes that will consciously encourage IDPs to return to their communities.

Studies that compared the management of IDPs in Nigeria and Cameroun revealed that though Nigeria have more national structures for managing IDPs compared to Cameroun, which depends heavily on the support of International Organizations, the issue of limited funding among Nigerian officials saddled with the responsibilities to provide for IDPs is a major challenge [14]. The study showed that although they lack a national structure, Cameroun has managed to reintegrate all IDPs in the Bakassi region while Nigeria is yet to reintegrate its IDP population. This may be due to the absence of a systematic framework to ensure that resettlement is done effectively. Another challenge is the dearth of studies or recommendations to the effective return of Nigerian IDPs to their communities or settling them in other locations out of camps. This Research will attempt to close some of these gaps by identifying major challenges that prevent the return of IDPs.

\section{Research Objectives}

This Research will be conducted among the IDP population living in camps within the northcentral geopolitical zone where the activities of most International and National Humanitarian Organizations is not focused. Little is known about this population of IDPs due to the minimal activities of International Organizations in this location. Since most IDPs are considered to come from far locations to their respective camps, it is important to understand their current situations and plans if any, for returning home.

The main focus of this study is to unveil the nature of the Humanitarian Crisis in the North Central Geopolitical zone of Nigeria and how to promote the resettlement of IDPs. The following are specific objectives:

1. To find out the causes of Displacement in Nigeria.

2. To determine how far IDP camps are from the original homes of the IDPs.

3. To determine the types of Displacement in Nigeria.

4. To estimate the average population in surveyed camps.

5. To identify amenities that are available in the camps being surveyed.

6. To determine readiness of IDPs to return to their communities. 
7. To list the challenges anticipated by IDPs in returning to their communities.

8. To list factors that will promote the quick return of IDPs to their communities.

\section{Research Question}

The following research questions are populated to sharpen the investigation.

1. Where are IDP camps located?

2. How far are the IDPs from the original homes?

3. What is the population of IDPs in surveyed camps?

4. What are the causes of Displacement in Nigeria?

5. What are the types of Displacement in Nigeria?

6. What type of shelter do IDPs have within the camps?

7. Is the available shelter adequate?

8. Are the shelters overcrowded?

9. How do IDPs access food within or around the camps

10. Are there Water Sanitation and Hygiene (WASH) facilities available at the camps?

11. Are there Health facilities available at the camps?

12. Are there educational facilities available at the camps?

13. Do the IDPs have access to employment opportunities?

14. Is there security in the IDP camps?

15. What population of IDPs are ready to return to their communities, and what population wants to be resettled in other communities?

16. What are the challenges of return anticipated by IDPs?

\section{Significance of the Study}

The Research is expected to provide knowledge for a better understanding of why IDPs remain in Camps even after their communities have been liberated from the Boko Haram Terrorist, Banditry, Floods, and or Communal Clashes. It will provide stakeholders with factors that can support the resettlement of
IDPs in Nigeria and contribute towards the effort to resettle over two million IDPs located across different states of the Country. Finally, it will identify factors that guide the return of the populations and present these findings in a structured manner to policymakers.

\section{Research Methods}

The Research looks at the issues of resettlement with regards to Internally Displaced Persons in the North Central Geopolitical Zone of Nigeria. Internal Displacement has become an ongoing issue since 2009 and has remained a national issue with an estimated population of two million persons living in IDP camps [15].

Currently, there is the dearth of Research on internally displaced persons in the Country. Hence studying the population requires preengagement with the affected population to determine the issues/themes that contribute to the problem. It required intensive review of data available in the public domain on IDPs, which came mainly from programme implementation in the Country. This includes the number of camps, their location, household size, number of individuals living in the camps as well as any other relevant information that is available pre visitation of the camps. Pre-engagement was conducted with leaders of the camps to determine common themes.

This helped to finalize the design of a questionnaire to have a structured instrument that will be administered and guide the determination of what to look out for during data collection in sampled camps. The Research explored the problem using three approaches within the North Central geopolitical zone of Nigeria. This constituted of structured interviews, focus group discussions, and observation.

\section{Research Design}

The Research used descriptive design by applying a mix method of Research with quantitative and qualitative approaches. It applied three research methodologies which are: 


\section{Focus Group Discussions}

This method of data collection involves interviews or discussions with several people at the same time on a specific topic or issue [16]. It entailed discussions with different subsets of the population in groups, led by a research assistant that moderated or facilitated the discussion to observe how group members respond to each other's views and determine where there is a collective understanding or opinion about an issue or if opinions vary vastly. This discussion took place among individuals within the camp in groups of 8 to 12. It explored various topics such as shelter, security, health, nutrition, and other issues that affect the lives of IDPs in camps and how this affects their decisions regarding resettlement.

\section{Structured Interviews}

This is a type of research interview that is commonly employed in survey research and involves the administration of an interview by an interviewer. The goal is to ensure respondents are interviewed in a standardized way in efforts to reduce variation and promote standardization in the method questions are asked and recorded [16]. It involved the administration of the questionnaire at the individual level to sampled IDPs that give consent to the research assistant. Sampled number of IDPs were interviewed in each camp.

\section{Observation}

This is an underused method of data collection in Research but is valuable in understanding some phenomena like living conditions, type of shelter, environment, and sanitation within a locality. During the Research, an observation tool was administered at each camp to identify issues around the type of shelter which IDPs use, availability of water, sanitation, and hygiene facilities, living conditions, the safety of the environment, population and overcrowding in the camps. One observation tool was administered per IDP camp visited in every state. The research assistant asked IDPs to show them where they sleep, their toilet facilities, drinking water, and how they carry out other basic activities. The research assistant then recorded this in the observation schedule.

\section{Target Population/ Sample Frame}

The population for this study are IDPs living in IDP camps and/or camp like structures in the North Central region of Nigeria. There are six states in the North Central geopolitical zone of the Country, which are Benue, Nasarawa, Niger, Kwara, Plateau, and the FCT. According to data collected from NEMA, the population of IDPs in the North Central geopolitical zone of Nigeria is 30,165 individuals living in 31 IDP camps in three states of the region. Based on the data received in these states, there are seven IDP camps in Niger, nine in Nasarawa, and fifteen in the FCT.

Camps in these 3 states will be surveyed, and the IDPs in the camps will form the population for the survey. The Federal Capital Territory is of particular interest since it is the capital city of Nigeria and one of the major locations of settlement for many citizens that are not even displaced. All individuals living within the sampled IDP camps were considered for the Research.

\section{Sample and Sampling Technique/Design}

The first level of sampling was to deploy a stratified random sampling technique to include all types of camps in the three states. While the three states do not have the same number of IDP camps, efforts was made to visit at least onethird of the camps in each state to get a good representation of happenings in the various locations. This comes up to about ten camps, made up of five camps in the FCT, three camps in Nasarawa, and two camps in Niger State. The second step is purposive sampling to select individuals within these camps for an interview. The third step was to administer the questionnaire among a representative sample of the population in each of the sampled camps. Below is the sampling procedure: 
1. Three states in the North Central zone were purposefully sampled because they have IDPs.

2. From each state, one third of the camps were selected. Out of the total thirty-one camps, ten camps were sampled for the Research.

3. In each camp, three instruments of data collection were applied.

\section{Structured Interview}

where stratified sampling was applied to provide a good representation of all individuals in the camps. This included different categories of individuals, including leaders, men, women, and youth. The sample size was determined based on 95\% Confidence Level and 5\% Confidence Interval. Considering a population of 30,165 individuals living in the camps, the sample size for the survey was 380 individuals. These individuals were interviewed, and they included Men, Women, and Youth.

\section{Focus Group Discussion}

Here, a group of 8 to 12 persons were interviewed in each camp. One focus group discussion was conducted in each camp which totals to 10 focus group discussions to be held during the Research.

\section{Observation}

Here, an observation guide was used to inspect some phenomena's in each camp. This came up to ten observation tools to be administered across ten camps that were sampled.

\section{Procedure for Data Collection}

Data was collected onsite by trained research assistants who interviewed the sampled population in their respective locations. This was conducted through a face-to-face interview.

The interview was estimated to be completed in 7 to 10 minutes; therefore, the time of interview commencement and conclusion was recorded on the interview schedule for quality checks.

\section{Instrumentation}

Three instruments were used to collect data for the Research.

1. Structured Interview Schedule

2. Focus Group Discussion Schedule

3. Observation Schedule

\section{Research Approach / Data Analysis/ Procedure}

There are two approaches to Research which are inductive and deductive research approach. The deductive approach starts with a theory and then collects data to test the theory to determine if it holds on to a given circumstance, while the inductive approach starts with collecting data in an attempt to develop a theory [17]. The deductive approach sets out to test an already established theory, while in the inductive approach, the theory is the outcome of Research. This Research adopted an inductive research approach where data is collected from IDP camps and then analyzed in an attempt to develop a theory that will guide future efforts at resettlement of displaced people living in camps. This approach is chosen because there are no clearly defined theories in the field of IDP resettlement to explain what factors lead to the decision of a person displaced by conflict or natural disaster to return home. The inductive approach will help us establish some theory, at least in the context of Nigeria, that may be applicable in other parts of Sub-Saharan Africa.

The inductive analysis will be deployed to determine important patterns and themes to confirm findings from the data collected. Data will be analyzed using simple statistical tools to determine inter-relationships in responses.

\section{Results}

The results are hereby presented with the research question that each provides an answer to:

1. Where are IDP camps located?

2. How far are the IDPs from the original homes? 
3. What is the population of IDPs in surveyed camps?

A total of 310 Internally Displaced Persons were interviewed during data collection on the field, out of which 173 IDPs were living in the Federal Capital Territory (FCT), 52 IDPs were living in Niger State, and 85 IDPs interviewed were living in Nasarawa states of the North Central Geopolitical Zone. These individuals are spread across four Local Government Areas
(LGA) of the various states. The IDP Camps were located in different cities and villages within the three states. A total of nine locations where IDP camps are found was visited by the data collection team. The tenth IDP camp was found to be closed on the visit by the data collection team, and all the IDPs living there were no longer in the location. Table 1 shows the distribution of the IDPs by State, their location, and the number interviewed in that location.

Table 1. Frequency and Percentage distribution of IDPs by State, Local Government Area and Villages in the North Central region where IDP Camps are located

\begin{tabular}{|l|l|l|l|l|}
\hline State & LGA & Camp & Frequency & Percent \\
\hline FCT & AMAC & Waru & 32 & 10.3 \\
\hline FCT & AMAC & Durumi & 25 & 8.1 \\
\hline FCT & AMAC & Yimitu/Kabusa & 51 & 16.5 \\
\hline FCT & AMAC & Wassa & 65 & 21 \\
\hline Niger & Rafi & Kagara & 47 & 15.2 \\
\hline Niger & Shirro & Shirro & 6 & 1.9 \\
\hline Nasarawa & Karu & Gurku & 25 & 8.1 \\
\hline Nasarawa & Karu & Koso & 21 & 6.8 \\
\hline Nasarawa & Karu & Kugwaru & 38 & 12.3 \\
\hline Total & & $\mathbf{3 1 0}$ & $\mathbf{1 0 0}$ \\
\hline
\end{tabular}

Data collected during focus group discussions on the number of IDPs in the camps indicates that a total of 19,208 individuals are living in the nine IDP camps. Most IDPs in the North Central Geopolitical zone come from the Northeast states of Borno, Adamawa, and Yobe. IDPs in four (4) of the camps totaling 10,597 individuals all come from Borno State, while those in three camps (2830) are from the three states of Borno, Adamawa, and Yobe. IDPs found in the two camps in Niger state (281) are from within Niger state and were displaced as a result of Banditry and Kidnapping.

Table 2. Population of IDPs and their states of Origin

\begin{tabular}{|l|l|l|l|}
\hline State & Number of Individuals & Number of IDP Camps & Percent \\
\hline Borno & 10597 & 4 & 55.2 \\
\hline Borno, Yobe and Adamawa & 2830 & 1 & 14.7 \\
\hline Borno and Adamawa & 5500 & 2 & 28.6 \\
\hline Niger, Madaka & 281 & 2 & 1.5 \\
\hline Total & $\mathbf{1 9 2 0 8}$ & $\mathbf{9}$ & $\mathbf{1 0 0 . 0}$ \\
\hline
\end{tabular}

4. What are the causes of Displacement in Nigeria?

5. What are the types of Displacement in Nigeria?
The causes of Displacement according to IDPs interviewed in the North Central Geopolitical Zone are shown in Table 3 below. The Data reveals that the reason for Displacement for the majority of IDPs 
interviewed was the Boko Haram insurgency, and this is closely followed by Insecurity, Banditry, and Kidnapping. The table also reveals that four of the individuals interviewed came to the Camp not as a result of any displacement, while forty-five of the sampled respondents refused to give a reason for their Displacement.

Table 3. Causes of Displacement among Internally Displaced Person found in the North Central Region of Nigeria

\begin{tabular}{|l|l|l|}
\hline Causes of Displacement & Frequency & Percent \\
\hline Banditry & 13 & 4.2 \\
\hline Kidnapping & 4 & 1.3 \\
\hline Banditry/kidnapping & 26 & 8.4 \\
\hline Boko Haram & 208 & 67.1 \\
\hline Insecurity & 10 & 3.2 \\
\hline None & 4 & 1.3 \\
\hline Total & 265 & 85.5 \\
\hline Missing & 45 & 14.5 \\
\hline Total & $\mathbf{3 1 0}$ & $\mathbf{1 0 0 . 0}$ \\
\hline
\end{tabular}

Displacement results in hardship for the individuals affected as well as their families. Some basic services like Shelter, Food, Water, Sanitation, Hygiene, Health, Education, and Security services may no longer be available to the individual and his/her family. Sometimes these basic services are not sufficient even when they are made available.

6. What type of shelter do IDPs have within the camps?

7. Is the available shelter adequate?

8. Are the shelters overcrowded?

Shelter is one of the basic facilities required by a displaced person. The majority of the IDPs about $44.4 \%$, revealed that they rent shelter from host communities, while $22.2 \%$ said they set up tents in open spaces to stay. In one IDP Camp, Government has provided resettlement estate for the IDPs, while in another location, the IDPs are building their own shelter. The type of shelter used by IDPs range from stick houses to mud houses and tents.

The number of IDPs that sleep in a unit of shelter varies, depending on the Camp. While $26.7 \%$ of the IDP Camps indicated that up to 19 individuals sleep per housing unit in their Camp, $24.4 \%$ indicated that less than or equal to 8 individuals stay in a housing unit, and 20.2\% indicated that 15 individuals sleep in a housing unit.

9. How do IDPs access food within or around the camps?

$55.5 \%$ of IDPs interviewed access food through farming, while $13.9 \%$ get their food from well-wishers or donors. Others did not give specific details on how they access food. Another factor assessed by the Research is how many times a day the IDP eats. Here most IDPs, about $34.5 \%$, indicated that they ate two times a day, while $29 \%$ indicated that they ate three times a day, and about $18.7 \%$ said they ate once a day.

10. Are there Water Sanitation and Hygiene (WASH) facilities available at the camps?

One of the basic services for survival by an individual is water. Various IDP camps visited were assessed for the availability of water, sanitation, and hygiene facilities. Data collected revealed that most of the Camps get water from a Borehole which was constructed at the Camp by Government, Donor, or Private Individual. IDPs in one of the Camps said they access water from the stream. This is shown in Table 4 below. 
Table 4. Water Source at the IDP Camp

\begin{tabular}{|l|l|l|l|}
\hline Availability of water at the camps & Number of Camps & Number of IDPs & Percent \\
\hline Borehole & 5 & 14727 & 76.7 \\
\hline Stream & 1 & 280 & 1.5 \\
\hline Buy from Borehole & 2 & 4200 & 21.9 \\
\hline None & 1 & 1 & .0 \\
\hline Total & 9 & 19208 & 100.0 \\
\hline
\end{tabular}

Table 5 below shows the types of Toilet Facilities available at the IDP Camp $66.7 \%$ of the IDP camps have no toilet facilities. These individuals use the bush. Only one out of nine
IDP camps has a toilet facility. In four of the nine camps, men and women share the same toilet facility, as indicated in Table 6.

Table 5. Type of Toilet Facility in the Camp

\begin{tabular}{|l|l|l|l|}
\hline Type & Number of Camps & Number of IDPs Affected & Percent \\
\hline Bush & $\mathbf{6}$ & 16307 & 84.9 \\
\hline WC & $\mathbf{1}$ & 2000 & 10.4 \\
\hline Bush/Pit & $\mathbf{2}$ & 900 & 4.7 \\
\hline Total & 9 & 19207 & 100.0 \\
\hline
\end{tabular}

Table 6. Do Men and Women use the same Toilet Facility?

\begin{tabular}{|l|l|l|}
\hline Type & Number of Camps & Percent \\
\hline Yes, Men and Women use the same Toilet Facility & 4 & 44.4 \\
\hline No, Men and women do not use the same Toilet Facility & 5 & 55.6 \\
\hline Total & 9 & 100.0 \\
\hline
\end{tabular}

11. Are there Health facilities available at the camps?

The third basic service investigated by this Research is the Internally Displaced Person's access to Health Services. $76.7 \%$ of the IDPs said they access health services through a clinic within the Camp, while $23.3 \%$ said they have no access. One of the camps has a clinic, while in another camp, the IDPs said they access health services from a nearby Government Health Centre. When the IDPs were asked how they get treatment when sick, $35.5 \%$ said they get services from a clinic within the IDP Camp, about $25.8 \%$ said they go to the Pharmacy/Chemist, while $20.3 \%$ go to a Hospital/Clinic. About $4.8 \%$ go to a local healer or native doctor.
12. Are there educational facilities available at the camps?

Data collected from the Research shows that many IDPs live within family structures and have dependents that are school age. Table 7 reveals that $60 \%$ of IDPs have a school located within or around their premise while $40 \%$ of IDPs do not have schools near them. Table 8 shows that about $68.1 \%$ of IDPs have school-age children, however, only $48.7 \%$ of the schoolaged children go to school. $58.9 \%$ of IDP dependents that go to school attend public schools, while about $10.3 \%$ attend a school within the IDP camp, and $9.7 \%$ go to Private school as shown in Table 9. 
Table 7. Is there school within the IDP Camp?

\begin{tabular}{|l|l|l|l|}
\hline Availability of School within IDP Camps & Frequency & Percent & Population \\
\hline IDPs that have access to a school within their camp & 4 & 60.0 & 11521 \\
\hline IDPs with no access to a school within their camp & 5 & 40.0 & 7687 \\
\hline Total & 9 & 100.0 & 19208 \\
\hline
\end{tabular}

Table 8. IDPs with School Aged Children that Go to School

\begin{tabular}{|l|l|l|l|l|l|}
\hline IDPs with school aged children & Frequency & Percent & \multicolumn{3}{|c|}{ Do they go to school } \\
\hline Yes & 211 & 68.1 & Yes & 151 & $48.7 \%$ \\
\hline No & 78 & 25.2 & No & 60 & $19.4 \%$ \\
\hline Total & 289 & 93.2 & Total & 211 & $68.1 \%$ \\
\hline
\end{tabular}

Table 9. If your Answer to Table 8 is Yes, Which Type of School do your Dependents Attend?

\begin{tabular}{|l|l|l|}
\hline Type & Frequency & Percent \\
\hline Public & 89 & 28.7 \\
\hline Private & 30 & 9.7 \\
\hline Within the IDP Camp & 32 & 10.3 \\
\hline Total & 151 & 48.7 \\
\hline
\end{tabular}

13. Do the IDPs have access to employment opportunities?

Access to employment opportunities will reduce the vulnerability of an Internally Displaced Person and provide them with a means to support their family. Data collected shows that $48.5 \%$ of IDPs in the camps surveyed are currently employed, while $51.5 \%$ are unemployed. The type of employment engaged by those IDPs that are employed shows $29 \%$ of the employed IDP are working in the farming sector, this is closely followed by Tailors $(5.5 \%)$, then Labourers (2.9\%) and then Drivers (1.9\%).

14. Is there security in the IDP camps?

Insecurity is identified as one of the biggest challenges currently faced in Nigeria. The majority of IDP camps assess (44.5\%) indicated that security in their Camp is Poor, while $22.2 \%$ said their Camps are secured. Another 22.2\% said they have no security while $11.1 \%$ indicated they have satisfactory security provision.

15. What population of IDPs are ready to return to their communities, and what population want to be resettled in other communities?

16. What are the challenges of return anticipated by IDPs?
Most IDPs engaged with during the focus group discussion revealed that they are willing to relocate back to their homes/communities before they were displaced. The major factor in the decision to relocate is the restoration of peace in their community as revealed by $77.7 \%$ of IDPs.

Focus group discussion response data on relocation was correlated by data collected from a questionnaire administered to individuals in the Camps. Table 10 shows that $54.8 \%$ of IDPs Strongly Disagreed or Disagreed with the notion to remain in the IDP camps. $80.3 \%$ are willing to return to their original homes within 6 months if the reason for their Displacement is addressed.

The four factors assess that influence the IDPs decision to return home are security, funds, government legislation, and family ties. This is shown in Table 10 above. Data collected revealed that the major factor in the decision of IDPs to return to their original community of inhabitance before Displacement is the restoration of security at $79 \%$, followed by family ties at $63.4 \%$, then funds to support relocation at $61.3 \%$ then finally, Government Legislation at $55.2 \%$. 


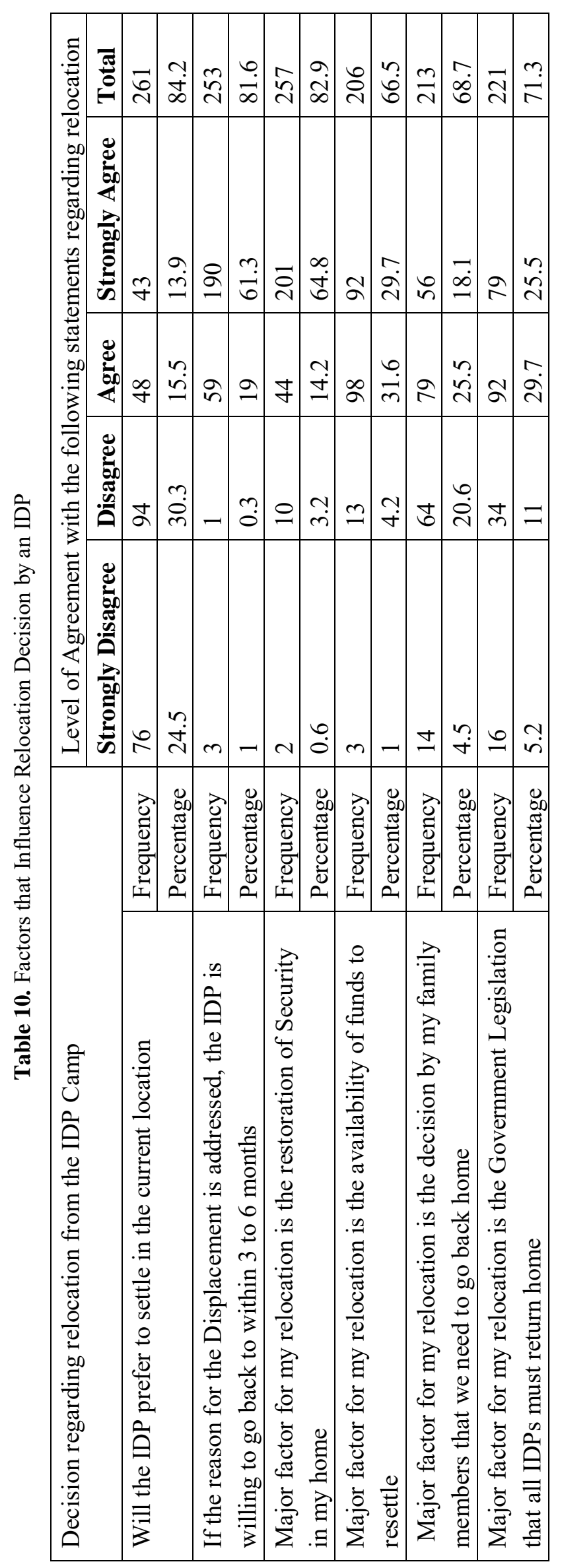




\section{Discussion}

Three states out of the six states in the North Central Geopolitical Zone were purposefully sampled for this Research, with ten camps scheduled for a visit. Eventually, nine IDP camps were visited as the last IDP Camp has been closed, and the IDP population no longer lived there.

Data collected revealed that the majority of IDPs in the North Central states of Nasarawa and the FCT come from Borno, Adamawa, and the Yobe States, which are in the Northeast Geopolitical Zone of Nigeria. This indicates that most IDPs have travelled a minimum of $850 \mathrm{~km}$ to about $1000 \mathrm{~km}$ from their communities/states in the Northeast to come to the North Central Geopolitical Zone. IDPs in the two camps in Shiroro and Rafi Local Government Areas of Niger state are from Madaka, within Niger. This indicates that they are displaced within their own state and have travelled a distance of $35 \mathrm{~km}$ to $200 \mathrm{~km}$ to escape Banditry and Kidnapping within their states. This is a common phenomena for IDPs across the world, as many of them travel several kilometers to escape their homes in times of disasters such as insecurity, banditry, or natural disasters like flooding [18].

The Federal Capital Territory (FCT) had the highest number of IDPs, with $55.8 \%$ of IDPs interviewed living in the FCT. This is followed by Nasarawa State with $27.4 \%$ of the population and then Niger State with $16.8 \%$. Internally Displaced Camps visited are located in four LGAs within the three states and found in nine different communities.

The Boko Haram Insurgency/Insecurity is the biggest cause of Displacement among the Internally Displaced Persons interviewed, as indicated by $70.3 \%$ of IDPs living in the North Central Geopolitical Zone, who stated it as their reason for Displacement. This data is supported by various studies of Internally Displaced Persons in Nigeria, such as in the Research by [19]. This reason is closely followed by Banditry and Kidnapping at $13.9 \%$, this cause of Displacement is closely becoming a sauce of major concern as indicated in studies conducted by [20].

Data collected from the Camp leadership reveals that about 19,208 households live in the Camp, and $81 \%$ of them have dependents. The information varies from data collected from the National Emergency Management Agency (NEMA) 2019 data on IDPs in Niger, Nasarawa, and the FCT. Data collected from the field shows a higher number of IDPs by about $10 \%$ than what is available in the records of the Agency. This can be explained by the fact that the data from NEMA is as of 2019, so there is a need for the Agency to collect fresh data especially in the face of increasing insecurity nationally.

Basic services like shelter, water, food, health, and education services are necessary for an individual or household's survival. Access to these services are contributing factors to whether individuals are willing to return to their communities of origin or prefer their newfound homes if they are getting better services at the Camps. Data collected reveals that most services are non-existent or inadequate at the IDP camps.

In $44 \%$ of the Camps, shelter is rented by IDPs, while $33 \%$ use Tents or Open spaces and $11 \%$ use Government resettlement estate as shelter. The type of Shelter is mostly Stick House (44.4\%), while others are mud houses and Open Space.

Farming is the most common strategy to access food by most IDP, as $55.5 \%$ of those interviewed indicated it as their way of feeding. $13.9 \%$ get their food from well-wishers or donations, which shows that there is some level of support offered to the IDPs by outsiders.

Availability of water was considerable in most IDP Camps visited as the majority had access to borehole facilities which was provided by various actors such as Donors, Government, Private Individuals, and even the IDPs themselves. Sanitation is carried out monthly in one of the Camp, and this was evident by the cleanliness of the environment in the camp. However, other camps did not make a conscious effort towards sanitation of the environment. 
Toilet Facilities are non-existent or inadequate in most of the camps. This is evident from information collected that only one camp out of the nine surveyed had access to WC. In 4 out of 9 IDP camps surveyed, men and women share the same toilet facility.

Five out of the nine IDP camps have a Health Centre within the camp where they access services. 35.5\% IDPs surveyed said they access medical treatment within the health facility at their Camp, 20.3\% said they go to Hospital, and $25.8 \%$ go to Pharmacy, while $4.8 \%$ go to local Healer/Native Doctors. This reveals the major gap in access to health services by the IDPs.

Four out of nine IDP Camps have a school within the camp, and $68 \%$ of IDPs have schoolaged Children, out of which $71.6 \%$ send their children to school while $28.4 \%$ do not send their children to school. Among those with children in school, $58.9 \%$ of the IDP children access educational services from Public Schools.

These data show that IDPs have received some level of support from well-wishers, Philanthropist, Non-governmental organizations in the areas of Water, food, health care, and education. They also have some level of support from the Government in terms of access to Public Health Facilities and Educational services in the community.

Employment is a major challenge for most IDPs, as the majority of them used to be farmers and have now lost their farmlands due to insecurity. The research revealed that $49 \%$ of IDPs are unemployed, while $46.1 \%$ are employed in part-time jobs. The majority of the IDPs, 29\%, are still farmers, even though they do not have their own farmlands. About 5.5\% are Tailors, $2.9 \%$ are Laborers, and others are Carpenters, Plumbers, Drivers, and other menial jobs.

Security remains a major challenge in the Camps, although most IDPs indicate that there is better security at the Camp than where they are coming from. Six out of the nine IDP Camps have security posts, and the majority of the camps have vigilante groups. Some of the camps have access to police or the military. Over $40 \%$ of IDPs said they are not aware of any security breach in their Camp, while another $40 \%$ said they have heard of security breaches within their camps. However, they indicated they feel more secured here at the IDP Camps than where they came from in the Northeast.

The data reveals that security is provided at two levels, the government that provides the IDPs with some level of support in the area of security, and their own local vigilante groups. The majority of the IDP Camps have a security post and have formed vigilante groups to defend themselves.

$100 \%$ of the IDP Camps surveyed said their members have a good relationship with the host community. This may be a factor in their decision to return home or resettle in their current location. $55.6 \%$ of IDPs indicated their interest to relocate back home if security is restored, while $44.4 \%$ do not want to go back to their original communities before Displacement. After the further engagement, $44.4 \%$ said they are not willing to return because the factors that resulted in their Displacement have not been address. This is primarily insecurity as revealed by $77.7 \%$ IDPs. Most IDPs $65.1 \%$ Strongly Disagreed or Disagreed with the notion to remain in the IDP camps. This was confirmed by the willingness of more than $80 \%$ to return to their original homes within 6 months if the reason for their Displacement is addressed. Four factors used to measure the determining factor for resettlement were security, funds, government legislation, and family ties. Security was revealed as the major factor, with $79 \%$ of IDPs saying it is the main deciding factor for their return to their communities. Family ties were cited by $63.4 \%$ of the IDPs, which was then followed by funding and then finally Government Legislation.

\section{Conclusion and Recommendation}

In conclusion, this study reveals that Internally Displaced Persons from the Northeast Geopolitical Zone are found in the North Central 
States of Nasarawa and the Federal Capital Territory in significant numbers. IDPs met in Niger state are mostly from Madaka, within Niger State. Most IDPs have settled well within the community, and they all have a cordial relationship with their host communities.

Major finding is that more than $50 \%$ of the IDPs are willing and ready to return to their original communities provided the challenges of insecurity that led to their Displacement has been addressed. Out of the four factors assessed as influencers of IDPS decision to return to their communities, Security was found to be the greatest influencer of the IDPs decision. This was followed by family ties, then the availability of funds, and finally government legislation. The majority are willing to return within the next 3 to

\section{Reference}

[1] National Population Commission, 2016, Date of access: 05-10-2020.

file://C:/Users/fatiy/Downloads/Demographic\%20S tatistics\%20Bulletin\%202017\%20(2).pdf.

[2] IDMC Report, 2021, Date of access: 28-03-2021. https://www.internal-displacement.org/globalreport/grid2021/.

[3] Norwegian Refugee Council, 2019, Report on 70.8-million-displaced-people, Date of access: 3103-2021. https://www.nrc.no/shorthand/fr/70.8million-displaced-people/index.html.

[4] IDMC, 2020, Nigeria IDMC, Date of access: 0102-2021.

https://www.internal-displacement.org/globalreport/grid2020/.

[5] Mooney, E., 2005, Refugee Survey Quarterly, Vol.24, Issue 3., Date of access: 10-04-2021. https://doc.rero.ch/record/299905/files/hdi049.pdf.

[6] IDMC Report, 2018, Date access: 03-04-2021. https://www.internal-

displacement.org/features/nigeria-internaldisplacement-crisis-conflict-floods.

[7] Adeyeye, A., 2013, Identity conflict, terror, and the Nigerian state: Between fragility and failure, Journal of Sustainable Development in Africa, 15, 116-129.
6 months if this issue is resolved. It is therefore recommended that security be considered as the number one factor to be addressed to facilitate the relocation of IDPs.

\section{Acknowledgements}

I wish to thank God Almighty, my family, and teachers for supporting me to conduct this Research.

I wish to appreciate the participants that provided us feedback which made this Research possible. This Research was successful because you have all supported my work.

\section{Conflict of Interest}

There is no conflict of interest in this Research.

[8] Imasuen, E., 2015, Insurgency and the humanitarian crises in the Northern Nigeria: The case of Boko Haram, African Journal of Political Science, and International Relations, 9(7), 284 - 296.

[9] Joshua, S., \& Olanrewaju, F. O., 2016, The impacts of terrorism on education: The North-eastern Nigeria's experience, JIPAD: Journal of International Politics and Development, 14, 59-74.

[10]NCFRMI, 2019, Persons of Concern Report, Date of accessed: 27-04-2020. https://ncfrmi.gov.ng/. [11]UNHCR., 2019, Nigeria Key Message update, September 2019, Date of access: 05-10-2020. https://reliefweb.int/report/nigeria/nigeria-keymessage-update-september-2019.

[12] Oluwole, I. O., Eme, O. I., and Aloh, R., 2017, Rehabilitation of Internally Displaced Persons in the Nigeria Northeast: challenges and prospects, Social Scientia, Vol 2, No 23.

[13] OXFAM, 2016, Africa's Fastest Growing Displacement Crisis, Date access 03-03-2020. https://www-cdn.oxfam.org/s3fs-

public/file_attachments/bn-lake-chad-refugees-idps190816-en.pdf.

[14] Osagioduwa, E. and Oluwakorede, O. T., 2016, Management of Internally Displaced Persons in Africa: comparing Nigeria and Cameroun, Afrrev, 
Vol $10 \quad(1), \quad$ No $\quad 40 \quad$ Doi: http://dx.doi.org/10.4314/afrrev.v10i1.15n.

[15]UNOCHA, 2020, Nigeria: Humanitarian Response Plan, Date of access: 02-10-2020. https://www.humanitarianresponse.info/en/operation s/nigeria/humanitarian-response-plan.

[16]Bryman, A., Becker, S., and Sempik, J., 2008, Quality Criteria for Quantitative, Qualitative and Mixed Methods Research: The view from Social Policy, International Journal of Social Research Methodology, 11:261 - 276.

[17]Bryman, A., 2012, Social research methods (Oxford, U.K.: Oxford University Press).
[18]UNHCR, 1992, Analytical Report of the Secretary-General on Internally Displaced Persons, UN Doc. E/CN.4/1992/23 (14 February 1992), para. 17.

[19] Olanrewaju, F. A., Olanrewaju, A., Omotoso, F., Alabi, J. O., Amoo, E., Loromeke, E., and Ajayi, L.A., 2019, Insurgency and the Invisible Displaced Population in Nigeria: A situational Analysis, $S A G E$, DOI: $10.1177 / 2158244019846207$.

[20] Okoli, C. A., 2019, What can be done to fight Rural Banditry in Nigeria. Date of access: 05-032021. https://reliefweb.int/report/nigeria/what-canbe-done-fight-rural-banditry-northern-nigeria. 


\title{
Integration of Mind and Skin; Psychological Co-morbidity in Dermatology and Skin Signs in Psychiatry
}

\author{
Bushra Khan ${ }^{1 *}$, Fawwaz A. Khan ${ }^{2}$ \\ ${ }^{1}$ Dermatology, Texila American University, Guyana, \\ ${ }^{2}$ Health Science, Queens University, Canada
}

\begin{abstract}
Being the largest organ of the body, the skin is known to respond to both exogenous and endogenous stimuli. Whereas it is known that having a dermatological ailment can have a negative effect on one's body image, in addition to one's mental state, it should also be noted that the opposite is also true. That is to say that possessing psychological issues can subsequently lead to dermatological ailments. Considering this, the study aimed to analyze the co-integration of the skin and mind, analyzing the comorbidity of psychiatric disorders and dermatological issues. 30 dermatological patients, 25 psychiatry patients, and 10 control patients were enrolled into the study. Patients were tasked to complete a 21-item Depression, Anxiety and Stress Scale (21-DASS) questionnaire and a 10-item Dermatology Life Quality Index. Each patient was then assessed by a dermatologist and a psychologist. It was found that when compared to the control group, the psychological out-patients were more likely to experience dermatological ailments ( $p<0.001)$. In addition, it was found that when compared to the control group, the dermatological patients experienced an overall lower quality of life and a higher 21 DASS test result. Ultimately, it can be seen that one's mental state does in fact, have the potential to affect one's dermatological condition. With that in mind, it has been proposed to utilize stress reduction techniques and psychological intervention as adjuvant treatments for dermatological ailments.
\end{abstract}

Keywords: Comorbidity, Dermatological, Mind, Mental, Psychological, Skin.

\section{Introduction}

The skin is the largest organ of the body, serving as a protective wrapper that defends the body against injury and infection while modulating environmental influences such as ultraviolet light, heat, cold, and air pollution. The skin is also involved in a range of complex biological processes through its array of nerve endings which are in constant contact with the brain, in addition to its set of immune system cells that help to fend off bacteria and viruses. The mind and skin are two disciplines which are interconnected at the embryonal level through the ectoderm.

The skin has the potential to respond to both exogenous and endogenous stimuli; it can sense and integrate environmental triggers and transmit intrinsic conditions externally. In several dermatological ailments, such as atopic dermatitis, the tissue level of nerve growth factors and neuropeptide, such as substance $P$ have been associated with the pathogenesis of disease and markers of disease activity [1].

The nervous system influences the skin's immunity through various receptors and neuropeptides.

Research suggests that chronic negative stress can disrupt the function of the skin's permeability barrier, which normally keeps out harmful substances and prevents the loss of fluid from skin cell layers. This kind of disruption is thought to be a major factor in many skin diseases. 


\section{Types of Mind-Skin Connections}

\section{Psychophysiological}

There are psychophysiological conditions that have a physiological basis but are exacerbated by stress and emotional influence. They include, among others, acne, alopecia areata (hair loss), various types of eczema or dermatitis (skin inflammation), herpes (oral and genital), hyperhidrosis (profuse sweating), pruritus (itching), psoriasis (skin scaling and redness), rosacea (skin flushing and eruption), urticaria and warts.

\section{Secondary Psychiatric}

A cosmetically disfiguring or potentially socially stigmatizing skin disorder such as severe acne, psoriasis, vitiligo (the loss of pigmentation in the skin), or genital herpes, that can produce feelings of shame or humiliation, an erosion of self-esteem, depression, anxiety and in produce a lower quality of life. There is much evidence of a correlation between skin disorders and depressive symptoms.

\section{Primary Psychiatric}

Some skin difficulties are symptoms of a psychiatric disorder, such as chronic hair-pulling (trichotillomania), the belief that the body is infested with organisms (delusional parasitosis), preoccupation with and distress about an imagined or minor defect (body dysmorphic disorder), and self-inflicted damage to the skin (dermatitis artefacta). Such illnesses require psychotherapy and sometimes psychiatric medications. But a dermatologist, who may be the first health professional the individual sees, can treat damage to the skin or scalp.

Not everyone responds emotionally through the skin, nor do all people react the same way to having a skin problem. But evidence suggests that in some people, psychological issues often intersect with skin physiology, and treating both may offer the best chance for improvement.

Psychiatric comorbidity is high in patients with dermatological conditions, and stress has a significant impact on the presentation and course of skin disease

The relationship between skin and the brain exists due to more than a fact, that the brain, as the centre of psychological functions, and the skin, have the same ectodermal origin and are affected by the same hormones and neurotransmitters [1].

Psychoderma are toses are the skin changes that are:

1. Caused by psychiatric problems.

2. Cause psychiatric or psychological disorders due to its clinical manifestation.

3. Influence the psychological state and is maintained or aggravated by it.

Psychodermatology refers to the interaction between the mind and skin. Psychiatry involves internal non-invisible disease, and dermatology deals with visible external diseases. Lack of positive nurturing during childhood may lead in adulthood to disorders of self-image, distortion of body image, and behavioral problems [2]. In more than one-third of dermatology patients, effective management of the skin condition involves consideration of associated psychological factors [3]. Dermatologists have stressed the need for psychiatric consultation in general, and psychological factors may be of particular concern in chronic intractable dermatologic conditions, such as eczema, prurigo, and psoriasis [4-6]. More than just a cosmetic disfigurement, dermatologic disorders are associated with a variety of psychopathologic problems that can affect the patient, their family, and society together. Increased understanding of bio-psychosocial approaches and liaison among primary care physicians, psychiatrists, and dermatologists could be very useful and highly beneficial. Psychophysiological disease: Here, psychiatric factors are instrumental in the etiology and course of skin conditions. The skin disease is not caused by stress but appears to be precipitated or exacerbated by stress [7]. The proportion of patients reporting emotional triggers varies with the disease, ranging from approximately 50\% 
(acne) to greater than $90 \%$ (rosacea, alopecia areata, neurotic excoriations, and lichen simplex) and maybe $100 \%$ for patients with hyperhidrosis [8]. Stress management, relaxation techniques, benzodiazepines, and selective serotonin reuptake inhibitors (SSRIs) have been found to be useful in these disorders, these will be the aspects in focus for this study.

Psychiatric disorders with dermatological symptoms: Most of these disorders occur in the context of somatoform disorder, anxiety disorder, factitious disorder, impulse-control disorder, or eating disorder. There is not much in the medical literature on this aspect of Psychodermatology, although these conditions have a greater incidence of suicidal tendency. Some examples are dermatitis artefacta, trichotillomania which is presented at a dermatology department and should be treated in liaison with a psychiatrist. Dysmorphophobia is a condition which is also called body dysmorphic disorder or dermatological nondisease [9]. Self-reported "complaints" or "concerns" usually occur in three main areas: the face, scalp, and genitals. Facial symptoms include excessive redness, blushing, scarring, large pores, facial hair, and protruding or sunken parts of the face. Other symptoms are hair loss, red scrotum, urethral discharge, herpes, and AIDS phobia. Associated comorbidity in Dysmorphophobia may include depression, impairment in social and occupational functioning, social phobias, OCD, skin picking, marital difficulties, and substance abuse [10-11]. SSRIs, clomipramine, haloperidol, and cognitive-behavioral therapy have been used in this condition with variable success [12-13].

Realistic goals in the treatment of Psychodermatology diseases include reducing pruritus and scratching, improving sleep, and managing psychiatric symptoms such as anxiety, anger, social embarrassment, and social withdrawal. Non-pharmacologic management may include psychotherapy, hypnosis, relaxation training, biofeedback, operant conditioning, cognitive-behavioral therapy, meditation, affirmation, stress management, and guided imagery. As research continues to show, the skin is intensely affected by everything that goes on in mind and retrogradely triggers thoughts and emotions. There is a permanent mind - nervous system - skin connection and reciprocal relation between these three areas. The skin sends messages to the nervous system and the mind, and this influences the skin [1415].

From this interaction, the field of Psychodermatology was developed, which can be defined as the concept that encompasses all the personal and social consequences of dermatoses and the mental and emotional mechanisms involved in their origin, maintenance, or aggravation.

The burden of skin disease represents more than just the economic burden and may not be measured by classic morbidity or mortality data. Rather, it represents the overall influence of skin disease on patients (including quality of life issues), their families, and society (Barendregt et al., 1997; Murray and Lopez, 1997; Lopez and Murray, 1998). There is a relative (almost absolute) lack of data for most of these burdens and, more importantly, a deficiency of valid instruments to measure them at this time [16] according to a history on movement on the association for psychocutaneous medicine of North America (APMNA) website reports that there are very few Psychodermatology clinics in North America and most medical school curriculum doesn't include Psychodermatology, as well as there, are limited researches and research funding in this area [18].

Skin diseases are not just a cosmetic concern; they have a strong relationship with psychiatric reactions that affect a patient's level of functioning and is agonizing for the family. Psychiatric disturbance resulting from dermatological disease or dermatological drugs is not fully understood. For instance, Isotretinoin which is used for recalcitrant acne, has been implicated in causing mood swings, depression, and suicidal tendencies. There are conflicting 
reports on the use of Isotretinoin and depression or suicidal tendencies. There should be more studies to support the exact cause in the use of Isotretinoin, acne itself and psychiatric symptoms. In a survey of the National Rosacea Society conducted in 2014, including 1,675 rosacea patients, revealed that $90 \%$ of respondents reported low self-esteem, 54\% reported anxiety and helplessness, and 435 of patients reported depression [18]. Since Psychodermatology is relatively a new field, there is relatively little literature to support the importance of mind and skin co-relation and hence building up an inter-professional relationship between a Psychiatrist and Dermatologist. There should be more researchbased literature available to support the pathophysiology and management of psychocutaneous disorders. There are multiple questionnaires that have been developed to measure the quality of life (QOL) in patients with skin diseases, but due to validation of research techniques, this still needs to be explored in the future [17].

The thesis would be focusing on Psychiatric disorders with dermatological symptoms and Dermatological disorders with psychiatric symptoms emphasizing the co-relation between mind and skin. The hypothesis will test the integration of Mind and skin, psychological comorbidity in dermatology, and skin signs in psychiatry.

\section{Methods}

A study was conducted to investigate the psychodermatology co-relation. The study had an observational case-control trial. The study was initiated within a dermatology department in a well-known medical clinic in Kuwait and psychiatry department in an out-patient clinic in Pakistan. There were 30 participants in the dermatology department, 25 adult out-patients and 10 co-employees volunteer participants that were assessed at the Clinical department of Dermatology and Venereology at a medical center in Kuwait.
The total number of subjects was 30 patients in the dermatology department and 25 patients in the psychiatry outpatient clinic. 10 patients were recruited as controls accompanying the psychiatric patients in the out-patient clinic. Out of 30 patients in the dermatology department, 20 were females and 10 males with a mean age of $38+(-) 8.7$ years. The number of subjects in the psychiatry department was 25 , among which 15 were psychiatric patients, and 10 subjects were controls. There were 22 female patients and 13 male patients, with the mean age being $42.7+(-$ ) 6.5 years.

The primary psychiatric disorders which were studied in the psychiatry OPD clinic included schizophrenia, depression, anxiety, obsessivecompulsive disorder; The patients' most frequent skin diseases in the dermatology department were Urticaria $41.67 \%$, Psoriasis $33.33 \%$, Vitiligo $28.57 \%$, and Atopic Dermatitis 20\% (Table-1).

The psychiatry department enrolled 25 patients who came with psychological issues but were observed to have skin signs, among which dermatitis artefacta 44\%, Trichotilomania 36\%, and Delusional Parastosis 20\% were common (Table-2). 15 control subjects were recruited for the study as control who were taken from those accompanying the patient.

The inclusion criteria in the dermatology department required participants to be 18 years old or above, being able to read, write while not suffering from any mental retardation to accurately answer the questionnaire. Depression, anxiety, and stress were self-assessed by participants using a 21-item Depression, Anxiety, and Stress Scale (DASS-21) [21-22].

Each item had four possible responses (never, sometimes, often, and almost always) represented by scores of $0,1,2$, and 3, respectively [21-22]. Participants were considered to have a negative emotional state if they suffered from at least one symptom of depression, anxiety, or stress, according to their questionnaire responses. Quality of life (QOL) was assessed using the validated Arabic version 
of the 10-item Dermatology Life Quality Index (DLQI) [23-24]. The DLQI is a selfadministered tool that evaluates the impact of dermatological diseases on QOL [23-24]. Items were scored on a four-point scale (range: 0-3); a score of $<1$ was considered to indicate an adequate QOL [23-24]. Also, GAD-7 was used to assess anxiety levels in the patients.

Psychologists ensured the professional informing of the participants. Each participant had to complete a questionnaire and give it to the consultant before being examined clinically. Dermatologists examined each patient and recorded their diagnosis, in addition, secondary diagnoses were recorded, such as cardiovascular disease, chronic respiratory disease, diabetes, and rheumatological disease.

The volunteer samples were recruited from co-employees and staff members of the dermatology department of private medical center Kuwait. A complete information about the study was given to the employees with skin conditions, and they were handed out a questionnaire about QOL and an anxiety questionnaire after giving informed consent. Information about co-morbidities were selfreported and recorded.

The inclusion criteria in the psychiatry department was age between 18-50 years while possessing a primary psychiatric disorder. Exclusion criteria was any patient that did not fulfill the inclusion criteria, patients with systemic disorders associated with these chronic diseases such as liver and renal problems, and patients with a debilitating disease. Psychiatric consultation by a psychiatrist was done, and statistical manual of mental disorders (DSM IV) criteria that describes the symptoms of mental disorders was used to meet the criteria for diagnosis of mental disorders. General clinical examination and investigations to exclude systemic diseases were done (complete blood count, liver, and renal function tests, fasting blood sugar) hormonal investigations were also performed.

\section{Selection of Subjects Free from Psychiatric Problems:}

Individuals free from psychiatric problems were recruited from those accompanying patients after explaining the purpose of the study and taking verbal consent.

\section{Inclusion Criteria}

Inclusion criteria for controls are Individuals free from psychiatric symptoms. Age, sex, and social class matched to patient's group.

\section{Exclusion Criteria}

Exclusion criteria for controls are Individuals with any systemic disease, such as liver problems, renal disease, or diabetes.

All participants underwent the following:

1. Psychiatric consultation by psychiatrist using the diagnostic and statistical Manual of Mental Disorders (DSM IV) Criteria that describes the symptoms for all mental disorders and the criteria that should be obtained to establish a diagnosis of each disorder or exclude psychiatric disease of healthy participants after taking a medical history of psychiatric disease of each patient.

2. A detailed history was taken on Skype by the dermatologist, and photographs of the involved areas were reviewed. In some cases, for skin examination, patients were referred to a local dermatologist and were advised to bring a report.

3. A specially designed form including the name, age, sex, address, marital history, smoking history, education, occupation, and special habits was to be filled by all participants.

4. Laboratory investigations were done $(\mathrm{CBC}<$ LFT's, RFT's, Blood glucose). In some cases, hormonal investigations.

\section{Measuring Instruments}

Quality of Life was measured using the Dermatology Life Quality Index (DLQI), from which a total score is calculated (ranging from 0 to 30). A high DLQI-value implicated severe 
detriment to the quality of life because of skin condition.

Generalized Anxiety Disorder - 7 items (GAD-7) scale was used to score the anxiety level.

DSM-IV: Psychiatric Diagnoses are categorized by the Diagnostic and Statistical Manual of Mental Disorders, $4^{\text {th }}$ Edition. Better known as the DSM-IV, the manual is published by the American Psychiatric Association and covers all mental health disorders for both children and adults. It also lists known causes of these disorders, statistics in terms of gender, age at onset, and prognosis as well as some research concerning the optimal treatment approaches.

\section{DASS-21}

The DASS is a clinical assessment that measures the three related states of depression, anxiety and stress. It has 21 questions. [22]

\section{Statistical Analysis}

Data collected was reviewed and given a unique ID. Skin issues and psychiatric illnesses were compared using $\mathrm{x} 2$ tests as categorical variables and $t$-tests for continuous variables, $p$ $<.05$ was used for statistical significance.

In order to exhibit a graphical display, the relationship between skin disease and psychiatric illness, the patients were classified to have a prevalent, intermittent, or incidental finding of skin issue (Figure-1). Patients who reported often having skin disease were prevalent cases, those who rarely said skin disease were intermittent cases, and those who never had skin issues were incidental cases.

\section{Results}

When compared to healthy controls or the general population, dermatology patients were more likely to suffer from anxiety and depression; in a $13 \%$ versus $3.7 \%$ and $5.8 \%$ versus $0.9 \%$ of dermatology patients versus controls suffered from anxiety and depression, respectively.

Prevalence rates of depression, anxiety and stress were $12.6 \%$ (95\% CI: 8.8-17.3\%), 22.1\%
(95\% CI: $17.1-27.7 \%)$ and $7.5 \%$ (95\% CI: 4.6$11.4 \%$ ), respectively. The prevalence of at least one of these negative emotional states was 24.4\% (95\% CI: 19.3-30.2\%). Table-1 presents rates of depression, anxiety, stress, or at least one of these negative emotional states in relation to demographic and clinical data. Those with poor QOL were also significantly more likely to be depressed compared to those with adequate QOL (15.6\% versus $1.9 \%$; $P=0.007)$.

It was found that there was a higher percentage of skin diseases in psychiatric patients (20 subjects; $80 \%$ ) as compared to the control group, which only had 2 patients $(20 \%)$ $(p<0.001)$. The number of psychiatric patients with skin infections was 20, and non-psychiatric patients (the control group) were 2 subjects with infectious skin disease. The number of patients with dermatitis artefacta was 9 , those who had delusional Parasitosis were 4, and 7 patients with obsessive-compulsive disorder had Trichotillomania and infectious disease. The frequency of infectious versus noninfectious diseases was higher in psychiatric patients $(\mathrm{p}<$ 0.001 ).

\section{Discussion}

The relationship between stress and skin has existed and been documented since ancient times. The recent clinical observations show that psychological stress is linked to various skin disease onset or aggravation. As mentioned, the skin is the largest organ of the body and the primary organ for external stressors such as heat, cold, pain, and mechanical tension. The skin and its appendages are also a local source for factors that cause various immune and inflammatory responses. Stress conditions exert their effects on the skin mainly through the HPA-axis. The peripheral HPA system is fully developed by the skin, which produces $\mathrm{CRH}, \mathrm{ACTH}$, and their receptors in the skin cells. CRH is produced by epidermal and hair follicle keratinocytes, melanocytes, sebocytes, and mast cells upon stress, including immune cytokines, UV irradiation, and cutaneous pathology [19-20]. 
Meanwhile, acute stress has an impact on innate and adaptive immune responses. Finally, chronic stress suppresses immunoprotection, increases skin infections, and exacerbates some allergic inflammatory diseases.

In the study, we attempted to co-relate the skin-brain connection, the detrimental effect of dermatological diseases on quality of life and skin signs in psychiatric patients which reveals the importance of emerging psychodermatology and treating patients holistically.

This study highlights the importance of Psychodermatology, considering the connection between the mind and skin when managing a patient with dermatological problems. A holistic approach should be considered; due to the fact that, as seen in our study, stress can aggravate or cause skin disease, and skin diseases itself can cause psychological issues. Our study highlights the importance of combining medical treatment with a psychiatric approach, including techniques for stress reduction to improve one's quality of life and a better prognosis for the patient. It also highlights the importance of the presence of a psychiatry department in collaboration with the dermatology department in order to manage the patient holistically and provide a better outcome with a good quality of life.
Stress reduction techniques and psychological intervention are proposed as adjunctive treatment in skin diseases. Since our study involves a small group of patients which limits the study, in addition to a long distance to examine skin signs in psychiatric patients is another limitation. The study examines a heterogeneous group rather than analyzing the skin disease individually for separate analysis. Considering the limitations of the study it is suggested that inclusion of clinical assessment of skin diseases as well as psychological interventions in a large-scale population-based cohort study is required.

\section{Conclusion}

The mind and skin inter-relationship has been studied extensively at the cellular and molecular level in various studies. The results of our study show that patients with depression undergo more physical illness and show skin signs while patients with chronic skin diseases suffer from a depressive illness which displays that the state of one's mind has a remarkable impact on how the illness is perceived its severity and its content. Stress reduction techniques and psychological intervention are proposed as adjunctive treatments in skin diseases.

\section{Figures and Tables}

Table 1. Dermatology Department Patients

\begin{tabular}{|l|l|l|l|l|l|}
\hline \multirow{2}{*}{ Dermatological Diseases } & \multirow{2}{*}{30 Patients } & \multicolumn{2}{|l|}{ 25 Adult O/P } & \multicolumn{2}{l|}{ 10 Volunteers } \\
\cline { 3 - 6 } & & Numbers & Percentage & Numbers & Percentage \\
\hline Psoriasis & 6 & 4 & $20.00 \%$ & 2 & $20.00 \%$ \\
\hline Vitiligo & 7 & 5 & $25.00 \%$ & 2 & $20.00 \%$ \\
\hline Urticaria & 12 & 4 & $20.00 \%$ & 5 & $50.00 \%$ \\
\hline Atopic Dermatitis & 5 & 7 & $35.00 \%$ & 1 & $10.00 \%$ \\
\hline Total & 30 & 20 & & 10 & \\
\hline
\end{tabular}

Table 2. Skin Diseases in Psychiatric Patients

\begin{tabular}{|l|l|l|}
\hline Skin Diseases & Patients & Percentage of Total Enrolled Patients \\
\hline Dermatitis Artefacta & 9 & $36.00 \%$ \\
\hline Trichotilomania & 7 & $28.00 \%$ \\
\hline Delusional Parastosis & 4 & $16.00 \%$ \\
\hline Total & 20 & $80 \%$ \\
\hline
\end{tabular}




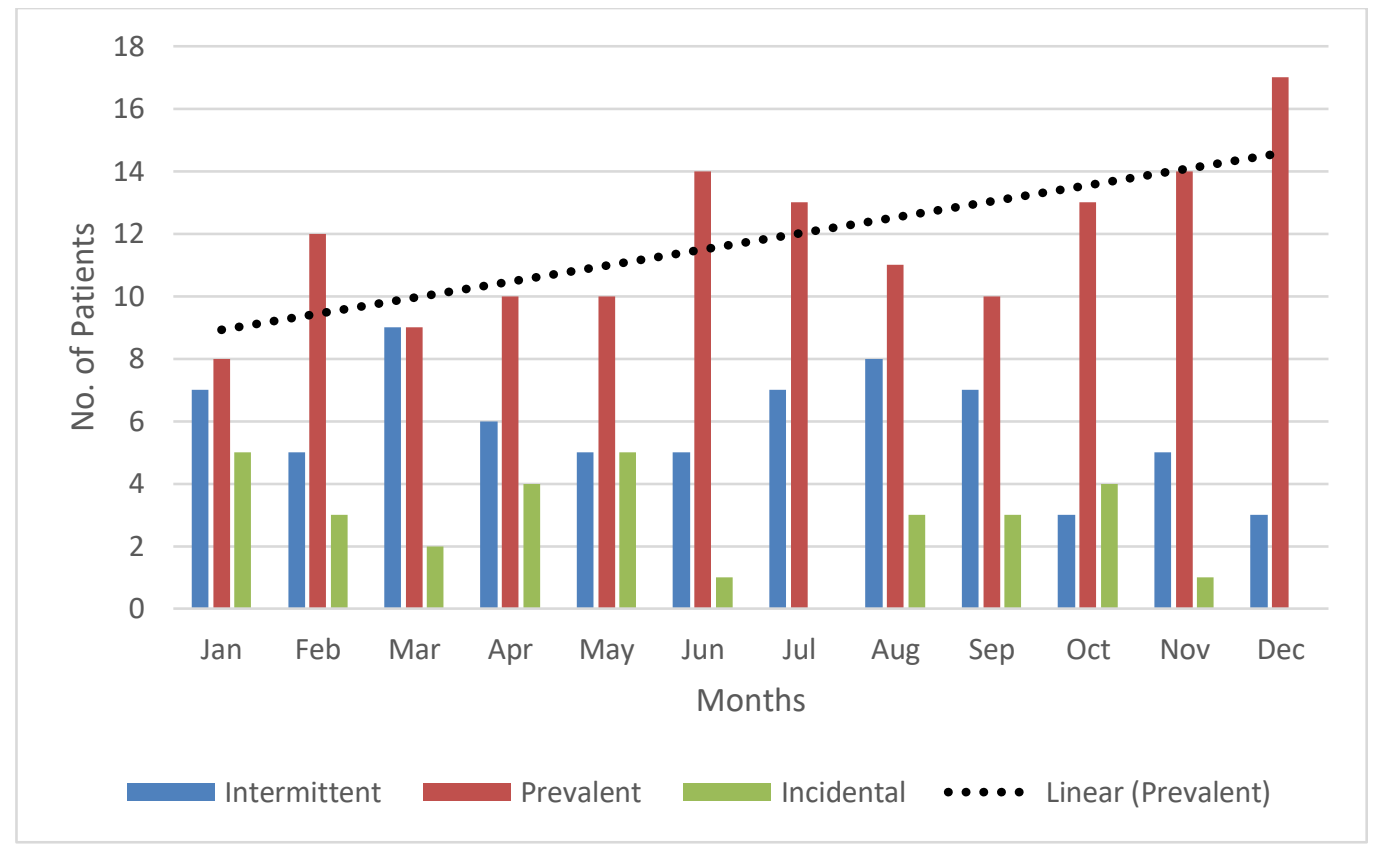

Figure 1. The Prevalence of an Impaired Quality of Life Amongst Patients with Skin Ailments Over the Course of One Year

Figure - 1 demonstrates that patients with prevalent skin problems have the highest level of impaired quality of life while patients with intermittent skin problems had the secondhighest level of QOL. Patients with incidental skin problems were the least impacted.

\section{Skin Problems \& Anxiety}

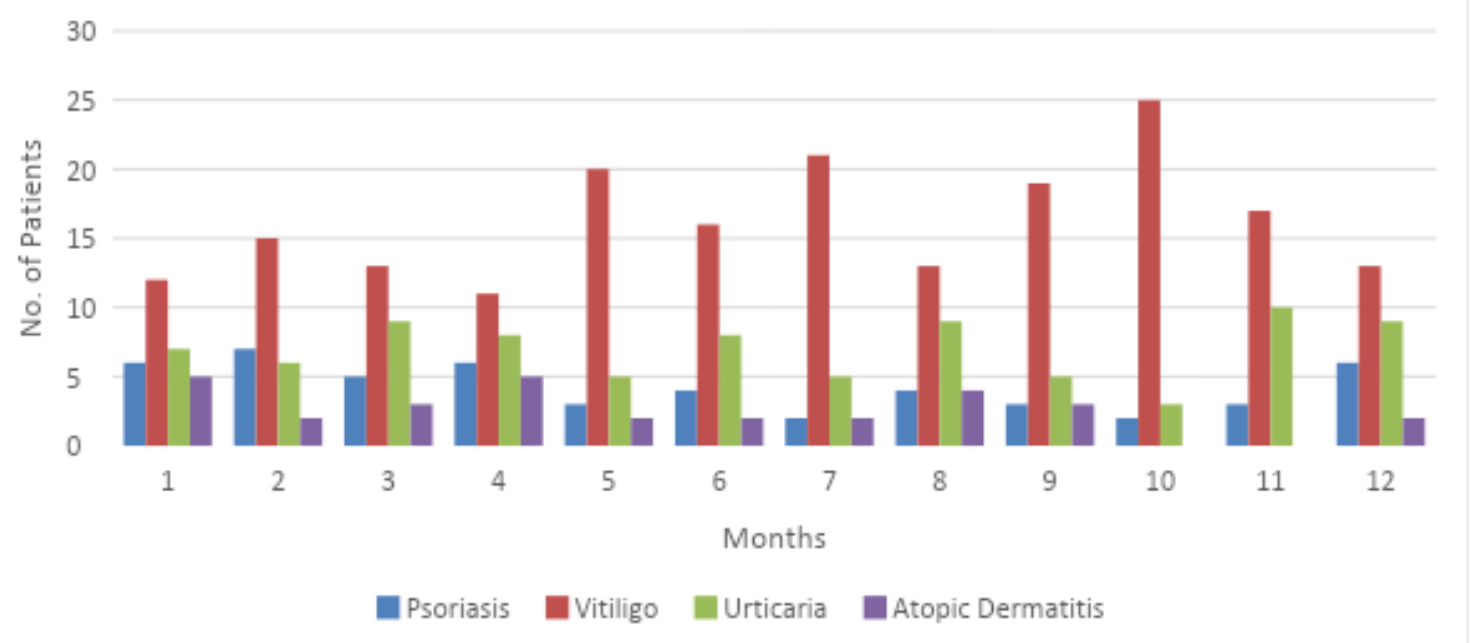

Figure 2. Reported Cases of Anxiety in Patients with Psoriasis, Vitiligo, Urticaria and Atopic Dermatitis Over the Course of One Year

Figure - 2 shows that Vitiligo and Psoriasis patients had the highest level of anxiety. Urticaria intermediate level and Atopic Dermatitis was at a minimal level. Generalized estimating equation (GEE) analysis was performed to determine the longitudinal relationship between skin diseases and psychological symptoms. In this, the dependent variable was skin disease, and the independent variable was the psychological symptoms. 


\section{References}

[1] Toyoda M, Nakamura M, Makino T, 2002, Nerve growth factor and substance $\mathrm{P}$ are useful plasma markers of disease activity in atopic dermatitis. $\mathrm{Br} J$ Dermatology. 147, 71-79.

[2] Sands, GE, 1996 Three monosymptomatic hypochondriacal syndromes in dermatology. Dermatol Nurs. 421-425.

[3] Savin JA, Cotterill JA, 1992, Psychocutaneous disorders. In: Champion RH, Burton JL, Ebling FJG, eds. Textbook of Dermatology. Oxford, England: Blackwell Scientific Publications; 1992, 2479-2496.

[4] Humphreys F, Humphreys MS, 1998, Psychiatric morbidity and skin disease: what dermatologists think they see. $\mathrm{Br} \mathrm{J}$ Dermatol. 679-681. https://pubmed.ncbi.nlm.nih.gov/9892914/.

[5] Attah Johnson FY, Mostaghimi H, 1995 Comorbidity between dermatologic diseases and psychiatric disorders in Papua New Guinea. Int J Dermatol. 244-248.

https://pubmed.ncbi.nlm.nih.gov/7790138/.

[6] Capoore HS, Rowland Payne CM, Goldin D, 1998, Does psychological intervention help chronic skin conditions? Postgrad Med J. 662-664.

[7] Koo JYM, Lee CS, 2003, General approach to evaluating psychodermatological disorders. Psychocutaneous Medicine. Marcel Dekker Inc. 129.

[8] Cotterill JA, 1990 Psychophysiological aspects of eczema. Semin Dermatol. 216-219. https://pubmed.ncbi.nlm.nih.gov/2206922/.

[9] Cotterill JA, 1981, Dermatological non-disease: a common and potentially fatal disturbance of cutaneous body image. Br J Dermatol. 611-619.

[10]Phillips KA, Dufresne RG Jr, 2002, Body dysmorphic disorder: a guide for primary care physicians. Prim Care 99-111. https://www.ncbi.nlm.nih.gov/pmc/articles/PMC178 $5389 /$.

[11]Hardy GE, Coterill JA, 1982, A study of depression and obsessionality in dysmorphophobic and psoriatic patients. $\mathrm{Br} \mathrm{J}$ Psychiatry. 19-22. https://pubmed.ncbi.nlm.nih.gov/7059736/.

[12] Phillips KA, Taub SL, 1995, Skin picking as a symptom of body dysmorphic disorder. Psychopharmacol Bull; 31:279-288. [PubMed].
[13] Phillips KA, Albertini RS, and Siniscalchi JM. et al. FIX Effectiveness of pharmacotherapy for body dysmorphic disorder: a chart review study. J Clin Psychiatry. 2001 62:721-7.

[14]Hoffmann FS, Zogbi H, Fleck P, Müller MC, 2005 Mind and body integration in psycho dermatology. Rev Psicol.;7:51-60.

[15] Silva MN, Silva RN, Soares GMT, 2011 Influence of dermatoses on the psyche of dermatological patients. Med Cut Iber Lat Am.; 39: 209-210.

[16]FIX Report on "Burden of Skin Disease" Workshop NIAMS, 2002 (J Investing Dermatol Symp Proc 9:111-119, 2004).

[17]Reebye, P, 2008, Psychodermatology: The Psychological Impact of Skin Disorders. J Can Acad Child Adolesc Psychiatry, 17(3), 169-171.

[18]Clay, R.A., 2015, The link between skin and psychology: how psychologists are helping patients with dermatological problems. American Psychological Association, 46(2), 56 http://www.apa.org//.

[19] Kono M, Nagata H, Umemura S, Kawana S, Osamura R Y, 2001, In situ expression of corticotropin-releasing hormone (CRH) and proopiomelanocortin (POMC) genes in human skin. FASEB J, 15(12), 2297-2299, https://pubmed.ncbi.nlm.nih.gov/11511529/.

[20] Slominski A, Wortsman J, Pisarchik A, Zbytek B, Linton E.A, Mazurkiewicz J.E, Wei E.T., 2001, Cutaneous expression of corticotropin-releasing hormone $(\mathrm{CRH})$ : urocortin and $\mathrm{CRH}$ receptors. FASEB J, 15(10), 1678-1693, https://pubmed.ncbi.nlm.nih.gov/11481215/.

[21] Antony MM, Bieling PJ, Cox BJ, Enns MW, Swinson RP, 1998, Psychometric properties of the 42-item and 21-item versions of the Depression Anxiety Stress Scales in clinical groups and a community sample. Psychological Assessment, 10, 176-81. https://psycnet.apa.org/record/1998-02891012.

[22]2021, Depression, Anxiety and Stress Scale, https://www.depression-test.net/support-

files/dass21-dmz.pdf.

[23] Finlay AY, Khan GK, 1994, Dermatology Life Quality Index (DLQI): A simple, practical measure 
for routine clinical use. Clinical and Experimental Dermatology,

19 ,

https://pubmed.ncbi.nlm.nih.gov/8033378/.

[24] Khoudri I, Lamchahab FZ, Ismaili N, Senouci K, Hassam B, Abouqal R, 2013, Measuring quality of life in patients with psoriasis using the Arabic version for Morocco of the Dermatology Life Quality Index. International Journal of Dermatology, 52, 795-802. https://pubmed.ncbi.nlm.nih.gov/8033378/. 


\title{
Basic Academic Research Structure and Format Guiding Principles for Students
}

\author{
Aquila Hakim M. Jongroor \\ School of Public Health, Texila American University, Guyana, South America
}

\begin{abstract}
The main purpose of the guideline is to develop a basic academic research structure and format guiding principles for students with two specific objectives; to develop a coherent research structure and academic research format for the public universities in South Sudan. One hundred and seventeen dissertations were reviewed, and a total of 88 teaching staff were interviewed, giving $91 \%$ response rate. The dissertations were selected randomly, and teaching staff were selected purposively by virtue of their positions and availability. The validity and reliability of the instruments was ensured through pretesting, CVI, and triangulations. SPSS $v 22$ was used to analyze data, both descriptive and thematic analysis were used. Permissions were sought from university administrations and one of the respondents before data collection. There is some significant variation on academic structure and format across the five universities in the republic of South Sudan. The research structural variations and inconsistencies were found in their contents and order of titles and subtitles of dissertations reviewed. In conclusion, this basic academic research guide is developed to set some standards and directions for students and their supervisors to complete the dissertation on time with less stress as it provides where to begin and the end. It will also enhance the objective grading of dissertations and evaluation levels of the university. The guideline will contribute to the development of consensus on academic research structure and format standards for students that will encourage young researchers to have an interest in research as a career.
\end{abstract}

Keywords: Basic academic research structure, Format guide.

\section{Introduction}

South Sudan is the newest country in the African Continent which got its independent in one decade ago on $9^{\text {th }}$ July 2011 from Sudan with a population of about 13 million [1]. The Country current has five public universities, namely the University of Juba, Bhar El Gazal University, Upper Nile University, Rubek University of Science and Technology, and Dr. John Garang Memorial of Science and Technology.

This study is one the first of its kind after the independent as part of efforts to improve the higher learning system in general and academic research quality in particular. The research focused on research structure and its format as the basic guiding principle for university students and researchers [2]. Learning to become a researcher is a process that requires step-bystep practice, which must start from basic research structure to complex one. Students need some basic standards to build a foundation for conducting research for academic purposes as a learning experience before endeavoring to real live experience research for decision making [3].

The fundamental expects of academic research are structure and format. A clearly written academic research guideline helps students and their supervisors to conduct 
research with a yardstick and a common understanding of the expected outcome [4]. The academic research structure and format layout and entails the beginning and the end of the academic research in a logically manner with sense of coherence of all its parts [5]. Writing an academic research is unique, and it is not the same as writing sermons, compositions, or a one-man write-up [6].

Academic research formatting provides consistency, user-friendly readability, focus on content, and facilitates the practice of discipline and adherence to the standards. It is the responsibility of an individual university to guide research formatting to determine font type/size, margins, pagination, among others [7].

Research format is important in academic writing because it helps to make your ideas clear, guides the reader's comprehension, and can strengthen a researcher argument [8]. Academic research structure helps in the development of ideas, skills and motivates students to identify their career path. When conducting research is made simple, the students become very interesting in research and will acquire necessary skills and knowledge that promote independence, collaboration, and innovations, which contribute to the production of new knowledge of which the society and university can benefit [9].

Basic structure of a typical dissertation or thesis contents and their sequence broadly include preliminary pages, body, and annexes. Preliminary pages contents sequentially start with cover page, inside title page, approval, declaration, dedication, acknowledgement, table of contents, list of table, list of figures, list of abbreviations and acronyms, and abstracts. Academic research body consist of section one, section two, section three, section four, and section five. The sections are titled as follows introduction 1 , literature review 2 , methodology 3 , research findings 4 , discussion, conclusion, and recommendations [10].

There is no one standard academic research structure and format across the universities globally. The inconsistencies are seen in the contents and sequence of subtitles of dissertations. On the other hands, dissertation formats are determined by referencing style adopted by the university. The African content and regional universities are not exceptional. The five public universities in South Sudan are the worst when it comes to academic research structure and format. Content and order of dissertations are not consistent between and within the universities [11-15].

The double standard research structure and format is the source of confusing, disorganization resulting to frustration and discouragement of students to become research. In the absent of researchers and competent enough in South Sudan will have a negative impact in the wellbeing of the humanity at all aspects of live [16].

The main aim of this guideline is to develop a basic academic research structure and format for students with two specific objectives; to develop a coherent research structure and academic research format. The public in Universities of the Republic of South Sudan do not consistent research structure.

This article attempted to provide a basic standard and coherent academic research structure and format for students to complete the dissertation within the time frame without frustration which can be evaluated in an objective manner. The guideline be used as a reference for the development of research policies, guidelines, and dissertation supervision, and marking guide as well.

\section{Methods and Materials}

This research adapted qualitative and quantitative approach, descriptive and crosssectional designs to assess research structure and format in five public universities in the Republic of South Sudan. Dissertations of the students in University of Juba, Upper Nile University, Bhar El Gazal University, Rumbek University, and Dr. John Garang Memorial University of Science and Technology were the target objects 
and teaching staff of the same universities. Both qualitative and quantitative approaches are useful triangulation of data [17]. Description of the existing research structure and format can be well-articulated using a descriptive design, which has the ability of providing in-depth information for a better understanding of the variables [18]. The cross-sectional design has no time dimension. This design was preferred as the information was collected from dissertations and teaching staff of the universities as they exist at the point in time. The research paradigm is epistemology because of the objectivity and subjectivity of the research design [19]. The sample size was determined proportionately based on the number of dissertations and teaching staff. A total of 225 participants and objects were participated in soliciting data. These include 25, 75, and 125 head of departments or Deans of faculties, teaching staff (Lecturers, teaching assistants etc.), and 225 dissertations, respectively [20].

Primary and secondary constituted the data source for this study. Primary data were collected from 100 teaching staff and secondary data from dissertations. Dissertations were selected randomly, while teaching staff were selected purposively by virtue of their positions and availability [21]. All participants consented verbally before they provide information. Permissions were sought from each university before accessing dissertations, policies, and guidelines from libraries.
Observation checklist, questionnaires, and interview guides were used to collect both quantitative and qualitative data. Validity and reliability of the data collection tools were ensured by pre-testing the tools, content validity index was used, and triangulation of the data collection instruments were the techniques used [22]. Descriptive analysis was used to run the frequencies for quantitative data using SPSS v21 and qualitative data was analyzed using thematic analysis [23].

This study is subjected to methodological, contents, and context limitations, these include but not limited to cross-sectional design does encounter casualty limitations, some degree of selection bias, recalled bias, social desirability bias, and scarcity of academic materials [24].

\section{Results}

All five public universities were included in the study, and Table 1 below depicts distributions of objects and participants. The number of respondents was determined proportionately.

There is significant variation in the contents and sequence of the academic research structure in the five public universities of the Republic of South Sudan. However, the major sections are consistent that's preliminary pages, research body, and appendixes. Research paper formatting generally is more consistent compared to the structure. Some of the notable disparities are seen in the cover page color of dissertations.

Table 1. Distribution of Participants and Objects by Public Universities

\begin{tabular}{|l|l|l|l|}
\hline Name of University & \% of Teaching staff & \% of Dissertations reviewed & Total \% \\
\hline University of Juba & $51 \%$ & $36 \%$ & $43.5 \%$ \\
\hline Bhar El Gazal University & $18 \%$ & $23 \%$ & $21.5 \%$ \\
\hline Upper Nile Univeristy & $15 \%$ & $17 \%$ & $16 \%$ \\
\hline Rumbek University & $10 \%$ & $13 \%$ & $11.5 \%$ \\
\hline Dr. John Garang University & $6 \%$ & $11 \%$ & $8.5 \%$ \\
\hline Total & $\mathbf{1 0 0 \%}$ & $\mathbf{1 0 0 \%}$ & $\mathbf{1 0 0 \%}$ \\
\hline
\end{tabular}




\section{Academic Research Structure}

The major variations and inconsistencies of academic research structure in the public universities in South Sudan were found to be in the contents and order of titles and subtitles.
The main contents of the preliminary pages were fairly well presented in the dissertations. However, there were notable inconsistencies in the order of the contents of the preliminary pages Figure. 1.

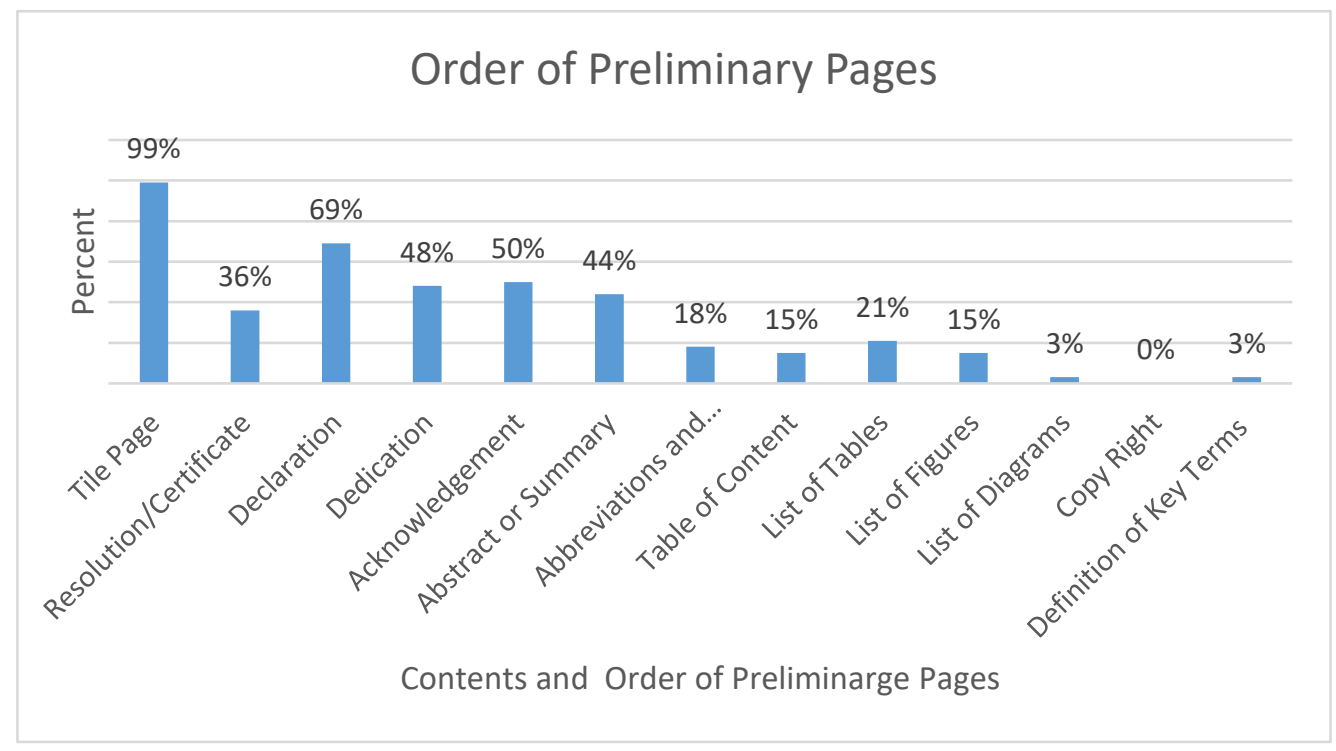

Figure 1. Order of Preliminary Pages Contents

The availability of the main sections in the dissertations written by students in the five public universities was observed using observation checklist. Figure 2 below shows the distribution. Only $50 \%$ of dissertations reviewed have references and appendixes. Majority of dissertations have five sections only.

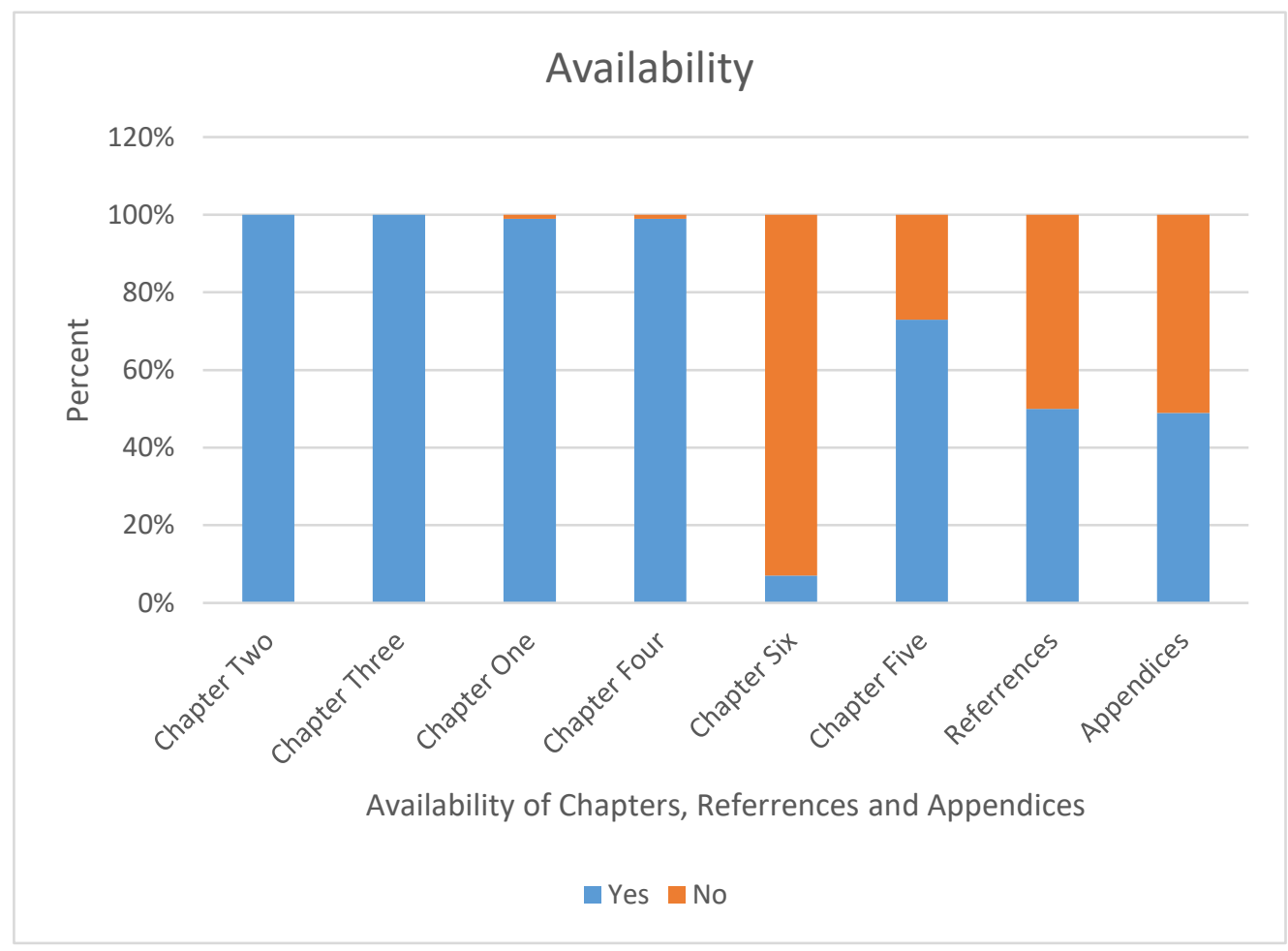

Figure 2. Availability of the Main Sections in the Dissertations 
There are different titles used for the main headings of the body of the academic research. Section one the following headings were used to represent the Section. Introduction and background $38 \%$, introduction $38 \%$, literature review $14 \%$, background $3 \%$ and other titles used $7 \%$. Section two headings were literature review $74 \%$, methods and materials $15 \%$, theoretical framework 3\%, conceptual framework $2 \%$, and $7 \%$ for others. Section three headings only $28 \%$ and $22 \%$ of dissertations wrote research methodology and methodology respectively as titles for the section. The remaining $50 \%$ of dissertations reviewed missed the right heading. The following are some of the headings used by the students instead to represent section three heading; results $21 \%$, designs $9 \%$, methods, and materials $7 \%$, procedure $7 \%$, and methods $6 \%$. About 50 different titles were used by students to represent section four in the dissertations. The two most frequent titles were data results and discussion $21 \%$ and result $10 \%$. The other 45 titles constitute $69 \%$, with an average of $2 \%$ each. Surprisingly $22 \%$ of dissertations did not have section five. One of the common title used was summary and conclusion $31 \%$ as the title for section five. The other titles were summary and findings $6 \%$, recommendations $5 \%$, discussions $3 \%$, and $32 \%$ others.

The below basic academic research structure is developed based on the findings and literature to be used by students and their supervisors as a guiding principle [24].

Figure 3 illustrates the structure of academic research showing major sections, titles, subtitles, and their sequential order from top to bottom.
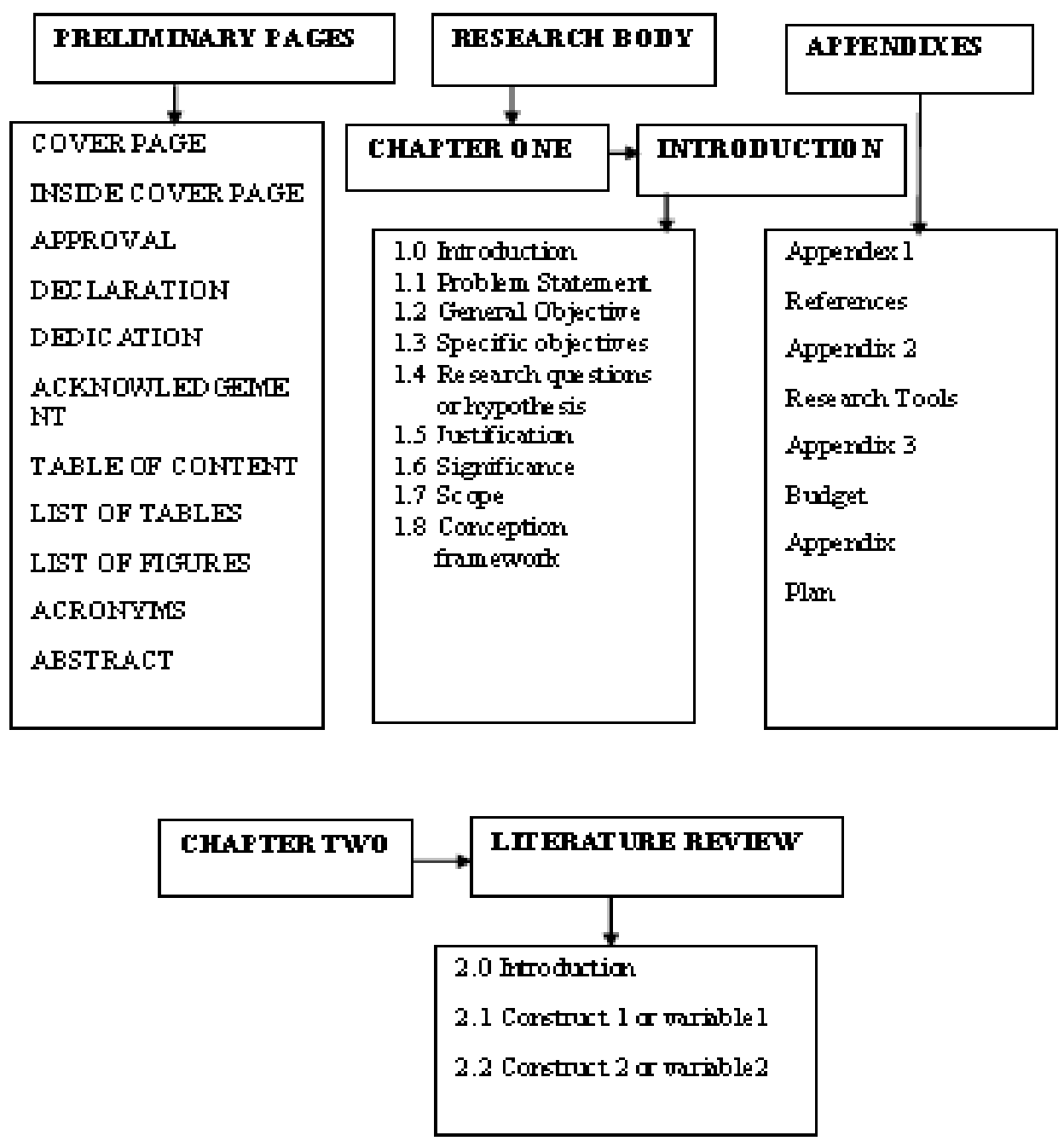

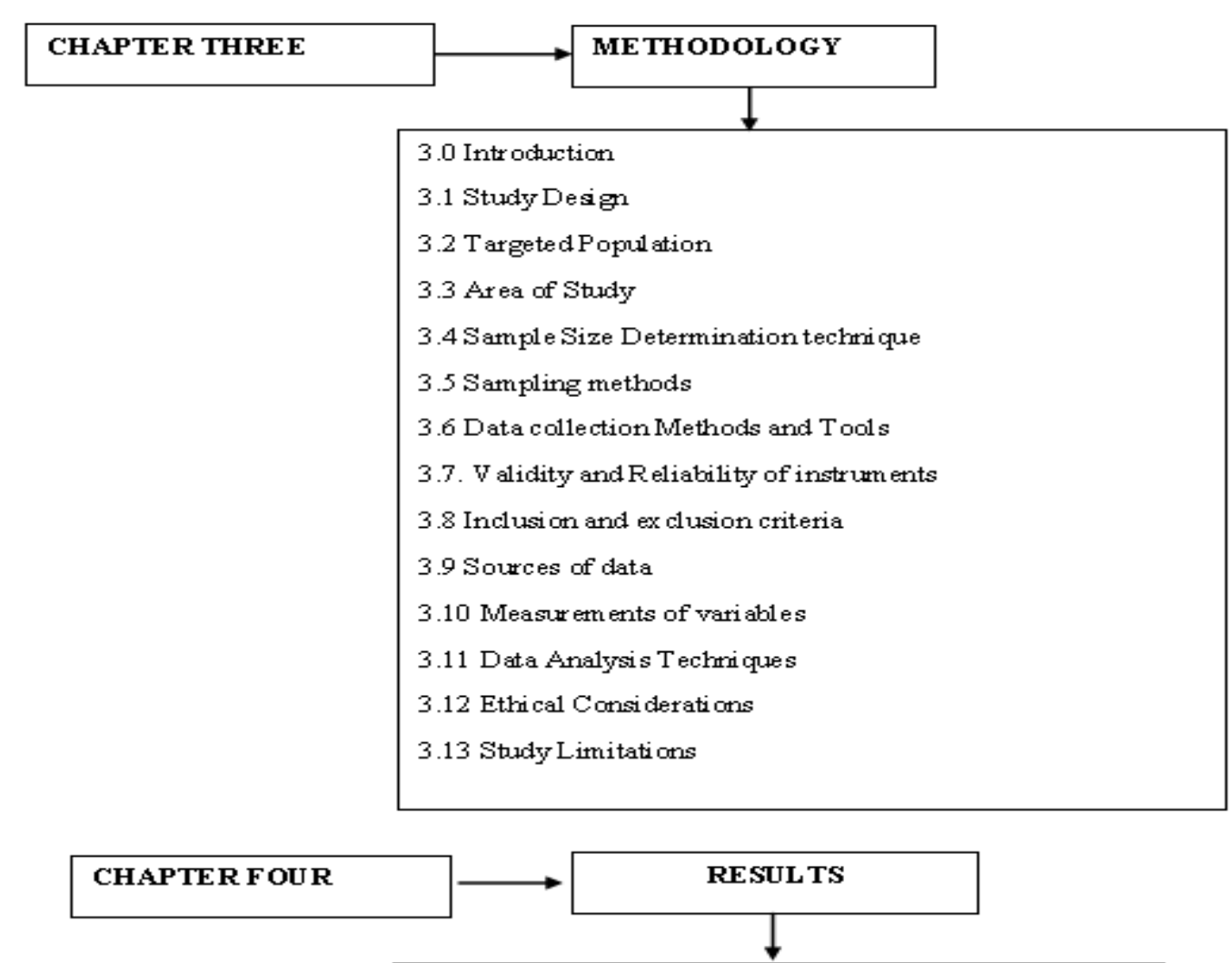

4.0 Introchuction

4.1 Response Rate

4.2 Demographic Characteristics

4.3 Objective one title

4.3.1 Subtitle e.g. Attribute

4.40 bjective two title

\section{CHAPTER YIVE}

\section{DISCUSSION, CONCLUSION AND REC OMMENDATIONS}

5.0 hitroduction

5.1 Dious findings

52 Concharian

53 Recamendition

\subsection{Sucented are a f further Re warch}

Figure 3. Basic Academic Research Structure

Table 2 depicted the recommended subheadings and order of preliminary pages. The variations were in order rather than the content. Table 3 propose the length of a research paper be 
estimating the number of pages for each title and subtitle as a guide.

Body of the Research is the largest part of the research paper. It consists of five sections that constitute a dissertation.

Appendixes are some parts of a dissertation that cannot be included in the main text. Table 4 shows some of the most common parts of an appendix in academic research.

\section{Academic Research Format}

The research paper format is largely determined by referencing style adapted by the university. However, some of the most common referencing styles, such as the American Psychological Association, AMA, Harvar, Chicago etc., use almost the same formatting with very minimal discrepancies. Table 4 depicted research format standards [25].

Table 2. Order and Contents of the Preliminary Pages

\begin{tabular}{|l|l|l|l|}
\hline Sections & Recommended Headings & Contents and their Order & Number of Pages \\
\hline \multirow{5}{*}{ None } & \multirow{4}{*}{$\begin{array}{l}\text { Initial Pages do not have a } \\
\text { Section }\end{array}$} & Title & 1 page \\
\cline { 3 - 4 } & & Approval & 1 page \\
\cline { 3 - 4 } & Declaration & 1 page \\
\cline { 3 - 4 } & Dedication (Optional) & 1 Page \\
\cline { 3 - 4 } & Acknowledgement & 1 page \\
\cline { 3 - 4 } & Table of content & Depend \\
\cline { 3 - 4 } & List of Tables & Depend \\
\cline { 3 - 4 } & List of Figures & Depend \\
\cline { 3 - 4 } & List of Equations (Optional) & Depend \\
\cline { 3 - 4 } & Abbreviations & Depend \\
\cline { 3 - 4 } & Abstract & 1 page \\
\hline
\end{tabular}

Table 3. Contents and Order of Research Body

\begin{tabular}{|c|c|c|c|}
\hline Sections & Recommended Headings & Contents and their Order & Number of Pages \\
\hline \multirow{8}{*}{ Section One } & \multirow{8}{*}{ Introduction } & Introduction & 1 - 2 Pages \\
\hline & & Statement of the Problem & \multirow{7}{*}{2 - 4 pages } \\
\hline & & Broad Objective & \\
\hline & & Specific Objectives & \\
\hline & & Research Question or Hypothesis & \\
\hline & & Justification & \\
\hline & & Scope & \\
\hline & & $\begin{array}{l}\text { Conceptual or Theoretical } \\
\text { Framework }\end{array}$ & \\
\hline \multirow[b]{2}{*}{ Section two } & \multirow[b]{2}{*}{ Literature Review } & Introduction & \multirow[b]{2}{*}{$3-6$ pages } \\
\hline & & $\begin{array}{l}\text { By objectives and variables or } \\
\text { Constructs and Attributes }\end{array}$ & \\
\hline \multirow{7}{*}{ Section Three } & \multirow{7}{*}{ Methodology } & Research Designs and approaches & \multirow{7}{*}{$3-6$ Pages } \\
\hline & & Study targeted Population & \\
\hline & & Study area & \\
\hline & & Sample Size Determination & \\
\hline & & Sampling methods and techniques & \\
\hline & & Inclusion and Exclusion Criterion & \\
\hline & & Ethical Considerations & \\
\hline
\end{tabular}




\begin{tabular}{|c|c|c|c|}
\hline & & Data Sources & \\
\hline & & Measurement of variables & \\
\hline & & Data Analysis techniques & \\
\hline & & $\begin{array}{l}\text { Research Limitations and } \\
\text { Delimitations }\end{array}$ & \\
\hline \multirow{4}{*}{ Section Four } & \multirow{4}{*}{$\begin{array}{l}\text { Research Finding and } \\
\text { Interpretation }\end{array}$} & Introduction & \\
\hline & & Response Rate (Optional) & \\
\hline & & $\begin{array}{l}\text { Demographic Characteristics } \\
\text { (Optional }\end{array}$ & \\
\hline & & $\begin{array}{l}\text { By objectives and variables or } \\
\text { Constructs and Attributes }\end{array}$ & 6 - 10 Pages \\
\hline \multirow{4}{*}{ Section Five } & \multirow{4}{*}{$\begin{array}{l}\text { Discussion, Conclusion } \\
\text { and Recommendations }\end{array}$} & Introduction & \multirow{4}{*}{ Max 3 pages } \\
\hline & & Conclusion & \\
\hline & & Recommendations & \\
\hline & & Further Research & \\
\hline
\end{tabular}

Sources of data: Primary and Makerere University 2011 [26].

Table 4. Order and contents of the Appendixes

\begin{tabular}{|c|c|c|c|c|}
\hline Major Categories & Sections & Recommended Headings & Contents and their Order & Number of Pages \\
\hline \multirow{7}{*}{ (3) Appendixes } & Appendix 1 & List of Referrences & $\begin{array}{l}\text { Complete references } \\
\text { using APA or Harvard } \\
\text { Referencing style }\end{array}$ & Depend \\
\hline & \multirow{3}{*}{ Appendix 2} & \multirow{3}{*}{ Recommended Tools } & $\begin{array}{l}\text { Questionnaires } \\
\text { (Optional) }\end{array}$ & Depend \\
\hline & & & $\begin{array}{l}\text { Interview Guide } \\
\text { (Optional) }\end{array}$ & 1 Page \\
\hline & & & $\begin{array}{l}\text { Observation Checklist } \\
\text { (Optional) }\end{array}$ & Depend \\
\hline & Appendix 3 & \multirow{3}{*}{$\begin{array}{l}\text { Plus, others not limited } \\
\text { to these items }\end{array}$} & Plan & 1 Page \\
\hline & Appendix 4 & & Budget & 1 Page \\
\hline & Appendix 5 & & Map (Optional) & 1 Page \\
\hline
\end{tabular}

Table 5. Academic Research Format

\begin{tabular}{|l|l|l|}
\hline Components & APA & Harvard \\
\hline Font type & Time New Roman & Time New Roman \\
\hline Font size & $11-12$ points size & $10-12$ Points size \\
\hline Font color & black & black \\
\hline Page size & & $8.5-11$ inch \\
\hline Page margins & 2inch top & 1 inch \\
\hline Top margin & 50 & 1 inch \\
\hline Bottom margin & 25 & 1 inch \\
\hline Both sides margins & Left 50 & 1 inch \\
\cline { 2 - 3 } & Right 25 & \\
\hline Spacing & double & double \\
\hline Line space & 1.5 & 2 \\
\hline
\end{tabular}




\begin{tabular}{|l|l|l|}
\hline Alignment & justified & justified \\
\hline $\begin{array}{l}\text { Preliminary pages } \\
\text { Research body }\end{array}$ & Roman numbers & Roman numbers \\
\cline { 2 - 3 } Page size & Arabic numeral & Arabic numeral \\
\hline Page \# position & Bottom Centered & $\begin{array}{l}\text { Top or bottom } \\
\text { centered }\end{array}$ \\
\hline How to print & One side & One side \\
\hline
\end{tabular}

Source: Primary data, Emma [27] and Harvard University.

\section{Discussion}

\section{Academic Research Structure}

The major sections of the academic research include Preliminary Pages, body, and appendixes. These main categories are the same for all universities globally.

Preliminary pages also differ much in the contents, however, the sequence of the contents vary significant. Here are the most common contents and their sequential order. Cover page, inside title page, approval, declaration, dedication, acknowledgement, list of contents, list of table, list of figures, abbreviations, and abstract [20].

The body of academic research consists of five main sections, and these are 1 introduction, 2 literature review, 3 methodology, 4 results, and 5 discussion, conclusion, and recommendations. Though there are some variations in the titles of the main sections, but the sequence is the same largely.

The basic contents of section one and their order are the introduction, problem statement, general objective, specific objectives, research questions or hypothesis, justification, significance, scope, and conception framework or theoretical frame.

Methodology describes section three perfectly compared to the other titles being used for the same section. This section may have many contents depending on the type of research. However, the following generic contents and order provide guiding principles for students. Research design (s), population, area of study, sample size determination, sampling methods, data collection techniques, sources of data, inclusion and exclusion criteria, validity and reliability of data collection tools, measurements of variables, data analysis techniques, ethical considerations, and limitations.

For simplicity and consistency, section four title is results, and the subtitle should be based on the objectives/attributes/variables after demographic characteristics of the respondents. The students in the public universities in the Republic of South Sudan use more than ten different titles for section four. These findings are also seen from Nairobi, Harvard, Makerere universities [22].

Discussion, conclusion, and recommendations constitutes section four, though other universities or faculties divide the section into section five and six, where discussion becomes section five and section six takes conclusion and recommendations.

The appendix is the last part of academic research that could contain any other part of research that cannot be included in the main text. Appendix should include references, data collection tools, plan, and budget.

\section{Academic Research Format}

Format of the academic research is largely determined by the referencing style adopted by the university or faculty. The format covers wide range of font, spacing, margins, pagination, paper, printing, and book color.

Research is preferred to be writing clearly and avoiding fancy styles at all form. The acceptable and recommended format are that one of APA, Harvard, etc. referencing style [23].

Type of font should be new time roman and font size 11 - 12-point size and text of a research body justified. The first level heading font 
should be 14-inch, second level 13 inch, and third level 12 inch. First-level heading capitalized and centered. Second level subheading aligned left with the first letter of each word capitalized, the same to third-level subheadings.

This is the most common, less complicated academic research format and promotes the readability of the text [24].

\section{Conclusion}

In conclusion, this basic academic research guide will give direction to students and their supervisors to complete the dissertation on time with less stress as it provides where to begin and the end. It also enhances objective grading of dissertations and evaluation level of the university. The guideline will contribute to the development of consensus on academic research structure and format standards for students that will encourage young researchers to have an interest in research as a career.

\section{References}

[1] National Bureau of Statistics 2021. South Sudan Population projection. Official circular for planning purpose.

[2] University of Michigan. Dissertation format guidelines. Rakham graduate school student services: academic records \& dissertation. www.rackham.umich.edu accessed on $3^{\text {rd }}$ November 2021.

[3] Alf Gunvald Nilsen 2019. What is Academic Writing? Structure in Academic Writing. Sociology Postgraduate Writing Seminar. PP 5.

[4] Baxis I. Patel 2019. Format and Contents of Academic Research Project report. Department of Commerce and Business Management, the Maharaja Sayajirao University of Baroda, Vadodara. Gujarat PP 4.

[5] Isabel Gómez, María Bordons, M. Teresa Fernández, Fernanda Morillo (2009). Structure and research performance of Spanish universities. Akadémiai Kiadó, Budapest Scientometrics, Vol. 79,

\section{Acknowledgement}

I would like to extend my sincere gratitude to my Co-guide Professor, Dr. Akway Cham, for his guidance from the beginning to the end of academic research work. Without underestimating the support provided by Dr. Joseph virtually as the university guide.

My joy and appreciation goes to Ms. Jesna, my long-serving mentor, for her immense encouragement and motivation for me to be on top of my academic assignments.

Omar Yaya is my senior colleague who encouraged me to do a Ph.D. in Public health with the Texila American University distance learning program three years ago.

Finally, I would like to thank my family for their moral supports and encouragement to study at this difficult time.

\section{Conflict of Interest}

I, Aquila Hakim M. Jongroor, declare there is no conflict of interest in all forms.

No. 1 (2009) 131-146 and Springer, Dordrecht DOI: 10.1007/s11192-009-0408-0.

[6] Dare E. Ajayi 2012. Foundational Guide to Research, Thesis and Dissertation Writing. A Practical Approach. PP 3 - 4 LIVING Peace Publication. ISBN: 978-978-50845-2-8 Federal Republic of Nigeria.

[7] Kenyatta University 2013. Guideline for Writing Academic Research Proposals and Theses in the School of Education.

[8] Thamara Fudge 2019. The Importance of Formatting. Purdue Global Academic Success Writing Center. School of Business and IT, Kaplan University PP 10.

[9] John K. Petrella and Alan P. Jung (2008). Undergraduate Research: Importance, Benefits, and Challenges. PP 1 Samford University, Birmingham, Alabama, USA.

[10] Ranjit Kumar 2021. Research Methodology. A step-by-step guide for beginners. SAGE Publications Ltd 1 Oliver's Yard 55 City Road London EC1Y 1SP. ISBN 978-1-84920-300-5. 
[11] Harvard University 2020. Harvard Formatting and Style Guide.

[12] University of Technology Sydney (2017). Research Proposal Writing. ELSSA Center: UTS. Accessed on 22 March 2020.

[13] Uganda Management Institute - UMI (2012). Research Methods module 1. Distance Learning Department.

[14] University of Nairobi 2021. Guidelines for Project Paper Thesis Proposal Writing. Faculty of Arts Postgraduates Studies Committee.

[15] Onen D. 2014, How to Write a Successful Doctoral Research Proposal: The Makerere Format. EASHESD, College of Education \& External Studies, Makerere University. P 3.

[16] John W. Creswell and J. David Creswell 2017 Research Design: Qualitative, quantitative, and mixed methods Approaches https://edge.sagepub.com/creswellrd5e.

[17] Andrew P. Johnson 2012. Short Guide to Action Research $4^{\text {th }}$ edition. Science Research and Teaching. Minnesota State University, Mankato.

[18] Muhammad Mahboob Ali and Kamrul Hossain (2016). Instruction Manual: Research Methodology Volume: 2 Institutional Quality Assurance Cell, Daffodil International University. ISBN: 978-98434-1757-2.

[19] Kjell E. R. and Rae R. N. 2017, Surviving Your Dissertation: A comprehensive guide to content and process $3^{\text {rd }}$ ed. P 90 - 94. Sage Publications, Inc. ISBN 978-4129-1678-3.

[20] Patino, C. M., \& Ferreira, J. C. 2018. Inclusion and exclusion criteria in research studies: definitions and why they matter. Jornal brasileiro de pneumologia: publicacao oficial da Sociedade Brasileira de Pneumologia e Tisilogia, 44(2), 84. https://doi.org/10.1590/s1806-37562018000000088.
[21] Hamed T. 2016, Validity and Reliability of the Research Instrument; How to Test the Validation of a uestionnaire/Survey in a Research. The University of Canada West. SSRN Electronic Journal 5(3):28-36 DOI:10.2139/ssrn.3205040.

[22] Siegmund B. 1998, Data Analysis Siegmund Brandt Statistical and Computational Methods for Scientists and Engineers $4^{\text {th }}$ ed, Department of Physics University of Siegen Siegen, Germany. Cham Heidelberg New York Dordrecht London. ISBN 978-3-319-03761-5 ISBN 978-3-319-03762-2 (eBook) DOI 10.1007/978-3-319-03762-2.

[23] Nilesh G. 2013, Ethical Consideration in Research. / International Journal for Research in Education Vol. 2, Issue:7.

[24]Benard Muma 2020. Basic Structured Guide for Writing Academic Research. Department of Management Science and Technology. The Technical University of Kenya. PP 1 -10.

[25] Dli, Unilag, Fednet. Research Project Format for All Students. www.fednetnigeria.wordpress.com [26] Makerere University 2011. Guidelines for Formatting Research Proposals, Research Reports, Thesis and Dissertations. Directorate of Graduate and Training PP $5-6$.

[27] Emma Geller How to Write APA Style Research Papers

http://www.psychology.ucsd.edu/undergraduateprogram/academic-writing-resources/ Arranged by S.C. Pan for UCSD Psychology accessed on $3^{\text {rd }}$ November 2021. 


\title{
An Assessment of Covid-19 Factors which Influence Non-Compliance of Payments in Respect of Social Security Contributions in Ghana
}

\author{
Samuel Nii Attoh Abbey \\ Ph.D. in Management, Texila American University, Ghana
}

\begin{abstract}
COVID-19 has been wreaking havoc on the business world for nearly two years, with most industries experiencing a significant decline in revenue. The major statutory agency in charge of regulating employee pension schemes in Ghana, the Social Security National Insurance Trust (SSNIT) Ghana, has also seen a drop in monthly contributions. As a result, the goal of the study was to see how the COVID19 epidemic is affecting non-compliance with Ghana's Social Security Monthly Contribution Payments. The study used a random sampling methodology to select 6 out of 19 decentralized governance structures in Accra, after which a purposive selection method was used to select 50 small and medium business enterprises for their perspectives on the study's goals. The major research tool was the questionnaire, and the Statistical Package for Social Science (SPSS) was used to analyze the data collected in the field. COVID-19 appears to be taking a toll on the finances of small and medium-sized businesses that have made deals with SSNIT authorities to reschedule obligations related to default contributions, according to the findings. Although new projects have been placed on hold due to diminishing inflows, SSNIT's commitment to employees and payment of pensions to elderly residents remains unaffected. In light of the a fore mentioned challenges posed by the pandemic, the study suggested that the Government of Ghana should seek concessionary loans from world-class lenders such as the World Bank to strengthen its local stabilization fund and inject a significant amount of funds to assist struggling SMEs in resuming operations.
\end{abstract}

Keywords: Accra Metropolis, Business Operations, COVID-19, Pandemic, Social Security, Virus.

\section{Introduction}

The fact that humans become weaker as they age supports the idea that plans should be taken to ensure their survival after a productive existence on this planet. Workers' futures are secured through social security plans around the world as they reach senior citizenship age, which varies by country. Members must comply with the monthly contributions or premiums controlling the program for it to function successfully. Failure to contribute regularly hinders the growth of most of these social security channels, making it difficult to pay pensions and other stipends when they become due. As a result, legislative instruments have been proposed in most countries to ensure that such "premiums" are paid for the system to continue to work.

The system of social security, according to [1], constitutes the right of any human being and aligns with the needs of the universe for protecting employees against the likelihood of life risk and needs of society. For social security to be effective, it should be able to guarantee regular income to enable the senior citizen or retired person to live reasonably through decent accommodation, clothing well as feeding, and other social responsibilities. Social security schemes are essentially able to discharge the 
above responsibilities to their contributors through payment of monthly stipends and lump sums of money depending upon the terms of the policy within the pension scheme. Social security programmes can therefore be described [2] as an essential investment into the future of workers within the country to enable them to carry on with living conditions in their roles and those of their families as consumers. As a consumer, the worker will feed, clothe, shelter, and educate his or her dependents even after retirement. The scheme is an indispensable one that must be assisted to grow and flourish as planned. Concerning the additional importance of the social security system, one could say that it helps to enhance productivity while creating avenues for job openings, thereby enhancing the economic development of a country, to the enterprises and employers, social security assists in maintaining a quality workforce through reducing employee turnover necessary for building the kind of work teams that will be able to adapt to any changing situations and circumstances [3].

Another important aspect of a strong social security base is in the area of corporate social responsibilities, where the fund administrators often select human enhancement projects in education, health, shelter, etc., for financing. From the foregoing, one can effectively say that the social security programme is an attempt by the government to stabilize income levels when the employee either becomes incapacitated or approaches the mandatory retirement age yet still has to live on to respond to life patterns as he or she was doing whiles underemployment [4].

The social security system is certainly a welfare-stricken area that ensures the protection of people socially or an attempt to protect an individual from the vagaries of economic pressure after retirement or when an unexpected happens in the course of employment which could render the employee incapacitated [5]. Social security also acts as a protectionist measure to ensure that in the event of a death of a contributor, his or her dependents will continue to live by way of education, feeding, and sheltering through the receipt of pension funds slated for that purpose. Globally, social security conforms to an international convention established by the International Labour Organization (ILO) which expects every member country to put in place structures for protecting existing employees against hardships when they retire or when they suddenly become incapacitated as a result of an industrial accident or some social eventuality [6].

The advent of the COVID-19 pandemic appears to pose a threat to the various social security schemes globally, and for that matter, stakeholders ought to brainstorm on strategies for averting any future calamity that COVID-19 is likely to precipitate. The pandemic brought in its wake the need to change the work system and in some cases, close down entirely companies, thereby reducing their propensity to generate revenue to even pay workers let alone honouring their monthly social security contributions. Although legally, management members of companies are bound to make such regular contributions, the fact of the matter is that revenue levels continue to dwindle so badly that workers emolument could hardly be met, let alone make arrangements to pay for their social security contributions.

COVID-19 could be described as the third huge outbreak in the universe after SARS in the year 2003 and MERS, which also came around 2012. Although these previous outbreaks also had the potential of creating a serious impact on the health of global citizens in addition to the serious effect on economies, COVID-19 has sharpened and influenced the way business is conducted and even gotten policymakers to sit up and change the way things were done to survive under the menace of the pandemic [7]. Companies had to run shifts while others had to work from home without supervision, yet, owing to information technology, monitoring was possible to meet targets towards enhancing the strategic direction of various organizations. 
COVID-19, in addition, brought untold additional costs to humanity in terms of efforts towards managing it while going about normal duties [8]. Organizations, for instance, had to incur additional costs in making provision for social distancing, procuring sanitisers, and in some cases providing nose or face masks to shield employees from the menace of contracting the virus from colleagues. With the future of the disease unknown, businesses continue to incur additional costs in making provisions to circumvent the dreadful effect of the virus [9]. Governments globally are doing well with containing the virus through nonpharmaceutical measures, especially advocacy on social distancing, use of nose masks, and handwashing, and these so far have proven to be effective [10]. COVID-19 is certainly affecting the liquidity and solvency levels of companies in meeting statutory obligations.

This study, therefore, attempted to investigate COVID-19 factors that are responsible for irregular contributions towards the Ghana National Social Security Insurance Scheme with the searchlight on contributors within the Accra business metropolis. Specific objectives of the study are:

1. To assess how COVID-19 is disrupting business operations within the Accra metropolis.

2. To investigate how the shortfall in revenue is affecting SSNIT operations.

3. To examine the effect of COVID-19 on the general wellbeing of the citizenry.

4. To explore strategies for accommodating the challenges confronting SSNIT amid the pandemic.

The paper is segmented into five main parts, notably the introduction which contains brief literature on social security and COVID-19. The second part examines the research methodology employed to conduct the study. The third segment presents and analyzes the results of the study, while the fourth part discusses the findings. The fifth segment concludes the paper while making appropriate recommendations in light of the challenges uncovered with how the COVID-19 pandemic is frustrating efforts at paying social security contribution premiums.

\section{Research Methodology}

\section{Study Area: Accra Business Metropolis}

The study took place at Accra business metropolis, where the recent population census indicates a population of 5.4million. Accra is the capital region of Ghana and harbours the offices of all the foreign missions by way of embassies, high commissions in Ghana. It also has the headquarters of all government ministries, commercial banks, insurance companies, mining companies, petroleum companies, the merchandise industries as well as the transport sectors of the economy. Business prospects can therefore be said to be very brisk in this area, with small, medium, and large-scale companies in addition to multinationals all pitching their tents to compete effectively. Also in this area are the headquarters of some UN regional organizations, reputable NGOs, some international universities, as well as local tertiary institutions and training centres.

\section{Sampling Technique}

The study employed a random sampling technique to select six of the nineteen metropolitan and municipal assemblies in the Accra business region. These are Ablekuma Central Municipal, Accra Central, Ayawaso Central Municipal, Korle Klottey Municipal, La Dadekotopon Municipal, and Ledzokuku Municipal, from which small and medium scale enterprises were picked up through purposive sampling technique, to enable the views of their officials to be solicited for addressing the objectives of the study as shown in Table 1 . The latter also indicates that for each of the 50 companies, 3 persons made up of the owner, the manager, and the accountant were interviewed.

The purposive sampling technique also enabled the study to interact with some key officers at the headquarters of SSNIT in the Ministries region in Accra Central. Care was 
exercised to ensure that various industries i.e., service, manufacturing, extractive, energy, education, hospitality, etc., were all included in the sample to ensure a sound representation of companies for a fair generalization of findings.

Table 1. Distribution of Respondents

\begin{tabular}{|l|l|l|l|l|l|}
\hline Municipality & No. of Businesses & Owners & Officials & Frequency & Percentage \\
\hline Ablekuma Central & 8 & 8 & 16 & 24 & 16.0 \\
\hline Accra Central & 10 & 10 & 20 & 30 & 20.0 \\
\hline Ayawaso & 8 & 8 & 16 & 24 & 16.0 \\
\hline Korle Klottey, Osu & 8 & 8 & 16 & 24 & 16.0 \\
\hline La Dadekotopon & 8 & 8 & 16 & 24 & 16.0 \\
\hline Ledzokuku & 8 & 8 & 16 & 24 & 16.0 \\
\hline Total & $\mathbf{5 0}$ & $\mathbf{5 0}$ & $\mathbf{1 0 0}$ & $\mathbf{1 5 0}$ & $\mathbf{1 0 0}$ \\
\hline
\end{tabular}

Source (Researcher's Estimation, 2021)

\section{Sources of Information}

Information for the study emanated from both secondary and primary data, with secondary data emanating from internet sources, published papers, articles as well as SSNIT company files. The primary data was obtained from information gathered through interaction with selected respondents within the study area.

\section{Research Instrument}

The questionnaire technique constituted the main research instrument, although face-to-face techniques and interview guide helped in certain areas where the respondents had challenges with the English language. By way of questionnaire administration and data collection strategy, two weeks were agreed upon, within which each respondent was expected to finish completing the questionnaire.

\section{Data Collection and Analysis Strategy}

Through the telephone, the researcher monitored the respondent for the period that the questionnaires were in their domain until the due date for collection. Care was exercised to ensure that all areas of the questionnaire were answered except areas that did not apply to the respondent. The Statistical Package for Social Sciences (SPSS) facilitated the analysis of data captured from the field. The formula propounded by Slovin in respect of calculating the minimum size of sample i.e., $\mathrm{n}=\mathrm{N} /\left(1+\mathrm{Ne}^{2}\right)$ where $\mathrm{n}$ is the sample size, $\mathrm{N}$ is the population size and e i.e., the margin of error used, was used in securing the 150 sizes of the sample, out of which 136 questionnaires were retrieved thereby registering a response rate of $90.67 \%$.

\section{Ethical Consideration}

All respondents volunteered their readiness to assist the study with no one being coerced or put under some kind of duress to give responses in any direction. No embarrassing questions were asked, nor were any sensitive issues touched on, and for that matter, respondents were free to offer responses based on their own volition. Accordingly, the study can be said to be ethically upright.

\section{Results}

Displayed under this segment are the results gathered from the field study in respect of the objectives of the study. The arrangements have been done in the order of the objectives of the research.

\section{COVID-19 and its Effect on Businesses in Accra}

Depicted in Table 2 is information gathered from the field concerning the first objective of assessing how COVID-19 is disrupting business operations within Accra Metropolis. 
COVID-19 Effect on Business Operations in Accra Business District
COVID-19 have affected the general investment of SSNIT.

Shown in Table 2 are the results on how

Table 2. Frequency Table showing the Effect of Covid-19 on Business Operations

\begin{tabular}{|l|l|l|l|l|l|}
\hline Statements & $\mathbf{N}$ & $\mathbf{M e a n}$ & $\mathbf{S T D}$ Dev & Variance & Rank \\
\hline $\begin{array}{l}\text { Revenue has reduced owing to citizens being cautious of } \\
\text { coming out to do business }\end{array}$ & 136 & 4.072 & 0.597 & 0.356 & 1 \\
\hline $\begin{array}{l}\text { Business operations have slowed down because of the } \\
\text { reduction in working hours }\end{array}$ & 136 & 3.890 & 1.023 & 1.046 & 2 \\
\hline $\begin{array}{l}\text { Suppliers are not forthright with supplies because COVID has } \\
\text { changed their production patterns }\end{array}$ & 136 & 3.861 & 0.838 & 0.702 & 3 \\
\hline $\begin{array}{l}\text { Banking operations have also slowed down, and this is } \\
\text { affecting cash administration }\end{array}$ & 136 & 3.644 & 0.977 & 0.955 & 4 \\
\hline $\begin{array}{l}\text { Owing to COVID-19 protocols, production plant size activities } \\
\text { are slowly leading to a reduction in the production targets }\end{array}$ & 136 & 3.610 & 1.037 & 1.075 & 5 \\
\hline $\begin{array}{l}\text { Deliveries through motorbikes have also slowed down as a } \\
\text { result of the COVID-19, thereby reducing sales }\end{array}$ & 136 & 3.570 & 1.185 & 1.404 & 6 \\
\hline $\begin{array}{l}\text { Vendors or sales agents are no longer active because they claim } \\
\text { the market is slow thereby affecting revenue }\end{array}$ & 136 & 3.500 & 0.988 & 0.976 & 7 \\
\hline $\begin{array}{l}\text { Adequate revenue cannot be made through sales to motivate } \\
\text { employees to produce more }\end{array}$ & 136 & 3.430 & 0.909 & 0.826 & 8 \\
\hline $\begin{array}{l}\text { Poor revenue has resulted in the inability to meet liabilities as } \\
\text { and when they fall due on schedule }\end{array}$ & 136 & 3.395 & 1.195 & 1.428 & 9 \\
\hline
\end{tabular}

Source: (Field Data, 2021)

Table 2 features findings on how COVID-19 is affecting business operations in the Accra business district. The first ranking was the issue concerning the idea that "revenue has reduced owing to citizens being cautious of coming out to do business". The ranking second had to do with the statement that "business operations have slowed down because of reduction in working hours". The issue relating to "suppliers are not forthright with supplies because COVID has changed their production patterns" was third in the ranking. The fourth ranking happened to be the response that "banking operations have also slowed down, and this is affecting cash administration". The statement that "owing to COVID-19 protocols, production plant schedules are slow leading to a reduction in production targets" was 5 th in the ranking. The sixth in the ranking was the response that "deliveries through motorbikes have also slowed down as a result of the COVID-19 thereby reducing sales". The seventh ranking with a mean score of 3.500 , a standard deviation of 0.988 , and variance of 0.976 was the statement that "vendors or sales agents are no longer active because they claim the market is slow thereby affecting revenue". The idea that "adequate revenue cannot be made through sales to motivate employees to produce more" came eight. The $9^{\text {th }}$ ranking was the response that "poor revenue has resulted in an inability to meet liabilities as and when they fall due on schedule".

\section{Effect of COVID-19 on Company's Relationship with SSNIT in Terms of Contribution}

Shown in Table 3 are the results on the effect of COVID-19 on the company's relationship with SSNIT in terms of paying workers contributions. 
Table 3. Frequency Table showing the Effect of Covid-19 on SSNIT Contributions

\begin{tabular}{|l|l|l|l|l|l|}
\hline Statements & N & Mean & STD Dev & Variance & Rank \\
\hline $\begin{array}{l}\text { Low revenue and therefore inadequate funds to even pay } \\
\text { salaries }\end{array}$ & 136 & 3.876 & 0.777 & 0.558 & 1 \\
\hline $\begin{array}{l}\text { With low revenue being unable to cover salaries, it is } \\
\text { logical that SSNIT contribution cannot be paid }\end{array}$ & 136 & 3.790 & 1.019 & 1.038 & 2 \\
\hline $\begin{array}{l}\text { Change in production arrangement as a result of COVID- } \\
19 \text { has reduced the revenue base leading to inability to } \\
\text { motivate staff let alone paying SSNIT contribution }\end{array}$ & 136 & 3.710 & 0.886 & 0.785 & 3 \\
\hline $\begin{array}{l}\text { As a result of COVID-19, the company registers low } \\
\text { patronage, and this affects the ability to meet human } \\
\text { resource costs which include SSNIT contribution }\end{array}$ & 136 & 3.670 & 1.029 & 1.059 & 4 \\
\hline $\begin{array}{l}\text { We have to close down operations owing to COVID-19 } \\
\text { and therefore no revenue is generated for even paying } \\
\text { salaries let alone SSNIT contribution }\end{array}$ & 136 & 3.560 & 1.294 & 1.673 & 5 \\
\hline
\end{tabular}

Source (Field Data, 2021)

Presented in table 3 are responses on the effect of COVID-19 on the company's relationship with SSNIT in terms of the ability to honour monthly contributions. The first in the ranking was the response that "low revenue and therefore inadequate funds to even pay salaries". Ranking second was the response that "with low revenue, which is not able to cover salaries, it is logical that SSNIT contribution cannot be paid". The statement that "change in production arrangement as a result of COVID-19 has reduced the revenue base leading to inability to motivate staff let alone paying SSNIT contribution" registered the third position. The $4^{\text {th }}$ ranking in terms of popular response was that "as a result of COVID-19, the company registers low patronage, which affects the ability to meet human resource cost, including SSNIT contribution". Ranking $5^{\text {th }}$ in terms of responses was the statement that "we have to close down operations owing to COVID-19 and therefore no revenue is generated for even paying salaries let alone SSNIT contribution".

\section{Objective Two i.e., Shortfalls in Revenue and their Effect on the Operations of SSNIT}

An interview with SSNIT officials at the head office in Accra at the Ministries area made very interesting revelations. It came out that revenue by way of contributions from the informal sector has reduced appreciably over the last two years within the pandemic COVID-19 period largely owing to slow down in business and closure of some business concerns, especially in the hospitality industry for close to one year. Although food joints, hotels, drinking spots have resumed operations, revenue generation continues to be low owing to poor patronage. SSNIT is liaising with the owners of such establishment for rescheduling of premium payment except in cases where employees had been dismissed. According to the SSNIT officials, some private schools that were also affected by the government shutdown order following the pandemic have also been in negotiation with SSNIT with the view to restructuring unpaid premiums throughout the shutdown. SSNIT indicated that the government was in the process of creating a bailout fund to cushion most of these companies in the private sector affected by the shutdown directive.

It also came out from discussions with SSNIT officials that a reduction in revenue for the period means new investment projects would have to wait until funds are available. The sources explain that the SSNIT board often comes out with directives in respect of new 
investment outplays to broaden the scope of the company's investment portfolio, and these are usually quoted in the annual budget. Projects earmarked for investments within the COVID19 period had to wait to owe to drop in revenue generation emanating from the COVID regime. The officials noted that as soon as the fund level improves, management will not hesitate to carry out such new investments. Perhaps it might be worth mentioning that such investments are strategically conducted in blue-chip areas with the view to generating good income to accommodate payment of pension claims and other lump sum funds to beneficiaries.

It came out from the interview with SSNIT officials that employees' emolument is not being affected by the reduction in revenue as a result of the COVID-19 pandemic because adequate reserves have been built over the years to strengthen the financial base of the Trust and, for that matter, their financial situation is resilient and robust enough to ward off any "attack" from COVID-19 pandemic and its ramifications.

It is also reassuring to note that payment of ongoing pensions has also not been affected in any way by the COVID-19 pandemic. This, the officials explained, has been made possible owing to the strong financial base of the organization. The officials also confirmed the fact that the SSNIT investment base remains strong against the effect of the COVID-19 pandemic effect, and for that matter, employees and contributors have nothing to worry about in respect of the financial strength of the Trust. The officials, however, admitted that dividends from investments reduced slightly owing to a fall in revenue and profits of those establishments in which investments were made. It is pertinent to understand that SSNIT has investment as shareholders in a good number of formal private sector companies like commercial banks, insurance companies, manufacturing concerns, oil companies who pay dividends to SSNIT from their profit and, therefore reduction in profit and revenue could also mean reduction in dividend levels. From time to time, SSNIT invests in some social projects such as renovating schools, hospitals, sponsoring tree planting exercises, etc., under its corporate social responsibility agenda. Owing to a fall in revenue as a result of COVID-19, SSNIT is unable to adequately handle such planned projects, although management hopes to reactivate most of these undertakings as soon as the income stream stabilizes.

On challenges facing some informal sector companies in paying a premium as a result of a drop in revenue, officials explained that SSNIT has entered into an arrangement to reschedule payment of premium for staff who are still working with such companies. This source explains it is a long-standing management policy of going to the aid of struggling companies even before the advent of the COVID-19 pandemic.

\section{Discussion of Findings}

This segment of the article discusses the findings by examining how they compare with or defer from existing contemporary literature on the subject of COVID-19 and its effect on business revenue as well as socio-economic life. The discussions have been conducted in the order of the research objectives. On objective one of assessing how COVID-19 is disrupting business operations within Accra Metropolis, it came to light that generally, the revenue base of companies has drastically reduced owing to citizens being cautious of coming out to do business. Studies confirmed these findings and pointed out that citizens are sceptical in going about general social life and therefore, the propensity to spend has been reduced markedly, leading to shortfalls within revenues of operators within the commercial centres [11]. Another finding that "business operations have slowed down because of reduction in working hours" has also been confirmed in a study which indicated that with the restructuring of business operations within factory floors, banking halls, back-office activities, etc. the number of workers had been reduced leading to a reduction in productive hours and by extension companies 
output which translates into revenue reduction for a good number of business operators [12]. The source continues that some resorted to running shifts to make room for the shortfall, yet it turned out that the shortfall was still registered owing to caution and the need to observe COVID-19 protocols, especially the frequent washing or sanitizing of hands. The discovery that suppliers delay with their supplies because COVID-19 has made it necessary for manufacturers to change their production patterns has also been mentioned in a similar study [13]. The source noted that changes in work patterns affect suppliers leading to delay in meeting orders. Findings that reduction in revenue is disrupting efforts at motivating employees to perform has also been corroborated in a paper on a similar study. The latter noted that even some employers in the SME sector have challenges in meeting the basic salary, let alone making enough to meet bonuses and other performance enhancement emolument. Another finding which has been widely published has to do with the fact that "poor revenue has resulted in the inability to meet liabilities as and when they fall due or on schedule". A study noted that this challenge is really disrupting a good number of business activities and therefore slowing down operations and affecting productivity. The good news according to the source however is that people understand the situation and therefore readily agree to reschedule debt payment as it is in the case of SSNIT which has agreed to allow a good number of small and medium-sized enterprises adequate time to pay continuing employees contribution using a rescheduled payment scheme [14].

On how the COVID-19 pandemic is disturbing the relationship between SSNIT and its developing partners especially the SME sector, the study noted that "low revenue and therefore inadequate funds to even pay salaries" continue to be the slogan for a large segment of these businesses. This finding is supported by a study that noted that, in situations where even salaries cannot be met by existing low revenue, it is only logical that such business establishment will default in payment of SSNIT contributions [15]. The source advised business owners to talk to SSNIT about the way forward since the circumstances are beyond their control. The finding that "as a result of COVID-19, the enterprise registers low patronage and this affects the ability to meet human resource cost which includes SSNIT contribution" makes it mandatory for SME business owners to speak to SSNIT on how their predicament can be addressed in terms of monthly contributions [16]. The source explains further that it behoves every creditor to examine the situation carefully and see how to help the debtor with means of deferring payment to maintain the business relationship. Another study supports the finding that companies have "to close down operations owing to COVID-19 and therefore no revenue is generated for even paying salaries let alone SSNIT contribution" and indicates that the COVID situation is an anti-business climax and for that matter, stakeholders ought to put their shoulders on the wheel to find an amicable way forward for all to survive.

The second objective sought to investigate how shortfalls in revenue are affecting SSNIT operations. The finding that "revenue by way of contributions from the informal sector has reduced appreciably over the last two years within the pandemic COVID-19 period" has been confirmed by a study that noted that most statutory organizations that receive periodic payment are all reporting a decline in their revenue mobilization effort [17]. The source also pointed to a jaw-jaw approach towards ensuring an amicable way forward. Another finding which has been supported by existing literature has to do with the notion that "reduction in revenue for the period means new investment projects would have to wait until funds are available". This, the study explains, is a general finance issue and that when no funds are available for a project, it has to be put on hold until prospects for securing funds are higher, 
then; initiatives will have to be made towards commencing the project. The study further noted that with COVID-19 around, a lot of projects are suffocating in terms of financing, and for that matter, there is the need to defer such project progressions until revenue streams appreciate tremendously to accommodate the execution of such projects [18]. The findings that "SSNIT workers' emolument has not been affected by the reduction in revenue" has been supported by a study which observed in a financial article that generally, public sector subvented institutions remain strong and resilient during periods of a general drop in revenues because they receive budgetary support which covers at least one year's expenditure which includes HR cost [19]. Another study, however, is of the view that should the COVID situation become serious and lockdown inevitable for a long period, then even strong public institutions will sense their limitations with continued payment of emolument [20]. The source, therefore, advises the public to endeavour to stick to the WHOapproved COVID-19 protocols to minimize the spreading menace of the disease, thereby keeping it under control and eventually wiping it off the surface of the earth. This way, business activities will bounce back to normal for all to enjoy an ordinary business environment towards enhancing socio-cultural and economic living systems. The study also found out that "SSNIT investment base remains resilient and robust against the effect of COVID-19 pandemic effect" and additionally, "payment of ongoing pensions have also not been affected in any way by the COVID-19 pandemic". The financial strength of public sector funds collection agencies like banks, insurance companies, SSNIT, etc., cannot easily be eroded by periods of pandemics unless such unfortunate events propagate for long periods over five years [20]. The source notes that investments made by such organizations are often solid and liquid enough to accommodate shortfalls within a mediumterm period to five years, and for that matter, for such organizations to be "wounded" financially would mean long-term devastation on their financial inflows. One study also supported this view and noted that commercial banks and insurance companies need not have challenges in meeting customers' demands, such as paying pensions or payment in respect of cheque withdrawals since adequate provisions have already been made for accommodating such contingencies. These sources indicate that when pandemics propagate for a much longer period, then the financial muscles of these statesupported organizations and strong formal private sector players will sense their limitations in honouring their core mandates. Here, the views in an article that all must cooperate towards eliminating the menace of COVID-19 should be relevant to delve a devastating blow to the pandemic for mankind and business climate to be free for normalcy to return. The study also discovered that "dividends from investments however reduced slightly owing to fall in revenue of those establishments in which investments were made". This, another study explains, is a normal finance consequence and that when business operations slowdown in terms of revenue, profit is affected, leading to a reduction in all payments that depend upon profits especially dividends. This, therefore, suggest that it is not surprising that SSNIT's income on investment has begun to show a downward trend. It is equally reasonable that "SSNIT investments to Corporate Social Responsibilities (CRS) projects have been reduced as a result of low revenue over the last two years". This, the source explains, is a financial consequence because SSNIT's core mandate excludes CRS activities. It is therefore only logical for the Trust to wait until conditions are favourable before helping the needy through its corporate social responsibility outlet.

The third objective sought to examine the effect of COVID-19 on the general wellbeing of the citizenry and noted that the government's spending arm has been "wounded" as a result of fallen tax revenue and that "planned employment of teachers, nurses, regimental 
sector officials, doctors, civil servants have to be put on hold". This, according to a study, is normal with most countries under the COVID19 period since engaging new employees comes with financial commitment, which means adequate revenue must be available to cover salaries and other emoluments [21]. The findings that "planned payment to government contractors for jobs done in terms of additions and modernizations to infrastructure and social amenities had to be suspended" is also seen by a study as a general consequence since revenue projections in the annual budget did not materialize in full and for that matter government should have difficulty in meeting all these commitments [22]. The source continues that if the pandemic progresses for a longer period, then it may even be difficult to meet the salary and remunerations levels of existing state employees. The finding that "awarding of contracts for new schools, hospitals, road were all suspended" has been corroborated by an article which indicated that with the gestation period of COVID-19 being unknown, it is difficult for the Central Government to go into big projects which will depend mainly on Internally Generated tax funds [23]. The source continues that infrastructure projects in this COVID era will have to be funded by external injections such as loans from the international monitoring fund (IMF) or its commercial wing International Finance Corporation (IFC). Such loans are often sovereign guaranteed, and therefore, donors are not too worried about default in repayment. The finding that in times of lockdown, there is the need for government to find other revenue to feed vulnerable citizens have been supported by an article that noted that some citizens in the lower-income group live by hand to mouth on a daily basis and therefore restricting their movement denies them of access to menial jobs and the attendant revenue. This explains why some arrangements ought to be put in place towards feeding and possibly ensuring their comfort throughout the COVID lockdown period [24]. Additional existing literature which supports this view mentions the fact that in some western economies, payment of rent was even frozen for the lockdown period, and the government made arrangements to subsidize such payment in addition to dishing out living allowances. COVID-19 is certainly a "monster" which, if not eliminated in good time, could glide activities on the surface of the earth to a halt. It is therefore essential that all stakeholders, especially opinion leaders as well as citizens, come on board and observe basic WHO protocols towards preventing contact with the virus to stem the tide of the spread, for mankind to be free and live peacefully as before on the surface of this God-given planet earth [25].

\section{Conclusions and Recommendations}

\section{Conclusions}

The study set out to examine the factors which contributed towards non-compliance of Social Security monthly contribution Payments in Ghana as a result of the advent of COVID-19, with the searchlight on 50 small and medium scale enterprises in the Accra Business Metropolis. It can be concluded from the field study that COVID-19 is responsible for low revenues registered by the operators of both formal and informal business sectors as well as statutory revenue collection agencies like SSNIT and Ghana Revenue Authority (GRA). SSNIT's payment of pensions and workers' emolument has not been disrupted by default in payment of monthly contributions, although its dividends by way of income from investments have shown a downward trend as a result of the dwindling revenue base of the commercial sector precipitated by COVID-19. SSNIT is also slowing down with its commitment to CSR projects as a result of the COVID-19 pandemic. Management of SSNIT is in contact with business operators who are experiencing challenges in paying workers contribution with the view to working out a mutually beneficial strategy for the way forward. COVID-19 pandemic is a menace that should not be allowed to propagate further, and therefore all 
stakeholders and citizens must cooperate by observing the basic protocols recommended by WHO towards preventing contact with the virus. This way, socio-economic systems will bounce back to normalcy for small and medium scale enterprises to continue to meet their monthly contributions regularly towards strengthening the financial muscle of SSNIT.

\section{Recommendations}

Taking cognizance of the issues uncovered in the study with regards to difficulties encountered by business houses in honouring their monthly contributions to SSNIT the following recommendations are worth considering:

1. Government should strengthen and be forthright with its business stabilization fund and help all small, medium, and large companies that have financial difficulties as a result of COVID-19 to assist them to bounce back to business and enhance their capacity. This way adequate revenue will be generated to ensure reasonable profit necessary to facilitate payment of taxes and other commitments, including SSNIT monthly contributions.

2. In the case of some business segments, especially those in the hospitality sector like hotels, food joints, drinking pubs, educational institutions, etc. experiencing longer periods of shutdown resulting in very low revenue levels, it is recommended that government instructs the social security regulator i.e. National Pension Regulatory Authority (NPRA) to suspend the payment of employees' contribution until a later date when businesses stand on their feet and can adequately pay workers and by extension make provision for monthly SSNIT contributions.

3. Taking cognizance of the fact that the majority of the development partners of SSNIT are small and medium scale enterprises that are also experiencing difficulty in revenue levels as a result of the COVID-19 pandemic, it is only logical for the SSNIT board of directors to turn their attention towards financially retooling such small and medium scale enterprises through soft loans which can be monitored effectively to resuscitate these businesses towards standing on their feet and continue paying their monthly employee contributions.

4. Judging from the intense pressure on government spending arm as a result of additional COVID-19 burdens and dwindling inflows, it is only fair and reasonable that government solicits international soft loans from such friendly creditors like International Finance Corporation (IFC) of the World Bank for onlending to the private sector at highly concessional rate. Such medium to longterm loans will certainly help in reviving most of the "dying" business enterprises.

5. Given the recent hike in the death toll of Ghanaians from 550 to nearly 1,200 , it behoves the government to strengthen COVID-19 protocol arrangements to protect the citizenry from the deadly effect of the virus through close monitoring by the security agencies to ensure compliance with the basic protocols such as social distancing, washing of hands, wearing of a mask. This way, citizens will live to work longer hours to make more money, pay higher SSNIT contributions to strengthen the scheme.

\section{Limitations of the Study}

COVID-19 pandemic is a countrywide problem and taking cognizance of the fact that the country now has 260 politically segmented jurisdictions, notably Metropolitan, Municipal, and District Assemblies (MMDA), using only six (6) in an important study like this suggests that the information may not be adequate for addressing the objective of the study. Moreover, the fact that the study questioned respondents on their employee management costs suggested to some respondents that government could be behind the research, and this made them 
sceptical in volunteering certain kinds of information. This means that disclosures by way of information were carefully conducted, and for that matter, some details might have been withdrawn. This also discounts the adequacy of information for the study. The researcher, as a senior company official, a family person, and a $\mathrm{Ph} . \mathrm{D}$. finalist certainly has difficulty in finding adequate time and cash resources for a much bigger scale of study thereby limiting the research only to Accra. Irrespective of the above challenges, the researcher was certain of coming up with an article that will be acceptable by all as far as the effect of the COVID-19 pandemic on the payment of SSNIT monthly contribution is concerned.

\section{Conflict of Interest}

I, Samuel Nii Attoh Abbey, hereby declare that except for references to other authors' work which have been duly cited and recognized, this Article is the result of my work. It has neither in part nor in whole been submitted nor exhibited in any Institution for any academic purposes.

\section{References}

[1] International Labour Organisation (2015). International Labour Office World Labour Report 2015: Income Security and Social Protection in a Changing World. Geneva International Labour Office.

[2] Haaga, Owen, and Richard W. Johnson. 2012.

"Social Security Claiming: Trends and Business Cycle Effects". Working Paper No. 2012-5. Chestnut Hill, MA: Center for Retirement Research at Boston College.

http://crr.bc.edu/wpcontent/uploads/2012/02/wp2012-5508.pdf.

[3] McKinnon, R. (2005). Extending coverage and increasing security. In Social Security: Toward Newfound Confidence, Levinsky and McKinnon, eds. Geneva: International Social Security Association.

[4] Miller, Billie Jean, and Sylvester J. Schieber. 2014. "Contribution of Pension and Retirement

\section{Acknowledgement}

Several good people worked behind the scenes towards coming up with this article. First Messrs Duncan and Mensah Addo of the operations department of SSNIT head office, Accra ought to be commended for creating the environment for the researcher to interview some of their colleagues to secure their views on the rationale behind the study. Business owners within the decentralized governing structures like the Ablekuma Central Municipal, Accra Central, Ayawaso Central Municipal, Korle Klottey Municipal, La Dadekotopon Municipal, and Ledzokuku Municipal who made themselves available to be interviewed also deserve mention. Kingsley Adu Gyamfi of Trust Jubilee Consult must also be acknowledged for the expert manner in which he handled the stenography aspect of this article. God richly bless them all.

Savings to Retirement Income Security: More Than Meets the Eye". Journal of Retirement 1(3): 14-29.

[5] Bailey, C., \& Turner, J. (2001). Strategies to reduce contribution evasion in social security financing. World Development (February), 385-393. [6] Purcell, Patrick J. (2016). "Employment at Older Ages and Social Security Benefits Claiming." Social Security Bulletin 76(4): 1-17.

[7] Anderson, R. M., Heesterbeek, H., Klinkenberg, D., \& Hollingsworth, T. D. (2020). How will countrybased mitigation measures influence the course of the COVID-19 epidemic? The Lancet, 395(10228), 931934.

[8] Inoue, H., \& Todo, Y. (2020). The propagation of the economic impact through supply chains: The case of a mega-city lockdown against the spread of COVID-19. PlosOne, 15(9), e0239251 doi. 10.1371/journal.pone.0239251.

[9] Peter, D. (2020). COVID-19: The Social Implication of a Pandemic. Proshare Finance. The 
Guardian. Saturday, March 28, 2020. PRNigeria (2020). COVID-19: ABU ZariaScientistsProduce4in-1 Sanitizing Machine. https://prnigeria.com/2020/05/11/Abuzaria/sanitizin g-machine/. Accessed 24th May 2020.

[10]Dell'Ariccia, G., Mauro, P., Spilimbergo, A, and Zettelmeyer, J., 2020. Economic policy for the COVID-19 war. Retrieved from https://blogs.imf.org/2020/04/01/economicpolicies for the-COVID-19-war/, April, 2020

[11]Levinsky, R. (2005). Social security and labour market developments: Facilitating flexibility by strengthening security. In Social Security: Toward Newfound Confidence, Levinsky and McKinnon, eds. Geneva: International Social Security Association.

[12]Loayza, N., \& Pennings, S. (2020). Macroeconomic policy in the time of COVID-19: A primer for developing countries. World Bank Malaysia hub.

[13] Walmsley, T., Rose, A., \& Wei, D. (2020). Impacts on the U.S. Macro-economy of mandatory business closures in response to the COVID-19 pandemic. CREATE working paper. The University of Southern California.

[14] Gillion, C., Turner, J., Bailey, C., \& Latulippe, D. (Eds.) (2000). Social Security Pensions and Reform. International Labour Office, Geneva, Switzerland.

[15] McKibbin, W., \& Fernando, R. (2020). The global macroeconomic impacts of COVID-19: Seven scenarios. In CAMA working paper No.19/2020. Centre for Applied Macroeconomic Analysis, Australian National University.

[16]Maliszewska, M., M, A., \& van der Mensbrugghe, D. (2020). The potential impact of COVID-19 on GDP and trade. World bank policy research working paper No. 9211. Washington DC: World Bank.
[17]Barrientos, A., and P. Lloyd-Sherlock (2003). Non-contributory pensions and social protection. Issues in Social Protection Discussion Paper (Geneva: International Labour Office).

[18]Eichenbaum, M.S., Rebelo, S., \& Trabandt, M. (2020). The macroeconomics of epidemics, NBER Working Paper, No.26882. doi. 10.3386/w26882 [19] SSNIT (2002), Medium-Term Strategic Plan: 2002 - 2006, Social Security and National Insurance Trust (SSNIT), Accra, May 2002.

[20] WHO. (2020). Novel coronavirus (2019-nCoV) Situation Report - 1, 21 January 2020. Geneva: World Health Organization.

[21] Morgan, J.P. (2020). The fallout from COVID19: global recession, zero interest rates, and emergency policy actions. Accessed on June 4th, 2020. [Retrieved from].

[22] MoFEP, 2020. Statement to parliament on the economic impact of the COVID-19 pandemic on the economy of Ghana. Retrieved from https://mofep.gov.gh/index.php/news-andevents/2020-03-30/statement-to-parliament-oneconomic-impact-of-the-covid-19-pandemic-on-theeconomy-of-ghana, March 2020.

[23]IMF. (2020). World Economic Outlook: The Great Lockdown. International Monetary Fund, Washington DC.

[24]Atkeson, A. (2020). What will be the economic impact of COVID-19 in the US? Rough estimates of disease scenarios. NBER Working Paper, No.26867. doi. 10.3386/w26867 Economic Commission of Africa (2020). Trade policies for Africa to tackle COVID-19. [Retrieved from].

[25] Hamzelou, J. (2020). UK's scientific advice on coronavirus is a cause for concern. New Scientist, 245(3275), 9. https://doi.org/10.1016/S02624079(20)30613-8. Online. 3275. 


\title{
Government Expenditure on Economic Growth: Empirical Evidence from Ghana
}

\author{
Charlotte Adamkie Atteh ${ }^{1}$, Joshua Akanyonge ${ }^{2 *}$, Alfred Asapeo ${ }^{3}$ \\ ${ }^{1}$ Department of Management, Regent University College of Science and Technology, Accra, \\ Ghana \\ ${ }^{2}$ Department of Accounting \& Finance, Regent University College of Science and \\ Technology, Accra, Ghana \\ ${ }^{3}$ Department of Library Services, C.K. Tedam University of Technology, Navrongo, Ghana
}

\begin{abstract}
The role of the government in a market economy cannot be underestimated. In reality, the public sector plays significant role in an economy. Markets do fail sometimes, and for that reason, government intervention is needed to provide public goods or handle externalities and enforce competition in an economy. In the quest of government playing its role in an economy, it faces the challenge of an appropriate level of government size (government final consumption \% of GDP) that can ensure sustained economic growth. Data on government fiscal behavior in Ghana over the last two decades generally shows a rising trend in government expenditure, yet the economic growth rate has not risen commensurately. The study set out to provide additional empirical evidence on the linkage between government size and economic growth in Ghana by a time series data analysis and to test the optimal threshold level of which government final consumption could lead to rapid growth in Ghana. The study concluded that total government expenditure has a direct positive impact on economic growth. As a result of that, the study recommended that government expenditure should not exceed the optimum threshold level of $0.114 \%$ to maximize economic growth. The study, therefore, advocates for fiscal discipline and control to keep government spending at the optimal level so as to trigger a positive ripple effect to other sectors of the economy and avoid a crowding out effect in the Ghanaian economy.
\end{abstract}

Keywords: Economic growth, Expenditure, Fiscal discipline, Government Size.

\section{Introduction}

The role of the government in a market economy cannot be underestimated. In reality, the public sector plays significant role in an economy. First of all, markets do fail sometimes, and for that reason, government intervention is needed to provide public goods or handle externalities and enforce competition in an economy. The scope and role of government have been accepted by society in a broader sense. Meanwhile, in Ghana, government activities have a powerful effect on the economy in areas like stabilization and growth; consumers and producers make most decisions that mold the economy based on government policy signals.

In recent times, there has been a public outcry in Ghana against the number of ministers government appoints. The public refers to the number of ministers as the size of government, which could affect government expenditure and slow growth. While obviously, the size of government does not refer to the number of ministers a government appoints, the public 
outcry is legitimate when considered in the context of the acknowledgement in literature and practical experiences that government expenditure levels clearly affect the rate of economic growth.

The public outcry also indicates that the level of government expenditure and rate of growth of the economy are important concerns for the public. Yet, knowledge on how public expenditure affects growth is scanty in the Ghanaian case, which calls for studies such as the present research.

Ghana, as a mixed economy, has a distinct nature of government involvement. The size of the public sector alone is a justification for the study of how it should best choose its means of revenue collection and its allocation of expenditure. Secondly, in determining the fair and efficient distribution of economic resources, the government is faced with the challenge of size. Over the years, several models have been developed to explain the public sector growth.

An example is Wagner's law. Hence this study investigates the linkage between government size and economic growth in Ghana. To achieve this goal and objective, the paper is specifically designed to: analyze the trends in government size and economic growth in Ghana, estimate the linkages between government expenditure and economic growth in Ghana, examine the optimal threshold level of government expenditure on economic growth.

The present study is organized in five sections. The rest of the study is structured as follows. Section II presents the theoretical and empirical literature review on the effect of growth in government spending. Research methodology (model specification, empirical strategy, and data issues) is discussed in Section III. Section IV deals with data analysis and interpretation of results, and Section V concludes the study with the summary of major findings and policy recommendations of the study.

\section{Related Work \\ Real GDP Growth (Economic Growth)}

The concept of economic growth was formulated and established in the early modern period when the western European nationals discovered that economies could produce a greater economic surplus which could, in turn, be spent on other aspects of the economy. According to scholars, the act of spending the surplus on projects which had a direct impact on the nationals as well as improving their livelihood could lead to the generation of more income for the country [1].

Mankiw [2] asserts that the term economic growth is used to indicate the increase of per capita gross domestic product or any other measure of aggregate income. It is either positive or negative depending on the quantity of goods and services which are produced. Generally, when a country post increased gross domestic product, economists relate that increase to improved standards of living. Minimal increase of the annual growth rate of any country's economy is fundamental in increasing the gross domestic product of the country, especially where the monetary policies are favourable for business.

\section{Theoretical Review}

Several theories have been used to explain the concept of economic growth and Government expenditure and its implications on the economy. However, none of the theories has been able to provide all answers to all the possible questions concerning economic growth-Government expenditure. For many years economist have been discussing the causes of growth and development and its association with Government expenditure. Here are some of the main lines of thought. The main theories relating to this study will be discussed.

\section{The Classical Growth Theory}

Classical economics is widely regarded as the first modern school of economic thought. Its major developers include Adam Smith, David 
Ricardo, Thomas Malthus, and John Stuart Mills [3]. Adam Smith and Malthus stressed the critical role of land in Economic growth. Adam Smith in explaining economic growth, began with a hypothetical idyllic age: 'that original state of things, which precedes both the appropriation of land and the accumulation of (capital) stock. This was, however, expressed at the time land was freely available to all and before capital accumulation had begun to matter. In the era of Adam Smith, because the land was freely available, people simply spread out onto more acres as population increases, just as settlers did in the American West. Because there was no capital, national output exactly doubles as population doubles. In this sense, wages earn the entire national income because there is no subtraction for land rent or interest on capital. Therefore, output expands in step with population, so the real wage per worker is constant over time.

This trend cannot continue forever because over time, as population growth continues, all the land will be occupied. Once this happens, balanced growth of land, labour, and output is no longer possible, resulting in new labour crowding onto already worked soils. The land, therefore, becomes scarce, and rents rise to ration it among different users.

As the population continues to grow, the national product also grows. But output must also grow more slowly than does population. This is because with new laborers added to fixed land, each worker now has less land to work with, and the law of diminishing returns comes into operation.

The increasing labour-land ratio leads to a declining marginal product of labour and hence to declining real wage rates. Malthus reasoned that population pressures would drive the economy to a point where workers were at a minimum level of subsistence. This implies that, whenever wages were above the subsistence, the population would expand; below-subsistence wages would lead to high mortality and population decline. Only at subsistence wages could there be a stable equilibrium of population [3]

According to Thomas Malthus, in the late eighteenth and early nineteenth century, growth in a country's output resulting from advances in technology is only temporary. Followers of this theory of growth argued that an increase in the real GDP per worker raises the subsistence level of wages per worker. This, in turn, will result in a population explosion and an increase in the available supply of labour. A greater supply of labour will depress the real wage, returning income per worker back to the subsistence level. The outcome is a fall in the rate of economic growth and an inevitable fall in the population itself at this subsistence level of income. The theory further indicates that, increase in the average real wage per worker to well above the subsistence level results in a population explosion. This implies that economic prosperity leads to more births and longer life expectancy. However, as the population grows, both capital per worker and output per worker fall, resulting in a fall in real wages per worker back to the subsistence level, and the population fall as a consequence, in line with falling living standards [4].

\section{The Neoclassical Growth Theory}

The classical theory led by Adam Smith and, in particular, Malthus did not recognize that technological innovation and capital investment could overcome the land of diminishing returns. Land did not become the limiting factor in production. Instead, the industrial revolution brought forth power-driven machinery that increased production, factories that gathered teams of workers into giant firms, railroads and steamships that link together the far points of the world, and iron and steel that made possible stronger machines and faster locomotives.

According to Solow, [5] the "neo-classical" model of growth was first devised by Nobel Prize-winning Economist Robert Solow over 40 years ago. The Solow model believes that a sustained increase in capital investment 
increases the growth rate only temporarily. This theory describes an economy in which a single homogeneous output is produced by two types of inputs, capital, and labour. In contrast to the Malthusian analysis, labour growth is determined by forces outside the economy and is unaffected by economic variables. In addition, they assume that the economy is competitive and always operates at full employment, so we can analyse the growth of potential output. This model emphasizes the importance of capital and technology change in economic growth.

For instance, if technology is held constant, then capital would be the focus of the growth process. Capital consists of durable produced goods that are used to make other goods. Capital goods include structures such as factories and houses, equipment like computers and machine tools, and inventories of finished goods and goods in process.

In the Economic growth process, economists stress the need for capital deepening, which is the process by which the quantity of capital per worker increases over time. Examples of capital deepening include the multiplication of farm machinery and irrigation systems in farming, of railroads and highways in transportation, and of computers and communication systems in banking. In each of these industries, societies have invested heavily in capital goods, increasing the amount of capital per worker. As a result, the output per worker has grown enormously in farming, transportation, and banking.

Further, this model asserts that, for a given state of technology, a rapid rate of investment in plant and equipment tends to depress the rate of return on capital. This occurs because the most worthwhile investment projects get constructed first, after which later investments become less and less valuable. Differences in the rate of technological change between countries are said to explain much of the variation in growth rates that we see. The neoclassical model treats productivity improvements as an 'exogenous' variable, meaning that productivity improvements are assumed to be independent of the amount of capital investment.

\section{Wagner's law}

There are two schools of thought called Wagner's law, named after the nineteenthcentury German Professor Adolf Wagner, and the other one the Keynesian views, which were suggested by the 20th-century British economist John Maynard Keynes. For Wagner's law, Sinha [6] reported that "Adolf Wagner was probably the first scholar to recognize a positive correlation between economic growth and the growth of government activity". In addition, Henrekson [7] pointed out from Wagner's law three main reasons for the increase in the government's role.

First, Industrialization and modernization would lead to a substitution of public for private activities and result in increasing government expenditures on law and order as well as on contractual enforcement. Secondly, an increase in real income would lead to an expansion of the income elastic "cultural and welfare" expenditures. Wagner cited two areas which are education and culture, in which the government could be a better provider than the private sector.

Thirdly, natural monopolies such as railroads had to be taken over by the government because the running cost of such kinds of activities are too expensive, and the private sector would be unable to obtain such huge investment to finance the development of these activities. In addition, he suggests that the private sector would also be unable to operate these activities efficiently. A study [8] concludes that Wagner's law is 'the law of expanding state activity, which in modern terminology posits that citizens' demand for government-provided goods and services is income-elastic, due to the "pressure for social progress" and the need for infrastructure investments. In a simple way, 
Wagner's law is interpreted as to say that government expenditure is a consequence of a growing economy.

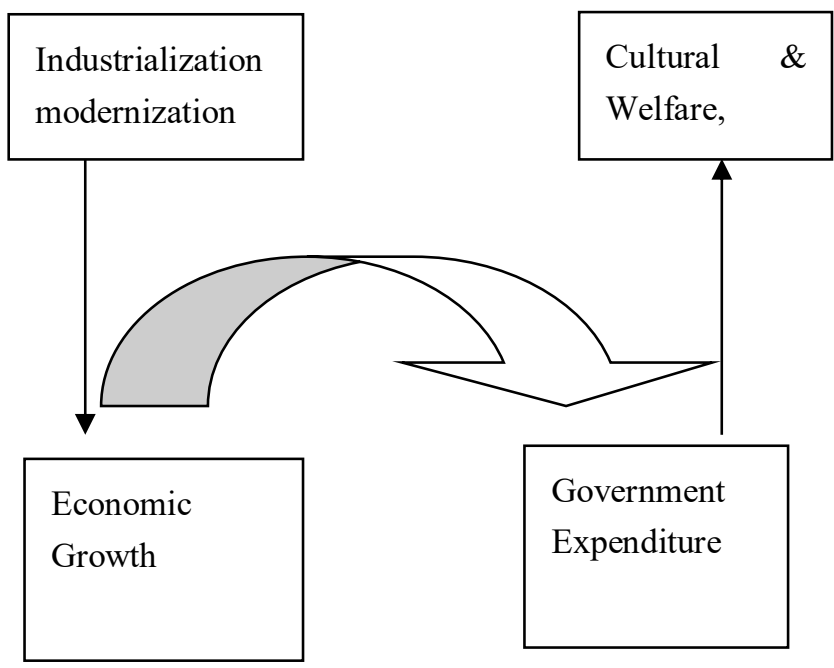

Figure 1. The circular flow of Wagner's law (drawn by author)
Source: Henrekson (1993)

On the other hand, the other economic interpretation for government expenditure and growth is explained by the Keynesian view. This view suggests that government expenditure contributes positively to economic growth through the multiplier effect on aggregate output; a high level of government consumption is likely to increase employment, profitability, and private investment. Branson [9] states that government expenditure raises aggregate demand that will lead to an increase in output. However, this situation depends on the multiplier effect, which in this case is the expenditure multiplier.

Therefore, it is very important to understand what actually the make-up of the expenditure multiplier is. Hence, several steps as shown below, are required in order to identify the expenditure multiplier. Furthermore, based on the Keynesian framework,

The comparison between increasing government expenditure with the reduction in tax is to show how tax cut can promote more private investment for economic growth. At the same time, the government expenditure through its activities can promote economic growth through other economic activities such as by creating more employment. The rule of thumb for this condition is that both activities should complement, instead of competing with, each other for economic growth. This rule is to avoid the argument on crowding-out effect theory. By complying to this rule, the function of the government expenditure can be through government activities such as providing education, healthcare, infrastructure development, defense, social security, judiciary, regulating externalities, pleasure marketplace, and others which complement the private sector and support the whole system for economic growth.

As a result, it will ensure a stable environment which will motivate investment in hopes of higher returns. Thus, for the Keynesian views, the circular flow can be drawn as below. 

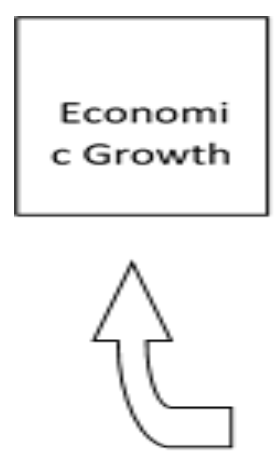
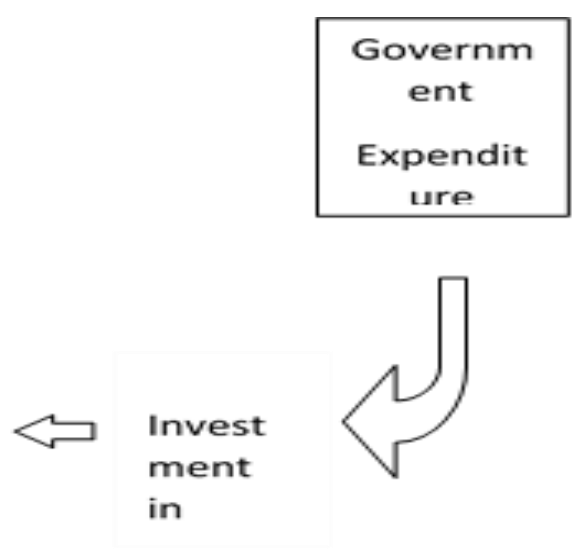

Figure 2. The Circular Flow of Keynesian Views (drawn by Author)

\section{Empirical Review}

In seeking to raise the well-being of its citizens, every government strives for growth. Yet, the relationship between the nature of government itself, specifically government spending, and economic growth is not an easy one. In this present research, the focus on this linkage between governments and economic growth is justified because, as Afonso and Jalles [10] succinctly put it, governments typically spend a sizeable share of society's resources and, therefore, they affect economic growth. It is also widely recognized that government plays a crucial role in the economy, including the provision of justice, health, education, defense, utilities, and physical infrastructure, among others. To this end, for its objective of examining this crucial linkage between government and growth, this present project draws from several other similar studies which explored this linkage from quite different angles.

In the literature, the size of government is conceived of as a level of government spending or expenditure, which is measured as a proportion of the Gross Domestic Product (GDP) of an economy [11]. Though the linkage between government size and economic growth is an important challenge, there is inconclusive evidence from several studies on these issues for any general theory to be formulated. While some works find that the level of government spending positively affects growth [13-15], others have found a negative relationship [10]; [16]. The present paper does not seek to support either side of these studies, but rather to draw lessons from them to investigate what effect public fiscal decisions and habits in Ghana, within the country's peculiar socioeconomic and political conditions, have had on the country's economic growth and development over the period 1992 to 2016.

Notwithstanding the mixed results of the studies on the relationship between government size and economic development, a number of works on this relationship reveal interesting dimensions. In Asimakopoulos and Karavias [11], there is an inverted U-shaped non-linear relationship between government spending and growth. The authors explain that increases in government spending have consistent positive effects on growth up to a certain threshold level, beyond which increases in spending begin to pose negative effects on growth. In this sense, the authors propose that the identification of the optimal level of government size to promote growth, which they found is around $20 \%$ of GDP, is the necessary big question to be addressed by academics, politicians, and bureaucrats. In this respect, it will be informative to find out the trend of Ghana's government expenditure relative to GDP and consequent growth patterns. Of course, it is acknowledged that other factors besides government spending may have affected the growth pattern of the Ghanaian economy, but 
such factors can be held constant in this present thesis.

Generally, positive, and negative effects of government spending on growth have been found along the developing/developed country divide as well as along quantity (size of government) and quality (institutional efficiency) lines. The literature is agreed that consistent increases in government expenditure result in expansionary impacts on the economy, most especially in developing countries. Countries with smaller economies tend to have large prospects for growth, such as in developing countries, and they tend to experience positive effects of increases in government spending on economic, all other things held constant, growth as compared to developed countries [11]. Similarly, smaller countries tend to expend bigger shares of their GDP on areas that are likely to be more directly productive [17]. Characteristic of developing countries, the negative effects of government spending on growth is attributed to government inefficiencies, crowding-out effects of government fiscal policies such as high taxation and domestic borrowing, the excess burden of taxation, financing of government spending through excessive borrowing and/or printing money $[10,11]$.

Not far from the developing/developed country divide in research results, Oto-Peralías and Romero-Ávil [18] make an interesting contribution. Directing attention from government size to government quality, they point out that government quality in terms of an efficient public sector is equally a significant factor that controls or mediates the effect of government spending on growth. By focusing specifically on public sector quality, which they conceptualize as characteristics and designs of public sector institutions, the authors also show that the linkage between government spending and growth is non-linear and varies with the quality of the public sector. Their findings are that government size negatively affects economic growth only when public sector quality (that is, institutional efficiency) is low. In other words, increases in government size either positively affect growth or is neutral when public sector institutions are highly efficient and working to satisfaction. In economies where institutions are weak or inefficient, corruption, rent-seeking, dishonesty, and abuse of power are rampant, and these work against the positive contribution of government spending to economic growth and development [18]. Such finding is consistent with remarks in Sheehey [19] and Afonso and Jalles [10] that the institutional contexts of government highly influence whether government spending positively or negatively affects growth.

Garey Durden and Barry Elledge studied the phenomenon at state, regional, and local levels of economy, still with mixed results at all these levels [20]. What this tells us is that regional data and not necessarily only national data can be used to estimate the relationship between government spending and growth. Their finding seems to confirm the earlier conclusion of Meltzer, and Richard [21] that the increased relative size of government appears to be independent of government at federal or national levels, budget and tax systems, and institutional arrangements, among others. These findings should, however, not be confused with saying that increases or changes in government spending is independent of these factors since it is conclusive that the relative rates of change in government spending will affect growth in different countries depending on the interplay of these factors.

From the general develop/developing country as well as quantity (size) and quality (institutional efficiency) line of analyses, pointers can be drawn to the critical contribution studies such as this present thesis can make to knowledge on the linkage between government size and government quality and economic growth. If developing country characteristics of small but growing economies, often being corruption, rent-seeking, excess 
taxation, and high borrowing, significantly mediate the ability of government spending to positively affect growth and development, it is imperative that a developing country such as Ghana pays high priority attention to addressing fiscal and institutional issues.

As Oto-Peralías and Romero-Ávila [18] conclude in their study, institutional context matters, and thus, this present research aims to contribute to efforts at understanding and to improve public sector institutions and government expenditure patterns so as to promote consistent growth.

\section{Methodology}

\section{Theoretical Framework}

The theoretical model underpinning my study is the neoclassical production function as follows,

$$
Y=f(K, L, A) \ldots \ldots(3.1)
$$

Where $\mathrm{Y}$ means economic growth, $\mathrm{K}$ represents Capital, L as Labour and $\mathrm{Y}$ as the output level, and A an index for the state of technology.

Scientific advances and technological change are key to the economic performance and social well-being of a nation. Government spends on intangible assets such as education, fundamental research in innovation, science, and technology, which leads to technological advancement for economic growth and social well-being. Education is important, as new technologies require skilled workers. Education stimulates more efficient ways of production organization as well as new and improved products and services. There is thus the possibility of sustained increases in investment which can lead to continuous rises in a country's growth rate. Knowledge can also spill over from one firm or industry to another, across borders, among universities, and from universities to businesses with new ideas used repeatedly at little extra cost. Such spillovers can ease the constraints placed on growth by the scarcity of capital.
Investment in technological transfer to improve health care has a profound effect in population growth rates. Better health care means more babies live to reproduce, and these people live to form the labour force of the economy and eventually get educated to bring about growth.

$A=g(G E$, Trade, inflation, population growth $)$

$$
\begin{gathered}
Y=f\{K, L, g(G E, \text { Trade, } \text { inflation }) \ldots . . .(3.1 .2) \\
Y=f(K, L, G E, \text { Trade, inflation }) \ldots . .(3.1 .3)
\end{gathered}
$$

We assume a Cobb- Douglas function,

$$
Y=\beta K t \alpha L t 1-\alpha G E t \gamma T t \theta I N F t \mu \mathrm{e} \varepsilon t \ldots
$$

$\mathrm{Y}$ is the real GDP growth rate, GE represents general government final consumption, $\mathrm{T}$ represents trade openness, INF represents inflation GDP deflator.

A normality test was conducted, and the distribution of sample means across independent samples was not normal. Therefore, the data was transformed, and the technique used was logarithm.

$$
\begin{gathered}
\operatorname{In} Y T=\operatorname{In} \beta+\alpha \operatorname{In} K+(1-\alpha) \operatorname{In} L+ \\
\gamma \operatorname{In} G E+\theta \operatorname{In} T+\mu \operatorname{In} \operatorname{IN} F+\varepsilon t \ldots \ldots \ldots(3.1
\end{gathered}
$$

\section{Model Specification}

\section{Model 1}

We first modelled a linear regression to determine the unique relationship that exists between the predictors (i.e., capital formation, population growth, general government final consumption, trade openness, inflation) on the criterion (i.e., economic growth).

$$
\begin{gathered}
\operatorname{In} Y T=\operatorname{In} \beta+\alpha \operatorname{In} K+(1-\alpha) \operatorname{In} L+\gamma \operatorname{InGE} \\
+\theta \operatorname{In} T+\mu \operatorname{In} \operatorname{IN} F+\varepsilon t
\end{gathered}
$$

\section{Model 2}

Secondly, the study employed the model estimation by Asimakopoulos and Karavias [11], where growth annual percentage will serve as the dependent variable and as explanatory variables; general government final consumption expenditure as a share of output, inflation rate as GDP deflator, gross capital 
formation to capture the share of investment to output, openness to trade and population growth. Asimakopoulos and Karavias [11] used panel data, but this study will make use of time series data for the period of 37 years from the World Development Indicators (WDI), as reported by the World Bank, and we perform a dynamic threshold estimation to estimate the optimal level of government spending in Ghana.

Model 2 was specified as:

$$
\begin{gathered}
\text { GDPt }=C t+\beta 1 G E t I(G E t \leq \mu)+ \\
\beta 2 G E t I(G E t>\mu)+\mathrm{nXt}+\pi \mathrm{t}
\end{gathered}
$$

Where $\mathrm{Ct}$ is the constant term, and it measures the value of economic growth when all the explanatory variables are constant. $\pi \mathrm{t}$ it is the remainder error term. GE is the government final consumption expenditure as a share of GDP and serves as the threshold variable where the threshold is given by the parameter. I (.) is the indicator function which takes the value 1 when the argument in the parenthesis is true and 0 otherwise. The inflation, capital formation, openness to trade, government expenditure, and population growth variables are in the vector Xt. $\eta$ is the coefficient of the vector variable $\mathrm{Xt}$. The above model specification was chosen because it has the advantage which allowing for endogenous independent and endogenous threshold variables.

\section{Data source and Data Type}

Secondary data was sourced from the World Development Indicator (WDI). The study utilized time series data for a period of 37 years within the period of 1980 to 2016. The data comprised figures on economic growth, gross capital formation, inflation rates, Openness, and population growth for the period.

\section{Variable Description}

An independent variable is the presumed cause, whereas the dependent variable is the presumed effect. In this study, the dependent variable was economic growth, and the independent variable comprised of Government expenditure, capital formation, inflation rate, openness to trade, and population growth.

According to WDI (World Development Indicators) General government final consumption expenditure (formerly general government consumption) includes all current government expenditures for purchases of goods and services (including compensation of employees). It also includes most expenditure on national defence and security but excludes government military expenditures that are part of government capital formation. General government final consumption expenditure \% of GDP is used as a proxy to measure government size.

The annual percentage growth rate of GDP according to WDI was defined at market prices based on constant local currency. Aggregates are based on constant 2010 U.S. dollars. GDP is the sum of gross value added by all resident producers in the economy plus any product taxes and minus any subsidies not included in the value of the products. It is calculated without making deductions for depreciation of fabricated assets or for depletion and degradation of natural resources.

Gross Capital formation was used as a proxy to capture the share of investment to output. According to WDI (World Development Indicators), Gross capital formation (formerly gross domestic investment) consists of outlays on additions to the fixed assets of the economy plus net changes in the level of inventories. Fixed assets include land improvements (fences, ditches, drains, and so on); plant, machinery, and equipment purchases; and the construction of roads, railways, and the like, including schools, offices, hospitals, private residential dwellings, and commercial and industrial buildings. Inventories are stocks of goods held by firms to meet temporary or unexpected fluctuations in production or sales and "work in progress". According to the 1993 SNA, net acquisitions of valuables are also considered capital formation. 
According to WDI, Inflation, as measured by the annual growth rate of the GDP implicit deflator, shows the rate of price change in the economy as a whole. The GDP implicit deflator is the ratio of GDP in current local currency to GDP in constant local currency.

\section{Trade Openness}

According to WDI, Trade openness was calculated by adding imports and exports of goods and services as a share of gross domestic product.

\section{Population Growth}

WDI defined population growth as the Annual population growth rate for year $t$ is the exponential rate of growth of midyear population from year t- 1 to $t$, expressed as a percentage. The population is based on the de facto definition of population, which counts all residents regardless of legal status or citizenship.

\section{Results and Discussion}

\section{Introduction}

The study focused on the linkage between Government expenditure ( $\%$ of GDP) and real GDP growth \% in Ghana. In addition, how other factors (inflation GDP deflator, gross capital formation $\%$ of GDP, population growth $\%$, and openness to trade) influence economic growth in Ghana. Moreover, it presents the results of the estimated model in chapter three. The chapter is structured into regression results, results from hypothesis tested, explanation of model summary, statistical significance, and trend analysis for the government expenditure and economic growth in Ghana. Since all variables are either percentages or ratios to GDP, 1 was added before the $\log$ transformation.

\section{Trends Analysis in the Growth Rate of Government Expenditure and GDP Growth}

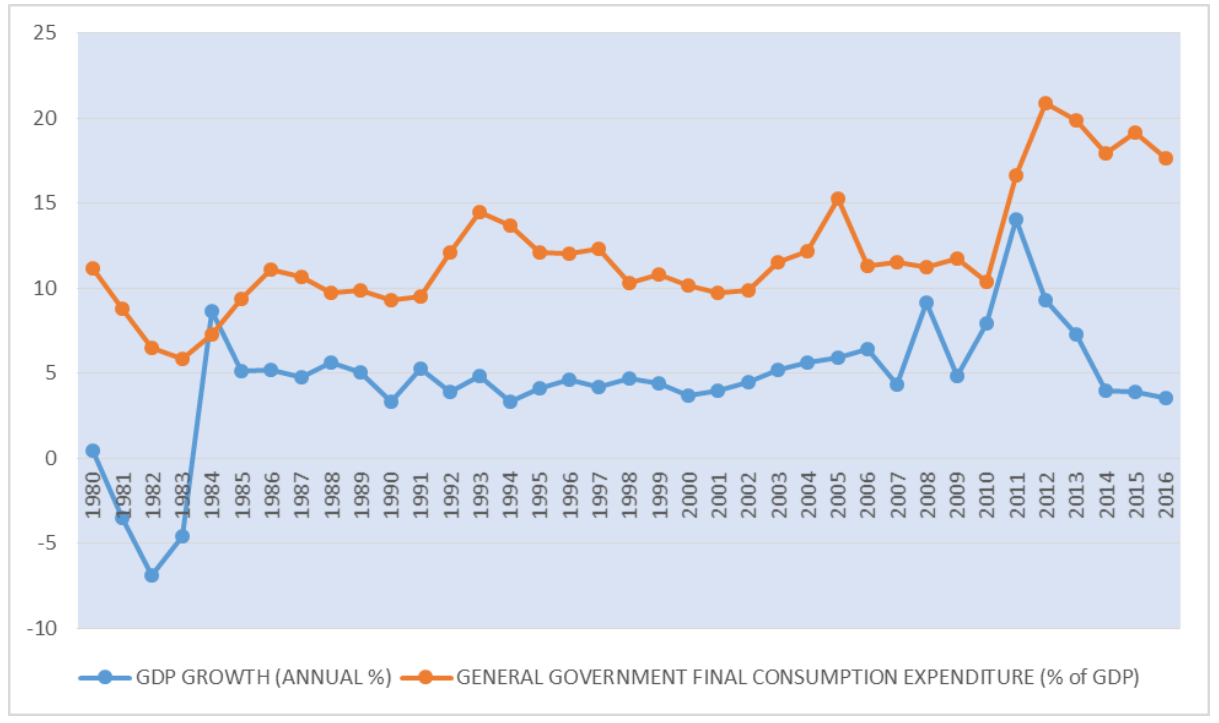

Figure 3. Trends in the Growth Rate of Government Expenditure and Real GDP Growth Rate

Source: World Development Indicator

Figure 1, according to the world development indicator, clearly shows that the rate of growth in government expenditure generally has a parallel influence on Gross Domestic Product (GDP) growth rate. A decline in government expenditure from about 1980 to around 1983 saw a corresponding decline in real GDP growth rate over roughly the same period. Subsequent significant rise in government expenditure around 1983-1984 saw a corresponding rise in growth rate, thereafter real GDP more or less maintaining a general 
steady rate even though government expenditure generally kept rising and falling marginally. The contention that government expenditure pulls real GDP along in a parallel direction is evident in fact, which is demonstrated in the movements of the curves in Figure 1 that along the year's government expenditure change occurs first before real GDP changes in a similar direction.

However, it is obvious from Figure 1 that a large government size (rising government expenditure) does not necessarily result in the growth or decline of the economy. Arguably, the generally steady rate of real GDP growth from about 1986 as against a generally marginal rise in government expenditure suggests that government expenditure affects growth, but there are intermediary factors that constrain or enhance the effect of government expenditure on growth. As is shown in the literature review below, possible factors include public sector institutional efficiency and structural challenges, especially in developing countries like Ghana.

The initiation of the Economic Recovery Program (ERP) and Structural Adjustment Program (SAP) by the Provisional National Defense Council (PNDC) government brought about an increase in government expenditure from 1984 to 1987. The ERP was aimed at promoting and boosting production. The government began to rebuild infrastructure through a facility of US\$ 4.2 billion programs, more than half of which was provided by external donors. Due to this, Ghana's real GDP registered a steady growth, most of which is attributable to the re-vamp of the export sector, including cocoa, minerals, and to some extent, timber processing.

As at the beginning of 1988 through to 1991 , after some slight decline in government expenditure in the preceding few years, the Government of Ghana had started investing into the economy again. The government initiated an eighty-five million Dollars (US\$ 85 million) Program of Action to Mitigate the Social Costs of Adjustment (PAMSCAD). The program sought to create 40,000 jobs over a two-year period and the rehabilitation and development of rural and urban social infrastructure throughout the country. The PAMSCAD program brought about growth in government expenditure, but for during this period, the growth rate of real GDP slowed down slightly.

Again by 1992 into 1994, Ghana had started experiencing about a five percentage points $(5 \%)$ increase in government expenditure. The government diversified some state-owned enterprises in 1990 and encouraged privatization throughout the country. This generated a lot of revenue for the government. As a result, the government invested back into the economy. Key priorities for 1992 were giving new impetus to state reforms, broadening the scope of banking-sector reforms, and liberalizing the administrative framework. Basic education and primary health care services were to receive attention over the long-term as well. However, was a corresponding marginal reduction in the rate of economic growth of about zero-point fifty-eight percent $(0.58 \%)$.

Circumstances subsequently changed significantly for the government. From 1995 to 1997, the government was not earning enough revenue and was being pressured by donor agencies to join the Highly Indebted Poor Country (HIPC) initiative since her indebtedness was high and growing. Government expenditure experienced about a two percent $(2 \%)$ reduction in its growth rate. Consequently, to salvage the economy the foregoing, the NPP government opted for the International Monetary Fund's (IMF) Highly Indebted Poor Country (HIPC) initiative in 2001, which run till 2008. The initiative led to a significant debt relief service to Ghana but after the program run to an end, the economy was stiffened and was faced with hardship since the government was not investing into capital projects due to the unwillingness of donor agencies to support the government's budget. 
Ghana was still signed on to the HIPC initiative from 2004 to 2008 . This was to enable the country to cancel even more of its debts owed the donor agencies such as the IMF. Thus, the growth rate of government expenditure moved up by about sixteen percent $(16 \%)$ in 2004 to 2008. As Ghana had entered the second face towards the completion point of the HIPC initiative, the Government of Ghana received a lot of debt relief from the IMF.

Moreover, getting to the end of 2008, the Ghanaian government sold its shares in the Ghana Telecom (GT) firm to Vodafone Ghana. Also, Ghana's new oil found at cape three points can be attributed to this change from state to private sector-led growth. There was an increase in the growth rate of government expenditure at about three percent $(3 \%)$.

In 2009, the introduction of the single spine salary structure gave the curve a higher slope. As the economy grows, the activities of the government increase, and more people will be hired to perform these tasks, which automatically raise the expenditure level.

As part of the policy, the then President of Ghana ensured no child was deprived of basic education from 2011, and this led to an intervention of supplying free school uniforms and 23 million free exercise books to pupils in deprived communities. The initiative used local fabrics and local textile industries in order to support the local textile industry as well as increase school enrolment. It contributed to a sharp increase in government expenditure and a corresponding increase in economic growth.

However, through 2011 to 2016, the shortage of power hobbled the growth of the economy and affected both business and residential customers. Many businesses had to resort to the use of generators to survive. According to Graphic Online (January 2017), statistics at the end of 2015 showed that in excess of 76 percent of both rural and urban residents have access to potable water. Moreover, massive investments in the construction of roads were much evident within the period of 2013 to 2016, leading to an increase in government expenditure. This shows that the trend between government expenditure and economic growth has not been consistent for the period.

\section{Regression Results}

Model 1 first modelled a linear regression to determine the unique relationship that exists between the predictors (i.e., gross capital formation, population growth annual $\%$, general government final consumption \% of GDP, trade openness, inflation GDP deflator) on the criterion (i.e., Real GDP Growth \%).

In addition, in Model 2, a threshold regression analysis was conducted to determine the non-linear relationship that exists between the key variable (general government final consumption \% of GDP) on Real GDP Growth $\%$ as well as gross capital formation $\%$ of GDP as a proxy for investment, inflation GDP deflator $\%$ and population growth $\%$ and openness to trade. Also, the significance of the overall model using the F-statistic and variance was conducted. In addition, test of autocorrelation was conducted using the figure of the Durbin Watson test to determine the existence of autocorrelation.

A Summary of the linear regression and the non-linear regression result is presented in Table 1 below. Details of the results and data used for the analysis are presented in the appendix. 
Table 1. Results of Linear and Non-linear Threshold Estimations

\begin{tabular}{|c|c|c|c|c|}
\hline \multirow[t]{2}{*}{ Variables } & \multirow{2}{*}{$\begin{array}{l}\text { Linear regression } \\
\text { Model } 1\end{array}$} & \multirow[t]{2}{*}{ Std Error } & \multirow{2}{*}{\begin{tabular}{|l|} 
Non-Linear regression \\
Model 2
\end{tabular}} & \multirow[t]{2}{*}{ Std Error } \\
\hline & & & & \\
\hline LNGE $^{\mathrm{b}}$ & - & - & $1.071052 * * *$ & 0.345131 \\
\hline LNGE $^{\mathrm{a}}$ & - & - & $0.674953 * * *$ & 0.242275 \\
\hline LNGE & 0.139419 & 0.255671 & 0.1142886 & - \\
\hline LNK & 0.287462 & 0.239172 & $0.347651^{* *}$ & 0.153454 \\
\hline LNL & 2.897317 & 2.978015 & $6.392493 * *$ & 2.562086 \\
\hline LNT & -0.001090 & 0.080799 & -0.011005 & 0.049447 \\
\hline LNINF & -0.067865 & 0.042126 & $-0.080238^{* *}$ & 0.033339 \\
\hline CONSTANT & $0.921897 * * *$ & 0.105215 & $0.741751 * * *$ & 0.098296 \\
\hline $\mathrm{r}^{2}$ & 0.423333 & - & 0.530949 & - \\
\hline $\mathrm{aDJ} \mathrm{R}^{2}$ & 0.330322 & - & 0.437139 & - \\
\hline F-stat & 4.551442 & - & 5.659821 & - \\
\hline pROB(F-STAT) & 0.003156 & - & 0.000501 & - \\
\hline \multicolumn{5}{|c|}{ Source from Eviews (Compiled by author) } \\
\hline \multicolumn{5}{|c|}{ a. Dependent Variable: Real GDP Growth \% (LNGRGDP) } \\
\hline \multicolumn{5}{|c|}{$\begin{array}{l}\text { b. Independent Variables: Government Expenditure ( } \% \text { GDP), gross capital formation ( } \% \text { of } \\
\text { GDP), population growth (annual } \% \text { ), trade openness, inflation GDP deflator. }\end{array}$} \\
\hline \multicolumn{5}{|c|}{ c. Threshold variable: Government Expenditure (\% GDP) } \\
\hline \multicolumn{5}{|c|}{ d. $* * *, * *$ indicates significance at $1 \%$ and $5 \%$ respectively. } \\
\hline \multicolumn{5}{|c|}{$\begin{array}{l}\text { e. The optimal threshold level below and above government expenditure as a percentage of } \\
\text { gdp respectively is LNGE }<0.1142886 \text { and } 0.1142886<=\text { LNGE }\end{array}$} \\
\hline
\end{tabular}

\section{Results from Hypothesis Tested}

All the hypotheses in the study were tested at $1 \%$ and $5 \%$ level of significance. Following from above, five variables were significant at $1 \%$ and $5 \%$ in both models.

Table 1 represents the results of the linear regression and the non-linear threshold regression estimation. The first, second, and fourth columns show the variables, coefficient of the independent linear regression variables, and the non-linear model coefficient. Lastly, columns three and five show the standard errors of the two models.

A Durbin Watson test results in the study found a figure of 1.41. This means that there is no positive serial or autocorrelation found between the independent variables in the study. It also means that the error term of the model was uncorrelated with the independent variables in the study.

\section{Model 1}

In the linear regression model, the constant term (0.921897) is the value of the dependent variable when all the independent variables and the error term is zero, but these values almost never equal zero. This is the intercept for the regression line. The constant term of the linear model was found to be significant at $1 \%$.

Moreover, the general government final consumption \% of GDP coefficient was 0.139419 , statistically not significant. That is, a $1 \%$ increase in general government final consumption leads to 0.13 dollars increase in real GDP growth (economic growth) and vice versa. This, however, confirms the expected relationship between general government final consumption and real GDP growth (economic growth). For gross capital formation, the results showed a positive and significant linkage on real GDP growth (economic growth). The coefficient of gross capital formation was 
statistically not significant at a coefficient of 0.287462 . Thus, a $1 \%$ increase in gross capital formation causes real GDP growth (economic growth) to increase by 0.28 dollars holding all other variables in the model constant.

A positive effect of population growth on real GDP growth (economic growth) was realized. Population growth was statistically not significant at a coefficient of 2.897317. Thus, a $1 \%$ increase in population growth leads to 2.89 dollars increase on real GDP growth (economic growth), holding all other variables in the model constant.

Furthermore, the result from the interaction of trade on economic growth was negatively related. Trade was not significant at a coefficient of -0.001090 . Thus a $1 \%$ increase in trade openness leads to a 0.001 dollar decrease on real GDP growth (economic growth), holding all other variables in the model constant.

Lastly, the estimated coefficient of inflation 0.04, decreases economic growth or real GDP growth by 0.04 dollars for every $1 \%$ increase in inflation, holding all other variables in the model constant.

The R2 of the model was 0.423 , which indicates that all the dependent variables, Government Expenditure (\% GDP), gross capital formation ( $\%$ of GDP), population growth (annual \%), trade openness, and inflation GDP deflator explains about $42 \%$ of the variations in real GDP growth (economic growth) in Ghana. This indicates that the variables fairly fit the model.

\section{Model 2}

According to Table 1, with respect to model 2 , the threshold variable is General government final consumption expenditure (\% of GDP). The optimal threshold level of government size is $1.301 \%$ of GDP. From the problem statement, the size of government is not necessarily the number of cabinet ministers. In this study, Government size was measured in terms of the volume of GDP that the economy can generate. For every $13 \%$ the government spends on appointed ministers, it should generate a corresponding $10 \mathrm{Ghc}$ of GDP. On individual countries, reports show that $\mathrm{Zhu}$ et al. [22]; Altunc and Aydin [23], and Chen and Lee [24] estimated a threshold within the range of $11-25 \%$ and Karras [25] in a sample of 20 European countries established an optimal level of government spending equal to $16 \%$.

Moreover, table 1 estimated the non-linear impact on real GDP growth (economic growth) when it is above and below the optimal level of government spending. Additionally, the coefficient of General government final consumption expenditure is positive and significant at $1 \%$ level for both above GE group $(\beta 2=0.67$; s.e. $=0.24)$ and below GE group $(\beta 1=1.07$; s.e. $=0.34)$. A $1 \%$ increase in government expenditure as a share of GDP will enhance economic growth approximately by $1 \%$ increase in government expenditure as a share of GDP will decrease growth by $0.67 \%$ when government size is above the threshold level at $1 \%$ significance level.

With regards to the non-threshold variables, which are gross capital formation (\% of GDP), population growth (annual \%), trade openness, and inflation GDP deflator, we find that inflation is negative and statistically not significant. The estimated coefficient of inflation -0.08 , decreases real GDP growth by 0.08 dollars for every $1 \%$ increase in inflation, holding all other variables in the model constant.

Gross Capital formation \%, which is a proxy for investment, was found to be positive and statistically significant at 5\% significance level within the period 1980 to 2016. As the estimated coefficient of the gross capital formation increases economic growth by 0.27 dollars for every $1 \%$ increase in capital formation, holding inflation, trade openness, and population growth constant. Moreover, the prediction for capital formation was supported. A Study [11] similarly reported a positive and a statistical significance for capital formation 
with respect to developed and non-developed counties.

Thirdly, a significant positive relationship between trade openness and economic growth was not supported. Trade openness revealed an insignificant negative linkage with economic growth. It statistically impacted on real GDP growth at $5 \%$ level of significance. Thus, a $1 \%$ increase in trade openness causes real GDP growth to decrease by 0.01 dollars.

Also, we find that population growth positively and insignificantly relates to economic growth.

Lastly, the study displayed a direct impact between government expenditure and economic growth. Government expenditure significantly impacted on economic growth. It shows that economic growth will increase by will increase by $0.38 \%$ for every $1 \%$ increase in government expenditure holding constant inflation rate, gross capital formation, openness to trade, and population growth.

\section{Conclusion and Future Scope}

\section{Summary of Major Findings}

The study showed that government final consumption $\%$ of GDP positively impacted on economic growth. It shows that economic growth will increase by $0.14 \%$ for every $1 \%$ increase in government final consumption $\%$ of GDP holding constant inflation rate, gross capital formation, and openness to trade and population growth.

We assessed the non-linear relationship between government size (using government final consumption \% of GDP as proxy) and real GDP growth under a sample of 37 time-series data set using a threshold regression model. We found that the optimal level of government size that maximizes economic growth is $0.114 \%$ of GDP. From table 1, a non-linear relationship between government final consumption \% of GDP and economic growth is statistically significant at $1 \%$ level around the optimal level, the upward and downward slopping part of the curve.
Also, with regards to the non-threshold variables, which are inflation GDP deflator, gross capital formation, trade openness, and population growth, the study, observed that there was an insignificant negative relationship between inflation and economic growth. The estimated coefficient of inflation -0.08 , decreases economic growth by 0.08 for every $1 \%$ increase in inflation, holding constant all other variables in the model.

Further, the gross capital formation was found positive and statistically significant within the period 1980 to 2016. The estimated coefficient of gross capital formation is 0.34 . As the estimated coefficient of the capital formation increases economic growth by 0.34 for every $1 \%$ increase in gross capital formation, holding constant all other variables.

Again, trade openness revealed an insignificant negative linkage with economic growth. A $1 \%$ increase in trade openness, holding all variables constant, decreases economic growth by 0.011 . Lastly, we found that population growth positively and insignificantly relates to economic growth.

\section{Conclusion}

The study estimated the linkage between government size and economic growth using general government final consumption expenditure (\% of GDP) as a proxy to measure government size in Ghana for a time period of 1980 to 2016. Moreover, the optimal threshold level of government expenditure on economic growth was examined.

Findings showed that Government expenditure directly impacted on economic growth holding inflation rate, gross capital formation, openness to trade, and population growth constant. Even though government expenditure did not significantly predict growth rate, the expected positive direction predicted in the study was obtained.

A non-linear relationship between government size and economic growth under a sample of 37 time-series data set using a 
threshold regression model. We found that the optimal level of government size that maximizes economic growth is $1.301 \%$ of GDP. From Table 1, a non-linear relationship between government expenditure and economic growth is statistically significant around the optimal level, the upward and downward slopping part of the curve.

The data used for the estimation was not primary information collected by the researcher personally but rather was obtained from International Finance Statistics of the World Bank. Thus, the validity and reliability of the data cannot be substantiated in the study. This may have the tendency to affect the outcome of the study. In addition, a test of relationship might not necessarily mean there is causation. For instance, a significant positive relationship between government expenditure and economic growth might not mean that government expenditure caused economic growth. Finally, some of the data used are several years old, and this might not reflect the current market or growth conditions.

\section{Recommendations of the Study}

Based on the general findings indicated in the previous section, the study recommends the following for policy makers to act upon them:

1. Total government expenditure has a direct positive impact on economic growth. As a result of that the study recommends that government expenditure should not exceed the optimum threshold level of $0.114 \%$ of GDP to maximize real GDP growth (economic growth).

2. Moreover, government consumption spending should be well coordinated by all arms of government to prevent the "crowd out" effect on government investment. There should be a high degree of transparency and accountability on government spending at various sectors of the economy in order to prevent the channeling of public funds to private accounts of government officials.

3. In addition, Government should monitor contracts awarding processes of projects closely to prevent against overestimation of execution cost. This will bring about a significant impact of public investment spending on economic growth.

4. Among many roles, the Bank of Ghana is expected to stabilize the inflation rate at a level supportive of sustainable economic growth. A single-digit and stable inflation is needed to minimize instabilities and uncertainties in the domestic financial market, and this will automatically lend enormous support to capital formation needed for investment in Ghana.

5. Lastly, an economy that specializes in the production of a particular good in which it has a comparative advantage in realizes sufficient economic growth as compared to producing everything. The study proposes that trade with the neighboring countries and the global world should be encouraged. National culture should be instilled in the citizens of Ghana to patronize in domestically manufactured products while a national policy is put in place to encourage the export of processed products. This will guarantee the country favorable terms of trade which is needed to repair the country's trading position.

\section{Acknowledgement}

Since no organization sponsored this work, no acknowledgment is made.

\section{Conflict of Interest}

The author declares that there is no conflict of interest. 


\section{References}

[1] Heijdra, J.B. and Ploeg, V.D., 2002, The foundations of modern macroeconomics: Oxford University Press, USA.

[2] Mankiw, G., 2007, The role of economic growth in macroeconomics: MIT Press.

[3] Heinz, D. And Kurz, C.L., 2000, Input-output Analysis and Classical Economic Theory. Economic Systems Research, 12(2): 139-140.

[4] Nellis, J.G., and Parker, D., 2004, Principles of Economics, $\left(1^{\text {st }}\right.$ ed.): Pearson Education LimitedEngland.

[5] Solow, Robert M., 1956, "A contribution to the theory of Economic Growth". Quarterly Journal of Economics, Vol. LXX.

[6] Sinha, D., 1998, Government Expenditure and Economic Growth in Malaysia. Journal of Economic Development, Vol. 23, Number 2, pp. 71-80.

[7] Henrekson, M., 1993, Wagner's Law - a Spurious relationship. Public Finance, 48, pp. 406415.

[8] Slemrod, J., Gale, W. and Easterly, W.,1995, What do Cross-Country Studies Teach about Government Involvement, Prosperity, and Economic Growth, Brooking Papers on Economic Activity, (2), pp. 373-431.

[9] Branson, W. H. 1989, Macroeconomic Theory and Policy, 3rd ed., New York: Harper \& Row.

[10]Afonso, A. and Jalles, J. T. 2011, Economic performance, and government size. Working Paper Series 1399 / November 2011. European Central Bank, 2011, Frankfurt.

[11] Asimakopoulos, S. and Y. Karavias, 2015, The impact of government size on economic growth: A threshold analysis (2015), Economics Letters, http://dx.doi.org/10.1016/j.econlet.2015.12.010.

[12]Caselli, F., Esquivel, G., and Lefort, F.,1996, Reopening the convergence debate: A new look at cross-country growth empirics, Journal of Economic Growth 1(3): 363-389.

[13]Romero-Ávila, D., and R. Strauch (2008). Public finances and long-term growth in Europe: Evidence from a panel data analysis, European Journal of Political Economy 24(1): 172-19.
[14]Bose, N., M. E. Haque, and D. R., Osborn (2007). Public expenditure and economic growth: A disaggregated analysis for developing countries, The Manchester School 75(5): 533-556.

[15] Guseh, J., 2007, Government size and economic growth in developing countries: A politicaleconomy framework. Journal of Macroeconomics 19(1): 175-192.

[16] Gray, C., T. Lane, and Varoudakis, A., 2007, Fiscal policy and growth in ECA: Lessons for Eastern Europe and Central Asia. Washington DC: The World Bank.

[17] Oto-Peralías, D. and Romero-Ávila, D., 2013, Tracing the link between government size and growth: The role of public sector quality. KYKLOS 66(2): 229-255.

[18] Sheehey, E.,1993, The effect of government size on economic growth. Eastern Economic Journal 19(3): 21-328.

[19] Durden, G. and Elledge, B. (n.d.), The effect of government size on economic growth: evidence from gross state product data. The Review of Regional Studies: 183-190.

[20] Meltzer, A. H., and Richard, S. F., 1981, A rational theory of the size of government. Journal of Political Economy. 89(5): 914-927.

[21]Zhu, Z, Chiou-Wei, S and Kuo, Y., 2010, Government size and economic growth: an application of the smooth transition regression model. Applied Economics Letters 17(14), 1405 1415.

[22] Altune, O.F., and Aydin, C, 2013, The relationship between the optimal size of government and economic growth: Empirical evidence from Turkey, Romania, and Bulgaria. Procedia-social and Behavorial sciences, 92, 66-75.

[23] Chen, S.T., and Lee, C.C, 200, Government size and economic growth in Taiwan: A threshold regression approach. Journal of policy modelling 27(9), 1051-1066.

[24] Karras (1997) Karras, B.E, 1999, Threshold effects in non-dynamic panels: estimation, testing, and inference. Journal of Econometrics, 93, 345-68. 


\title{
Impact of Human Resources Budgeting on Human Resource Management Accountability in Metropolitan, Municipal, and District Assemblies in the Ashanti Region
}

\author{
Laar David Diam \\ Doctor of Philosophy in Business Management, Texila American University, Ghana
}

\begin{abstract}
The Metropolitan, Municipal, and District Assemblies in Ghana have adopted, have been practicing Human Resource Budgeting for effective accounting of human resources. However, little is done to determine its impact on Human Resource Management Accountability. This study, therefore, focused on the impact of Human Resource Budgeting on Human Resource Management Accountability in Metropolitan, Municipal, and District Assemblies (MMDAs) in the Ashanti Region of Ghana. The study purposively sampled Heads of Departments since they have the responsibility of supervising, directing, coordinating the activities of other employees within the MMDAs. The study collected primary data from 387 Heads of Departments in 43 MMDAs in the region. The study employed mean and standard deviation for descriptive analysis. The study employed a structural equation model for the estimation of the impact of Human Resource Budgeting on Human Resource Management Accountability. The sex, educational level, and years of experience of the respondents were controlled for in the model estimation. Human Resource Budgeting in the MMDAs was occasionally done. Human Resource Budgeting had a significant positive impact on Human Resource Management Accountability in the MMDAs. Ministry of Local Government and Rural Development should see Human Resource Budgeting as a strategic tool for enhancing Human Resource Management Accountability in MMDAs. For this reason, Human Resource budgeting practices should be enforced to the latter.
\end{abstract}

Keywords: Human Resource Budgeting, Human Resource Management Accountability, Metropolitan, Municipal and District Assemblies.

\section{Introduction}

Human capital is an important component since it has the capacity to improve or degrade an organization's performance [1]. For this reason, every organization or institution deems it appropriate to it manage human resource with maximum care. In recent times, Human Resource Budgeting has been introduced to provide $\mathrm{s}$ standard practice for measuring the value and cost of people in an organization, cost of recruitment, hiring, training, and development [2]. The human resources budget refers to the funds that human resource allocates to all human resource processes enterprise wide. The Human resource budge includes funds allocated to hiring, salaries, benefits, talent management, training, succession planning, workforce engagement, and employee wellness planning. HR budgets use financial information, performance results, and historical data from every department. Since the HR budget considers HR activities company-wide, it is an incredibly complex yet essential document to determining a company's future Human activities and accountability [3]. Any accounting practice, including Human Resource Budgeting practice, is to help ensure accountability. Human 
Resource Management Accountability of Departmental Heads in Metropolitan, Municipal and District Assemblies (MMDAs) entails establishing and maintaining effective human resource management policy, delegating human resource management responsibilities through formal delegation agreements, monitoring and providing corporate and organizational-level reporting on human resources matters; representing the employer at the corporate-wide level and ensuring that non-delegated human resource management responsibilities are carried out in a manner consistent with applicable legislation, collective agreements [4]. Human Resource Budget is designed to improve Human Resource Management Accountability and performance [5].

Empirically, the link between Human Resource Budgeting and HRM accountability has been established in corporate entities in developed countries. For example, Enyi and Akindehinde [6] has demonstrated Human Resource Budgeting significantly affects management decisions and enhanced accountability. Similarly, Islam, Kamruzzaman, and Redwanuzzaman [7] noted that Human Resource Budgeting practice has helped improve accountability in organizations and the productivity of employees as well. However, the outcomes of these studies cannot be applied to Ghana since Ghana has political, economic, social, and cultural characteristics different from those developed countries where such studies were done. More importantly, all the empirical studies were carried out in private corporate entities but not the public sector, where accountability is a major issue. In Ghana, the public's desire for accountability from public workers at all levels is increasing [8]. The Metropolitan, Municipal, and District Assemblies (MMDAs) in Ghana have all been at the forefront of the debate over accountability, though Human Resource Budget is being implemented. This has raised many questions, including, what is the extent to which Human Resource Budgeting is practiced in MMDAs? and Does Human Resource Budgeting really improve HRM accountability within the MMDAs in Ghana? Addressing the above questions would help the human resources practitioners and the Government of Ghana to be aware of what should be done to promote the effective practice of Human Resource Budgeting in MMDAs to enhance HRM accountability.

\section{Methods}

\section{Description of the Site}

This study was conducted in Ashanti of Ghana. The Ashanti Region is located in south Ghana, and it is the third largest of 16 administrative regions, occupying a total land surface of $24,389 \mathrm{~km}^{2}(9,417$ sq. mi) or 10.2 percent of the total land area of Ghana. In terms of population, however, it is the most populated region with a population of 4,780,380 according to the 2010 census, accounting for $19.4 \%$ of Ghana's total population. Kumasi is the capital town of the Ashanti Region. The region has 1 Metropolitan Assembly, 20 Municipal Assemblies, and 24 District Assemblies as Shown in Table 1.

Table 1. MMDAs in the Ashanti Region of Ghana

\begin{tabular}{|l|l|l|l|}
\hline Region & Metropolis & Municipals & Districts \\
\hline Ashanti Region & Kumasi Metropolis & Ahafo Ano North Municipal & Adansi Asokwa \\
\cline { 3 - 4 } & & Asante Akim Central & Adansi North \\
\hline \multirow{5}{*}{} & Asokore Mampong & Adansi South \\
\hline \multirow{5}{*}{} & Asokwa & Afigya-Kwabre North \\
\hline & Atwima Nwabiagya & Afigya-Kwabere South \\
\hline & Asante Akim South & Ahafo Ano Southwest \\
\hline & Amansie East & Ahafo Ano Southeast \\
\hline
\end{tabular}




\begin{tabular}{|l|l|l|}
\hline & Bekwai & Akrofuom District \\
\hline & Kwadaso & Amansie Central \\
\hline Ejisu & Amansie West \\
\hline Mampong & Amansie South \\
\hline & Obuasi & Asante Akim North \\
\hline & Offinso & Atwima Kwanwoma \\
\hline & Oforikrom & Atwima Mponua \\
\hline Old Tafo & Atwima Nwabiagya North \\
\hline Suame & Bosome Freho \\
\hline Kwabere East & Bosomtwe \\
\hline & EjuraSekyedumase & Obuasi East \\
\hline Juaben & Offinso North \\
\hline & Sekyere Afram Plains \\
\hline & Sekyere Central \\
\hline & Sekyere East \\
\hline & Sekyere South \\
\hline
\end{tabular}

Source: Ministry Local Government and Rural Development (2021)

\section{Description of Experiment}

The study, through the purposive sampling technique, sampled Departmental Heads in MMDAs in the Ashanti Region. However, two District Assemblies could not give their consent on time; hence they were ignored in the study.
Therefore, the Metropolitan Assemblies was 1, and Municipal Assemblies were 20, and District Assemblies were 22, making a total of 43 MMDAs in the study. The total number of Heads of Departments from the Metropolitan Assembly, Municipal Assemblies, and District Assemblies are shown in Table 2.

Table 2. Number of Respondents

\begin{tabular}{|l|l|}
\hline Departments & Number of Heads \\
\hline Finance & 43 \\
\hline Administration & 43 \\
\hline Community Development and Works & 43 \\
\hline Social Welfare & 43 \\
\hline Physical Planning & 43 \\
\hline Trade and Industry & 43 \\
\hline Health & 43 \\
\hline Agriculture & 43 \\
\hline Education & 43 \\
\hline Total & 387 \\
\hline
\end{tabular}

Source: Author's Construct (2021)

Thus, the total number of respondents used in this study was 387 . The study used questionnaire to collect the data from respondents. The questionnaire had three sections. Part I: Sociodemographic characteristics of respondents comprised of gender, educational level, and years of working experience. Part II focused on human resource budgeting practice which had 8 items with a four-point Likert scale from rarely (1) to very often (4). Part III focused on Human 
Resource Management accountability of Departmental Head, and it had 5 items with four point-Likert scale ranging from strongly disagree (1) to strongly agree (4) with no neutral position. The questionnaire was reliability with an overall Cronbach's Alpha of 0.891 (i.e., $\alpha=0.891$ ) and valid with Factor Loading Score for each item more than 0.4 and the KaiserMeyer-Olkin (KMO) for each construct was more than 0.8 .

\section{Statistical Method}

The data were analysed using Statistical Package for Social Sciences (SPSS), version 21.0, and STATA version 15.0. The study edited the data, coded the data, and entered them into the software for analysis. The study used SPSS, version 21.0, for all the descriptive analysis, whiles STATA was used to estimate of the model. The used mean and standard deviation for the descriptive analysis. The mean scores ranged 1.00-1.49, 1.50-2.49, 2.50-3.49, 3.504.00which rarely represented, occasionally, often, and very often respectively for Human
Resource Budgeting statements and strongly disagree, disagree, agree, and strongly agree respectively for Humans Resource Management accountability. To determine the effect of human resource budgeting on human resource accountability of Departmental Heads, this study used Structural Equation Model as suggested by Kline [9]. The models are specified below.

$H R M A o D H=\propto_{0} H R M B+\propto_{1} S E X+$ $\propto_{2} E D U L+\propto_{3} Y E X+\varepsilon \ldots \ldots \ldots \ldots . .$. Model 1

Where HRMAoDH is the human resource management accountability of the Departmental Head and HRMB is the Human Resource Budgeting. SEX, EDUL, and YEX denote sex, educational level, and years of working experience in the assemblies, respectively. The acceptable level of significance was $5 \%$.

\section{Results}

\section{Personal Information of Respondents}

The study gathered relevant personal information of the respondents, and they are presented in Table 3.

Table 3. Socio-demographic Characteristics of Respondents ( $\mathrm{N}=387)$

\begin{tabular}{|l|l|l|l|}
\hline Variables & Categories & Frequency & Percentage \\
\hline \multirow{3}{*}{ Sex } & Male & 263 & 67.96 \\
\cline { 2 - 4 } & Female & 124 & 32.04 \\
\hline \multirow{5}{*}{ Yevel of education } & Diploma & 43 & 11.11 \\
\cline { 2 - 4 } & Degree & 187 & 48.32 \\
\cline { 2 - 4 } & Masters' Degree & 157 & 40.57 \\
\hline \multirow{3}{*}{ Years of experience } & $1-5$ years & 78 & 20.16 \\
\cline { 2 - 4 } & 6-10 years & 179 & 46.25 \\
\cline { 2 - 4 } & Above 10 years & 130 & 33.59 \\
\hline
\end{tabular}

Source: Field Data (2021)

The results in Table 3 indicate that males dominated $(67.96 \%)$ as Heads of Departments in MMDAs in the Ashanti Region of Ghana. It is further indicated in Table 3 that almost all the respondents have first degree or master's degree. Given their level of academic qualification, the management members of the MMDAs are expected to have much knowledge in human resource management issues. Most of the respondents $(79.84 \%)$ have served in their respective MMDAs for more than 5 years, and this implies that almost all the respondents are familiar with the human resource accounting practice of the MMDAs.

\section{Human Resource Budgeting Practices Used by MMDA's}

The extent of Human Resource Accounting Practices of the MMDAs are shown in Table 4. 
Table 4. Human Accounting Practices

\begin{tabular}{|l|l|l|l|l|}
\hline Practices & $\begin{array}{l}\text { Weighted } \\
\text { Mean }\end{array}$ & $\begin{array}{l}\text { Standard } \\
\text { deviation }\end{array}$ & $\begin{array}{l}\text { Frequency of } \\
\text { practice }\end{array}$ & Ranking \\
\hline $\begin{array}{l}\text { The assembly practices capitalising and } \\
\text { amortizing over the expected useful life } \\
\text { of human resource for the acquisition } \\
\text { cost of human resource }\end{array}$ & 2.338 & 0.94218 & Occasionally & $5^{\text {th }}$ \\
\hline $\begin{array}{l}\text { The assembly practices capitalising and } \\
\text { amortizing over the expected useful life } \\
\text { of human resource for training and } \\
\text { development cost of human resource }\end{array}$ & 2.4832 & 0.95581 & Occasionally & $3^{\text {rd }}$ \\
\hline $\begin{array}{l}\text { The assembly practices capitalising and } \\
\text { amortizing over the expected useful life } \\
\text { of human resource for the welfare cost } \\
\text { of human resource }\end{array}$ & 2.3333 & 1.09165 & Occasionally & $6^{\text {th }}$ \\
\hline $\begin{array}{l}\text { The assembly practices capitalising and } \\
\text { amortizing over the expected useful life } \\
\text { of human resource for the other } \\
\text { expected costs for human resource. }\end{array}$ & 2.9276 & 1.18056 & Often & $1^{\text {st }}$ \\
\hline $\begin{array}{l}\text { The assembly practices capitalising and } \\
\text { amortizing over the expected useful life } \\
\text { of human resource acquisition cost to } \\
\text { replace human resource presently } \\
\text { employed }\end{array}$ & 2.3127 & 0.83195 & Occasionally & $7^{\text {th }}$ \\
\hline $\begin{array}{l}\text { The assembly practices capitalising and } \\
\text { amortizing over the expected useful life } \\
\text { of human resource learning cost to } \\
\text { replace human resource presently } \\
\text { employed }\end{array}$ & 2.2351 & 1.04510 & Occasionally & $8^{\text {th }}$ \\
\hline $\begin{array}{l}\text { The assembly practices capitalising and } \\
\text { amortizing over the expected useful life } \\
\text { of human resource separation cost to } \\
\text { replace human resource presently } \\
\text { employed }\end{array}$ & 2.4625 & 1.01824 & Occasionally & $4^{\text {th }}$ \\
\hline $\begin{array}{l}\text { The assembly practices capitalising and } \\
\text { amortising bidding cost of scarce } \\
\text { employees within bid the organisation }\end{array}$ & 2.8346 & 1.13974 & Often & \\
\hline Total score & 2.4909 & 1.14251 & Occasionally & \\
\hline
\end{tabular}

Source: Filed Data (2021)

Table 4 above shows that Human Resource budgeting practices is occasionally practiced in the MMDAs in the Ashanti region of Ghana. The MMDAs occasionally capitalise and amortize the expected useful life of human resource for the acquisition cost of human resources; for training and development cost of human resource, for the welfare cost of human resource, and to replace human resource presently employed. However, the MMDAs often 
capitalise and amortize the expected useful life of human resource for the other expected costs for human resource and the bidding cost of scarce employees.

\section{Effect of Human Resource Budgeting on Human Resource Management Accountability}

The study employed Structural Equation Model to estimate the effect of Human Resource Budgeting on the human resource accountability of Departmental Heads. The study, through Principal Component Analysis, obtained one construct for Human Resource Budgeting from 8 items and another construct for human resource management accountability from 5 items. The study used the personal information of the respondents in Table 3 (sex, educational level, and years of working experience) as control variables. The results of the Structural Equation Model are shown in Figure 1 and Table 5.

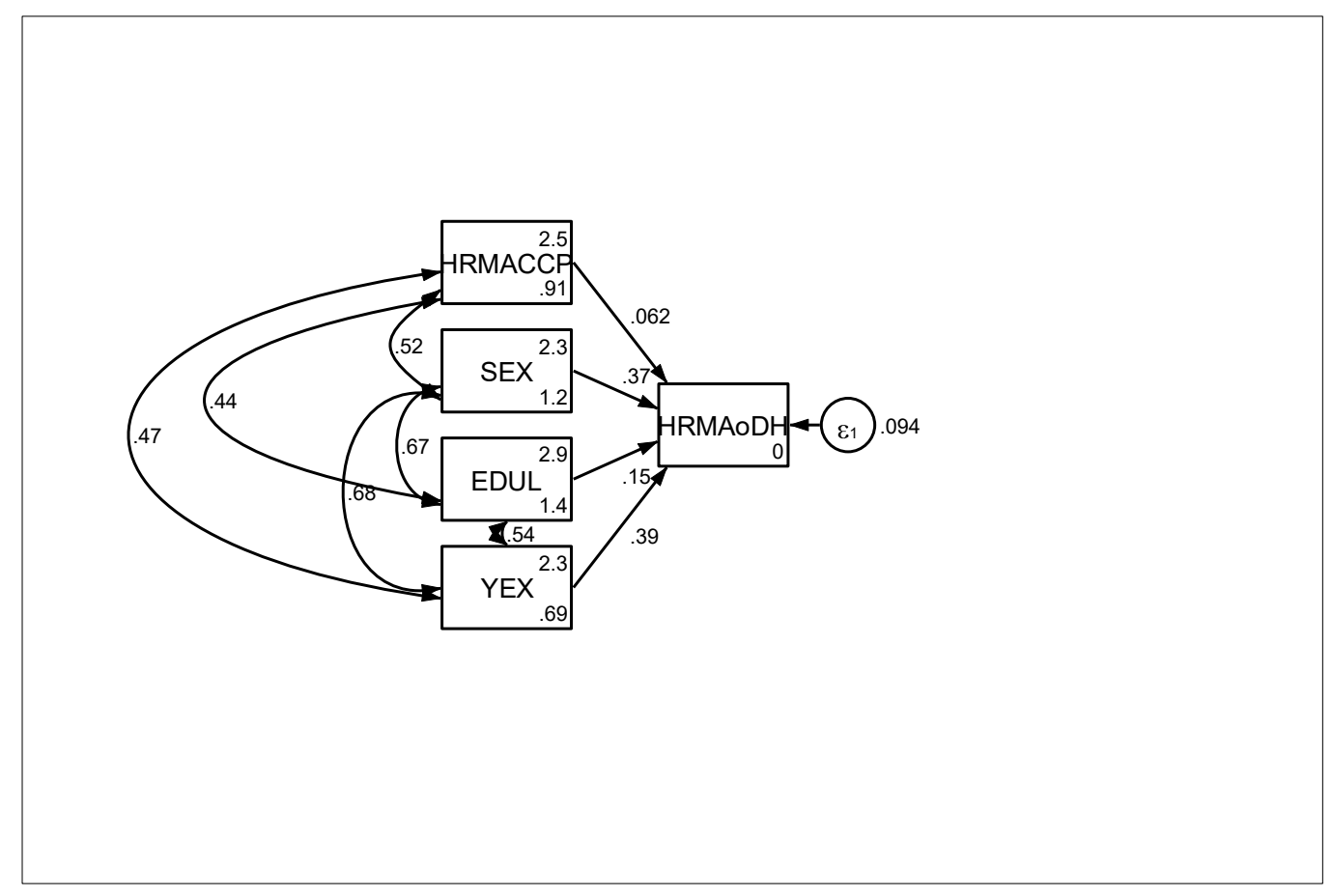

Figure 1. Impact of Human Resource Budgeting on HRM Accountability

Table 5. Impact of Human Resource Budgeting on Human Resource Management Accountability

\begin{tabular}{|l|l|l|l|l|l|}
\hline Variables & Coeff. & OIM & $\mathbf{z}$ & $\mathbf{p}>/ \mathbf{z} /$ & {$[\mathbf{9 5 \%}$ Conf. Interval } \\
\cline { 3 - 6 } & & Std. Err & & & \\
\hline $\begin{array}{l}\text { Human Resource } \\
\text { Accounting }\end{array}$ & 0.0624878 & 0.0192019 & 3.25 & 0.001 & 0.2485280 .1001228 \\
\hline Sex & 0.3658908 & 0.02222 & 16.47 & 0.000 & 0.32234050 .4094411 \\
\hline Educational Level & 0.1505726 & 0.0154103 & 9.77 & 0.000 & 0.1203690 .1807762 \\
\hline $\begin{array}{l}\text { Years of Working } \\
\text { Experience }\end{array}$ & 0.3935086 & 0.0305883 & 12.86 & 0.000 & 0.33355670 .4534605 \\
\hline Constant & 0.13252 & 0.01247 & 10.62 & 0.000 & 0.1173010 .254312 \\
\hline Chi ${ }^{2}$ bs (4) $=889.540 ; \mathrm{p}>\mathrm{Chi}^{2}=0.000$ & & & & \\
\hline
\end{tabular}

Source: Field Data (2021)

The results in Table 5 and Figure 1 show that Human Resource Accounting has a significant positive impact on HRM accountability of Departmental Heads (Coeff. $=0.0624878$; Std. 
Err $=0.0192019 ; p$-value $=0.001)$. As the practice of Human Resource Accounting increases by one unit, HRM accountability significantly increases by 0.0624878 . Sex, educational level, and years of working experiencing of Heads of Departments in MMDAs have a significant positive impact on Human Resource Management accountability. The estimated model is statistically fit for predicting the impact of Human Resource Accounting on HRM accountability in MMDAs in the Ashanti Region of Ghana $\left(\mathrm{Chi}^{2}\right.$ bs (4) $=889.540 ; \mathrm{p}>\mathrm{Chi}^{2}=$ $0.000)$.

\section{Discussions}

The results show that Human Resource Budgeting is occasionally practiced in the MMDAs. This is consistent with some of the previous studies that found that awareness and practice of human resource budgeting is very low, especially in developing countries $[10,11$, 12].

However, the effect practice of Human Resource Accounting significantly improves HRM accountability of Departmental Heads in MMDAs. Similar findings were observed by some previous studies in developed countries in private entities. This finding is consistent with some previous studies. For example, Islam Kamruzzaman and Redwanuzzaman [7] revealed that Human Resource Accounting or Budgeting helps the management in taking various decisions for achieving their organizational goals by accurate estimation of the human resources. The study further revealed that Human Resource budgeting system helps in the personnel selection process, recruitment, estimate cost and budget for the acquisition and development of human resources and also helps in the utilization of human resource effectively by providing better reward administration and it is important in the evaluation process by developing reliable methods of measuring the value of employees to an organization. All these indicate that Human Resource Budgeting enhances accountability of Human Resource
Management within an organization or institution [7]. Dhanabhakyamand Mufliha [13] noted that when human resources activities are quantified and reported, it would help to insist on accountability of Human Resource Management. Other study [14-17] have also confirmed that human resource budgeting improves accountability, leading to higher organizational performance as measure by profitability. However, Shukla and Naghshbandi [18] note that human resource budgeting has no effect on accountability both in the financial and human resource sense. This has been confirmed by other studies that there is limited evidence on the relationship between human resource budgeting and human resource accountability $[19,20]$.

\section{Conclusion}

The study assessed the practice of Human Resource Accounting and its effect of HRM accountability in MMDAs in the Ashanti Region of Ghana. The based on the findings from the study, it is concluded that Human Resource Accounting is occasionally practiced in MMDAs. Effective practice of Human Resource Accounting significantly improves HRM accountability. The study recommends the effective and efficient practice of Human Resource Accounting as a strategy to promote accountability in the area of HRM in MMDAs.

Though the study is very relevant and first in its king, it is limited to the MMDAs in the Ashanti Region. Future studies should replicate this study in other regions and in other public institutions and organizations for a comprehensive understanding of Human Resource Accounting practice and its effect in HRM accountability in Ghana.

\section{Acknowledgement}

My sincerest gratitude to Dr. Freda Ocansey, Mr. Prince Amoako who offered very valuable contributions and were very supportive in the compilation of this article. I take this opportunity to thank Anitha, my research mentor, my office 
secretary, who did the typesetting of this manuscript. Ms. Mary Yigal, how can I forget you? Your kindness and love were just indescribable.

I will remain grateful. Mrs. Diam Lilian Laar, my wife, you were, and you remain, my solid

\section{References}

[1] Kodwani, D., Deo, A., and Tiwari, R., 2007, Human resource accounting-a new dimension. In Canadian Accounting Association (CAAA) 2006 Annual Conference.

[2] Fremont-Smith, M., 2004, Pillaging of Charitable Assets: Embezzlement and Fraud. Exempt Organization Tax Review, 46(33), pp. 333-346.

[3] Akintoye, I. R., Awoniyi, O., Jayeoba, O., and Moses Ifayemi, O., 2016, Improvement of human resource accounting disclosure practice in financial statements through IFRS: evidence from Nigerian Banks. International Journal of Business and Commerce, 5(7), 1-17.

[4] Ministry of Local Government and Rural Development.

[5] Surarchith N. K. Vaddadi K. M. and Cura F., 2017, Impact of Human Resource Accounting (HRA) on the Performance of a Firm, International Journal of Management and Applied Science, Volume-3, Issue-10.

[6] Enyi E. P. and Akindehinde A.O., 2014, Human Resource Accounting and Decision Making in PostIndustrial Economy, International Journal of Accounting and Taxation, Vol. 2, No. 1, pp. 19-35.

[7] Islam A., Kamruzzaman, R. and Redwanuzzaman, M., 2013, Human Resource Accounting: Recognition and Disclosure of Accounting Methods \& Techniques, Global Journal of Management and Business Research Accounting and Auditing, Volume 13 Issue 3.

[8] Asiedu, K. F., and Deffor, E. W., 2017, Fighting corruption by means of effective internal audit function: Evidence from the Ghanaian public sector. International Journal of Auditing, 21(1), 82-99.

[9] Kline, R. B., 2011, Principles and practice of structural equation modeling ( $3 \mathrm{rd}$ ed.). Guilford Press. aids and support. I could not have made it without you.

\section{Conflict of Interest}

The author declares that there is no conflict of interest with regard to this paper.

[10] Oluwatoyin, A.S., 2014, Human Resource Accounting and Disclosure in Financial Statements: Literature Review. Research Journal of Finance and Accounting 5 (22) 72. Retrieved from http://www.iiste.org/journals.

[11]Cherian, J. and Farouq, S., 2013, A Review of Human Resource Accounting and Organizational Performance. International Journal of Economics $\begin{array}{llll}\text { and } \quad \text { Finance, } & 5 & \text { (8) }\end{array}$ http://dx.dpo.org/10.5539/ijef.v5n8p74.

[12]Bullen, M.L., 2007, Human Resource Accounting: A Useful Tool for Measurement and Management in Organizations. Leadership and Organizational Management Journal, 2 (8), 85-103. [13] Dhanabhakyam M. and Mufliha S., 2016, Impact of human resource accounting system on the decisions making areas of human resource management practices, International Journal of Applied Research 2016; 2(5): 505-508.

[14]Ezejiofor R. A., John-Akamelu R. C., and Iyidiobi F. C., 2017, Appraisal of human resource accounting on profitability of the corporate organization. Economics. 6(1), 1-10.

[15]Edom, G.O., Inah, E.U. and Eyisi, A.S., 2015, The impact of human resource accounting on the profitability of a firm: empirical evidence from Access Bank of Nigeria. European Journal of Accounting, Auditing, and Finance Research, 3(7).

[16] Enofe, A.O., Mgbame, C. Sunday O.S. and Ovie, O., 2013, Human resources accounting disclosures in Nigeria quoted firms. Research Journal of Finance and Accounting, 4(13), 1-15.

[17]Rao, A. L., 2014, Human Resource Accounting: A Framework for Better Financial Accounting and Reporting. IOSR Journal of Business and Management, 16, 86-90.

[18] Shukla, A. and Naghshbandi, M., 2015, Comparative Analysis of Human Resource 
Accounting (HRA) Practices in Indian Companies, International Journal of Research and Development - A Management Review (IJRDMR), 4(4), 1-7.

[19] Marler, J. H. and Boudreau, J. W., 2017, An Evidence-Based Review of HR Analytics. The International Journal of Human Resource Management, 28, 3-26.
[20] Kariyawasam, H., 2016, Relationship between Accounting Information and Human Resource Management Related Strategic Decision Making in Sri Lankan Manufacturing Companies. IOSR Journal of Business and Management, 18, 8-12. 


\title{
Tales of Early Childhood Education Teachers in Government Schools in Chipata, Zambia
}

\author{
Daniel L. Mpolomoka ${ }^{1 *}$, Moono, Muvombo ${ }^{2}$, Mutinta N. Matimba ${ }^{3}$, Tuke Chulu ${ }^{4}$, Joseph \\ Mate $^{2}$, Mubita Situmbeko ${ }^{2}$ \\ ${ }^{1}$ Research and Consultancy Unit, Zambian Open University, Zambia \\ ${ }^{2}$ School of Education, Nkrumah University, Lusaka, Zambia \\ ${ }^{3}$ Educationist and Consultant, Lusaka, Zambia \\ ${ }^{4}$ Education Standard Office, Chadiza District, Ministry of Education, Zambia
}

\begin{abstract}
This article houses findings of a study that uncovered the provision of early childhood education (ECE) in government schools with a bias towards learners with special education needs. It focused on challenges faced by teachers in providing educational services to children with special education needs at the early childhood education level in the targeted government schools. The rationale of the study was to solicit trends-in-practice among ECE teachers through their stories, thus partly help other teachers who shall read findings of this study tap into their engagements with ECE learners; and partly nurture children's development in a right way in early years. Qualitative methodology was used because it allowed for in-depth realities faced in 5 schools in Chipata. The study employed a descriptive research method for two years from 2016 to 2017, comprising five primary schools in Chipata District, Zambia, were conveniently sampled for the study. Interviews, focus group discussions, and questionnaires were used to collect data, which was analysed qualitatively. The study revealed challenges that are quite universal for teaching early childhood education learners. Teachers in this study expressed the need for reduced class sizes, adequate learning and teaching materials, teacher extrinsic motivation, additional support services from the government, and an accommodative curriculum. The study further revealed that early childhood education centres in government schools in Zambia at large have poor learning environments specially to support the learners with special education needs. The study showed that collaboration between early childhood education teachers and parents is necessary for the wellbeing of their children. The study recommends that the government should invest in infrastructure development for ECE centres; and that schools should purchase appropriate learning and teaching materials and stock ECE centres.
\end{abstract}

Keywords: Early Childhood, Learner, Schools, Special Education Needs, Teacher.

\section{Introduction}

Early childhood education, commonly referred to as ECE which, is a broad term used to describe the education programs of children in their pre-school years before they are old enough to enter grade one or elementary school. ECE is important because it is a stage that a child acquires basic language and numeric skills while contributing a child's fundamental foundation to cognitive, social, moral, physical spiritual and personality development. In Zambia, for a long time, early childhood education was only offered by private schools despite government training ECE teachers is some teachers training colleges. It was not until 2013 when the government 
decided to establish early childhood education centers across the country mostly in primary schools. This paper will, therefore, discuss challenges early childhood education teachers face in government schools.

Early Childhood Care and Education (ECCE) is defined as "service and programme that support children survival, growth, development, and learning including health, nutrition and hygiene and cognitive social, emotional and physical development from birth to entry into primary school" [1]. From this definition, it can be seen that early childhood education involves a lot of things because it is taken as a full package. It also serves as a preparatory phase for entry into primary school [2-4].

The introduction of early childhood education in Zambia was a good move because it meant that early childhood education was being earmarked to be available for all Zambian children [5-8]. However, only a small percent of the Zambian children population was benefiting from this programme, and these were children mostly from urban areas and from well-to-do families. Good as the move was, teachers of early childhood education in government schools are facing various challenges in their work.

\section{Statement of the Problem}

Most schools mandated to teach early childhood learners need to be furnished with adequate resources among other, recreation facilities, sensory equipment, books, in order to make the centres provide a conducive environment. Despite the emphasis by UNESCO in the Salamanca statement that every child must be provided with quality and relevant education [9], the overall quality of early childhood education in government schools in Zambia remains far below the expected standard $[7,8]$.

Lack of teaching facilities and inappropriate environment have a negative effect on the delivery on quality education provided to preschool learners, especially children with special education needs. In many schools, over- enrollment is eminent against few teachers who are expected to facilitate learning in most ECE centres.

\section{Objectives}

1. To establish approaches and methods used to teach early childhood learners in government schools.

2. To determine the extent to which parents of children in government early childhood education centres collaborate with early childhood teachers.

3. To establish common activities between private early childhood education centres and government schools.

\section{Rationale}

The rationale of the study was to tap into the tales of ECE teachers, thus cultivating the holistic development of a child's social, emotional, cognitive, and physical needs on the one hand, and build an enriched and firm foundation for lifelong learning and wellbeing, on the other.

\section{Materials and Methods}

A convenient sampling procedure was used for the study. This technique was chosen because it allowed for the target and selected ECE teachers in the schools with a bias to those teaching children with special needs. The study used a descriptive research method that took two years, 2016 - 2017 [10]. The selected schools were representative of early childhood learning in the primary school level of education. In addition, the selected schools for the study were representative of the social classes of the community also representative of all the income bracket groupings of the population in which the schools were located.

Ten (10) parents of children with special needs and twenty-five (25) selected teachers from five (5) schools participated in the study. The reason for selecting twenty-five (25) teachers was for the purpose of reducing the degree of bias during data collection. The researchers selected twenty-five (25) teachers 
from five primary schools, of which fifteen (15) were special education teachers while ten (10) were general education teachers.
The school's sample size consisted of five primary schools. These primary schools were Msekera Primary, Mpezeni, Nadalistika, St. Atanazio, and Katopola.

Table 1. School Categories, Schools and Population of Respondents

\begin{tabular}{|l|l|l|l|}
\hline School Category & Name of school & Community Class & School population \\
\hline \multirow{5}{*}{ Primary level } & Msekela Primary & Low-cost area & 1000 pupils \\
\cline { 2 - 4 } & Meena Primary & High-cost area & 1000 pupils \\
\cline { 2 - 4 } & Nadalistika Primary & High-cost area & 500 pupils \\
\cline { 2 - 4 } & St. Atanazio Primary & Low-cost area & 800 pupils \\
\cline { 2 - 4 } & Katopola Primary & Low-cost area & 1000 pupils \\
\hline
\end{tabular}

Unstructured questionnaires were distributed to and completed by respective teachers of special education and general education and, in some cases, senior teachers who were delegated authority by the headteacher. Other participants who responded to questionnaires were class teachers, school zonal coordinators, retired headteachers, and retired teachers. Focus group interviews were also conducted with some of the mentioned study participants.

Data was analysed qualitatively using themes guided by the research objective (thematic analysis). This method of data analysis was chosen because the larger part of the research findings were descriptive responses from the questionnaire and interviews.

\section{Results}

\section{Issues in Early Childhood Education}

The following is a presentation of results providing answers to the three research questions. The research findings were in the form of responses to the questionnaires. The information was drawn from parents and teachers with many years of experience in the education system. In order for early childhood education to be effective, the teacher-pupils ratio must be low and reasonable.

"There are few early childhood education teachers; hence, in a class, there are usually a lot of learners to be handled by one teacher, making it so difficult to focus on individual learners".

\section{Early Childhood Education Teaching and Special Education}

Results when teachers were asked on how they were managing early childhood education teaching. The findings indicated most teachers' inability to manage such classrooms as evident in the caption below.

'Sometimes the lack of specialized skills to handle some disabilities in case of a class with learners of different conditions' makes it difficult to effectively manage classes and children (School Administrators at school A, school C, and school D).

From the results on appropriate or relevant early childhood education training of teachers for learners with special needs, some parents interviewed revealed the following:

"For learners with Visual Impairment, mobility challenge is a common factor even at pre-school level, therefore there is need for personnel who can train these learners with selfmobility skills vital for play activities, both at home and at school."

From the research findings on playgrounds in schools, teachers in government schools said this:

The suitable playgrounds are either not there or not suitable for ECE children especially those with disabilities.

When teachers were asked on whether they had the appropriate infrastructure for ECE in 
centres, one teacher's sentiment was in tandem with other teachers views when she said that:

'There is generally lack of appropriate infrastructure in ECE centres as infrastructure is usually that which is meant for primary age groups.'

Further results on infrastructure showed that most pre-schools lack adequate sanitation, ventilation, clean water and food in order for ECE children to grow and develop physically, emotionally, socially, and mentally and be health. Most teachers said that most infrastructure was just adapted and not built for ECE; toilets for example, were not suitable for such young learners.

Results on prioritizing ECE, one parent further revealed that schools tend to support extra-curricular instead of investing in the programme of early childhood education.

'My child was diagnosed with a condition said to be cerebral palsy, he faces problems to access the toilet such that it's difficult to let child go to school alone without a helper to take him to the toilet especially the ones in primary schools. Schools need to invest in suitable toiles, but they seem to spend more on sports than on making sanitation facilities accommodative to all children', (Female Parent, Aged 47, Business Lady).

When it came to financial issues, it was revealed that most children in Zambia who are in government schools are from families who have financial challenges. And most parents cannot afford to take their children to pre-school, they thus wait until children reach primary school age.

Results indicated that the children's first language and his or her second language had an influence on ECE children, thus providing challenges in learning. Children learn local languages first, and then they are exposed to the learning of English. One teacher commented that:

'Learners with special needs find it difficult to adapt from local languages to English during the learning process. This situation was noted among children at school D' (Male, Special education teacher, aged 46, School $d_{2}$ ).

\section{Early Childhood Teachers and learners with Special Needs}

Teachers who teach children with special needs also face difficulties coming from the socalled 'normal' teachers or traditional teachers. An example of this cited by such teachers reveals the following:

'Teaching learners who are slow may require time, but normal teachers would attach a stigma to it and perceive work of special education teachers who teach learners with disabilities work as less important and because of their lack of understanding about the principle of working with small groups of children with disabilities.

Special education teachers find themselves having to do a lot of work, such as conducting assessment planning for the child's individualized education plan and a lot of other paperwork for each child's file.

'Every child with special education need requires an individualized program but looking at the pupil-teacher ratio, we fail to do all necessary paperwork like evaluating child's individual plan' (Female, Special education teacher, aged 37, School $A_{2}$ ).

\section{Community Support for Early Childhood Education}

The results pertaining homework given to children indicated that very few parents help the learner's homework.

'It takes time to teach, and the activities take more time too; I tried to help her with her homework, but the same homework was given to my child and neighbors; you find_my child can't color maybe only the teacher can manage, otherwise, at home, we have tried and have failed as we have other important tasks to do such as home chores' (Male Parent, Aged 50, a Farmer, whose child is autistic).

When it came to whether salaries had an influence on teaching, teachers in Zambian government schools indicated that the salaries 
are the same for teachers and that this was very unfair because teachers for E.C.E are most stressed and do a lot of work than any other teacher in the primary section. One teacher explained the following:

'In our case as special education teachers at our schools, we are supposed to attend to learners with disabilities sent to us by 'ordinary' teachers. We are supposed to handle such learners with disabilities despite having our own classes that we teach. This gives us more workloads, including planning for all learners plus those that need special attention like the blind and hearing impaired in our inclusive classes' (Teachers aged 34, 27, 24 school $A_{1}$, school $B_{2}$, and school $C_{1}$, respectively).

\section{Transport System - for ECE Learners}

The effective provision of quality early childhood education also faces the challenge of providing transport to the learners or children.

The government did well by establishing early childhood centres across the country, but the technocrats must have consulted wide enough, and there is a need to invest more money in this programme, especially in the transport facilities for ECE children and those with disabilities for this education to be successful (Female, aged 28, School $A_{1}$ ).

\section{Whose Mandate Should it be to Run ECE?}

On whose mandate is it to run ECE, results by teachers indicated that the government should leave early childhood education for private schools in urban areas and invest it in rural areas. It was also revealed that the government should provide financial and human resources to remote and rural early childhood centres.

From the focus group discussions on whose mandate is it in implementing ECE, Teachers explained that the school is also expected to play a key role in implementing early childhood education programmes.

This programme can also be successful if schools reserved a space for early childhood education and invested more in such by building modern infrastructures for early childhood education and provide security and transport (Male, aged 31, School $B_{2}$ ).

This can be a good move, and it can be like having two schools in one school. The challenges can then be alleviated, and early childhood education can be a success (Female, aged 40, School $C_{1}$ ).

\section{Discussion}

The discussion of findings is drawn from the results presented above.

\section{Issues in Early Childhood Education}

The findings on issues in early childhood education established that early childhood education in government schools faces several challenges, one of which is the lack of enough teachers and maids in government schools. Farrant [11] alludes to this when he states that many African schools have a shortage of teachers at all levels of education, the worst being the early childhood department. The Zambian Government has deployed some teachers of early childhood education in the country, but the number is very negligible and could not meet the demands of such teachers in public schools.

\section{Early Childhood Education Teaching and Special Education}

Most teachers interviewed stated that early childhood education is a very sensitive job that needs well-qualified teachers from recognized colleges and universities.

Further posits that a standard early childhood care education class must have two key personnel per setting; a teacher of early childhood education and a maid in attendance to assist the teacher in caring for children during the teaching and learning experiences [12].

A teacher will teach content and facilitate learning and play activities to the children in class while a maid takes care of children's welfare such as feeding, napping, toileting, general cleanliness, cleaning the class, and 
ensuring the safety of the children. To expect a teacher to deal with all these at the same time would be expecting too much from one person. This is worse for teachers teaching learners with special education as such learners demand more attention and care.

The Zambian government does not train or deploy any maids to schools. The teacher, therefore, does the teaching and the work that the maid is supposed to do. Teachers handling learners with special education needs are often overwhelmed especially when they handle inclusive learners in their classrooms.

From the findings in the focus group dissuasions, it was evident that teachers for early childhood education are finding it a challenge to play with children because there are no suitable playgrounds in most schools housing ECE children. Without appropriate playgrounds, early childhood education can never be effective and a good preparation for entry into primary schools. According to [13], a perfect pre-school needs to have a perfect playground with suitable playing equipment, a conducive environment, and with strict supervision. This is because, at pre-school, there are children who are aged 6 and below who can easily get hurt during play activities. Therefore, the most effective method of teaching and care should be involved or utilised during 'play' [8, 14-17]. This calls for government schools and teachers to ensure that there is a suitable playpark or playground at the school.

A Study contends that children in the kindergarten stage of pre-schools need proper sanitation, ventilation, and clean water food in order to grow and develop physically, emotionally, socially, and mentally and be healthy $[7-8,18]$. This is one of the basic needs in life, and children must have these in place [2, $3,7,8,19]$. In line with the findings, most government schools use latrines which are not suitable for children who are below the age of six because they are old models where a child has to squat. The structures of the schools are poorly ventilated are normally dusty and unclean as they are cleaned sometimes without disinfectants. On financial challenges, [1] states that most children in Africa who are in government schools are from families who have financial challenges. This is true in Zambia because records of children show that these learners are from a background of low socioeconomic status. As a result of this, children under early childhood education are unable to pay for their schools because the parents cannot afford the fees. The money realized from the fees of pre-school learners is not enough to sustain the running of the centres. Funding from the government is also inadequate, making it difficult for teachers to modify their teaching, especially for children with special needs.

From the discussions on education materials, the findings were in line with [20] statement that most children in African countries are not exposed to educational materials until they are about 10 years. This is one of the descriptors of the learners in Zambia. Children in Zambia start schooling at the age of 7 years, and they are not well developed cognitively, are too playful, their intelligence quotient IQ is low, especially those from families of low socio-economic status, lower and middle class. Children in Zambia mostly use the local language (LI) and very little of speaking English as an official language or learnt as a second language (L2).

Due to the challenges in learning the English language, Early childhood education has a lot of tasks as these children need to start from the beginning to learn things around them and be able to use instruments and equipment which seem to be new to them. The learner descriptors stated above need to be changed so that early childhood education is going children can be helped to become good at school activities and improve their livelihood status in future life and be able to speak the offered language, English.

\section{Early Childhood Teachers and Learners with Special Needs}

From the findings in the results, it is evident that dealing with multiple disabilities is one 
challenge teachers of early childhood education face as learners with disabilities exhibit unique disabilities. This calls for them to have a special education program planned yearly specifically modified to meet their learning needs to be called an Individualized Education Programme (IEP). The discipline of learners with special needs in a classroom is one challenge that teachers of early childhood learning face. Some learners may have behavioural issues, attention problems, being moody, to mention a few. This may need the teacher to understand the child and know how to help the child despite the large numbers of learners, especially in inclusive education [21-23].

\section{Community Support for Early Childhood Education}

In relation to community support for early childhood Education, what early childhood education teachers face is that some parents and communities are not helping them or supplementing their work. Some parents do not care about the education and welfare of the children and only leave the work for teachers. This is evident in the attitude of parents who would rather start investing their children's education at the primary level and not at early childhood education hence the low enrolment levels in some schools.

From the findings, most teachers explained that early childhood education is hard work. This is in line with findings by other scholars that the most hardworking teachers in any education system are teachers for early childhood education because their work involves taking care of babies by looking after them at all times, feeding them properly, teaching them, and ensuring that they are safe $[8,11,19,21,23]$.

\section{Motivation for ECE Teachers}

From the discussions, Early childhood teachers complained of meagre salaries. Like any other employee, salaries for early childhood teachers must be motivating enough to enable them to stay in the profession and perform their work well. Poor remuneration of ECE teachers can be seen as a challenge because teachers remain less motivated, and this is the reason why most teachers for early childhood education decide to upgrade so that they teach at other levels of education, namely primary or secondary. Unanimously, teachers also complained about the lack of support from administrators in terms of teaching and learning materials. The negative attitude from parents was another challenge, especially from rural areas, because they do not value the benefits of taking their children early to school. This led to low enrolment levels for children in rural areas.

\section{Transport System - for ECE Learners}

Early childhood education also faces the challenge of providing transport to the learners or children. A standard early childhood education must have, according to [12], a school transportation system where children can be transported from home to school, school to home, and on tours. This is not so in government schools because there are no transportation means such as school buses. Parents are the ones that take learners to schools, and they must pick up children from schools on a daily basis. This is the challenge the teachers face in government schools in trying to market their services as parents in urban areas prefer private ECE schools to government ones. But private schools have systems and have school buses and have employed drivers to pick learners from homes, taking them to schools and back home daily.

In order to improve the provision of ECE in government schools, especially those in rural areas, the Government of Zambia should provide a school bus and employ a driver to pick up children from their home and to take children on educational tours, a bus at least for every government school.

\section{Whose Mandate should it be to Run ECE?}

From the discussions on whose mandate is to provide ECE, teachers questioned the realism of 
government running ECE centres in rural areas. This is because many social-economic amenities do not follow such pronouncements and new establishments. Unanimously, teachers indicated that the government should leave early childhood education for private schools in urban areas and invest it in rural areas. It was also revealed that the government should provide financial and human resources to remote and rural early childhood centres.

\section{Infrastructure for ECE}

In relation to infrastructure, Zambia was found to be one of the countries in Africa were the infrastructure and facilities in government schools are not safe and conducive for early childhood education to be conducted. The infrastructure that accommodates the early child sections are as old as the primary schools when early childhood education started in 2013 [5, 8, 21, 23]. Finding further indicated that each school is also expected to play a key role in investing in ECE and implementing early childhood education programmes. The school can help by rehabilitating some classrooms for early childhood education, procuring relevant books and other learning materials, reserve an area for a suitable playpark. This is, however, hampered by the poor funding of the schools.

\section{Conclusion}

This article has brought out the plight of early childhood teachers in government schools. Amongst the challenges they face are the lack of resources and materials and appropriate infrastructures such as toilets, water points, classrooms, and playparks with relevant equipment. This includes the lack of teachers in some schools and maids, no transport and security, poor sanitation, and ventilation (toilets and bathrooms), poor enrolment in most government schools, and the parents' not paying school fees. Like most research findings in ECE, the findings of the study contend that the general provision of education services at the early childhood educational level needs a multisectoral approach so as to attend to the individual needs of children at the pre-school level if a holistic educational life is to be achieved. For instance, early childhood education for children with special education needs extra attention in terms of curriculum adaptation, teaching methods, assistive technology, assessment systems as well as other resources and funds in adapting to the school environment to suit the needs of ECE learners, especially those with special needs.

\section{Conflict of Interest}

None of the authors of this manuscript has declared any conflict of interest which may arise from being named as authors (on this manuscript).

\section{Acknowledgements}

This paper and the research behind it would not have been possible without the exceptional support of colleagues who have co-authored it. We also extend gratitude to Febby Mbewe and Phydes Nguni, whose invaluable input is highly appreciated. We further appreciate initial comments on the paper made various delegates when it was presented at the $6^{\text {th }}$ International Conference on Education for Sustainable Development (ICESD-2020) held at Kwame Nkrumah University, Kabwe, Zambia June 28 29, 2021. 


\section{References}

[1] United Nations Education, Scientific and Cultural Organization (UNESCO) (2010). The World Conference in Early Childhood Care and Education Building the Health of Nations. Paris: UNESCO.

[2] Tuntufye, S.M. (2014). Early Childhood Education in Africa. Mediterranean Journal of Science, Roma: MCSER publishing.

[3] Richter, L.M., Daelmans, B., Lombardi, J., Heymann, J., Boo, F. L., Behrman, J. R., Dua, T. (2016). Investing in the foundation of sustainable development: Pathways to scale up for early childhood development. The lancet.

[4] Mwanza-Kabaghe, S. (2015). Preschool, Executive functions, and Oral Language as Predictors of Literacy and Numeracy skills in First Grade. Ph.D. Thesis: Unpublished. University of Zambia.

[5] Mulunda, T.M. (2017). Provision of early childhood education to children with special educational needs in selected inclusive primary schools of Kabwe District, Zambia. Master of Education in Special Education dissertation, University of Zambia (Unpublished).

[6] MESVTEE (2013). Early Childhood Education National Policy (draft). Lusaka: MESVTEE.

[7] Matafwali, B. and Zingel, M. (2017). Early childhood development program for children affected by HIV and AIDS in rural Zambia. A report on the Program of Episcopal Relief \& Development and Zambia Anglican Council Outreach Programmes (ZACOP).

[8] Matafwali, B. and Munsaka, E. (2011). An evaluation of community-based early childhood Programmes in Zambia: A case of four selected districts. Journal of Early Childhood Development, 5, 109-131.

[9] UNESCO (1994). The Salamanca Statement and Framework for Action on Special Needs Education. Paris: UNESCO.

[10]Banda, S., Mpolomoka, D.L., Mbono, D. and Sampa, R.L. (2017). Use of questions in qualitative research: How questions guided our study, International Journal of Development Research, 7, (12).

[11]Farrant, J.S. (1980). Principles and practices of education. London: Longman.
[12] Clark, R.M. (2015). Childhood Education in society ( $2^{\text {nd }}$ Edition). London: Learning matters cetre. [13] Wesley, W.P. and Buysee, V. (2005). Consultation in Early Childhood Settings. Baltimore: PH Brookes.

[14] Lungu, S. and Matafwali, B. (2020). Play based learning in early childhood education (ECE) centres in Zambia: A teacher perspective. European Journal of Education Studies, 7(12), 356-369.

[15] UNESCO (2016). Education for people and planet: Creating sustainable futures for all, Global Education Monitoring Report. UNESCO: Paris.

[16] UNICEF (2018). Learning through play: Strengthening learning through play in early childhood education programmes. New York: UNICEF.

[17] United Nations Children's Fund (2019). A World Ready to Learn: Prioritizing quality early childhood education. New York: UNICEF.

[18] Chikopela, R., Chitundu, D. and Mpolomoka, D.L. (2020). Perceptions on Teachers in Commuter Marriages. Chalimbana University Multidisciplinary Journal of Research, 1(2)80-87.

[19] Mabenga, M.M. and Mpolomoka, D.L. (2017). Critical factors in early childhood education: policy and practice. Palgo Journal of Education Research, 5(4), 292-297.

[20] United Nations Educational, Scientific and Cultural Organization UNESCO (2006). Education for all. Global Monitoring Report Strong Foundation. Early childhood Care and Education. Paris: UNESCO.

[21]Zuilkowski, S. S., Fink, G., Moucheraud, C. and Matafwali, B. (2012). Early childhood education, child development and school readiness: Evidence from Zambia. South African Journal of Childhood Education, 2(2), 20.

[22]Fink, G., Matafwali, B., Moucheraud, C., Simmons-Zuilkowski, S. (2012). The Zambian Early Childhood Development Project: Round I Final Report. Cambridge: Harvard Center on the Developing Child.

[23] Fink, G., Zuilkowski. S.S, Matafwali, B. (2011). The Zambian Early Childhood Development Project: Round I Final Report. Cambridge, MA: Harvard Center on the Developing Child.

[24] Steven, B.S. (2001). Teaching Children in Elementary Courses and Schools. London: Longman. 


\title{
The Role Professional Accountant Firms play within the Liberian Market in Terms of Strategic Implementation of Financial Statement Audit
}

\author{
Jerome M. Kesselly \\ College of Business and Management, Texila American University, Monrovia, Liberia
}

\begin{abstract}
The study has evaluated the role Professional Accountant Firms play in the Liberian market and to understand the strategic tools used in implementing financial statement Audits [1]. A deductive approach was adopted, and information was collected from thirty respondents via Unstructured faceto-face interviews. Purposive sampling was engaged as this technique aided the cognizant arrangement of targeted respondents (Audit Associates, Staff Auditors, Semi Senior Auditors, Senior Auditors, Asst. Audit managers, Audit Managers, and Audit Partners). The findings show that Professional Accountant Firms in Liberia play a positive and significant role in the Liberian market. Professional Accountant Firms make great contributions in keeping Liberian businesses at full compliant with international financial reporting standards, legal and regulatory requirements, and their own policies and procedures. It is recommended that to be more efficient, Liberian businesses should embrace the role Professional Accountant Firms play within the Liberian market. It is concluded that the Liberia Institute of certified Public Accountants (LICPA) should strengthen, trained, and Licensed all Professional Accountant Firms to meet the growing need of the Professional Accounting industry in the Country.
\end{abstract}

Keywords: Professional Accounting Industry, Financial Statement, Reporting Standards, Liberian Businesses.

\section{Introduction}

The role professional accountants play in business is to examine the quality of financial reporting. [2] It is the management's responsibility for the financial information. Like their counterparts in taxation or auditing, professional accountants in business play important roles that contribute to the overall stability and progress of society. Without a public understanding of all these diverging roles and responsibilities of different accounting specialists working in business, public perceptions of their value may be misinformed.

Accountants are trained in the theory and practice of accounting and in the Analysis and evaluation of the company's business accounts through an Audit. Accountants typically evaluate annual reports, other periodic reports, and financial statements for planning, decisionmaking purposes, and investment opportunities. Accountants performed an independent examination of evidence from which the financial statements of a business or other entities are derived in order to give the reader of such financial statement's confidence as to the truthfulness and fair presentation of the affairs of the entity as disclosed in the financial statements [3].

Professional Accountants in Liberia are authorized by a statutory body, the Liberia Institute of Certified Public Accountants (LICPA) in the country to practice as individual, or as a firm, holding a practicing Licensed. The institute is the accounting standard-setting body 
in Liberia, established by an Act. The act was established by the institute to represent, promote, and regulate the accountancy profession in Liberia, in the public interest [4].

\section{Methodology}

In this study, both primary and secondary data were collected and analyzed. An unstructured questionnaire was developed to collect responses from professional accountants working in various professional firms within Liberia, precisely Monrovia. Also, face to face meetings was held with Audit Associates, Staff Auditors, Semi Senior Auditors, Senior Auditors, Assistant Audit managers, Audit Managers, and Audit Partners from different Professional Accountant Firms in Liberia, Baker Tilly Liberia, BICON, Inc., Deon, and Noed International (DnI) Liberia LLC, Farhat Carew Inc., Pan African Consultants, Parker \& Co., LLC, PKF-Liberia, PricewaterhouseCoopers Liberia (PwC), Seekie \& Associates, SovConsult Limited, T. D. Joseph \& Associates (now Crowe Liberia LLC), MGI-Monbo \& Company, and Gedei \& Associates [5]. All the respondents from those firms were asked questions at their level within their respective firms. Regarding the secondary, data were collected from the Liberia Institute of Certified Public Accountants Official site [6].

Based on the data collected and analyses to define the conclusion of the topic, hereafter, this study has been presented by using a qualitative approach with an emphasis on interview report analysis to derive the qualitative result. The qualitative study is anchored on the distinct understanding of the methodological traditions of enquiry that evaluate social or human issues. The qualitative study work postulates an empirical view by understanding social issues to describe and understand human behavior (Timmermans, S. Tavory, I (2012) [7].

\section{Literature Review}

The idea of professional accountancy came about when petitioners were induced to form themselves into a Society called the Institute of Accountants in Edinburgh, with a view to unite into one body, those at present practicing the profession, and to promote the objects which they entertain in common; and that the Petitioners conceive that it would tend to secure in the members of the profession, the qualifications which are essential to the proper performance of its duties, and would consequently conduce much to the benefit of the public [8]. Today, Competent professional accountants now become a valuable asset to Accounting firms, their working is based on their knowledge of various company's financial statements, Audit, and advisory services. Using their skills and intimate understanding of companies and their control environment. Their training in accounting and Auditing enables them to adopt a pragmatic and objective approach to solving issues, provide advice, and help businesses to strengthen their internal controls in order to prevent losses. Professional accountants represent the interest of their firms. Their roles ordinarily include investigating financial statements for errors and fraud, performing audits on operations, and reporting on findings, and expressing opinions on Audit Reports [9].

\section{The Credibility of Professional Accountant Firms}

The services provided by Professional Accountant Firms in the country is to have an independent view express an opinion on an institution's financial statements [10]. The professional Accountant assesses whether the financial statements are prepared, in all material respects, in accordance with an applicable financial reporting framework and whether they present fairly the financial position of an organization. They serve as a framework for credible and high-quality professional accountancy organizations focused on serving the public interest by adopting, or otherwise incorporating, and supporting the 
implementation of international standards and maintaining adequate enforcement mechanisms to ensure the professional behavior of their individual members [11].

\section{Education and Certification Capacity for Professional Accountants}

Professional Accountant firms in Liberia need systems of certification that include appropriate entry criteria, professional accountancy education, assessment, practical experience, and continuing professional development (CPD) requirements in line with International Education Standards (IESs) [12]. Although many professional accountant firms in Liberia have made significant gains in this area, additional assistance is needed to target weaknesses, build human capacity in the area of accountancy, and provide higher quality in performing financial statement Audits for both public and private sectors.

Those assistances could also help support the creation of formal systems to undertake the process of translating and incorporating updates to international standards on a timely basis. Additionally, those supports should be directed toward the design, development, and operation of the systems of certification, quality assurance, oversight, investigation, and discipline will further the implementation of international standards and enhance the realization of their benefits, both the firms and clients within Liberia.

\section{Further Implementation of International Standards by professional Accountant firms in Liberia}

Although many businesses in Liberia have adopted international accountancy standards through the LICPA (e.g., International Standards of Auditing, International Financial Reporting Standards, International Public Sector Accounting Standards, and the Code of Ethics for Professional Accountants), the inappropriate modification of standards by many businesses in Liberia may cause serious deficiencies in the application of standards and may reduce their international comparability, consistency, and cross-border understanding.

Experience has shown that a solid understanding of the following standards is essential when auditing client's financial statements. (See Table 1).

Table 1. Audit process as per ISA Standard

\begin{tabular}{|l|l|}
\hline Code & Standards \\
\hline ISA 200 & Audit Planning \\
\hline ISA 230 & Audit Documentation \\
\hline ISA 240 & $\begin{array}{l}\text { Auditor's Responsibilities Relating to Fraud in an Audit of Financial } \\
\text { Statements }\end{array}$ \\
\hline ISA 250 & Consideration of Laws and Regulations in an Audit of Financial Statements \\
\hline ISA 260 & Communication with those Charged with Governance \\
\hline ISA 265 & $\begin{array}{l}\text { Communicating Deficiencies in Internal Control to Those Charged with } \\
\text { Governance }\end{array}$ \\
\hline ISA 300 & Audit Risk Assessment \\
\hline ISA 315 & $\begin{array}{l}\text { Identifying and Assessing the Risks of Material Misstatement Through } \\
\text { Understanding the Entity and its Environment }\end{array}$ \\
\hline ISA 330 & The Auditor's Responses to Assessed Risks \\
\hline ISA 320 & Materiality in Planning and Performing an Audit \\
\hline ISA 620 & Using the Work of an Auditor's Expert \\
\hline ISA 700 & Forming an Opinion on the Financial Statements \\
\hline
\end{tabular}


The Work of a Professional Accountant Firm in Liberia is Guided by Professional Standards

International Standards of Auditing (ISA) are widely recognized as high-quality standards for the performance of audits of financial information by professional Accountants firms in Liberia. They are issued by the International Auditing and Assurance Standards Board (IAASB), and most jurisdictions use ISA as their national or benchmark norms for auditing.

In July 2015, the Governing Council of the Liberia Institute of Certified Public Accountant (LICPA) issued Regulation 1: Professional Standards and Related Practice Statements that, among other things, adopted International Financial Reporting Standards (IFRS) as the accounting framework in Liberia effective 31 December 2018, with earlier application encouraged. (The effective date of Regulation 1 was initially 31 December 2016, but the LICPA subsequently amended that to 31 December 2018.) [13].

Public Perception of the Role of Professional Accountant Firms in Liberia

Sections 8, 9, and 16 of the LICPA Act stipulate that the LICPA is responsible for the adoption of ethical requirements and that the Code of Professional Ethics is appropriately responsive to the needs of stakeholders that rely on the work of accountants. Furthermore, Section 16 stipulates that LICPA should be in compliance with the requirements of IFAC's SMO 4 relating to the adoption of the IESBA Code of Ethics. This is a concern with the degree of responsibility for detecting fraud, legal irregularities, and other matters that are not within the financial reporting area [14]. In the Liberian context, the expectation gap can also relate to assurances on the effectiveness of LICPA regulations. An unmodified audit report may be mistakenly perceived as a clean bill of health to businesses in the country. Under ISA, however, Professional Accountant firms express their opinion only on whether the financial statements are prepared, in all material respects, in accordance with the applicable accounting framework. While a report on internal controls (i.e., a management letter) may also be provided, the professional Accountant firms are concerned with fraud and control weaknesses that cause a material misstatement in the financial statements [15].

\section{Professional Accountant Firms Approach to Executing an Audit Engagement}

Most of the professional Accountant firm's approach is top-down and risk-based, emphasizing planning and a thorough understanding of client operations, that is to Identify and test controls intended to address the risks of material misstatement; Test the design and effectiveness of management review controls; Obtain evidence needed to update test results on controls in the roll-forward period; Test controls on data and reports that themselves to support other important controls, and Sufficiently evaluate control deficiencies [16].

\section{Result and Discussions}

There were thirty-two (30) respondents that partake in this study. Audit Associates, Staff Auditors, Semi Senior Auditors, Senior Auditors, Assistant Audit managers, Audit Managers, and Audit Partners from different Professional Accountant Firms in Liberia were interviewed (See Table 2). The questionnaire was tailored as per different levels within the Professional Accountant firms. During our discussion with the respondents, they pointed out how important their roles are within the industry in turn of financial statement Audit and how effective their recommendations have help strengthen businesses in the country. 
Table 2. List of Respondents and Firms

\begin{tabular}{|l|l|l|l|}
\hline Firm Name & Position & $\begin{array}{l}\text { Year of } \\
\text { Experience }\end{array}$ & $\begin{array}{l}\text { Number of } \\
\text { Respondents }\end{array}$ \\
\hline Baker Tilly Liberia & Audit Managers & $7-10 \mathrm{yrs}$ & 2 \\
\hline BICON, Inc. & Audit Seniors & $5-6 \mathrm{yrs}$ & 5 \\
\hline $\begin{array}{l}\text { Deon and Noed International (DnI) } \\
\text { Liberia LLC }\end{array}$ & Audit Seniors & $4-6 \mathrm{yrs}$ & 3 \\
\hline Farhat Carew Inc. & Audit Associates I\&II & $1-2 \mathrm{yrs}$ & 4 \\
\hline Pan African Consultants & Audit Associates I\&II & $1-2 \mathrm{yrs}$ & 3 \\
\hline Parker \& Co. LLC & Asst. Audit Managers & $5-7 \mathrm{Yrs}$ & 2 \\
\hline PricewaterhouseCoopers Liberia (PwC) & Audit Partners & $10 \mathrm{yrs}$ & 2 \\
\hline Seekie \& Associates & Audit Seniors & $4-6 \mathrm{yrs}$ & 1 \\
\hline SovConsult Limited & Semi Senior Auditor & $4-6 \mathrm{yrs}$ & 1 \\
\hline $\begin{array}{l}\text { T. D. Joseph \& Associates (now Crowe } \\
\text { Liberia LLC), }\end{array}$ & Asst. Audit Managers & $5-7 \mathrm{Yrs}$ & 3 \\
\hline MGI-Monbo \& Company & Staff Auditors & $2-4 \mathrm{yrs}$ & 3 \\
\hline Gedei \& Associates & Audit Seniors & $4-6 \mathrm{yrs}$ & 1 \\
\hline Total Respondents & \multicolumn{2}{|l}{} \\
\hline
\end{tabular}

Source: Field data report (Oct. 2021)

\section{Discussion on the Role Professional Accountant Firms Play in Liberia}

$90 \%$ of the respondents find the profession unique. They stated that the best place to start a career in the profession is at a professional accountant firm. According to the Audit Manager at Baker Tilly Liberia, the firm recruits young accountants from universities and trains them to become professional accountants by given them the opportunity to participate in professional exams and attend professional Auditing webinars. He further stated that the firm is responsible for financing the Audit staff professional exams and webinars as a way of capacity building for Liberian working at various accountant firms to be more efficient and effective during the Audit engagement. 98\% also claimed that the accountant firms are hired by businesses in the country to review and audit their financial statements. According to Sarah Ovaska, becoming a professional accountant takes intention and effort, but the rewards for joining the profession known for its trustworthiness and rigor are numerous for those who meet the requirements [17].

\section{Discussion on the Implementation Process of Financial Statement Audit}

According to the Audit Senior at Crowe Liberia, when the firm is successful in winning an audit engagement contract from a client, an engagement letter is prepared and send to the client to execute the Audit. In executing an Audit engagement, the firm goes through the four stages of the Audit process: Plan the Audit; a pre Audit questionnaire (survey or preliminary review questions) is prepared, this process is performed to assess the risks of the client entity, and it environment; perform fieldwork, before carrying out the fieldwork, the Audit team holds an entry meeting with the client in order to understand the client operations, carryout test of controls and substantive testing procedures to ascertain whether there were fraud or control weaknesses within the client's organization that cause a material misstatement in the financial statements; reporting, during the reporting stage of the audit engagement, management letter is provided to the client highlighting issues that are a risk to the organization and issue of best practice. The last stage of the Audit process is 
the follow-up, where previous Audit recommendations are reviewed based on changes made in status (e.g., Implemented; not implemented; ongoing). [17]

\section{Recommendation}

It is critically important to for professional Accountant firms to incorporate more females into the profession in order to reduce the gender gaps. To do that, professional accountant firms should change their strategy by approaching universities in the country and pinpointing potential females majoring in accounting in their early junior year and offering them internship opportunities to develop a passion for the profession by becoming Audit managers and partners. It is recommended that for better decision making by business owners, there is a need to have professional accountant firms to review and investigate businesses financial information for prompt decision-making thus performing Financial Statements Audit as essential to business enterprise in the country.

\section{Conclusion}

It is imperative clearer for businesses to adopt the use of having professional Accountant firms in the country to review and investigate their financial information's in order for prompt management decision making. It is becoming increasingly crucial for professional accountant firms to focus more on training and developing young female accountants to be more effective and efficient in performing full Audit engagement. A financial statement audit is the examination of business financial statements and accompanying disclosures by an independent auditor (professional Accountant Firm). The result of the examination is a report by the auditor attesting to the fairness of the presentation of the financial statements and related disclosures. It can also be used to add credibility to the reported financial position and performance of businesses in the country.

Table 3 below highlights that the selected population has enough experience in financial Statement Audit, of which $23 \%$ has up to ten years' experience and serving in the position of Audit managers with the ability to managed more than five to six Audit Engagements at the same time. It also shows that there is enough Audit managers working at various professional Accountant firms in Liberia.

Table 3. Year of Experience

\begin{tabular}{|l|l|l|l|}
\hline \# Of Respondents & Year of Experience & Age Group & $\mathbf{\%}$ \\
\hline 7 & $1-2 \mathrm{yrs}$ & $18-25 \mathrm{Yrs}$ & $23 \%$ \\
\hline 3 & $2-4 \mathrm{yrs}$ & $30-35 \mathrm{Yrs}$ & $10 \%$ \\
\hline 11 & $4-6 \mathrm{yrs}$ & $36-45 \mathrm{Yrs}$ & $37 \%$ \\
\hline 7 & $7-10 \mathrm{yrs}$ & $46-50 Y r s$ & $23 \%$ \\
\hline 2 & 10 yrs. above & 50 and Above Yrs. & $7 \%$ \\
\hline
\end{tabular}

Sources: Field data report (Oct. 2021)

Figure 1 below of this study indicates that $77 \%$ of the respondents from the various professional accountant firms were male, and
$23 \%$ were female. Hence, this is evident that there are gender gaps within the professional accountant firm in Liberia (Field data). 


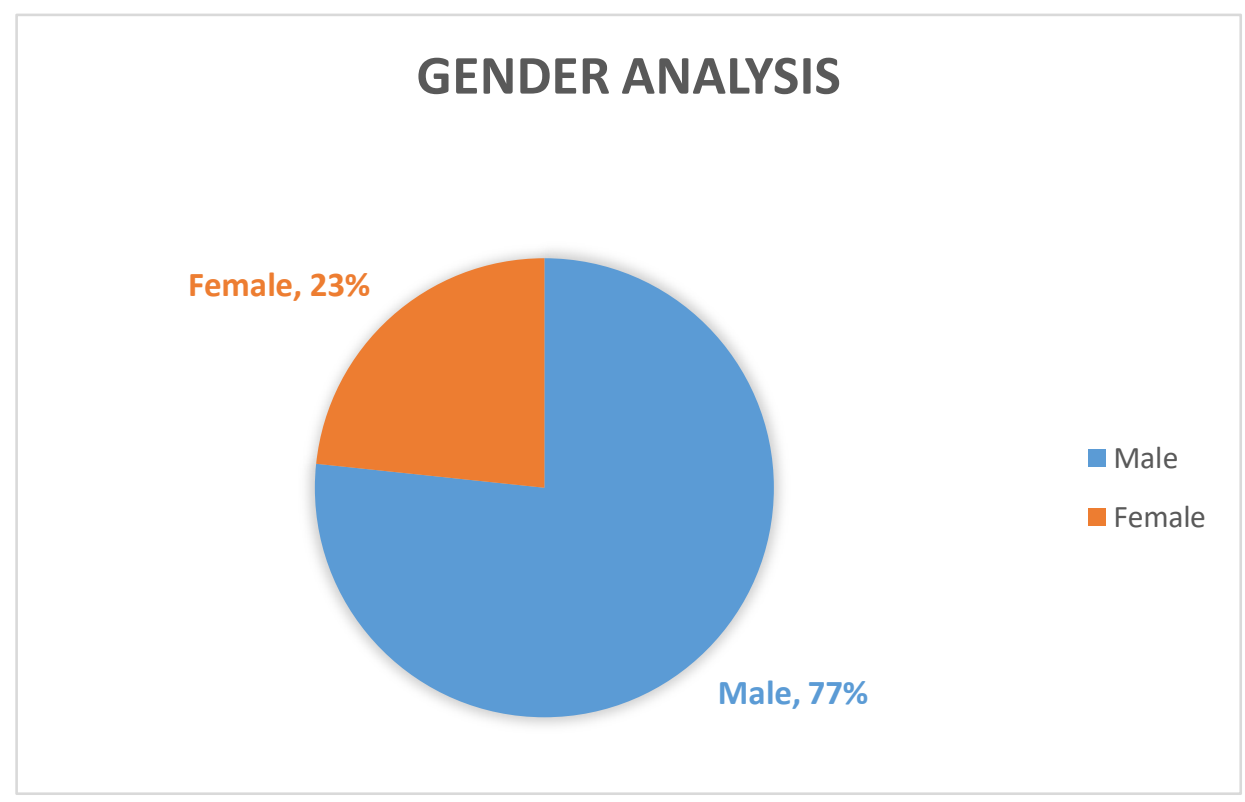

Figure 1. Respondents by Gender group

Sources: Field data report (Oct. 2021)

Figure 2 below shows that $37 \%$ of the overall population of professional accountants between the age 36 to $45 \mathrm{yrs}$ of age hold Senior Auditor positions in professional Accountant firms in
Liberia. The data collected shows that most of these respondents are from an accounting background.

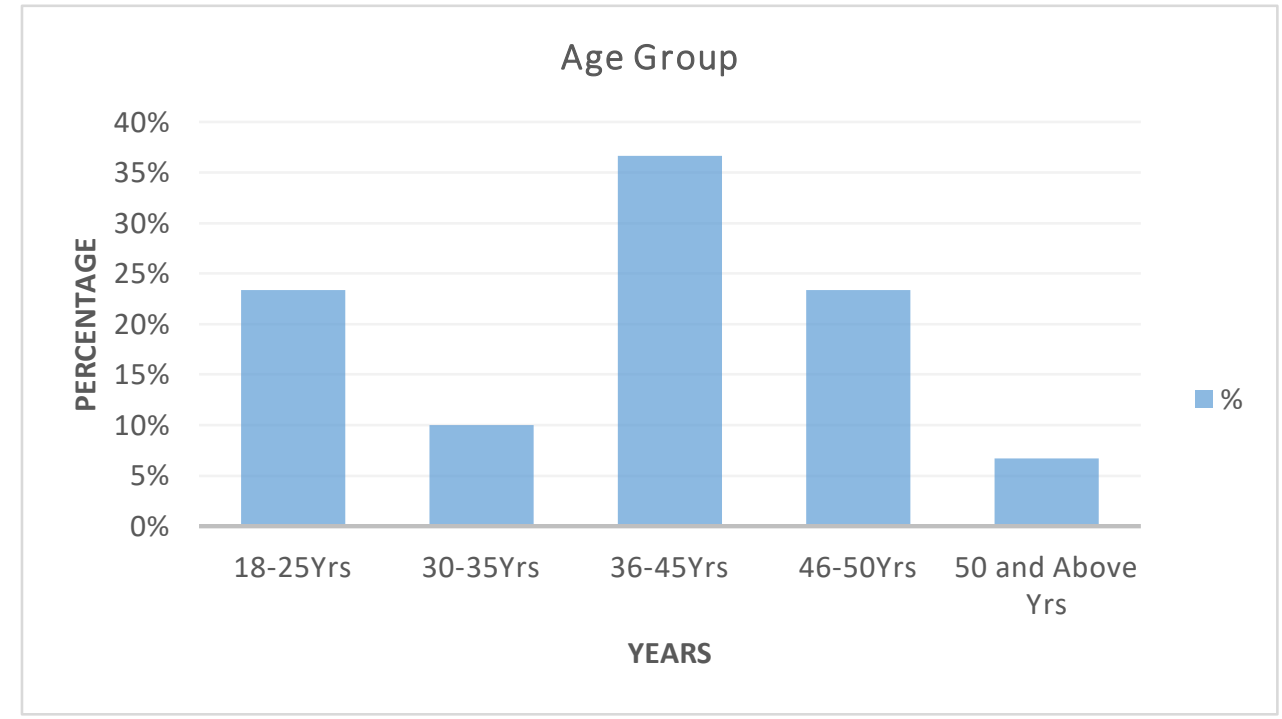

Figure 2. Respondents by Age Group

Sources: Field data report (Oct. 2021)

\section{Conflicts of Interest Statement}

This paper Title: The Role Professional Accountant Firms play within the Liberian Market in terms of strategic implementation of Financial Statement Audit.
The author, whose name is mentioned immediately below, certified that he has NO affiliation with or involvement in any institution with the financial interest, such as honoraria; educational grant; employment; or non-financial interest such as personal or professional 
relationship, affiliations in the subject matter, or materials discussed in this paper.

\section{Acknowledgment}

The Author of this research would like to take this time to thank the Almighty for giving him

\section{References}

[1] Teri Saylor, 2020. Developing a strategic audit plan Retrieved From:

https://www.journalofaccountancy.com/newsletters/

2020/nov/developing-strategic-audit-plan.html.

[2] Len Jui, CPA, MBA, and Jessie Wong, CPA, Ph.D., 2013, Roles and Importance of Professional Accountants in Business Retrieved From: https://www.ifac.org/about-ifac/professionalaccountants-business/news-events/2013-10/rolesand-importance-professional-accountants-business.

[3] Wiki Accounting, Management Responsibilities on Financial Statements Retrieved From https://www.wikiaccounting.com/managementresponsibilities-on-financial-statements/.

[4] The LICPA Act (2011) P 25-26 Retrieved From: https://www.moci.gov.lr/doc/Certified\%20Public\%2 0Accountants.pdf.

[5] The LICPA Member Firm Retrieved From: https:/licpa.org.lr/index.php/firm-membership/.

[6] The LICPA Official Site Retrieved From: https://icpa.org.lr/index.php/downloads/.

[7] Timmermans, S. Tavory, I. (2012). Theory construction in Qualitative Research Retrieved From grounded theory. To abductive Analysis sociological theory, $\quad 30, \quad 167-186 . \quad$ Googles scholar/sage/journal/ISI.

[8] Institute of Chartered Accountants of Scotland, Royal Charter of 1854 and Supplementary Charter of 1951, Scotland: ICAS, 1854 and 1951, accessed, 2013 Retrieved From:

http://icas.org.uk/CharterRulesRegulationsafter10July/.

[9] AS 2810, Evaluating Audit Results Retrieved From:

https://pcaobus.org/oversight/standards/auditingstandards/details/AS2810. the strength and knowledge in doing this work. And the staff of various Professional Accountant firms in Monrovia in helping with all the necessary pieces of information for the success of this study.

[10] Kimberlee Leonard, 2019. What Services Are Provided by Accounting Firms Retrieved From: https://smallbusiness.chron.com/services-providedaccounting-firms-62323.html.

[11]IFAC Report, 2020. the credibility of professional accountant firm Retrieved From https://www.ifac.org/aboutifac/membership/members/liberian-institutecertified-public-accountants.

[12]IAESB Report, 2018, P4 Retrieved From: https://www.ifac.org/system/files/publications/files/I AESB-International-Education-Standard-7_0.pdf. [13]Regulation 1 IFRS, 2018 Retrieved From: https://www.ifrs.org/use-around-the-world/use-ofifrs-standards-by-jurisdiction/viewjurisdiction/liberia/.

[14] The LICPA Act, 2011 Sections 8, 9, and 16 Retrieved

From: https://www.moci.gov.lr/doc/Certified\%20Public\%2 0Accountants.pdf.

[15] ISA 700 (revised), forming an opinion and reporting on financial statements Paragraphs 25-26 deal with the phrases used to express this opinion in the case of a fair presentation framework and a compliance framework, respectively. Retrieved From:

https://www.ifac.org/system/files/publications/files/I SA-700-Revised 8.pdf.

[16]Resolver official Site Retrieved From: https://www.resolver.com/resource/developing-atop-down-risk-based-approach-to-sox.

[17] Sarah Ovaska (2021) Retrieved From: https://www.journalofaccountancy.com/news/2021/n ov/bright-future-young-cpas.html. 


\title{
4Dimensional X Strain and 2Dimensional Speckle Tracking Echocardiographic Study: Normative Values of Strain Parameters of Left Ventricle and Tissue Doppler Imaging of Ascending Aorta in Healthy Adults -A Single Centre Indian Study
}

\author{
Akhil Mehrotra $^{1 *}$, Ajay Sharma ${ }^{2}$, Mohammad Shadab $^{2}$, Mukesh Srivastava $^{3}$, \\ Naveen Chandra ${ }^{4}$, Alok Kumar Singh ${ }^{5}$. \\ ${ }^{1}$ Ph.D in Cardiology, Texila American University, India \\ ${ }^{2}$ Prakash Heart Station and Diagnostics, Lucknow, India \\ ${ }^{3}$ Central Drug Research Institute, Lucknow, India \\ ${ }^{4}$ Vivekanand Hospital Lucknow, India \\ ${ }^{5}$ Heart India Journal, Varanasi, India
}

\begin{abstract}
Global longitudinal strain $(G L S)$ is a sensitive measure of $L V$ dysfunction and is better than EF at predicting CVD events and deaths. Recently 3D/4D/4D X strain speckle tracking echocardiography (STE) is used to analyse complex LV mechanics. Interestingly, HFpEF is related to both GLS and increased Aortic stiffness. TDI of ascending Aorta is an effective technique to assess Aortic stiffness. The aim of the present study is to establish normal values of TDI of AA by $2 D E$ and $4 D X$-strain volumetric and strain parameters of LV of healthy adults. 102 subjects were enrolled, 72 assessed by 2DE-GROUP-A, and 30 were analysed by $4 D X$-strain echocardiography-GROUP-B. Important TDI parameters of Aortic stiffness were $3.90 \pm 3.79 \& 5.23 \pm 10.55,(p=N S)$, in males \& females respectively and Aortic strain were $10.55 \pm 7.67 \%$ and $9.49 \pm 5.56 \%,(p=N S)$, in males \& females respectively. Volumetric data of EF were $64 \pm 7.0 \%$ \& $65 \pm 6.0 \%,(p=N S)$, in males \& females respectively and CO were $5.6 \pm 1.5 \mathrm{l} / \mathrm{min} \& 4.91 \pm 1.53 \mathrm{l} / \mathrm{min},(p=N S)$, in males \& females respectively. Moreover, $4 D$ $X$-strain STE indices of GLS being -17.29 $\pm 2.71 \&-19.00 \pm 3.51,(p=N S)$, in males \& females, respectively GCS being $-15.46 \pm 7.1 \&-14.12 \pm 6.15,(p=N S)$, in males \& females respectively and GRS being $-24.53 \pm 9.8 \&-21.93 \pm-8.81,(p=N S)$, in males \& females respectively. No previous data is available, making the research a singular experience.
\end{abstract}

Keywords: 2Dimensional Speckle Tracking, 4Dimensional X Strain echocardiography, Echocardiography, LV segmental strain, $4 D$ volumetric data.

\section{Introduction}

Left ventricular (LV) function can be evaluated using directional components of myocardial deformation or strain. Longitudinal LV strain, also referred to as global longitudinal strain (GLS), appears to be a sensitive measure of impaired LV systolic function [1-3] and has been shown in several studies to be better than ejection fraction at predicting cardiovascular disease events and death [4-7]. Recently, 3Dimensional Speckle Tracking Echocardiography (3D STE) has been introduced by applying speckle tracking technologies to 3D echocardiography images. Images are usually acquired using a matrix-array transducer from the apical position in a wideangled acquisition "full-volume" mode. In this

*Corresponding Author: sadhnamehrotra14@gmail.com 
mode, a number of wedge-shaped subvolumes are acquired over consecutive cardiac cycles during single breath-hold and stitched together to create one pyramidal volume sample. A major limitation of 3D STE to date is the temporal resolution of the volumetric pyramidal data sets. Usually, the rate of acquisition does not exceed 20-30 volumes/s, and, in most cases, to obtain a higher temporal resolution, the field of view needs to be considerably narrowed. By fusing 2D speckle tracking information obtained from standard apical $4 \mathrm{CH}, 2 \mathrm{CH}$, and $3 \mathrm{CH}$ views, $\mathrm{X}$ -
Strain $^{\mathrm{TM}}$ four-dimensional (4D) aims to make myocardial quantification imaging interpretation easier by the 3D/4D reconstruction of the $\mathrm{LV}$. The Beutel can be freely rotated, zoomed, and super imposed on the echocardiographic scanning planes to better evaluate the contractility properties of the LV, using a physiological tool to analyze the complex multidimensional LV mechanics [7], including a parallel assessment of myocardial regional and global function (Figure 1).

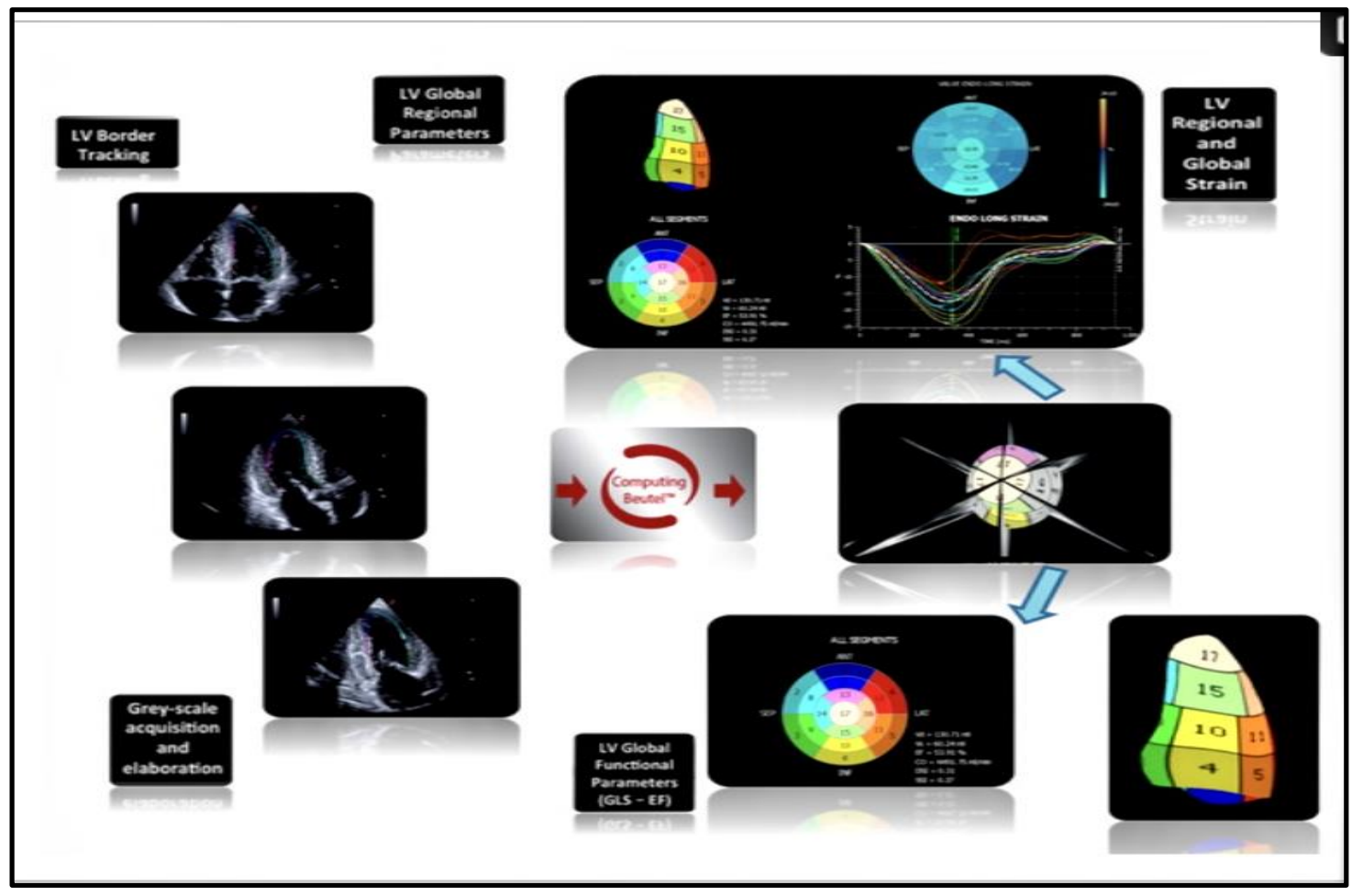

Figure 1. X Strain Global LV Analysis

Longitudinal shortening of the LV produces aortic displacement during systole [8-10] and stretches the ascending Aorta [11]. The force required to produce a longitudinal strain of the Aorta represents an often-overlooked form of direct mechanical load on the LV that may have important implications for the relation between aortic stiffness and LV systolic function, particularly in the long axis. [11, 12]. Alterations in both LV and aortic physiology may play an important role in predisposition to heart failure and especially heart failure with preserved ejection fraction (HFpEF). Whereas HFpEF is almost as common as heart failure with reduced ejection fraction, HFpEF has proven relatively refractory to treatment in a number of randomized clinical trials [13-15] underscoring the importance of efforts to better understand its pathophysiology. Interestingly, HFpEF has been related to both reduced GLS and increased aortic stiffness in a number of prior studies [3, 16-20]. Furthermore, both HFpEF and aortic stiffness are prevalent in older individuals, particularly women [16, 17] suggesting possible pathophysiological links between aortic stiffness and subclinical alterations in LV systolic 
function that may promote the development of HFpEF in susceptible individuals.

Several procedures have been used for the determination of aortic stiffness and or/distensibility, such as MRI, Angiography, applantation tonometry, Velocity vector imaging (VVI) [22-25]. But the vast majority of this technique was invasive and time-consuming and may require complex equipment and training. Tissue Doppler imaging (TDI) echocardiography of AA has been analysed in a number of studies and was found to be a useful method in the evaluation of elastic properties of Aorta [26, 30]. Increased arterial stiffness index has been formerly determined in various patient groups, including those with $\mathrm{CAD}$, diabetes mellitus, overt hypothyroidism, and on different vascular beds and at different sites such as the radial artery, carotid artery, and Aorta [27-33]. As earlier stated, 4D XSTRAIN $^{\mathrm{TM}}$ echocardiography is a reliable, intuitive, affordable, and simple tool for quantification of regional myocardial function [7]. Studies regarding normal reference values of $\mathrm{LV}$ volumetric and strain parameters by $\mathrm{X}$ strain 4DE and TDI indices of AA by 2DE in healthy adult population could not be found despite exhaustive and thorough review of the literature.

Hence, we embarked on this study of Indian healthy adults without overt cardio-vascular disease, with the aims to establish normal values of LV volumetric and strain parameters by 4D X strain echocardiography and moreover of TDI parameters of AA by 2D echocardiography. To the best of our knowledge, there is no study published till date on normal reference values of volumetric and strain parameters of LV by $4 \mathrm{D} X$ strain echocardiography and neither any on TDI parameters of AA by 2DE, in the healthy adult population and, more importantly, in Indian subsets.

\section{Materials \& Methods}

\section{Study Population \& Design}

The present study was performed at Prakash Heart Station \& Diagnostic, Lucknow, India an approved centre of Texila American University for the current Ph.D. Cardiology program of the author. We state that our study confirms to the ethical guidelines of the 1975 declaration of Helsinki and that informed consent has been obtained from the study participants (or their guardians), and final approval was done by our Prakash Heart Station \& Diagnostic Institutions' Ethical Committee.

The study comprised of 426 healthy adult subjects from which 324 cases were excluded due to inferior image quality, and 102 participants were finally enrolled for the study after a careful selection process, during a period of spanning for 7 months from May to November 2021.

Healthy adults of age group 18-60 years, of either sex, were included if they were asymptomatic, free from overt cardiovascular disease, not receiving any drugs, non-smoker, non-tobacco chewer, non-diabetic, nonhypertensive according to JNC-8 guidelines, having normal thyroid and lipid profile, normal resting ECG in Sinus Rhythm with a normal 2 Dimensional color echocardiography and Treadmill Stress ECG with a normal physical examination, BMI- 23 or less, waist- size $85 \mathrm{~cm}$ or less in men and $80 \mathrm{~cm}$ or less in women. Those individuals were excluded if there was the presence of thyroid disease, valvular heart disease, history of cardiac rhythm abnormalities, heart failure systemic hypertension, and significant pulmonary hypertension. Moreover, the presence of diabetes mellitus, neurological or psychiatric illness, malignany, CAD Aortic root abnormalities, and aortic dilatation lead to the exclusion of such participants from the present study.

\section{Biochemical \& Hormonal Assessment}

Blood samples were withdrawn, in the morning, after 12 hours of overnight fasting for HBAIC, T3, T4, TSH, Serum creatinine, Serum uric acid, Total cholesterol (TC), Triglycerides (TG) \& high-density cholesterol (HDL-C). Serum Low-density Lipoprotein cholesterol 
(LDL-C) was calculated according to Freidwald's formula [34].

\section{Echocardiography Imaging}

In the current study, 2Dimensional echocardiography system of GE HEALTH CARE -VIVID T8 was utilized for comprehensive assessments of cardiac functions in left lateral decubitus position for M-MODE, 2D mode, Doppler, Global Longitudinal Strain analysis of LV by Speckle Tracking Echocardiography (STE) \& Tissue Doppler Imaging of Ascending Aorta from May 1 September 9, 2021, and the data of the enrolled 72 healthy subjects was obtained (2D group Group A). From September 10, 2021 - Nov 30, 2021, 30 additional healthy subjects were enrolled for a similar exhaustive evaluation of cardiac functions on MY LAB X7 4D $\mathrm{X}$ STRAIN echocardiography machine of ESAOTE, ITALY (4D X STRAIN group GROUP B). In addition to the procurement of data as in Group A, GLS, Global circumferential strain (GCS), strain rate (GCSR), Global Radial strain (GRS) strain rate (GRSR), and volumetric data by 4D X Strain echocardiography was further derived. The study on both the echocardiography machines was performed with consistent system presets, according to the prespecified protocols $[35,36]$.

A minimum of 3 cardiac cycles were recorded. Standard LV APICAL views (APLAX, 4CH \& $2 \mathrm{CH}$ views) were acquired, avoiding foreshortening with a frame rate of 50 - 80 frames/sec, thus compatible with speckle tracking analysis. For TDI, images were obtained from LV septal and lateral MV annulus walls in $4 \mathrm{CH}$ views and from the superior wall of ascending Aorta $3 \mathrm{~cm}$ above the aortic valve in the parasternal long-axis view. Similarly, 3 $\mathrm{cm}$ above the aortic valve, systolic and diastolic inner diameters of as ascending Aorta were recorded by M-MODE echocardiography. Aortic systolic diameter (AOS) and diastolic aortic diameter (AOD) were measured [Figure 2]. Distensibility and stiffness index of the ascending Aorta were calculated by using the following formula's [37-40]:

1. AORTIC DISTENSIBILITY $=2 \mathrm{X}$ AOS$\mathrm{AOD} /[(\mathrm{SBP}-\mathrm{DBP}) \mathrm{X}$ AOD (10-6 cm2 dyn1)].

2. AORTIC STIFFNESS INDEX: $\ln$ $(\mathrm{SBP} / \mathrm{DBP}) /[$ (AOS - AOD)/AOD] (pure number),

3. $\ln =$ natural logarithm.

4. AORTIC PULSATILE CHANGE $=$ AOS AOD $(\mathrm{cm})$.

5. AORTIC SYSTOLIC INDEX will be estimated by dividing AOS, AOD and pulsatile.

6. AORTIC DIASTOLIC INDEX change by BSA respectively.

7. AORTIC PULSATILE INDEX.

8. ELASTICITY MODULUS $=(\mathrm{SBP}-\mathrm{DBP}) /$ [(AOS - AOD)/ AOD] $(\mathrm{Pa})$.

9. AORTIC STRAIN $=(\mathrm{SAO}-\mathrm{AOD}) \mathrm{X} 100 /$ AOD (\%).

Following data was estimated by TDI of the superior wall of ascending aorta - (Figure - 3).

1. SAO - Aortic superior wall velocity in systole- will be calculated at the same point used in M-mode measurement.

2. EAO- Early diastolic velocity.

3. AAO- late diastole velocity.

LV myocardial deformation was analysed offline by the Speckle Tracking software package.

1. 72 subjects in GROUP A were analysed by GE-VIVID T8 2D Echocardiography software package AFI 2.0 echopac version 202. The transducer used was adult probe $35 \mathrm{c}-\mathrm{RS}(1.3-4.0 \mathrm{Mhz})$.

2. 30 subjects in GROUP B were analysed by $\begin{array}{lllll}\text { MYLAB } & \mathrm{X} 7 & 4 \mathrm{D} & \mathrm{X} & \text { STRAIN }\end{array}$ echocardiography software package $\mathrm{X}$ STRAIN TM advanced technology with TOMTEC GMGH 3D/4D rendering and Beutel $^{\mathrm{TM}}$ computation compatibilities [55]. Imaging was performed by $1-5 \mathrm{Mhz}$ electronic single-crystal array transducer. Speckle Tracking Echocardiography (STE) 
was performed to analyse appropriate images, acquired, and captured according to the standardized protocol [35, 36]- (Figure $4,5)$.

\section{Statistical Methods}

The data were summarized as mean $\pm \mathrm{SD}$. The $95 \%$ confidence interval $(\mathrm{CI})$ of the mean was also calculated. The mean of male and female was tested by t-test for independent groups. The level of significance used was 0.05 . A higher t- value having a probability smaller than 0.05 was marked significant. A p-value smaller than 0.01 was marked highly significant.

\section{Result}

The study comprised of 426 healthy adults, from which 324 were excluded due to inferior image quantity on echocardiography. 102 subjects were finally enrolled for the study after a careful selection process, during a period spanning 7 months from May - November 2021.

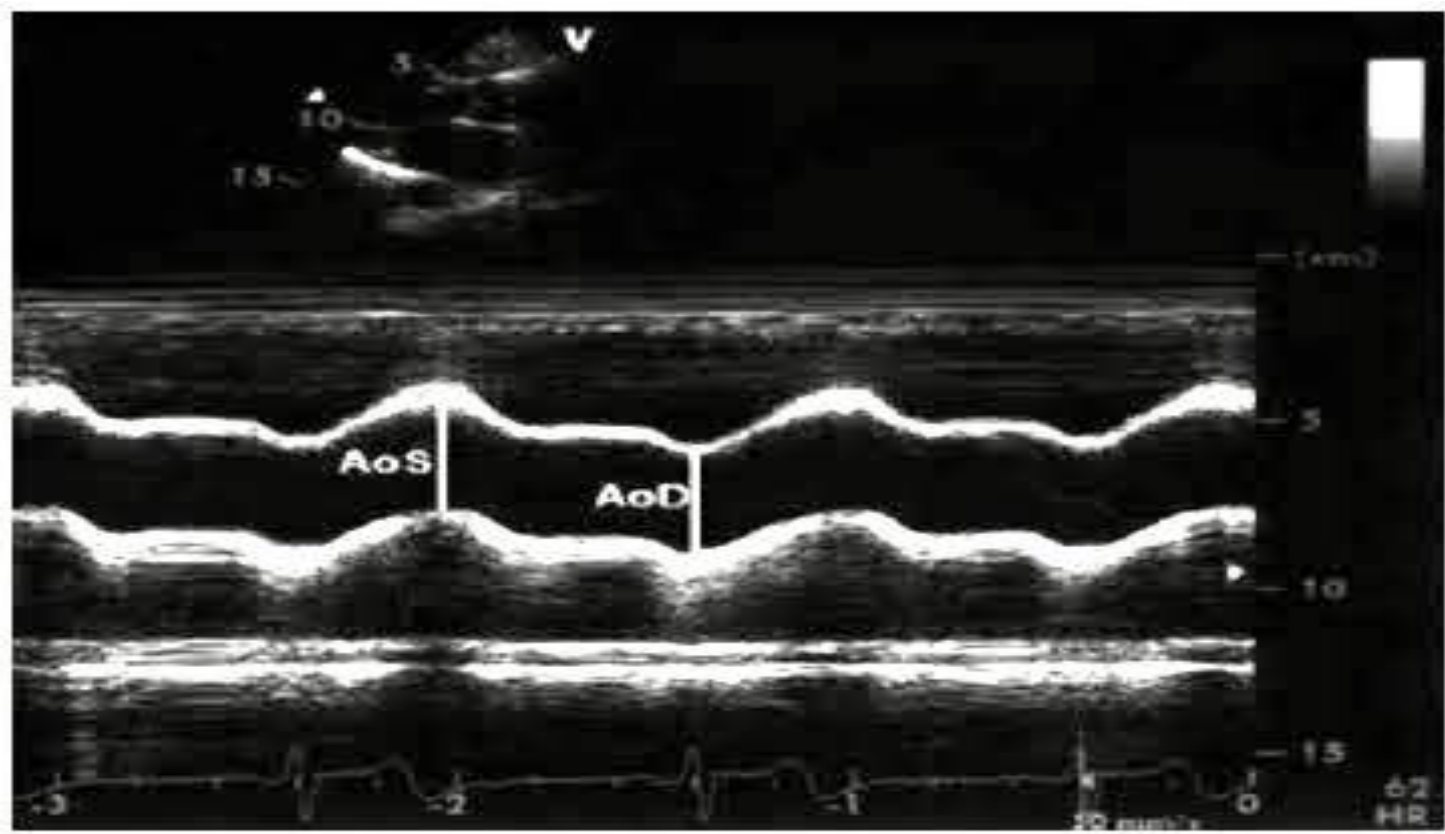

Figure 2. M Mode of Ascending Aorta

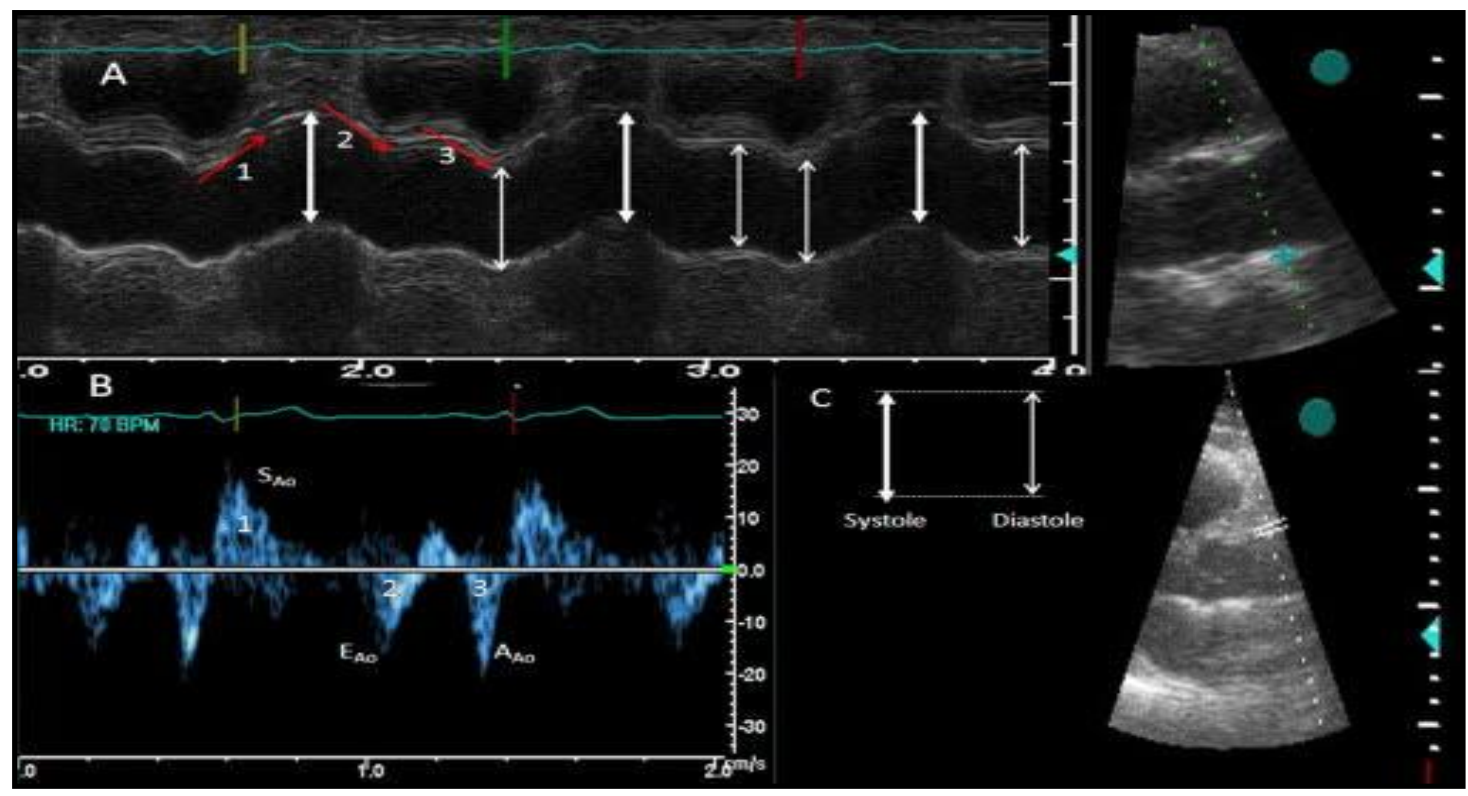

Figure 3. M-Mode and TDI of Ascending Aorta 


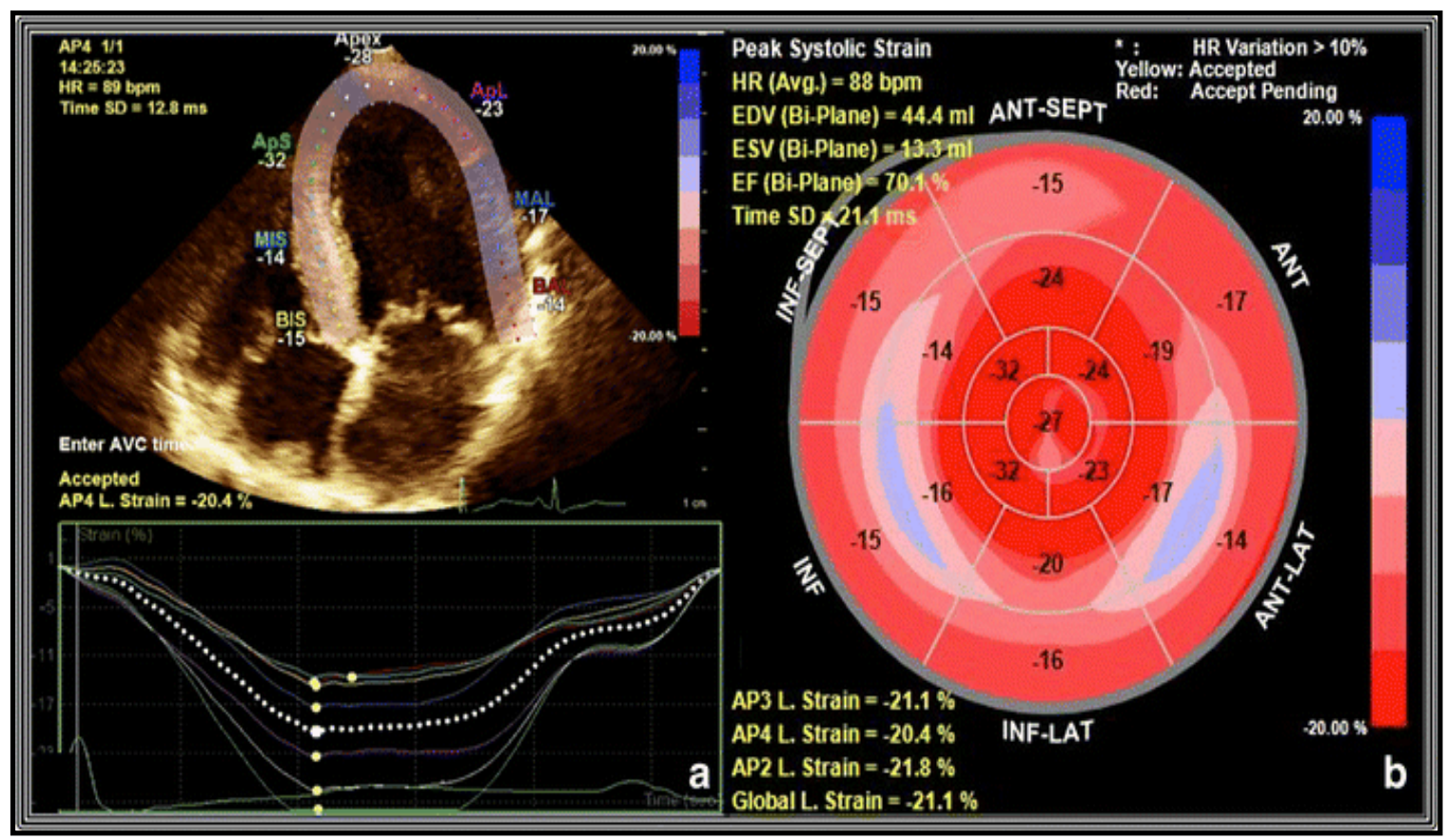

Figure 4. Speckle Tracking Echocardiography Images

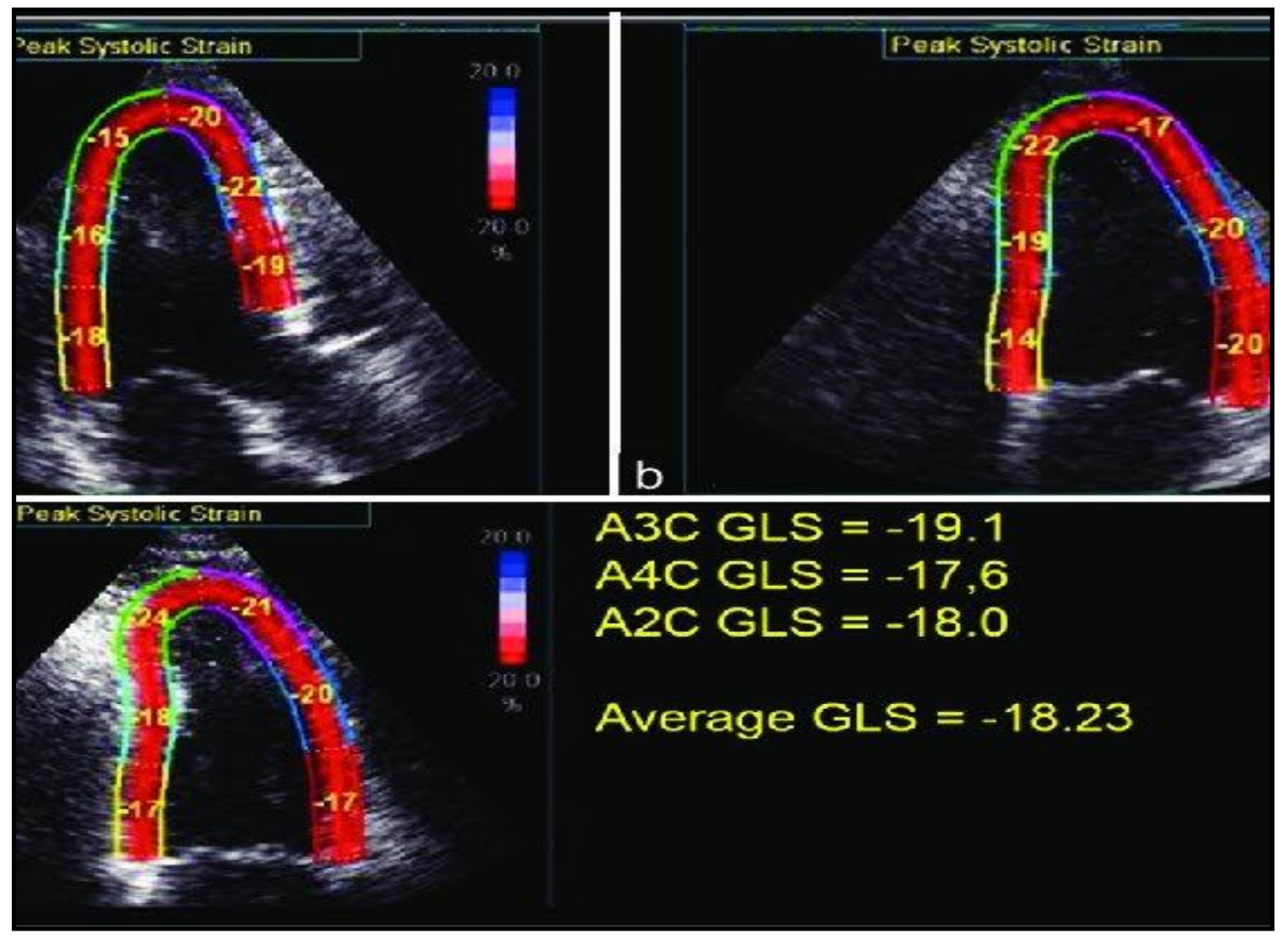

Figure 5. Speckle Tracking Echocardiography Images

Table 1 shows the characteristics of the study population of the 102 participants 72 consisted of the 2D group-Group A, and additionally, 30 subjects constituted the 4D group -Group B. In group A there are 44 males (age $32.55 \pm 9.63$ years) and 28 females (age 29.11 \pm 11.83 years). In group B, there are 16 males (age 38.81 \pm 12.94 years) and 14 females (age $38.50 \pm 11.65$ years). 


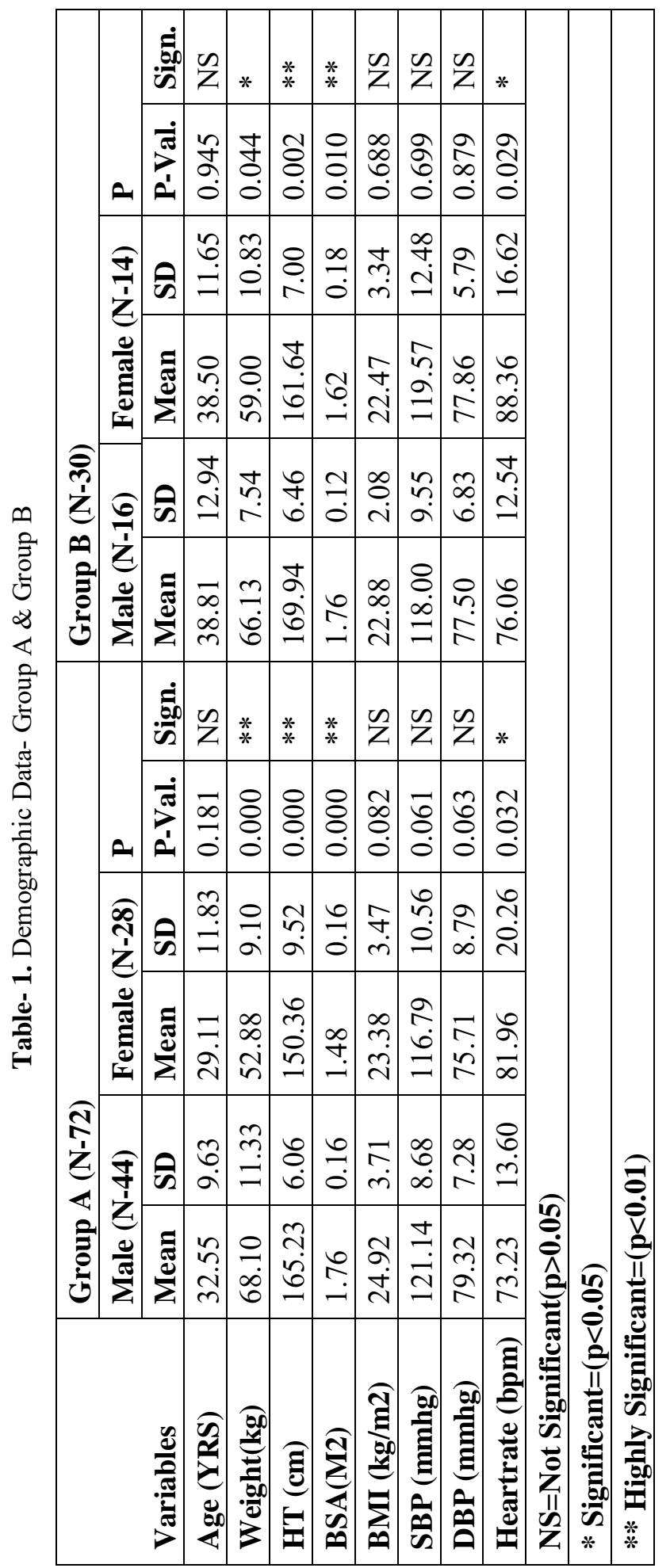

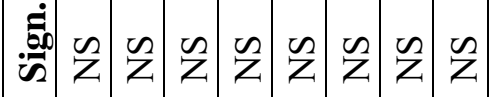

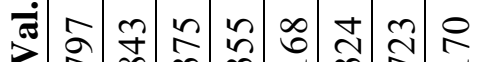

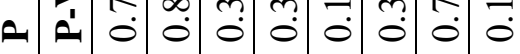

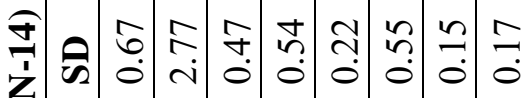

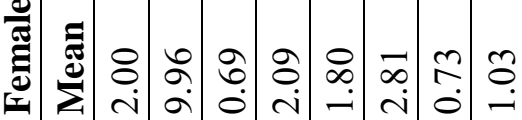

$\infty$

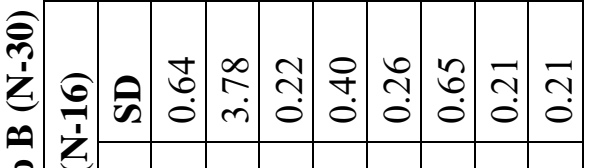

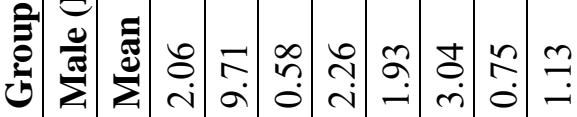

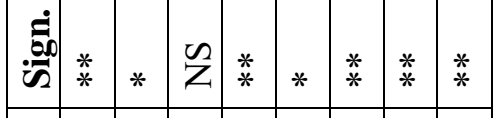

至

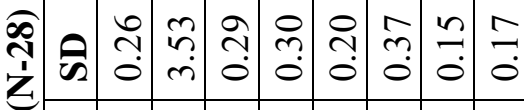

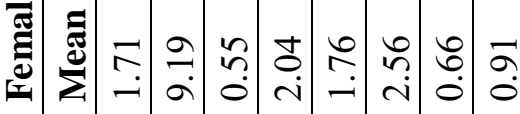

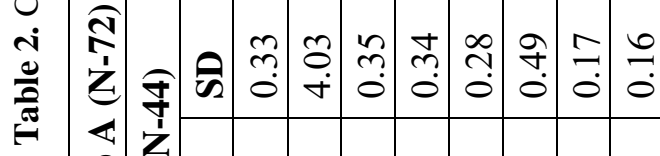

言竎离

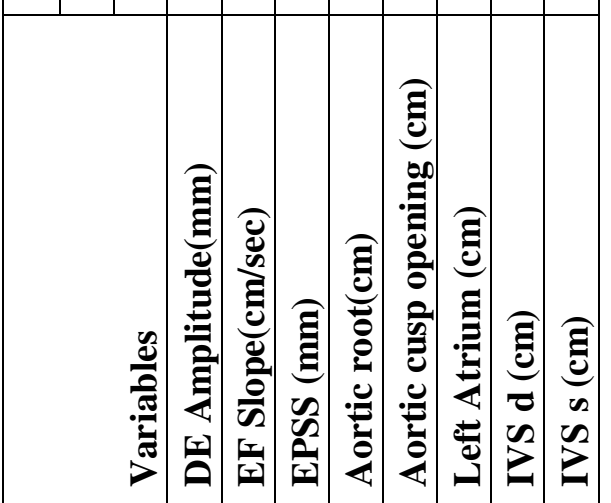




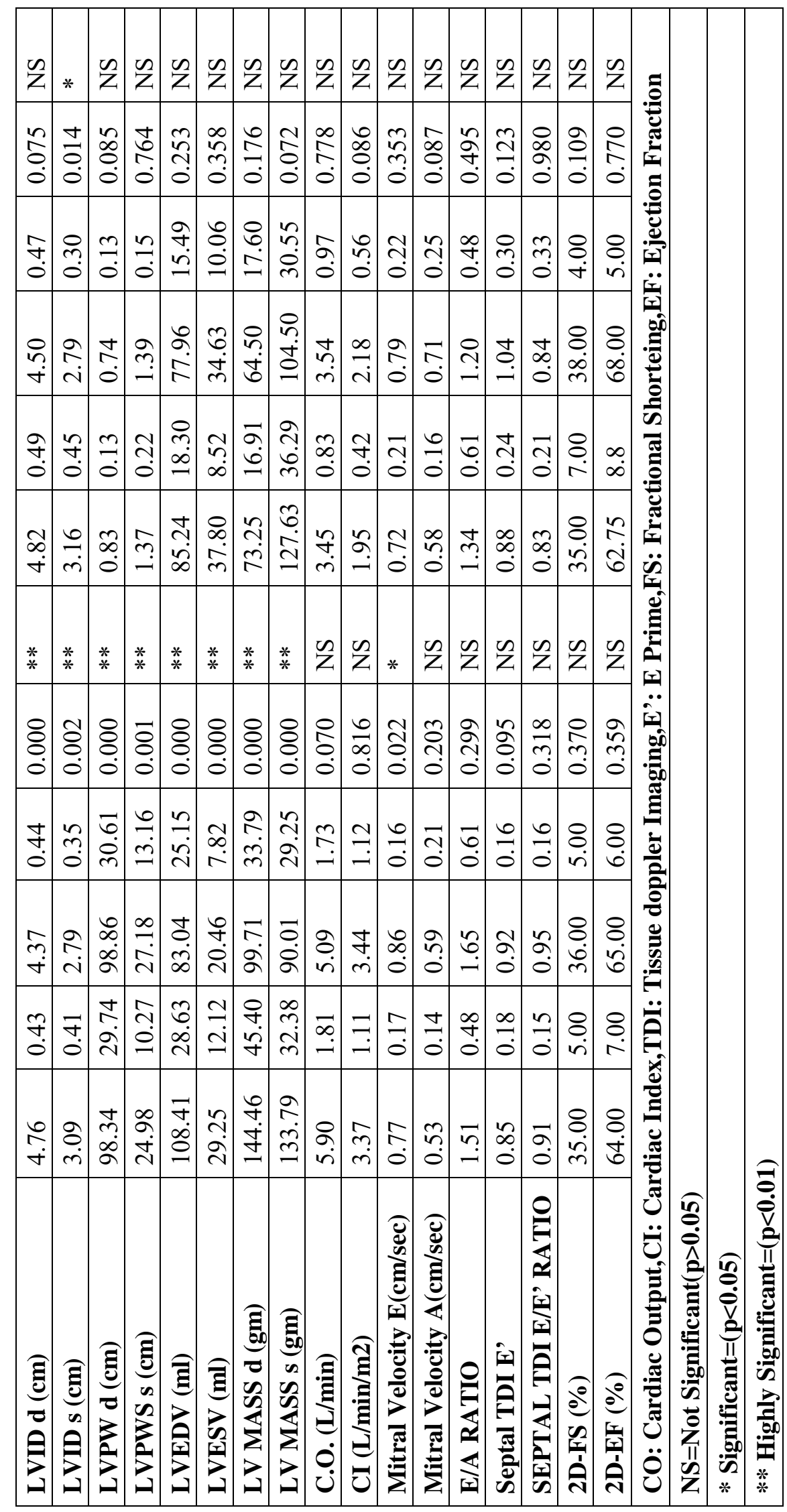


Table 2. Comprising of the conventional 2D echocardiographic data. In group A the LVEDV is $108.41 \pm 28.63 \mathrm{ml}$ in males $83.04 \pm 25.15 \mathrm{ml}$ in females $(\mathrm{p}<0.01)$, LV Mass is $144.46 \pm 45.40$ $\mathrm{gm}$ in diastole in males and $99.71 \pm 33.79 \mathrm{gm}$ in females $(\mathrm{p}<0.01)$, Cardiac output $(\mathrm{CO})$ being $5.90 \pm 1.81 \mathrm{1} / \mathrm{min}$ in males and $5.09 \pm 1.73 \mathrm{1} / \mathrm{min}$ in females ( $\mathrm{p}=\mathrm{NS})$ and $\mathrm{EF}$ is $64 \pm 7 \%$ in males and $65 \pm 6 \%$ in females $(\mathrm{p}=\mathrm{NS})$. In group B, the LVEDV is $85.24 \pm 18.30 \mathrm{ml}$ in males and $77.96 \pm 15.49 \mathrm{ml}$ in females ( $p=$ NS), LV Mass in diastole being $73.25 \pm 16.91 \mathrm{gm}$ in males and $64.80 \pm 17.60 \mathrm{gm}$ in females ( $\mathrm{p}=\mathrm{NS}), \mathrm{CO}$ is $3.45 \pm 0.83 \mathrm{~L} / \mathrm{min}$ in males and $3.54 \pm 0.97$ $\mathrm{L} / \mathrm{min}$ in females $(\mathrm{p}=\mathrm{NS})$ and $\mathrm{EF}$ is $62.75 \pm 8.8$ $\%$ in males and $68 \pm 5 \%$ in females $(\mathrm{p}=\mathrm{NS})$.

In Table 3. data of various parameters of TDI of AA and GLS of LV are enumerated in detail. In group, A pulsatile change, Aortic distensibility, Aortic stiffness index, Aortic pulsatile index, Aortic systolic and diastolic index, Aortic strain, and elasticity modulus did not reveal any significance in their values when the data of male subjects was compared to females $(p=N S)$. However, the Aortic diastolic diameter (AOD) \& Systolic diameter (AOS) were significantly higher in males when compared with females. The AOD \& AOS in males being $2.79 \pm 0.45 \mathrm{~cm}$ and $3.05 \pm 0.49 \mathrm{~cm}$ respectively, when compared to females, who had a AOD \& AOS of $2.49 \pm 0.37 \mathrm{~cm}$ and 2.72 $\pm 4.40 \mathrm{~cm}$ respectively $(\mathrm{p}<0.01)$. Furthermore, the average GLS values in group A males is $16.64 \pm 1.90 \%$ and $-17.87 \pm 2.1 \%$ in females suggesting that GLS values is higher in healthy adult females. $(\mathrm{p}<0.05)$.

Likewise, elaborate data values of a various parameter of TDI of AA GLS of LV of Group B is presented. It is important to note that the values are not significantly different in between male $\&$ female subjects $(\mathrm{p}=\mathrm{NS})$.

In Table 4. 2D volumetric data of Group A and 4D volumetric data of Group B are summarized. The Group A values of LVEDV, $\mathrm{EF}, \mathrm{CO}$ have already been mentioned earlier while discussing Table 2. 4D volumetric data of group B shows the sphericity index values in males is $0.44 \pm 0.13$ and $0.37 \pm 0.15$ in diastole $\&$ systole, respectively. In females the sphericity index values are $0.39 \pm 0.09$ and $0.33 \pm 0.11$ in diastole and systole $(\mathrm{p}=\mathrm{NS})$, LVEDV being $85.24 \pm 18.30 \mathrm{ml}$ in males and $77.96 \pm 15.49 \mathrm{ml}$ in female ( $\mathrm{p}=\mathrm{NS}$ ) LVESV being $37.80 \pm 8.5 \mathrm{ml}$ in males and $34.63 \pm 10.06 \mathrm{ml}$ in females $(\mathrm{p}=$ NS) and EF being $55.56 \pm 5.53 \%$ in males and $56.21 \pm 6.58 \%$ in females $(p=N S)$, respectively. 


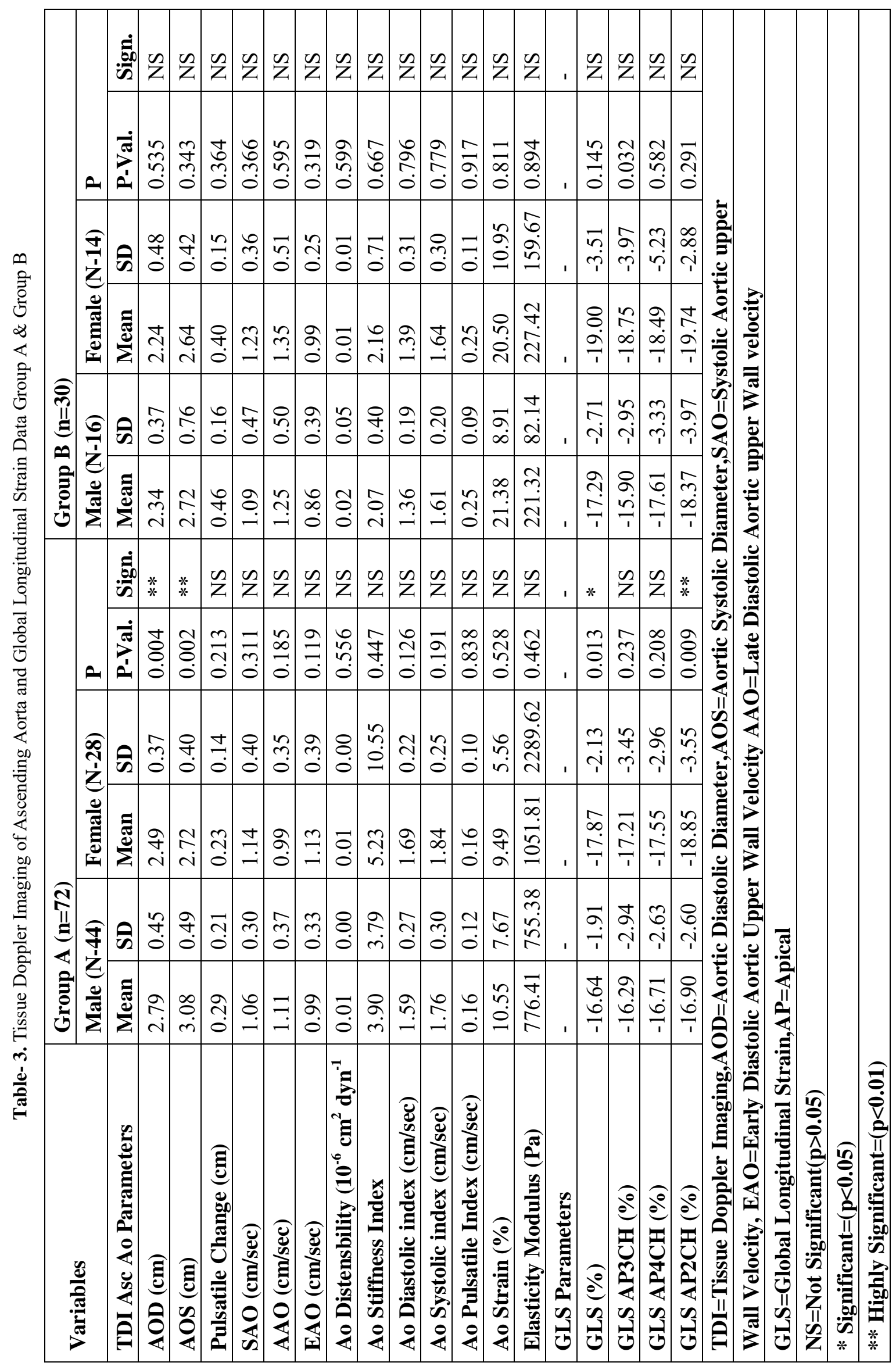




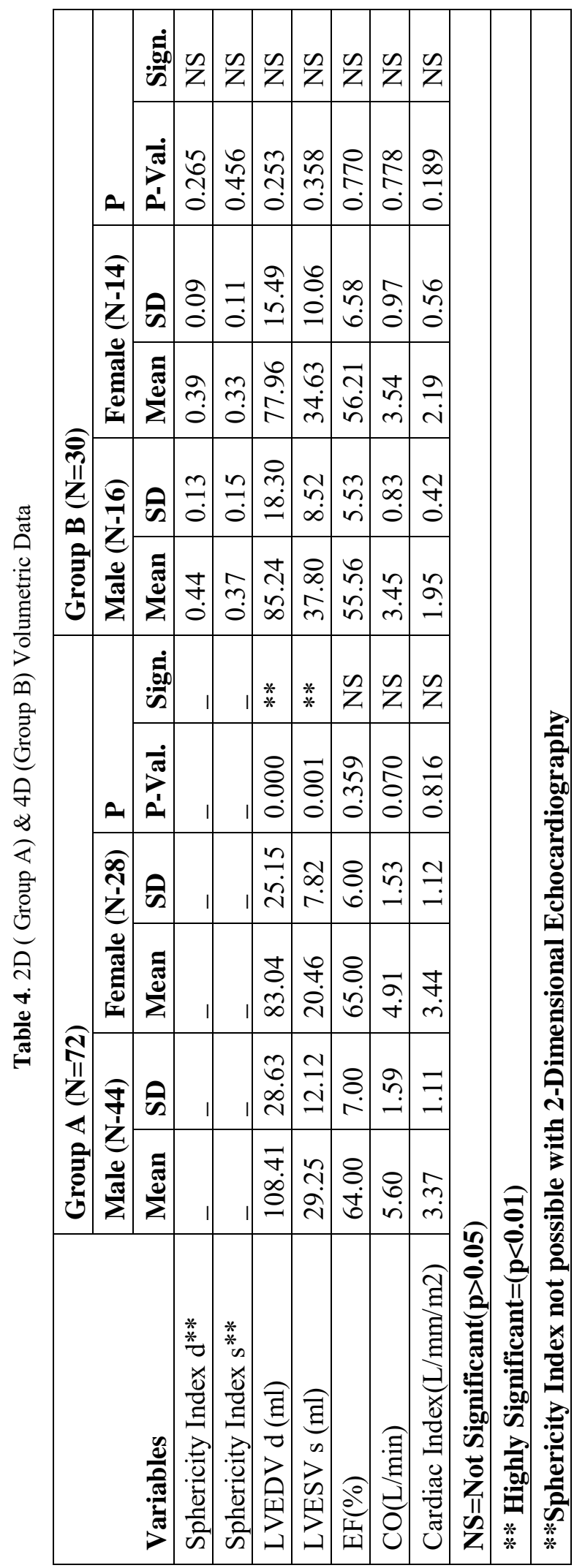


Table 5. consists of segmental strain data of there is no significant difference in values of 16 segment models of GLS of Group A. Largely, male $\&$ female subsets $(\mathrm{p}=\mathrm{NS})$.

Table-5. LV Segmental Strain Data-Group A $(\mathrm{N}=58) * *$

\begin{tabular}{|c|c|c|c|c|c|c|}
\hline \multirow[b]{2}{*}{ Variables } & \multicolumn{2}{|c|}{ Male (N-35) } & \multicolumn{2}{|c|}{ Female (N-23) } & \multicolumn{2}{|l|}{$\mathbf{P}$} \\
\hline & Mean & SD & Mean & SD & P-Val. & Sign \\
\hline \multicolumn{7}{|l|}{ AVC } \\
\hline GLS Avg (\%) & -16.64 & -1.91 & -17.87 & -2.13 & 0.013 & $*$ \\
\hline $\operatorname{APLAX}(\%)$ & -16.30 & -2.95 & -17.21 & -3.45 & 0.237 & NS \\
\hline $\mathrm{AP} 4 \mathrm{CH}(\%)$ & -16.71 & -2.63 & -17.55 & -2.96 & 0.208 & NS \\
\hline $\mathrm{AP} 2 \mathrm{CH}(\%)$ & -16.90 & -2.60 & -18.85 & -3.55 & 0.009 & $* *$ \\
\hline \multicolumn{7}{|l|}{$\mathrm{AP} 4 \mathrm{CH}$} \\
\hline Basal sep (\%) & -17.03 & -4.82 & -17.35 & -8.86 & 0.860 & NS \\
\hline Mid sep (\%) & -20.94 & -3.83 & -17.91 & -9.03 & 0.083 & NS \\
\hline Ap sep (\%) & -17.63 & -4.48 & -15.78 & -7.82 & 0.258 & NS \\
\hline Basal lat(\%) & -17.91 & -5.99 & -18.70 & -8.22 & 0.677 & NS \\
\hline Mid lat (\%) & -16.94 & -5.09 & -20.04 & -5.15 & 0.028 & $*$ \\
\hline Ap lat (\%) & -10.66 & -5.48 & -13.74 & -7.02 & 0.066 & NS \\
\hline \multicolumn{7}{|l|}{ AP 2CH } \\
\hline Basal inf $(\%)$ & -19.00 & -5.69 & -21.30 & -6.65 & 0.164 & $\mathrm{NS}$ \\
\hline Mid inf $(\%)$ & -21.94 & -5.30 & -24.17 & -5.49 & 0.128 & NS \\
\hline Apical inf (\%) & -18.71 & -5.50 & -20.09 & -5.42 & 0.354 & $\mathrm{NS}$ \\
\hline Basal ant (\%) & -19.11 & -4.85 & -22.43 & -7.81 & 0.050 & $*$ \\
\hline Mid ant (\%) & -16.74 & -5.35 & -16.30 & -8.55 & 0.811 & NS \\
\hline Ap ant (\%) & -11.23 & -6.62 & -10.57 & -6.23 & 0.704 & NS \\
\hline \multicolumn{7}{|l|}{ APLAX } \\
\hline Basal post (\%) & -14.51 & -7.03 & -19.70 & -8.68 & 0.015 & NS \\
\hline Mid Post (\%) & -17.94 & -7.09 & -20.39 & -4.65 & 0.150 & NS \\
\hline Apical post (\%) & -13.86 & -6.18 & -13.70 & -6.15 & 0.923 & NS \\
\hline Basal ant $(\%)$ & -19.54 & -5.67 & -15.17 & -10.62 & 0.046 & $*$ \\
\hline Mid ant $(\%)$ & -17.11 & -6.24 & -15.09 & -8.67 & 0.305 & NS \\
\hline Ant Ap sep. (\%) & -10.20 & -7.05 & -11.57 & -6.65 & 0.464 & NS \\
\hline \multicolumn{7}{|c|}{ AVC $=$ Aortic Valve Closure } \\
\hline \multicolumn{7}{|c|}{$\begin{array}{l}* * \text { Out Of } 72 \text { healthy subjects segmental strain data of only } 58 \text { subjects } \\
\text { could be properly procured during acquisition. }\end{array}$} \\
\hline \multicolumn{7}{|c|}{ NS=Not Significant $(p>0.05)$} \\
\hline \multicolumn{7}{|c|}{$*$ Significant $=(\mathbf{p}<0.05)$} \\
\hline \multicolumn{7}{|c|}{$* *$ Highly Significant $=(\mathbf{p}<0.01)$} \\
\hline
\end{tabular}

In Table 6, 17 segment model of GLS inclusive of LV apex is outlined, and overall, the values are insignificant when comparing males and females $(\mathrm{p}=\mathrm{NS})$. 
Table-6. LV Segmental Strain Data-Group B(N=30)

\begin{tabular}{|c|c|c|c|c|c|c|}
\hline \multirow{2}{*}{ Variables } & \multicolumn{2}{|c|}{ Male (N-16) } & \multicolumn{2}{|c|}{ Female (N-14) } & \multicolumn{2}{|l|}{$\mathbf{P}$} \\
\hline & Mean & SD & Mean & SD & P-Val. & Sign. \\
\hline \multicolumn{7}{|l|}{ AVC } \\
\hline GLS Avg (\%) & -17.29 & -2.71 & -19.00 & -3.51 & 0.145 & NS \\
\hline APLAX $(\%)$ & -15.90 & -2.95 & -18.75 & -3.97 & 0.032 & NS \\
\hline AP 4CH (\%) & -17.61 & -3.33 & -18.49 & -5.23 & 0.582 & NS \\
\hline AP 2CH (\%) & -18.37 & -3.97 & -19.74 & -2.88 & 0.291 & NS \\
\hline Basal ant (\%) & -20.58 & -5.90 & -24.25 & -6.52 & 0.117 & NS \\
\hline Basal ant septal (\%) & -16.06 & -5.48 & -20.05 & -6.68 & 0.083 & NS \\
\hline Basal septal (\%) & -16.99 & -8.41 & -17.99 & -5.77 & 0.711 & NS \\
\hline Basal Inferior (\%) & -22.00 & -7.79 & -23.34 & -7.70 & 0.640 & NS \\
\hline Basal posterior $(\%)$ & -20.57 & -6.20 & -25.10 & -6.30 & 0.058 & NS \\
\hline Basal Lateral (\%) & -21.04 & -6.49 & -18.97 & -7.93 & 0.438 & NS \\
\hline Mid Anterior (\%) & -13.98 & -5.07 & -18.40 & -6.44 & 0.045 & $*$ \\
\hline Mid ant septal (\%) & -16.77 & -4.21 & -18.01 & -4.66 & 0.449 & NS \\
\hline Mid Septum (\%) & -18.62 & -4.12 & -19.67 & -3.83 & 0.476 & NS \\
\hline Mid inf $(\%)$ & -20.48 & -5.16 & -19.48 & -4.49 & 0.581 & NS \\
\hline Mid Posterior (\%) & -15.74 & -6.03 & -18.59 & -4.20 & 0.149 & NS \\
\hline Mid Lateral (\%) & -14.52 & -4.56 & -18.48 & -5.62 & 0.042 & $*$ \\
\hline Apical ant $(\%)$ & -13.90 & -5.05 & -16.09 & -6.49 & 0.309 & NS \\
\hline Apical septal (\%) & -25.99 & -6.49 & -27.78 & -9.39 & 0.544 & NS \\
\hline Apical inf $(\%)$ & -19.04 & -4.61 & -18.80 & -5.65 & 0.901 & NS \\
\hline Apical lateral (\%) & -21.07 & -7.18 & -23.34 & -10.96 & 0.504 & NS \\
\hline Apex $(\%)$ & -16.09 & -3.67 & -17.65 & -5.30 & 0.350 & NS \\
\hline \multicolumn{7}{|c|}{ AVC=Aortic Valve Closure } \\
\hline \multicolumn{7}{|c|}{ NS=Not Significant $(p>0.05)$} \\
\hline \multicolumn{7}{|c|}{$*$ Significant $=(\mathbf{p}<0.05)$} \\
\hline
\end{tabular}

Table 7. is displaying Global circumferential strain (GCS), strain rate (GCSR), Global Radial strain (GRS) and strain rate (GRSR) of LV. GCS values at mitral valve and papillary muscle level are $-15.46 \pm 7.10 \% \&-20.28 \pm 6.78 \%$ respectively in males, and $-14.12 \pm 6.15 \% \&$ $19.69 \pm 7.98 \%$ respectively, in females $(p=N S)$.
GRS values at the mitral valve and papillary muscles level are $-24.53 \pm 9.82 \% \&-24.40 \pm$ $10.52 \%$ respectively in males, and $-21.93 \pm 8.81$ $\%$ \& $-22.12 \pm 11.00 \%$ respectively in females ( $p$ $=$ NS). Likewise, the GCSR \& GRSR values were insignificant in male $\&$ female subsets $(p=$ NS).

Table-7. 4-Dimensional X Strain and Strain rate Data - Group-B (N=30)

\begin{tabular}{|c|c|c|c|c|c|c|}
\hline \multirow{2}{*}{ Variables } & \multicolumn{2}{|c|}{ Male $(n=16)$} & \multicolumn{2}{|c|}{ Female $(n=14)$} & \multicolumn{2}{|l|}{$\mathbf{P}$} \\
\hline & Mean & SD & Mean & SD & P-Val. & Sign. \\
\hline GLS (\%) & -17.29 & -2.71 & -19.00 & -3.51 & 0.145 & NS \\
\hline GCS & 0 & 0 & 0 & 0 & & \\
\hline at mv level (\%) & -15.46 & -7.10 & -14.12 & -6.15 & 0.587 & NS \\
\hline at pap level (\%) & -20.28 & -6.78 & -19.69 & -7.98 & 0.831 & NS \\
\hline
\end{tabular}




\begin{tabular}{|l|l|l|l|l|l|l|}
\hline GRS & 0 & 0 & 0 & 0 & & \\
\hline at mv level (\%) & -24.53 & -9.82 & -21.93 & -8.81 & 0.455 & $\mathrm{NS}$ \\
\hline at pap level (\%) & -24.40 & -10.52 & -22.12 & -11.00 & 0.567 & $\mathrm{NS}$ \\
\hline GCSR & & & & & & \\
\hline at mv level (1/sec) & 1.78 & 0.62 & 1.97 & 0.68 & 0.433 & $\mathrm{NS}$ \\
\hline at pap level (1/sec) & 1.88 & 0.59 & 2.09 & 0.64 & 0.353 & $\mathrm{NS}$ \\
\hline GRSR & & & & & & \\
\hline at mv level (1/sec) & 2.87 & 0.97 & 2.70 & 1.04 & 0.649 & $\mathrm{NS}$ \\
\hline at pap level (1/sec) & 2.30 & 0.58 & 2.89 & 1.20 & 0.090 & NS \\
\hline GLS: global Longitudinal Strain GCS=Global circumferential Strain,GRS=Global Radial Strain \\
\hline GCSR=Global circumferential Strain rate, GRSR=Global Radial Strain rate \\
\hline
\end{tabular}

\section{Discussion}

Studies reporting a comprehensive assessment of LV strain in the healthy adult population, including data of TDI of ascending Aorta and myocardial deformation and the impact of age and sex on these parameters, are scarce. Furthermore, the publications on reference values of TDI of Ascending Aorta, 4D volumetric and 4D X Strain data of GLS, GCS, GCSR, GRS, GRSR in healthy individuals could not be found even after vigourous \& profound review of the literature. Perhaps this is the first research article on normative values of TDI of Ascending Aorta, 4D volumetric \& 4D X Strain data on healthy Indian subjects.

Echocardiography is perhaps the most useful non-invasive imaging technique available at present due to its pristine and peerless ability to combine safety and ease with high diagnostic yield. Accurate assessment of cardiac chamber size and function is a key objective of any echocardiographic examination. During echocardiography, such assessment is performed by comparing observed measurements with the normal ranges available for those parameters. The normal values published by ASE/EACVI are currently the most used reference for this purpose [41]. However, these reference values are mostly derived from the western populations, whereas previous studies have demonstrated that ethnicity may significantly affect cardiac chamber dimensions and functions [42, 46]. Accordingly, the applications of ASE/EACVI reference values to other ethnic groups is fraught with the potential to lead to erroneous interpretations. This underscores the need to develop ethnic-specific reference values.

In the present study, we have described normal reference ranges for cardiac chamber size and functions in Indian men and women. It was found that the LV dimensions and volumes were larger in men as compared to women. These findings are consistent with those reported in the western populations (ASE/EACVI guidelines) [41] as well as a migrant (WASE and LOLIPOP studies) or native Indians [43, 44, 47].

Several previous studies have demonstrated that Indians have a smaller cardiac chamber than the western populations [43-45, 47]. Chahal et al. (2010) compared 499 European men and women with 479 Indians living in London who were recruited in the LOLIPOP (London Life Sciences Prospective Population) study [43]. They found that the Indians had significantly smaller LV volumes as compared to the Europeans. More recently, the WASE study has again demonstrated smaller cardiac chamber dimensions in Indians as compared to several other ethnic groups, even though the number of Indians studied was small [47].

Earlier studies have shown that ethnicity is an important determinant of cardiac chamber sizes. Indians have smaller chamber sizes and mildly 
thicker LV walls, not classifiable as hypertrophy based on the thickness, than Europeans but equivalent LVEF [48, 49] It was also observed earlier that LVESVI and LVEDVI indexed to BSA were smaller in Indian Asian men and women compared with their European white counterparts while LVEF was similar between ethnicity- sex subgroups [44]. It was observed that indexing to BSA reduced the LVEDV and LESV differences between Indian measurements and ASE-defined normal values considerably [45]. These references make a strong point for the collection of different population-based normative data useful for comparison and reference by the medical community researchers. Our findings have revealed lower values for global and longitudinal strain in our healthy adult subjects as compared to European and Americans. Whether it is due to smaller LV with thicker walls or is it a racial variation or the study was carried out during the corona pandemic period while all the subjects were wearing face masks throughout their echocardiography workup remains to be answered.

Accurate quantification of LV systolic function has important prognostic implications and is helpful to determine treatment decisions for a variety of therapies. 2D LVEF is the most commonly used echocardiographic parameter to evaluate the LV function in clinical practice. However, measurement of LVEF is limited by geometric structure, image quality, load dependence and poor reproducibility [66]. Therefore, it is necessary to develop a more sensitive and accurate technique to quantify LV systolic function.

2D STE has been validated by cardiac MRI and 3D echocardiography as an effective method to assess LV function [51]. Many previous studies have shown that 2D STE provides more accurate prognostic implications than traditional 2D LVEF in the assessment of a variety of clinical heart diseases, such as heart failure [52, 53], valvular heart disease [54, 55], ischemic heart disease [56]. However, 2D STE has the potential limitation of out-of-plane motion tracking of speckles, which can lead to increased noise and reduced accuracy [57, 58].

4D echocardiographic techniques, including real-time 3D speckle tracking program and 3D echocardiography allow volumetric analysis and simultaneous measurements of multidirectional components of strain in a single data set. The acquisition of the entire LV within a single data set allows global assessment of LV longitudinal, circumferential, and radial functions across all myocardial segments [7].

An interesting observation in the assessment of a healthy population was the difference found in the average values of strain between individual segments, as well as different walls and levels of the LV. Functional non-uniformity is a known failure of normal LV that may have a consequence for the validity of the assessment of segmental function [59-62]. Indeed, some differences in the performance measures of segmental wall motion assessment were previously observed between different LV levels, although none were substantial enough to warrant separate cut-off values [61]. In the current study, the general consistency in the magnitude of segmental area strain seems to confirm these previous findings. The longitudinal strain was lower in the midventricular wall compared with the basal and apical levels, as previously noted in an analysis of normal segments inpatient [60]. Moreover, there is considerable heterogeneity in mean longitudinal strain between individual segments. The apical, anterior wall, in particular, demonstrated a surprisingly low mean strain value compared with other segments, which may in part be due to the known difficulty with adequate visualization and tracking of this particularly challenging area of the LV. For these reasons, segment-specific cut-off values are warranted for these strain parameters for the adequate distinction between what is normal and what should be considered pathological, particularly if diagnostic or therapeutic decisions are based on their assessment. Ultimately, future 
clinical studies will determine whether 4D X Strain STE-derived LV strain parameters have a value for diagnosis and prognosis of heart disease in clinical practice.

Multiple studies have evaluated normal strain values with 2D speckle tracking echocardiography (2DSTE), showing a wide reference range of LV strain in apparently normal subjects. [59-62] Moreover, studies have demonstrated discordant results between 2DSTE and 3DSTE, which may be explained by the 3D cardiac motion that is partly lost when imaging in two dimensions. [63-64] Longitudinal and radial strains by 3DSTE are significantly smaller than by 2DSTE. whereas circumferential strain in significantly larger using 3DSTE. In our studies, all the 2D LV strains were lower in men than in women. Recent 2D and 3D speckle tracking echocardiography (STE) studies in healthy populations have shown that GLS is higher in women $[65,67]$.
The current study provides contemporary normal reference values of 2DE measurements of conventional echocardiographic data, TDI of Ascending Aorta, GLS of LV, and additionally 4D volumetric and 4D X Strain data of GLS, GCS, GCSR, GRS \& GRSR in healthy Indian adults. It demonstrates differences between men and women, different age groups, as well as the functional non-uniformity of the normal LV. These findings are important, because they may signify the necessity for gender, age, and segment-specific normal ranges. We have presented Table 8. which furnishes the summarized values of the above-mentioned parameters achieved from the present study. Table 8 is particularly meant for contemporary and prospective medical researchers to conceptualize further on these interesting original research findings.

Table-8. Summary of Normal Reference Values of Important Parameters

\begin{tabular}{|l|l|l|}
\hline \multicolumn{3}{|l|}{ Data of Tissue Doppler imaging of Asending Aorta } \\
\hline Variables & Male & Female \\
\hline AOD (cm) & $2.7 \pm 0.45$ & $2.491 \pm 0.37$ \\
\hline AOS (cm) & $3.07 \pm 0.49$ & $2.721 \pm 0.40$ \\
\hline Pulsatile Change (cm) & $0.28 \pm 0.21$ & $0.231 \pm 0.14$ \\
\hline SAO (cm/sec) & $1.05 \pm 0.30$ & $1.142 \pm 0.40$ \\
\hline AAO (cm/sec) & $1.10 \pm 0.37$ & $0.992 \pm 0.35$ \\
\hline EAO (cm/sec) & $0.99 \pm 0.33$ & $1.129 \pm 0.39$ \\
\hline Ao Distensbility (dyn/cm2) & $0.0052 \pm 0.00$ & $0.005 \pm 0.00$ \\
\hline Ao Stiffness Index & $3.90 \pm 3.79$ & $5.23 \pm 10.55$ \\
\hline 2D Global longitudinal Strain data & $16.63 \pm 1.91$ & $17.87 \pm 2.13$ \\
\hline GLS (\%) & \multicolumn{2}{|l|}{} \\
\hline 4D Volumetric data & $0.44 \pm 0.13$ & $0.39 \pm 0.09$ \\
\hline Sphericity Index d & $0.3656 \pm 0.15$ & $0.32 \pm 0.11$ \\
\hline Sphericity Index s & $85.23 \pm 18.30$ & $77.95 \pm 15.49$ \\
\hline LVEDV d (ml) & $37.8 \pm 8.52$ & $34.62 \pm 10.06$ \\
\hline LVESV s (ml) & $55.56 \pm 5.53$ & $56.21 \pm 6.58$ \\
\hline EF (\%) & $3.45 \pm 0.83$ & $3.54 \pm 0.97$ \\
\hline CO(L/min) & $1.94 \pm 0.42$ & $2.18 \pm 0.56$ \\
\hline CI (L/min/m2) & $-17.29 \pm 2.71$ & $-19.00 \pm 3.51$ \\
\hline 4D X STRAIN speckle Tracking Echocardiography data \\
\hline GLS (\%) & \multicolumn{2}{|l|}{} \\
\hline \multicolumn{2}{|l|}{ ( $)$} \\
\hline
\end{tabular}




\begin{tabular}{|c|c|c|}
\hline \multicolumn{3}{|l|}{ GCS } \\
\hline at mv level (\%) & $-15.46 \pm 7.10$ & $-14.12 \pm 6.15$ \\
\hline at pap level (\%) & $-20.27 \pm 6.78$ & $-19.69 \pm 7.98$ \\
\hline \multicolumn{3}{|l|}{ GRS } \\
\hline at mv level (\%) & $-24.52 \pm 9.82$ & $-21.92 \pm 8.81$ \\
\hline at pap level (\%) & $-24.4 \pm 10.52$ & $-22.12 \pm 11.00$ \\
\hline \multicolumn{3}{|l|}{ GCSR } \\
\hline at mv level $(1 / \mathrm{sec})$ & $1.78 \pm 0.62$ & $1.97 \pm 0.68$ \\
\hline at pap level $(1 / \mathrm{sec})$ & $1.88 \pm 0.59$ & $2.09 \pm 0.64$ \\
\hline \multicolumn{3}{|l|}{ GRSR } \\
\hline at mv level $(1 / \mathrm{sec})$ & $2.86 \pm 0.97$ & $2.7 \pm 1.04$ \\
\hline at pap level $(1 / \mathrm{sec})$ & $2.3 \pm 0.58$ & $2.89 \pm 1.20$ \\
\hline \multicolumn{3}{|c|}{$\begin{array}{l}\text { TDI=Tissue Doppler Imaging,AOD=Aortic Diastolic Diameter,AOS=Aortic } \\
\text { Systolic Diameter,SAO=Systolic Aortic }\end{array}$} \\
\hline \multicolumn{3}{|c|}{$\begin{array}{l}\text { upper Wall Velocity,EAO=Early diastolic Aortic Upper Wall Velocity } \\
\text { AAO=Late Diastolic Aortic upper Wall velocity }\end{array}$} \\
\hline \multicolumn{3}{|c|}{ GLS=Global Longitudinal Strain,AP=Apical } \\
\hline \multicolumn{3}{|c|}{$\begin{array}{l}\text { GLS: global Longitudinal Strain GCS=Global circumferential } \\
\text { Strain,GRS=Global Radial Strain }\end{array}$} \\
\hline
\end{tabular}

\section{Conclusions}

Normal ranges of tissue Doppler imaging of Ascending Aorta, global and segmental longitudinal LV strain using 2D STE and additionally 4D volumetric data and GCS, GCSR, GRS, GRSR by 4D X strain echocardiography in healthy Indian adults are being presented for clinical use. Differences in the magnitude of LV strain are present in men and women, as well as between different segments, walls, and levels as part of the functional non-uniformity of normal LV.

\section{Acknowledgement}

We thank Mrs. Sadhna Mehrotra for her incredible support by providing numerous healthy subjects for the present study through her NGO- MOTHER \& CHILD WELFARE ORGANISATION. Our earnest, heartfelt gratitude to Mrs. Laxmi for her tireless efforts in typing the manuscript repeatedly throughout all the phases of the study.

\section{Conflicts of Interest}

These are no conflicts of interest. 


\section{References}

[1] Quninones MA, Greenberg BH, Kopelen HA, Koilpillai C, Limacher MC, Shindler DM, et al. Echocardiographic predictors of clinical outcome in patients with left ventricular dysfunction enrolled in the SOLVD registry and trials: Significance of left ventricular hypertrophy, Studies of left ventricular dysfunction. J Am CollCardiol2000; 35(5):12371244.

[2] Thune JJ. Kober L, Pfeffer MA, Skali H, Anavekar NS, Bourgoun M, et al. Comparison of regional versus global assessment of left ventricular function in patients with left ventricular dysfunction, heart failure, or both after myocardial infarction; the valsartan in acute myocardial infarction echocardiographic study. J Am Soc Echocardiogr 2006; 19(12):1462-1465.

[3] Kocabay G, Muraru D, Peluso D, Cucchini U, Mihaila S, Padayattil-Jose Sanjay Pandey MD., et al. Normal left ventricular mechanics by twodimensional speckle-tracking echocardiography. Reference values I healthy adults. Rev Esp Cardiol (Engl Ed)2014; 67(8):651-658.

[4] Quinones MA, Douglas PS, Foster E, Gorcsan J 3rd, Lewis JF, Pearlman AS, et al.; American Society of Echocardiography; Society of Cardiovascular Anesthesiologists; Society of Pediatric Echocardiography. ACC/AHA clinical competence statement on echocardiography: A report of the American College of Cardiology/ American Heart Association/ American College of physiciansAmerican Society of Internal Medicine Task Force on Clinical Competence. J Am Soc-Echocardiogr.2003; 16(4):379-402.

[5] Nakatani S. Left ventricular and twist: Why should we learn? J Cardiovasc Ultrasound 2011: 19(1): 1-6.

[6] Poveda F, Git D, Marti E, Andaluz A, Ballester M, Carreras F, Helical Structure of the cardiac ventricular anatomy assessed by diffusion tensor magnetic resonance imaging with multiresolution tractography. Rev Esp Cardiol (Engl Ed)2013; 66(10): 782-790.

[7] Muraru, D.; Niero, A.; Zanella, H.R.; Cherata, D.; Badano, L.P. Three-dimensional speckle-tracking echocardiography: Benefits and limitation of integrating myocardial mechanics with threedimensional imaging. Cardiovasc. Diagn. Ther. 2018, 8, 101-117.

[8] Kang Y, Sun MM, Cui J, Chen HY, Su YG, Pan $\mathrm{CZ}$, et al. Three-dimensional speckle tracking echocardiography for the assessment of left ventricular function and mechanical dyssynchrony. Acta Cardiol 2012; 67(4):423-430.

[9] Chen R, Wu X, Shen LJ, Wang B, Ma MM, Yang $\mathrm{Y}$, et al. Left ventricular myocardial function in hemodialysis and nondialysisuremia patients: A three-dimensional speckle-tracking echocardiography study. PLoS One 2014; 9(6):e100265.

[10]Zhu M, Streiff C, Panosian J, Zhang Z, Song X, Sahn DJ, et al. Regional Strain determination and myocardial infarction detection by three-dimensional echocardiography with varied temporal resolution Echocardiography 2015; 32(2):339-348.

[11]Zhu M, Streiff C, Panosian J, Roundhill D, Lapin $\mathrm{M}$, Tutschek B, et al. Evaluation of stroke volume and ventricular mass in a fetal heart model: A novel fourdimensional echocardiographic analysis. Echocardiography 2014; 31(9): 1138-1145.

[12] Jenkins C, Leano R, Chan J. Marwick TH. Reconstructed versus real-time 3-dimensional echocardiography: Comparison with magnetic resonance imaging. J Am Soc Echocardiogr 2007; 20(7): 862-868.

[13] Jenkins C, Leano R, Chan J, Marwick TH. Reconstructed versus real-time 3-dimensional echocardiographic measurements of left ventricular parameters using real-time three-dimensional echocardiography. J Am Coll Cardiol 2004; 44 (4):878-886.

[14] Pedrizzetti G, Mangual J and Tonti G. On the geometrical relationship between global longitudinal strain and ejection fraction in the evaluation of cardiac contraction. J Biomech. 2014 47:746-9.

[15] Stampehi MR, Mann DL, Nguyen JS, Cota F, Colmenares C, and Dokainish H. Speckle strain echocardiography predicts outcome in patients with heart failure with both depressed and preserved left ventricular ejection fraction. Echocardiography. $2015 ; 32: 71-8$ 
[16]Perk G, Tunick PA and Kronzon I. Non-Doppler two-dimensional strain imaging by echocardiography from technical consideration to clinical application. J Am Soc Echocardiogr.2007; 20:234-43.

[17] Mizuguchi Y, Oishi Y, Miyoshi H, luchi A, Nagase $\mathrm{N}$ and Oki $\mathrm{T}$. the functional role of longitudinal, circumferential, and radial myocardial deformation for early impairment of left ventricular contraction and relaxation in patients with cardiovascular risk factors: a study with twodimensional strain imaging. J Am Soc Echocardiogr. 2008; 21:1138-44.

[18] Share BL, La Gerche A, Naughton GA, Obert P, and Kemp JG. Young Women with Abdominal Obesity Have Subclinical Myocardial Dysfunction. Can J cardiol 2015; 31:1195-201.

[19] Yingchoncharoen T, Agarwal S, Popovic ZB, and Marwick TH. Normal ranges of left ventricular strain: a meta-analysis. J Am Soc Echocardiogr. 2013; 26:185-91.

[20]Kleijn SA, Pandian NG, Thomas JD, Perez de Isla L, Kamp O, Zuber M, Nihoyannopoulos P, Forster T, Neser HJ, Geibel A, Gorissen W and Zamorano JL. Normal reference values of left strain using three-dimensional speckle tracking echocardiography: result from a multicenter study. Eur Heart J Cardiovasc Imaging:2015; 16:410-6. [21]Bernard A, Addetia K, Dulgheru R, Caballero L, Sugimoto T, Akhaladze N, Athanasopoulos GD, Barone D, Baroni M, Cardim N, Hristova K, Ilardi F, Lopez T, de la Morena G, Popescu BA, Penicka M, Ozyigit T, David Rodrigo Carbonero J, van de Veire N, Stephan Von Bardeleben R, vinereanu D, Luis Zamorano J, Martinez C, Magne J, Cosyns B, Donal E, Habib G, Badano LP, Lang RM and Lancellotti P, $3 \mathrm{D}$ echocardiographic reference ranges for normal left ventricular and strain results from the EACVI NORRE study. Eur Heart J Cardiovasc Imaging 2017; 18:475-483.

[22] Cheng S, Larson MG, McCabe EL, Osypiuk E, Lehman BT, Stanchev P, Aragam J, Benjamin EJ, Solomon SD and Vasan RS. Age- and sex- based reference limits and clinical correlates of myocardial strain and synchrony: the Framingham Heart study. Circ Cardiovasc Imaging 2013; 6:692-9.
[23] Menting ME, mcGhie JS, Koopman LP, Vletter WB, Helbing WA, van de Bosch AE and RoosHesselink JW. Normal myocardial strain values using 2D speckle tracking echocardiography in healthy adults aged 20 to 72 years. Echocardiography .2016;33:1665-1675.

[24]Dalen H, Thorstensen A, Aase SA, Ingul CB, Trop H, Vatten LJ, and Stoylen A. Segmental and global longitudinal strain and strain rate based on echocardiography of 1266 healthy individuals: the HUNT study in Norway. Eur J Echocardiogr .2010; 11:176-83.

[25] Moreira HT, Nwabuo CC, Armstrong AC, Kishi S, Gjesdal O, Reis JP. Schreiner PJ, Liu K, Lewis CE, Sidney S, Gidding SS, Lima JAC, and AmbaleVenkatesh B. Reference Ranges and Regional Patterns of Left Ventricular Strain and Strain Rate Using Two-Dimensional Speckle-Tracking Echocardiography in a Healthy Middle-Aged Black and White Population: The CARDIA study. J Am Soc Echocardiogr.2017;30:647-658 e2.

[26] Park JH, Lee JH, Lee SY, Choi JO, Shin MS, Kim MJ, Jung HO, Park JR, Sohn IS, Kim H, Park SM, Yoo NJ, Choi JH, Kim HK, Cho GY, Lee MR, Park JS, Shim CY, Kim DH, Shin DH, Shin GJ, Shin SH, Kim KH, Kim WS, and Park SW. Normal 2Dimensional Strain Values of the Left Ventricular: A Substudy of the Normal Echocardiographic Measurements in Korean Population Study. J Cardiovasc Ultrasound.2016;24:285-293.

[27]Kaku K, Takeuchi M, Tsang W, Takigiku K, Yasukochi S, Patel AR, Mor-Avi V, Lang RM and Otsuji Y. Age-related normal range of left ventricular strain and torsion using three-dimensional speckletracking echocardiography. J Am Soc Echocardiogr.2014;27:55-64.

[28]Liu CY, Lai S, Kawel-Boehm N, Chahal H, Ambale-Venkatesh B, Lima JAC and Bluemke DA. Healthy aging of the left ventricle in relationship to cardiovascular risk factors: The Multi-Ethnic Study of Atherosclerosis (MESA). PLoS One.2017; 12: e0179947.

[29]Bjornstad P, Truong U, Pyls L, Dorosz JL, CreeGreen M, Baumgartner A, Coe G, Regensteiner JG, Reusch JE and Nadeau KJ. Youth with type 1 diabetes have worse strain and less pronounced sex 
differences in early echocardiographic markers of diabetic. Cardiomyopathy compared to their normoglycemic peers: A RESistance to Insulin in Type 1 ANd Type 2 diabetes (RESISTANT) Study. J Diabetes Complications. 2016; 30:1103-10.

[30] Szelenyi Z, Fazakas A, Szenasi G, Tegze N, Fekete B, Molvarec A, Hadusfalvy-Sudar S, Janosi O, Kiss M, Karadi I and Vereckei A. The mechanism of reduced longitudinal left ventricular systolic function in hypertensive patients with normal ejection fraction. J Hypertens. 2015; 33:1962-9; discussion 1969.

[31]Huang J, Yan ZN, Rui YF, Fan L, Shen D and Chen DL. Left ventricular Systolic Function Changes in Primary Hypertension Patients Detected by the Strain of Different Myocardium Layers. Medicine (Baltimore).2016;95: e2440.

[32] Almeida AL, Teixido-Tura G, Choi EY, Opdahi A, Fernandes VR, Wu CO, Bluemke DA and Lima JA. Metabolic syndrome, strain, and reduced myocardial function: multi-ethnic study of atherosclerosis. Arq Bras Cardiol. 2014; 102:327-35. [33] Pascual M, Pascual DA, Soria F, Vicente T, Hernandez AM, Tebar FJ and Valdes M. Effects of isolated obesity on systolic and diastolic left ventricular function. Heart. 2003; 89:1152-6.

[34]Friedewald WT, Levy RI, Fredrickson DS. Estimation of the concentration of low densitylipoprotein in plasma, without use of the preparative ultracentrifuge. Clin Chem. 1972; 18:499-502.

[35] Wagner M, Tiffe T, Morbach C, Gelbrich G, Stork S, Heuschmann PU and Consortium S. characteristics and Course of Heart Failure Stages A$B$ and Determinants of Progressiondesign and rationale of the STAAB cohort study. Eur J Prev Cardiol. 2017; 24:468-479.

[36] Morbach C, Gelbrich G, at al. Impact of acquisition and interpretation on total inter-observer variability in echocardiography: results from the quality assurance program of the STAAB cohort study. Int J Cardiovasc Imaging. 2018.

[37]Bia D, Aguirre I, Zocalo Y, Devera L, Cabrera Fischer E, Armentano R. [Regional differences in velocity, elasticity and wall buffering function in systemic arteries: pulse wave analysis of the arterial pressure-diameter relationship]. Rev Esp Cardiol. 2005; 58:167-74.

[38]Lehmann ED. Non invasive measurements of aortic stiffness: methodological considerations. Pathol Biol. 1999; 47:716-30.

[39] Lantelme P, Mestre C, Lievre M, Gressard A, Milon $\mathrm{H}$. Heart rate AN important confounder of pulse wave velocity assessment Hypertension. 2002; 39:1083-7.

[40]Benetos A, Laurent S, Hoeks AP, Boutouyrie $\mathrm{PH}$, Safar ME. Arterial alterations with ageing and high blood pressure: a non-invasive study of carotid and femoral arteries. Arterioscler Thromb. 1993; 13:90-7.

[41]Lang RM, Badano LP, Mor-Avi V et al (2015) Recommendations for cardiac chamber quantification by echocardiography in adults: an update from the American Society of Echocardiography and the European Association of Cardiovascular Imaging. J Am Soc Echocardiogr 28:1-39.

[42] Ethnic-Specific Normative Reference Values for Echocardiographic LA and, size LV (2015) Mass, and systolic functions: \&nbsp; the EchoNoRMAL study.JACC Cardiovas Imaging 8:656-665.

[43] Chahal NS, Lim TK, Jain P, Chmabers JC, Kooner JS, Senior R (2010) Ethnicity-related differences in left ventricular functions, structure, and geometry: a population study of UK Indian Asian and European white subjects. Heart 96:466-471.

[44] Chahal NS, Lim TK, Jain P. Chmabers JC, Kooner JS, Senior R (2012) Population-based references values for $3 \mathrm{D}$ echocardiographic $\mathrm{LV}$ volumes and ejection fraction. JACC Cardiovasc Imaging 5:1191-1197.

[45] Bansal M, Mohan JC, Sengupta SP (2016) Normal echocardiographic measurements in Indian adults: how different are we from the western populations? A pilot study. Indian Heart J 68:772775.

[46] Poppe KK, Doughty RN, Walsh HJ, Triggs CM, Whalley GA (2014) A comparison of the effects of indexation on standard echocardiography measurements of the left heart in a healthy multiracial population. Int J Cardiovasc Imaging 30:749758. 
[47] Asch FM, Miyoshi T, Addetia K et al (2019) Similarities and differences in left ventricular size and function among races and nationalities: results of the world alliances of echocardiography normal values study. J Am Soc Echocardiogr 32:1396-1406. [48] Chahal NS, Lim TK, Jain P, Chambers JC, Senior R. Population-based reference values for 3D echocardiographic LV volumes and ejection fraction JACC Cardiovasc Imaging. 2012; 5:1191-1197.

[49] Bansal M, Mohan JC, Sengupta SP. Normal echocardiographic measurements in Indian adults: how different are we from the western populations? A pilot study. Indian Heart J. 2016; 68:772-775. [50]Luis SA, Yamada A, Khandheria BK, Speranza $\mathrm{V}$, Benjamin $\mathrm{A}$, Ischenko $\mathrm{M}$, et al. Use of threedimensional speckle-tracking echocardiography for quantitative assessment of global left ventricular function: A comparative study of three-dimensional echocardiography. J Am Soc Echocardiogr 2014;27 (3):285-291.

[51]Brown J, Jenkins C, Marwick TH, Use of myocardial strain to assess global left ventricular function: a comparison with cardiac magnetic resonance and 3-dimensional echocardiography. Am Heart J. 2009; 157(1):102. e1-e5.

[52] Mignot A, Donal E, Zaroui A, Reant P, Saleem

A, Hamon C, et al. Global longitudinal strain as a major predictor of cardiac events in patients with depressed left ventricular function: A multicenter study. J Am Soc Echocardiogr 2010; 23(10):10191024.

[53] Cho GY, Marwick TH, Kim HS, Kim MK, Hong KS, Oh DJ. Global2-dimensional strain as a new prognosticator in patients with heart failure. J Am Coll Cardiol 2009; 54(7):618-624.

[54] Kearney LG, Lu K, Ord M, Patel SK, Profitis K, Matalanis G, et al. Global longitudinal strain is a strong independent predictor of all-cause mortality in patients with aortic stenosis. Eur Heart J Cardiovasc Imaging 2012; 13(10):827-833.

[55] Dahi JS, Videbaek L, Poulsen MK, Rudbaek TR, Pellikka PA, Moller JE, Global Strain in severe aortic valve stenosis: Relation to clinical outcome after aortic valve replacement. Circ Cardiovasc Imaging 2012;5(5):613-620.
[56] Woo JS, Kim WS, Yu TK, Ha SJ, Kim SY, Bae $\mathrm{JH}$ et al. Prognostic value of serial global longitudinal strain measured by two-dimensional speckle tracking echocardiography in patients with ST-segment elevation myocardial infarction. Am J Cardiol 2011; 108(3):340-347.

[57] Chen X, Xie H, Erkamp R, Kim K, Jia C, Rubin $\mathrm{JM}$, et al. 3-D correlation-based speckle tracking. Ultrason Imaging 2005; 27(1):21-36.

[58] Mor-Avi V, Lang RM, Badano LP, Belohlavek M, Cardim NM, Derumeaux G, et al. Current evolving echocardiographic techniques for the quantitative evaluation of cardiac mechanics: ASE/EAE consensus statement on methodology and indications andorsed by the Japanese Society of Echocardiography. J Am Soc Echocardiogr 2011;24(3):277-313.

[59] Perez de Isla L, Balcones DC, Fernandez-Golfin C, Marcos-Alberca P, Almeria C Rodrigo JL et al. Three-dimensional-wall motion tracking; a new and faster tool for myocardial strain assessment; comparison with two-dimensional-wall motion tracking. J Am Soc Echocardiogr 2009; 22:325-30. [60] Maffessanti F, Nesser HJ, Weinert L, SteringerMascherbauer R, Niel J. Gorissen $\mathrm{W}$ et al. Quantitative evaluation of regional left ventricular function using three-dimensional speckle Tracking echocardiography in patients with and without heart disease. Am J cardiol 2009;1041755-62.

[61]Kleijn SA, Aly MF, Terwee CB, van Rossum AC, Kamp O. Three-dimensional speckle tracking echocardiography for automatic assessment of global and regional left ventricular function based on area strain. J Am Soc Echocardiogr 2011; 24:314-21. [62] Marwick TH, Leano RL, Brown J, Sun JP, Hoffmann R, Lysyansky P et al. Myocardial strain measurements with 2-dimensional speckle-tracking echocardiography: definition of normal range. JACC Cardiovasc Imaging 2009; 2:80-4.

[63] Maffessanti F, Nesser HJ, Weinert L, SteringerMascherbauer R, Niel J, Gorissen $\mathrm{W}$ et al. Quantitative evaluation of regional left ventricular function using three-dimensional speckle tracking echocardiography in patients with and without heart disease. Am J Cardiol 2009; 104:1755-62. 
[64] Saito K, Okura H, Watanabe N, Hayashida A, Obase K, Imai K et al. Comprehensive evaluation of left ventricular strain using speckle tracking echocardiography in normal adults: comparison of three-dimensional and two-dimensional approaches. J Am Soc Echocardiogr 2009; 22:1025-30.

[65] Bernard A, Addettia K, Dulgheru R, Caballero L, Sugimoto T, Akhaladze $\mathrm{N}$ et al. 3D echocardiographic reference ranges for normal left ventricular volume and strain: results from the EACVI NORRE study. Eur Heart J Cardiovasc Imaging 2017; 18:475-83.
[66] Kocabay G, Muraru D, Peluso D, Cucchini U, Mihaila S, Padayattil-Jose $S$ et al. Normal left ventricular mechanics by two-dimensional speckletracking echocardiography. References values in healthy adults. Rev Esp Cardiol (Engl Ed) 2014:67:651-8.

[67] Muraru D, Cucchini U, Mihaila S, Miglioranza $\mathrm{MH}$, Aruta $\mathrm{P}$, Caralli $\mathrm{G}$ et al. Left ventricular myocardial strain by three-dimensional speckletracking echocardiography in healthy subjects: reference values and analysis of their physiologic and technical determinants. J Am Soc Echocardiogr 2014; 27:858-71 


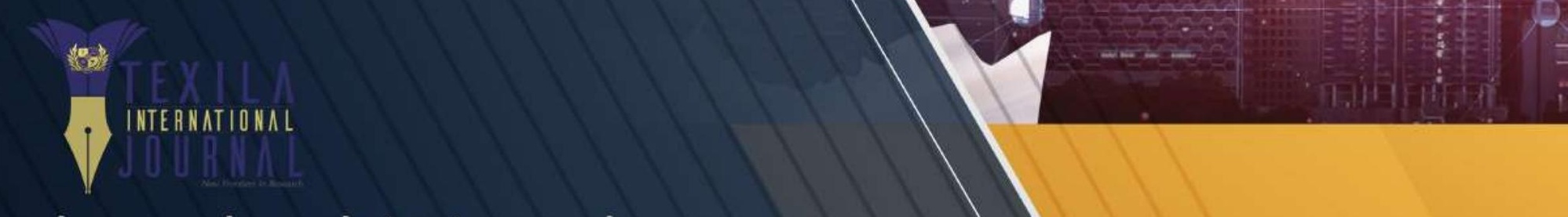

ejournal.assist@tau.edu.gy

wwww.texilajournal 